\author{
Universidade de São Paulo \\ Instituto de Astronomia, Geofísica e Ciências Atmosféricas \\ Departamento de Ciências Atmosféricas
}

Paulo Eduardo Plana Junior

\begin{abstract}
A contribuição do JBNAS para a precipitação em um episódio de ZCAS: análises físicas e simulações com o modelo WRF
\end{abstract}

São Paulo 



\section{A contribuição do JBNAS para a precipitação em um episódio de ZCAS: análises físicas e simulações com o modelo WRF}

Dissertação apresentada ao Departamento de Ciências Atmosféricas do Instituto de Astronomia, Geofísica e Ciências Atmosféricas da Universidade de São Paulo como requisito parcial para a obtenção do título de Mestre em Ciências.

Área de Concentração: Meteorologia Orientador: Prof. Dr. Ricardo Hallak

Versão Corrigida. O original encontra-se disponível na Unidade.

São Paulo 



\section{Resumo}

A Zona de Convergência do Atlântico Sul (ZCAS) é o principal sistema precipitante durante o período úmido do Sistema de Monções da América do Sul (SMAS). O Jato de Baixos Níveis da América do Sul (JBNAS) é um dos mecanismos atuantes em caso de ZCAS, estendendo-se desde a região Amazônica até o Sudeste brasileiro. O papel principal do JBNAS é transportar calor e umidade dos trópicos até latitudes mais elevadas. O transporte de umidade pelo JBNAS durante uma ZCAS é um tema pouco abordado na literatura científica e por isso o objetivo deste trabalho é avaliar, quantificar e associar este transporte de umidade causado pelo JBNAS na precipitação, por meio de um estudo de caso. O evento ZCAS estudado atuou entre 11 e 18 de janeiro de 2016, e foi escolhido por apresentar o JBN e o fluxo de umidade associado bem definidos e direcionados para o Sudeste brasileiro. Em associação à ZCAS, foram também observados a Alta da Bolívia (AB) e o Vórtice Ciclônico de Altos Níveis (VCAN) do Nordeste do Brasil, presentes e bem configurados durante todo o período. Além da análise do Climate Forecast System Version 2 (CFSv2), também foram realizadas simulações numéricas utilizando o modelo regional Weather, Research and Forecast (WRF) para todo o período de atuação do sistema. O WRF foi rodado com 3 grades aninhadas, onde a convecção foi resolvida explicitamente durante o período de maior intensidade do sistema na grade de $3 \mathrm{~km}$ de espaçamento horizontal. Foram testadas as parametrizações cúmulos de Kain-Fritch (mais antiga) e Grell-Freitas (mais recente), analisando-se as diferenças entre suas soluções. Os resultados mostram que ambos os experimentos numéricos fornecem soluções com características sinóticas próximas ao mostrado pela análise do CFSv2, mas com divergências tanto no posicionamento quanto na intensidade do JBNAS e do fluxo de umidade associado. Por consequência disso, a precipitação gerada pelas duas parametrizações tiveram baixo desempenho. Conclui-se que 
a precipitação modelada neste caso ZCAS sofre forte dependência da correta simulação do JBNAS. A análise na série temporal da média do fluxo de umidade em três diferentes áreas do domínio simulado confirma sua maior intensidade na região onde o JBN está bem definido. Constatou-se um ciclo diurno bem definido, que se intensifica durante a noite e enfraquece ao longo do dia. Uma análise da precipitação média nas mesmas três áreas mostrou que um aumento no fluxo de umidade nas áreas 1 e 2 gera uma diminuição da precipitação nesta mesma região, enquanto na área 3 o oposto é observado. Por fim, testes estatísticos mostraram que a parametrização Grell-Freitas foi a que mais se aproximou do observado, além de confirmar que o modelo regional gera melhores resultados ao resolver a convecção explicitamente.

Palavras-chave: ZCAS, JBN, transporte de umidade, precipitação, WRF 


\section{Abstract}

The South Atlantic Convergence Zone (SACZ) is the main precipitating system during the wet period of the South American Monsoon System (SAMS). The Low Level Jet of South America (LLJSA) is one of the mechanisms at work in the case of SACZ, extending from the Amazon region to the Southeast of Brazil. The main role of LLJSA is to transport heat and humidity from the tropics to higher latitudes. The transport of moisture by LLJSA during a SACZ is a topic rarely addressed in the scientific literature and therefore the objective of this work is to evaluate, quantify and associate this transport of moisture caused by LLJSA in precipitation, through a case study. The studied SACZ event took place between January 11 and 18, 2016, and was chosen for presenting the LLJAS and the associated moisture flow well defined and directed to the Southeast of Brazil. In association with the SACZ, Bolivia High and the High Levels Cyclonic Vortex of Northeast Brazil were also observed, present and well configured throughout the period. In addition to the analysis of the Climate Forecast System Version 2 (CFSv2), numerical simulations were also carried out using the regional model Weather, Research and Forecast (WRF) for the entire period of the system. The WRF was run with 3 nested grids, where the convection was solved explicitly during the period of highest system intensity in the grid of $3 \mathrm{~km}$ of horizontal spacing. The cumulus parameterizations of Kain-Fritch (oldest) and Grell-Freitas (most recent) were tested, analyzing the differences between their solutions. The results show that both numerical experiments provide solutions with synoptic characteristics close to those shown by the CFSv2 analysis, but with divergences both in the positioning and in the intensity of the LLJSA and the associated moisture flow. As a result, the precipitation generated by the two parameterizations performed poorly. It is concluded that the precipitation modeled in this case SACZ is strongly dependent on the 
correct LLJSA simulation. The time series analysis of the average moisture flow in three different areas of the simulated domain confirms its greatest intensity in the region where the LLJSA is well defined. A well-defined daytime cycle was found, which intensifies during the night and weakens throughout the day. An analysis of the average precipitation in the same three areas showed that an increase in the flow of moisture in areas 1 and 2 generates a decrease in precipitation in this same region, while in area 3 the opposite is observed. Finally, statistical tests showed that the Grell-Freitas parameterization was the one that came closest to what was observed, in addition to confirming that the regional model generates better results when resolving the convection explicitly.

Keyword: SACZ, LLJ, moisture transport, precipitation, WRF 


\section{Lista de Figuras}

2.1 Representação das principais estruturas integrantes do SMAS em baixos, médios (setas finas) e altos níveis (setas grossas) Fonte: Adaptado de Zhou e Lau (1998). . . . . . . . . . . . . . . . . . . . 24

2.2 Regiões onde JBNs são conhecidos ou suspeitos de ocorrerem com alguma regularidade (sombreado) e onde complexos convectivos ocorrem frequentemente durante o verão (caixas abertas). Os quadrados denotam locais onde JBNs foram observados. Fonte: Stensrud $(1996) \ldots \ldots$

2.3 Esquema do JBNAS (LLJ na figura). A seta azul (verde) representa o transporte de umidade da Bacia Amazônica (do Atlântico Sul) em direção à Bacia do Prata, indicada em sombreado azul. O quadro menor é uma seção vertical esquematizando o fluxo meridional de umidade pelo JBNAS. MCS denota Sistemas Convectivos de Mesoescala (SCMs); ET é evapotranspiração na Amazônia. Fonte: Vera et al. $(2006)$. . . . . . . . . . . . . . . . . 31

3.1 Região de integração do modelo WRF. Grades de 27 km, 9 km e 3 km. . . 40

3.2 A esquerda são exibidos os pontos de lançamento das sondagens que coletaram os dados utilizados para análise do perfil vertical do vento. A direita é possível notar o posicionamento do corte vertical realizados tanto nos dados de magnitude do vento (linhas continuas) quanto do fluxo de umidade (linhas tracejadas). . . . . . . . . . . ........ 46 
3.3 Áreas de análise do fluxo de umidade e precipitação. A área 1 abrange parte do corredor de umidade entre a região amazônica e o Sudeste do Brasil (seta azul). A área 2 exibe amostras da região sob efeito das circulações dos alísios de nordeste e da ASAS, que entram pelo Nordeste do Brasil e seguem em direção ao Sudeste brasileiro (setas verdes). A área 3 abrange o Sudeste do Brasil e parte norte do estado do Paraná, afetada por ambas as circulações.

4.1 Médias do vento horizontal (vetores) e convergência de massa $\left[10^{-5} s^{-1}\right]$ (sombreado) no nível de 850 hPa entre os dias 11 e 18 de janeiro de 2016 para (a) análises do CFSv2; (b) simulação CTRL; (c) simulação GF. . . . . . 50

4.2 Médias altura geopotencial [m] (linhas de contorno) e movimento vertical ascendente $\left[\mathrm{m} \mathrm{s}^{-1}\right]$ (sombreado) em $500 \mathrm{hPa}$ entre os dias 11 e 18 de janeiro de 2016 para (a) análises do CFSv2; (b) simulação CTRL; (c) simulação GF. 50

4.3 Médias do vento horizontal (linhas de corrente) e divergência de massa $\left[10^{-5}\right.$ $s^{-1}$ ] (sombreado mostrando apenas valores positivos) no nível de $200 \mathrm{hPa}$ entre os dias 11 e 18 de janeiro de 2016 para (a) análises do CFSv2; (b) simulação CTRL; (c) simulação GF . . . . . . . . . . . . . . . . . . .

4.4 Campos do dia 11 de janeiro de 2016, mostrando: Vento horizontal (vetores) e convergência de massa $\left[10^{-5} s^{-1}\right]$ (sombreado) no nível de $850 \mathrm{hPa}$ para (a) análises CFSv2, (b) simulação CTRL e (c) simulação GF. Altura geopotencial $[\mathrm{m}]$ (linhas de contorno) e movimento vertical ascendente $\left[\mathrm{m} s^{-1}\right]$ em 500 hPa para (d) análises CFSv2, (e) simulação CTRL e (f) simulação GF. Vento horizontal (linhas de corrente) e divergência de massa $\left[10^{-5} s^{-1}\right]$ (sombreado) no nível de 200 hPa para (g) análises CFSv2, (h) simulação CTRL e (i) simulação GF . . . . . . . . . . . . . . . . 52

4.5 Campos de água precipitável [mm] (sombreado) do dia 11 de janeiro de 2016 para (a) análises CFSv2, (b) CTRL e (c) GF). . . . . . . . . . 5 53

4.6 Mesmos campos da Figura 4.4, porém para o dia 12/01/2016. . . . . . 5 54

4.7 Mesmos campos da Figura 4.5, porém para o dia 12/01/2016. . . . . . . 55

4.8 Imagem de satélite geostacionário GOES-13 no canal infravermelho, com temperatura realçada por cores, para os dias: (a) 11/01/2016; (b) 12/01/2016. Fonte: DSA-CPTEC . . . . . . . . . . . . . . 5 56 
4.9 Mesmos campos da Figura 4.4, porém para o dia 13/01/2016.

4.10 Mesmos campos da Figura 4.5, porém para o dia 13/01/2016 . . . . . . . 58

4.11 Mesmos campos da Figura 4.4, porém para o dia 14/01/2016. . . . . . . . 60

4.12 Mesmos campos da Figura 4.5 , porém para o dia 14/01/2016 . . . . . . . 61 61

4.13 Imagem de satélite no canal de temperatura realçada para os dias: (a) 13/01/2016; (b) 14/01/2016. Fonte: DSA-CPTEC . . . . . . . . . . 61

4.14 Mesmos campos da Figura 4.4, porém para o dia 15/01/2016 . . . . . . . 63

4.15 Mesmos campos da Figura 4.5, porém para o dia 15/01/2016. . . . . . . 64

4.16 Mesmos campos da Figura 4.4, porém para o dia 16/01/2016. . . . . . . . 65

4.17 Mesmos campos da Figura 4.5, porém para o dia 16/01/2016. . . . . . . 666

4.18 Imagem de satélite no canal de temperatura realçada para os dias: (a) 15/01/2016; (b) 16/01/2016. Fonte: DSA-CPTEC . . . . . . . . . 67

4.19 Mesmos campos da Figura 4.4 , porém para o dia 17/01/2016. . . . . . . 68

4.20 Mesmos campos da Figura 4.5, porém para o dia 17/01/2016. . . . . . . . 69

4.21 Mesmos campos da Figura 4.4, porém para o dia 18/01/2016. . . . . . . . 70

4.22 Mesmos campos da Figura 4.5, porém para o dia 18/01/2016 . . . . . . . 717

4.23 Imagem de satélite no canal de temperatura realçada para os dias: (a) 17/01/2016; (b) 18/01/2016. Fonte: DSA-CPTEC . . . . . . . . . . 71

4.24 Média da magnitude e direção do vento (sombreado $[\mathrm{m} / \mathrm{s}]$ e vetor, respectivamente) em $850 \mathrm{hPa}$ pelos dados do CFSv2 durante janeiro de 2016, para os dias: a) 11; b) 12 ; c) 13 ; d) 14; e) 15 ; f) 16 ; g) 17 ; e h) $18 . \ldots . .$.

4.25 Média diária da magnitude do vento em $850 \mathrm{hPa}$ (sombreado [m/s] e vetor) para 11 de janeiro de 2016 pelas simulações: a) CTRL; b) GF. . . . . . . . 73

4.26 Idem à Figura 4.25 , porém para o dia $12 / 01 / 2016 \ldots$. . . . . . . . . . 74

4.27 Idem à Figura 4.25 , porém para o dia 13/01/2016 . . . . . . . . . . . 75

4.28 Comparação do perfil vertical entre as medidas de radiossondagens (linha preta), análise do CFSv2 (linha vermelha), simulação CTRL (linha azul), simulação GF (linha verde) em 11 de janeiro de 2016 às 0000 UTC, nos aeroportos de: a) Campo de Marte, na cidade de São Paulo; b) Campo Grande; c) Curitiba; d) Cuiabá 
4.29 Comparação do perfil vertical entre as medidas de radiossondagens (linha preta), análise do CFSv2 (linha vermelha), simulação CTRL (linha azul), simulação GF (linha verde) em 11 de janeiro de 2016 às 1200 UTC, nos aeroportos de: a) Campo de Marte, na cidade de São Paulo; b) Campo Grande; c) Curitiba; d) Cuiabá. . . . . . . . . . . . . . . . . 77

4.30 Comparação do perfil vertical entre as medidas de radiossondagens (linha preta), análise do CFSv2 (linha vermelha), simulação CTRL (linha azul), simulação GF (linha verde) em 12 de janeiro de 2016 às 0000 UTC, nos aeroportos de: a) Campo de Marte, na cidade de São Paulo; b) Campo Grande; c) Cuiabá; d) Londrina. . . . . . . . . . . . . . . . . . . . . . .

4.31 Comparação do perfil vertical entre as medidas de radiossondagens (linha preta), análise do CFSv2 (linha vermelha), simulação CTRL (linha azul), simulação GF (linha verde) em 12 de janeiro de 2016 às 1200 UTC, nos aeroportos de: a) Campo de Marte, na cidade de São Paulo; b) Campo Grande; c) Cuiabá; d) Galeão, no Rio de Janeiro; e) Londrina; f) Vitória. . 79

4.32 Comparação do perfil vertical entre as medidas de radiossondagens (linha preta), análise do CFSv2 (linha vermelha), simulação CTRL (linha azul), simulação GF (linha verde) em 13 de janeiro de 2016 às 0000 UTC, nos aeroportos de: a) Campo de Marte, na cidade de São Paulo; b) Campo Grande; c) Confins, em Belo Horizonte; d) Cuiabá; e) Vitória. . . . . . . . .

4.33 Comparação do perfil vertical entre as medidas de radiossondagens (linha preta), análise do CFSv2 (linha vermelha), simulação CTRL (linha azul), simulação GF (linha verde) em 13 de janeiro de 2016 às 1200 UTC, nos aeroportos de: a) Confins, na cidade de Belo Horizonte; b) Cuiabá; c) Vitória. 84

4.34 Cortes verticais da magnitude do vento (sombreado, $[\mathrm{m} / \mathrm{s}]$ ) entre os pontos $\left(27^{\mathrm{O}} \mathrm{S} ; 51^{\mathrm{O}} \mathrm{W}\right)$ e $\left(16^{\mathrm{O}} \mathrm{S} ; 46^{\mathrm{O}} \mathrm{W}\right)$ no dia $11 / 01 / 2016$ às $000 \mathrm{UTC}((\mathrm{a})$ CFSv2; (c) Simulação CTRL; (e) Simulação GF) e 1200 UTC ((b) CFSv2; (d) Simulação CTRL; (f) Simulação GF) . . . . . . . . . . . . . . . . . .

4.35 Cortes verticais da magnitude do vento (sombreado, $[\mathrm{m} / \mathrm{s}]$ ) entre os pontos $\left(23^{\mathrm{O}} \mathrm{S} ; 54,5^{\mathrm{O}} \mathrm{W}\right)$ e $\left(15^{\mathrm{o}} \mathrm{S} ; 51^{\mathrm{o}} \mathrm{W}\right)$ no dia $12 / 01 / 2016$ às $0000 \mathrm{UTC}((\mathrm{a})$ CFSv2; (c) Simulação CTRL; (e) Simulação GF) e 1200 UTC ((b) CFSv2; (d) Simulação CTRL; (f) Simulação GF) . . . . . . . . . . . . . . . . . 
4.36 Cortes verticais da magnitude do vento (sombreado, $[\mathrm{m} / \mathrm{s}]$ ) entre os pontos $\left(22^{\mathrm{o}} \mathrm{S} ; 56^{\mathrm{o}} \mathrm{W}\right)$ e $\left(14^{\mathrm{o}} \mathrm{S} ; 54^{\mathrm{o}} \mathrm{W}\right)$ no dia $13 / 01 / 2016$ às 0000 UTC ((a) CFSv2; (c) Simulação CTRL; (e) Simulação GF) e 1200 UTC ((b) CFSv2; (d) Simulação CTRL; (f) Simulação GF). . . . . . . . . . . . . . . . . .

4.37 Transporte de umidade $\left[\mathrm{kgm}^{-1} \mathrm{~s}^{-1}\right]$ médio diário pelo CFSv2 para os dias: a) 11 de janeiro de 2016; b) 12 de janeiro de 2016; c) 13 de janeiro de 2016; d) 14 de janeiro de 2016; e) 15 de janeiro de 2016; f) 16 de janeiro de 2016; g) 17 de janeiro de 2016 ; h) 18 de janeiro de 2016 . . . . . . . . . . .

4.38 Campos de fluxo de umidade $\left[\mathrm{kg} \mathrm{m}^{-1} \cdot \mathrm{s}^{-1}\right]$ do dia 11 de janeiro de 2016. (a) Simulação CTRL; (b) diferença de fluxo de umidade entre a simulação CTRL e o CFSv2 (CTRL - CFSv2); (c) simulação GF; (d) diferença de fluxo de umidade entre a simulação GF e o CFSv2 (GF - CFSv2). . . . . . . . . 95

4.39 Mesmos campos da Figura 4.38, porém para o dia 12/01/2016 . . . . . . . 97

4.40 Mesmos campos da Figura 4.38, porém para o dia 13/01/2016 . . . . . . . 98

4.41 Cortes verticais do vento horizontal (barbelas), magnitude do vento horizontal (linhas de contorno, $[\mathrm{m} / \mathrm{s}]$ ) e fluxo de umidade (sombreado $\left[\mathrm{kg}^{-\mathrm{m}^{-1}} \cdot \mathrm{s}^{-1}\right]$ ) entre os pontos $\left(15^{\mathrm{O}} \mathrm{S} ; 60^{\mathrm{O}} \mathrm{W}\right)$ e $\left(25^{\mathrm{O}} \mathrm{S} ; 45^{\mathrm{O}} \mathrm{W}\right)$ no dia $11 / 01 / 2016$ às 0000 UTC ((a) CFSv2; (c) Simulação Controle; (e) Simulação Grell Freitas) e 1200 UTC ((b) CFSv2; (d) Simulação Controle; (f) Simulação Grell Freitas). 100

4.42 Cortes verticais do vento horizontal (barbelas), magnitude do vento horizontal (linhas de contorno, $[\mathrm{m} / \mathrm{s}]$ ) e fluxo de umidade (sombreado $\left[\mathrm{kg} \cdot \mathrm{m}^{-1} \cdot \mathrm{s}^{-1}\right]$ ) entre os pontos $\left(15^{\underline{\mathrm{O}}} \mathrm{S} ; 60^{\mathrm{O}} \mathrm{W}\right)$ e $\left(25^{\mathrm{O}} \mathrm{S} ; 45^{\mathrm{O}} \mathrm{W}\right)$ no dia $12 / 01 / 2016$ às 0000 UTC ((a) CFSv2; (c) Simulação Controle; (e) Simulação Grell Freitas) e 1200 UTC ((b) CFSv2; (d) Simulação Controle; (f) Simulação Grell Freitas).102

4.43 Cortes verticais do vento horizontal (barbelas), magnitude do vento horizontal [linhas de contorno, $(\mathrm{m} / \mathrm{s})]$ e fluxo de umidade (sombreado $\left[\mathrm{kg}^{-\mathrm{m}^{-1}} \cdot \mathrm{s}^{-1}\right]$ ) entre os pontos $\left(15^{\mathrm{O}} \mathrm{S} ; 60^{\mathrm{O}} \mathrm{W}\right)$ e $\left(24^{\mathrm{O}} \mathrm{S} ; 45^{\mathrm{O}} \mathrm{W}\right)$ no dia $13 / 01 / 2016$ às 0000 UTC ((a) CFSv2; (c) Simulação Controle; (e) Simulação Grell Freitas) e 1200 UTC ((b) CFSv2; (d) Simulação Controle; (f) Simulação Grell Freitas). 103

4.44 Série temporal da média de fluxo de umidade nas áreas, utilizando os dados do CFSv2, CTRL e GF na grade 1. . . . . . . . . . . . . . . 105 
4.45 Série temporal da média de fluxo de umidade nas áreas 1, 2 e 3, utilizando os dados das simulações CTRL e GF na grade 3. . . . . . . . . . . . . 107

4.46 Precipitação acumulada $(\mathrm{mm})$ durante toda a atuação do sistema, pelos dados do(a) (a) MERGE; (b) simulação CTRL; (c) simulação GF. . . . . . 109

4.47 Acumulados diários de precipitação (mm) do dia 11/01/2016: a) MERGE;

b) CTRL - GF; c) Simulação CTRL; d) CTRL - MERGE; e) Simulação GF;

f) GF- MERGE. . . . . . . . . . . . . . . . . . . . . . 110

4.48 Mesmos campos da Figura 4.47, porém para o dia 12/01/2016 . . . . . . . 112

4.49 Mesmos campos da Figura 4.47, porém para o dia 13/01/2016. . . . . . . . 113

4.50 Mesmos campos da Figura 4.47, porém para o dia 14/01/2016 . . . . . . 115

4.51 Mesmos campos da Figura 4.47, porém para o dia 15/01/2016 . . . . . . . 116

4.52 Mesmos campos da Figura 4.47, porém para o dia 16/01/2016 . . . . . . . 118

4.53 Mesmos campos da Figura 4.47, porém para o dia 17/01/2016 . . . . . . . 119

4.54 Mesmos campos da Figura 4.47, porém para o dia 18/01/2016 . . . . . . . 120

4.55 Série temporal da média de precipitação acumulada na área, utilizando os

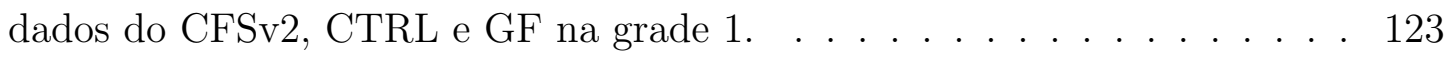

4.56 Gráfico de dispersão entre a precipitação média observada pelo MERGE e o resultado da grade 1 das simulações CTRL e GF nas áreas 1, 2 e 3. . . . 124

A.1 Ciclo diurno idealizado da CLA sob forçante sinótica fraca, dividida em três partes principais: camada de mistura, camada residual e camada limite estável noturna. Fonte: Kannenberg (2019), adaptado de Stull (2009) . . . 146

B.1 Transporte de umidade médio diário pela simulação CTRL para os dias: a) 14 de janeiro de 2016; b) 15 de janeiro de 2016; c) 16 de janeiro de 2016; d) 17 de janeiro de 2016; e) 18 de janeiro de 2016 . . . . . . . . . . . 149

B.2 Transporte de umidade médio diário pela simulação GF para os dias: a) 14 de janeiro de 2016; b) 15 de janeiro de 2016; c) 16 de janeiro de 2016; d) 17 de janeiro de 2016; e) 18 de janeiro de 2016.

C.1 Valor e nível de máxima intensidade do vento nos baixos níveis da atmosfera nos pontos de lançamento de radiossondagens entre os dias 11/01/2016 e $13 / 01 / 2016$. 


\section{Lista de Tabelas}

3.1 Principais configurações do WRF utilizadas nas simulações. . . . . . . . . . 41

3.2 Principais parametrizações físicas utilizadas nas simulações com o WRF. 42

4.1 BIAS e RMSE da precipitação simulada por ambos os experimentos entre os $\operatorname{dias} 11$ e $13 / 01 / 2016 . \ldots \ldots \ldots \ldots$ 



\section{Sumário}

1. Introdução . . . . . . . . . . . . . . . . . . . . . . 19

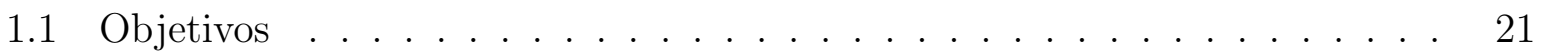

2. Revisão Bibliográfica . . . . . . . . . . . . . . . . . . . . . . . . 23

2.1 O Sistema de Monções da América do Sul (SMAS) . . . . . . . . . . . [ 23

2.1.1 Estruturas Associadas ao SMAS . . . . . . . . . . . 24 24

2.1.2 Evolução do SMAS . . . . . . . . . . . . . . . . 25

2.2 A Zona de Convergência do Atlântico Sul (ZCAS) . . . . . . . . . . . . [26

2.2.1 Características e Critérios de Identificação da ZCAS . . . . . . . . . 26

2.2.2 Forçantes e Variabilidade da ZCAS . . . . . . . . . . . . . . . 27

2.2.3 Transporte de Umidade Associado à ZCAS . . . . . . . . . . . . . . 28

2.3 O Jato de Baixos Níveis $(\mathrm{JBN}) \quad \ldots \ldots \ldots$

2.3.1 O JBN da América do Sul (JBNAS) . . . . . . . . . . . . . 30

2.3.2 Critérios de Identificação dos JBNs . . . . . . . . . . . . . . . 33

3. Dados e Metodologia . . . . . . . . . . . . . . . . . . . . . 35

3.1 Caso Selecionado . . . . . . . . . . . . . . . . . 35

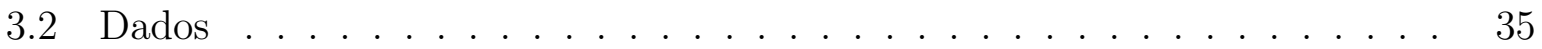

3.2.1 Análises CFSv2 . . . . . . . . . . . . . . . . . 35

3.2 .2 Imagens de Satélite . . . . . . . . . . . . . . . . . . . 37

3.2 .3 Precipitação pelo MERGE . . . . . . . . . . . . . . 37

3.2.4 Sondagens Atmosféricas . . . . . . . . . . . . . . . . 38

3.3 Simulações Numéricas . . . . . . . . . . . . . . . . . . . . . . . . . 38

3.3.1 Modelo WRF ....................... 38 
3.3.2 Parametrizações de Processos Subgrade no WRF . . . . . . . . 39

3.3.3 Configurações do Modelo . . . . . . . . . . . . . . . . . . . . 40

3.3.3.1 Parametrização Cúmulos de Kain-Fritsch . . . . . . . . . 42

3.3.3.2 Parametrização Cúmulos de Grell-Freitas . . . . . . . . . . 43

3.4 Métodos de Análise dos Dados . . . . . . . . . . . . . . . . . . . . 44

3.4.1 Características Sinóticas da ZCAS . . . . . . . . . . . 44

3.4.2 Estimativa das Contribuições Físicas do JBN . . . . . . . . . . 44

3.4 .3 Análise da Precipitação . . . . . . . . . . . . . . . . . . . . . 46

3.4.4 Análise de Séries Temporais . . . . . . . . . . . . . . . . 47

3.4.5 Validação dos Resultados de Precipitação . . . . . . . . . . . . . . 48

4. Resultados e Discussões . . . . . . . . . . . . . . . . . . . . . 49

4.1 Análise Sinótica . . . . . . . . . . . . . . . . . . . . . . . . . 49 49

4.1.1 Características Gerais do Caso . . . . . . . . . . . . . . 49 49

4.1 .2 Evolução Diária . . . . . . . . . . . . . . . . . . . . . . . . . . . 51

4.2 Jato de Baixos Níveis . . . . . . . . . . . . . . . . . . 72

4.2 .1 Campos Espaciais . . . . . . . . . . . . . . . . . . 72

4.2 .2 Perfis Verticais do Vento . . . . . . . . . . . . . . . 75

4.2 .3 Cortes Verticais . . . . . . . . . . . . . . . . 86

4.3 Fluxo de Umidade . . . . . . . . . . . . . . . . . . . . . . . . . . . . . 92

4.3 .1 Campos Espaciais . . . . . . . . . . . . . . . . . . . . 92

4.3 .2 Cortes Verticais . . . . . . . . . . . . . . . . . . . . 99

4.3 .3 Séries Temporais . . . . . . . . . . . . . . . . . . . . . . 104

4.4 Análise da Precipitação . . . . . . . . . . . . . . . . . . . . . . . . . . . . 108

4.4 .1 Acumulado Total . . . . . . . . . . . . . . . . . . . . 108

4.4 .2 Acumulados Diários . . . . . . . . . . . . . . . . . 109

4.4.3 Séries Temporais e Testes de Erro . . . . . . . . . . . . . . . 122

5. Conclusões . . . . . . . . . . . . . . . . . . . . . . . . . . . . . . . . 127

5.1 Considerações Finais … . . . . . . . . . . . . . . . . . . 127

5.2 Sugestões Para Trabalhos Futuros . . . . . . . . . . . . . . . . 130

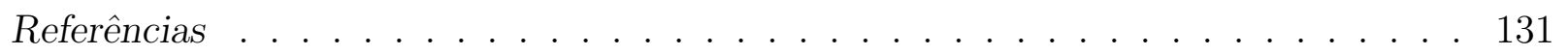


A. Mecanismos de Formação do JBN . . . . . . . . . . . . . . . . . . . . . . . . . . 145

A.1 Oscilação Inercial . . . . . . . . . . . . . . . . . . . . . . 145

A.2 Efeitos Topográficos . . . . . . . . . . . . . . . . 147

A.3 Forçantes de escala sinótica . . . . . . . . . . . . . . . . . . . . 148

B. Figuras Complementares . . . . . . . . . . . . . . . . . . . . 149

B.1 Fluxo de Umidade da Simulação CTRL . . . . . . . . . . . . . . . . . 149

B.2 Fluxo de Umidade da Simulação GF . . . . . . . . . . . . . . . . . . . . 150

C. Tabela de Atuação do JBN . . . . . . . . . . . . . . . . . . . . . . . . . . 151 

Capítulo 1

\section{Introdução}

A presença de um Sistema de Monções na América do Sul (SMAS) foi formalmente estabelecida por Zhou e Lau (1998). Segundo os mesmos, embora os ventos em superfície na região tropical da América do Sul (AS) sejam de leste ao longo de todos os meses do ano, os campos de anomalia destes ventos durante o verão (DJF) e o inverno (JJA) evidenciam uma reversão na circulação (principal característica de todos os sistemas de monções, segundo Webster (1987)). Esta circulação de monção é induzida pelo contraste térmico entre o continente sul-americano e o oceano Atlântico Tropical. Esta característica, somada à presença de outras estruturas e sistemas típicos para cada época do ano, definem o SMAS.

Um dos fenômenos atmosféricos que compõe o SMAS é a Zona de Convergência do Atlântico Sul (ZCAS). Ela corresponde a uma banda de nebulosidade convectiva que se estende normalmente desde o sul da Amazônia até o oceano Atlântico Sudoeste e é o principal sistema precipitante durante o verão nas regiões Sudeste e Centro-Oeste do Brasil (Kodama, 1992, 1993, Satyamurty et al., 1998), afetando diversos setores importantes, como recursos hídricos, agricultura, saúde humana e a atividade econômica em geral.

Durante os dias 11 e 18 de janeiro de 2016, um evento de ZCAS foi observado sobre os estados do Paraná (PR), São Paulo (SP), Rio de Janeiro (RJ), Espírito Santo (ES), Minas Gerais (MG), Goiás (GO), Tocantins (TO), Mato Grosso (MT), Mato Grosso do Sul (MS), Rondônia (RO), Acre (AC) e Amazonas (AM). O fenômeno causou diversos danos materiais e ambientais, afetando a população desses estados. Segundo o banco de dados do Sistema Integrado de Informações sobre Desastres (S2ID), durante o evento, 4 pessoas vieram a óbito, 43 ficaram feridas, 972 desabrigadas e 10.282 desalojadas (dados disponíveis em: https://s2id.mi.gov.br/paginas/relatorios/). A configuração atmosférica deste evento de 
ZCAS estava bem definida, ou seja, todos os sistemas sinóticos responsáveis pela estrutura do fenômeno estavam presentes, especialmente o corredor de umidade em baixos níveis caracterizado como Jato de Baixos Níveis (JBN), que se apresentou intenso e direcionado para a Região Sudeste do Brasil (vide seção 4.1). Sendo assim, este evento de ZCAS foi escolhido para embasar este trabalho, devido à sua relevância tanto socioambiental quanto meteorológica.

O JBN é um fenômeno caracterizado por um máximo relativo no perfil vertical da magnitude do vento na baixa troposfera (entre 900 e $600 \mathrm{hPa}$, aproximadamente), sendo observado em várias regiões do mundo, geralmente a leste de grandes cadeias montanhosas ou sobre regiões de intensos gradientes térmicos (Stensrud, 1996). O JBN da América do Sul (JBNAS) corresponde a um máximo de intensidade do vento entre aproximadamente 1 e $2 \mathrm{~km}$ de altitude, com escoamento de norte-noroeste em direção ao sudeste da América do Sul, a leste da Cordilheira dos Andes (Marengo et al., 2004). As regiões mais frequentemente afetadas pelo JBNAS são o norte da Argentina e o Sul do Brasil.

Os JBNs desempenham um papel fundamental na circulação atmosférica global ao realizarem o transporte de calor e umidade de regiões tropicais para latitudes sub e extratropicais (Stensrud, 1996; Vera et al., 2006). Na AS, este transporte é um dos principais ingredientes para a formação de Sistemas Convectivos de Mesoescala (Salio et al., 2002), de Complexos Convectivos de Mesoescala sobre a região da Bacia do Prata (Velasco e Fritsch, 1987) e da ZCAS (Herdies et al., 2002), sendo esta última de especial interesse para este trabalho.

Embora a literatura sobre os JBNs seja vasta e rica em termos de características físicas, dinâmicas e climatológicas, bem como em termos do transporte de umidade efetuado por este fenômeno (Uccellini e Johnson, 1979; Berri e Inzunza, 1993; Stensrud, 1996; Santos et al. 2008), há uma lacuna no que diz respeito ao papel específico do JBNAS no transporte de umidade junto aos episódios ZCAS. Nesta perspectiva, estudos aprofundados sobre observações e o uso de modelos numéricos tornam-se extremamente relevantes para o melhor entendimento do sistema e sua atuação em casos concretos e apontam caminhos em relação à simulação numérica do fenômeno em escala regional.

O modelo regional de previsão numérica de tempo e simulação atmosférica Weather, Research and Forecasting (WRF) (SKAMAROCK et al., 2008), desenvolvido em conjunto pelo National Center for Atmospheric Research (NCAR) e pelo National Center 
for Environmental Prediction (NCEP) permite a obtenção de uma ampla gama de dados meteorológicos por meio de simulações numéricas, com alta resolução temporal e espacial.

Na próxima subseção, são apresentados os objetivos deste trabalho (seção 1.1). Na sequência, encontra-se a Revisão Bibliográfica (seção 2), a descrição de Dados e Metodologia utilizados para o desenvolvimento do estudo (seção 3) e os Resultados e Discussões acerca dos mesmos (seção 4). Por fim, no Capítulo 5, são apresentadas as Considerações Finais e em seguida estão dispostas as Referências Bibliográficas que fundamentam a pesquisa.

\subsection{Objetivos}

Dada a relevância do JBNAS para os sistemas precipitantes da AS, em especial a ZCAS, o principal objetivo deste trabalho é determinar a importância do vapor d'água transportado pelo JBNAS na precipitação durante o evento ZCAS observado na Região Sudeste do Brasil entre 11 e 18 de janeiro de 2016 por meio de reanálises globais e simulações regionais com o modelo WRF.

Os objetivos específicos deste trabalho são:

i. Simular o evento o ZCAS selecionado com o modelo WRF, a fim de verificar a reprodutibilidade de sistemas sinóticos e regionais que estruturalmente compõem o fenômeno atmosférico;

ii. Avaliar qualitativa e quantitativamente as diferenças geradas por experimentos numéricos resultantes de duas parametrizações cúmulos, acionadas apenas nas grades de 27 e 9 km de espaçamento de grade;

iii. Avaliar a reprodutibilidade da ZCAS numa terceira grade com espaçamento de 3 km entre os pontos horizontais, onde a convecção é resolvida explicitamente. 
Capítulo 2

\section{Revisão Bibliográfica}

\subsection{O Sistema de Monções da América do Sul (SMAS)}

Existem diferentes definições na literatura científica para caracterizar as regiões do globo que se enquadram no regime de monção. O conceito mais tradicional é associado à reversão sazonal dos ventos em superfície e a presença de estações secas e chuvosas bem definidas (Webster, 1987). Um dos principais mecanismos físicos responsáveis pela circulação monçônica é a interação provocada pelo contraste térmico continente-oceano (Trenberth et al. 2000). As características e aspectos climatológicos dos sistemas de monção têm sido amplamente abordadas em estudos feitos para diversas regiões do mundo, como a Ásia (Webster et al., 1998; Ding, 2007; Sperber et al., 2013), Austrália (Holland, 1986; Kim et al., 2006; Sheng-Ping, 2015), América do Sul (AS) (Zhou e Lau, 1998; Gan et al., 2004; Carvalho e Cavalcanti, 2016) e África (Sultan e Janicot, 2003; Segele et al., 2015).

$\mathrm{Na}$ AS, a presença de um regime de monção só foi realmente admitida quando Zhou e Lau (1998) identificaram uma reversão sazonal na direção dos ventos em baixos níveis, que fica evidente quando a componente média anual dos ventos é removida. Esta característica difere de outros sistemas de monções, em que a reversão aparece no campo do vento observado em superfície, sendo desnecessário o uso de filtros. Nos campos anômalos, os ventos aparecem com direção noroeste (sudeste) durante o verão (inverno), convergindo para a região central do Brasil devido ao efeito de deflexão causado pela Cordilheira dos Andes.

Segundo Reboita et al. (2010), o ciclo anual de precipitação na região que compreende de noroeste a sudeste do Brasil, o Equador e o norte do Peru corresponde ao SMAS, com os máximos pluviométricos ocorrendo no verão. A estrutura atmosférica que compõe o 
SMAS, bem como sua evolução no tempo, são abordadas com mais detalhes nas próximas subseções.

\subsubsection{Estruturas Associadas ao SMAS}

São várias as estruturas dos campos meteorológicos e sistemas atmosféricos que compõe o SMAS, sendo os principais sumarizados na Figura 2.1. Em baixos níveis (item 1), tem-se a presença de um escoamento desde o extremo noroeste da África até a região da baixa do Chaco, estudada por Gandu e Silva Dias (1998a) (item 3). Este escoamento inicia-se com os ventos alísios de nordeste (AN) atravessando o Oceano Atlântico Tropical e virando de noroeste ao chegarem no continente sul-americano e colidirem na Cordilheira dos Andes, gerando um fluxo de umidade a leste das montanhas denominado JBNAS (Marengo et al., 2004), item 2 da Figura 2.1. A ZCAS também aparece como elemento estruturante do SMAS (item 5), sendo resultado da junção entre o ramo norte da Alta Subtropical do Atlântico Sul (ASAS) (item 4) e os ventos de oeste de latitudes subtropicais da média troposfera (Kodama, 1992) (item 6), onde atua um cavado próximo à região da Foz do Rio Prata.

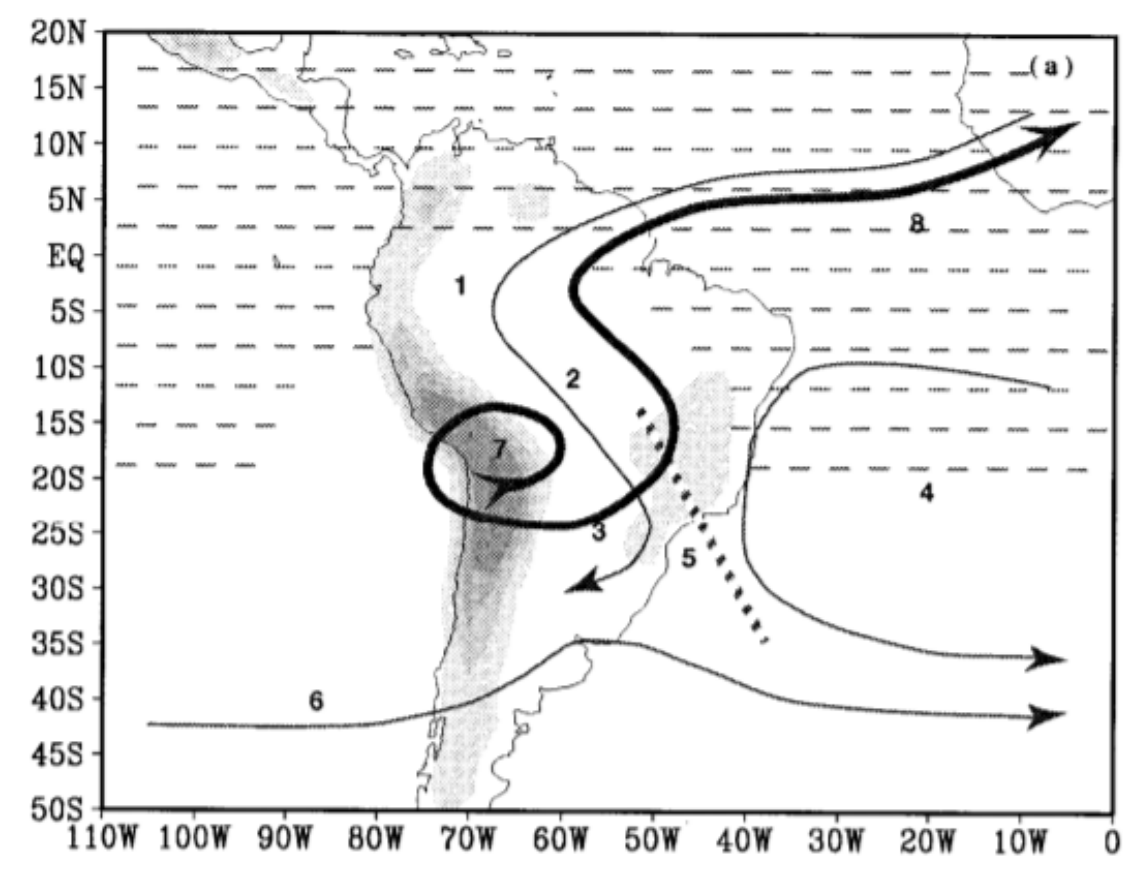

Figura 2.1: Representação das principais estruturas integrantes do SMAS em baixos, médios (setas finas) e altos níveis (setas grossas) Fonte: Adaptado de Zhou e Lau (1998).

Em altos níveis, o escoamento representado pela seta negra mais espeça na Figura 
2.1 evidencia a formação de uma circulação anti-ciclônica, denominada Alta da Bolívia (AB) (item 7) e de um cavado na região nordeste do Brasil (que pode se amplificar em algumas situações e desprender um Vórtice Ciclônico de Altos Níveis (VCAN) (Kousky e Alonso Gan, 1981)) ligado a um escoamento que cruza a região Equatorial no sentido contrário ao fluxo em superfície (item 8). A Cordilheira dos Andes também desempenha um papel fundamental no desenvolvimento do SMAS, uma vez que, embora não seja uma fonte de calor e evapotranspiração como é a floresta amazônica, representa uma barreira orográfica que é a responsável por grande parte do posicionamento da circulação de grande escala em baixos níveis da AS, assim como da ZCAS (Figueroa et al., 1995).

\subsubsection{Evolução do SMAS}

O ciclo de vida do SMAS é subdividido em 5 fases (Zhou e Lau, 1998). As fases I e II equivalem à fase onset de Vera et al. (2006), tal como a fase III corresponde à fase madura e as fases IV e V à fase de decaimento da monção. No período pré-monçônico (fase I), inicia-se o aquecimento sobre a região amazônica, associado a um forte cisalhamento vertical dos ventos. Durante a fase II, atividades ciclônicas de baixos níveis a sudoeste do Altiplano andino começam a surgir, juntamente com a intensificação dos alísios de nordeste, que cruzam o equador em direção aos Andes, onde são defletidos e formam um forte escoamento de noroeste. Nesta fase, a precipitação se desloca para a região central da AS e Região Sudeste brasileira, dando início aos episódios de ZCAS. O calor latente oriundo da atividade convectiva em nuvens tipo cummulus aquece a região, aumentando o contraste térmico entre o continente e os oceanos vizinhos, característica que representa o estabelecimento da estação de monção.

A precipitação atinge todo o Sudeste brasileiro durante o estágio maduro do SMAS (fase III). Nesta fase, dois giros se consolidam na atmosfera: a AB e o cavado do Nordeste brasileiro. Nesta fase, o ar quente está mais disperso sobre o continente, devido ao calor latente emitido pela intensa atividade convectiva. Na fase IV, inicia-se o decaimento da estação de monção, caracterizado pelo enfraquecimento dos alísios de nordeste e consequente redução da entrada de umidade no continente. O contraste de temperatura entre continente e oceano também diminui, o que desfavorece o cisalhamento vertical do vento. Ocorre também o enfraquecimento da AB, assim como enfraquece o Cavado do Nordeste. A fase $\mathrm{V}$ (pós-monção) é caracterizada pela reorganização da circulação da alta troposfera, 
com predominância de ventos de oeste e a diminuição do contraste de temperatura, que indica o fim da estação chuvosa.

O estabelecimento de um início para o SMAS, bem como sua duração e seu enfraquecimento foi objetivo de diversos trabalhos, com diferentes dados e metodologias Kousky, 1988; Marengo et al., 2001; Jones e Carvalho, 2002; Gan et al., 2004; da Silva e CarvaIho, 2007; Bombardi e Carvalho, 2011). No geral, há uma concordância nos resultados, que indicam o início da estação chuvosa entre outubro e novembro, com os máximos de precipitação ocorrendo de dezembro a fevereiro e o decaimento acontecendo entre março e abril.

\subsection{A Zona de Convergência do Atlântico Sul (ZCAS)}

A ZCAS corresponde a uma banda de nebulosidade persistente com orientação noroestesudeste, que se estende desde o sul da Amazônia até o sudoeste do oceano Atlântico Sul Kodama, 1992, 1993; Satyamurty et al., 1998; Liebmann et al., 2001; Carvalho et al., 2002, 2004). Ela atua sobre as Regiões Norte, Centro-Oeste e Sudeste do Brasil, podendo ser observada inicialmente por imagens de satélite e/ou pelo campo de OLR (Outgoing LongWave Radiation, em Inglês). A ZCAS é uma importante feição do sistema de monção, junto à atividade convectiva na Bacia Amazônica (Jones e Carvalho, 2002).

\subsubsection{Características e Critérios de Identificação da ZCAS}

Além da banda de nebulosidade com orientação típica de noroeste para sudeste quando vista por imagens de satélite, cobrindo boa parte das Regiões Norte, Nordeste, CentroOeste e Sudeste do País com oscilações em sua posição ao longo do tempo, algumas outras características sinóticas da atmosfera atuam em conjunto para a formação e a manutenção da ZCAS por períodos maiores do que alguns dias. Quadro (1994) definiu um evento de ZCAS quando os seguintes critérios são atendidos: 1) persistência da banda de nebulosidade por pelo menos 4 dias seguidos; 2) convergência de umidade na baixa e média troposfera; 3) zona de movimento ascendente do ar orientada no sentido NO-SE acompanhada do cavado semi-estacionário a leste dos Andes em 500 hPa; 4) intenso gradiente de temperatura potencial equivalente acompanhando a faixa de alta umidade específica do ar na média troposfera e 5) ocorrência de precipitação associada à zona de convergência. 
Nielsen et al. (2019) propõe que algumas características devem ser observadas para a definição e identificação de eventos de ZCAS, tais como: 1) em baixos níveis, uma convergência de umidade ao longo da orientação NO-SE, favorecida pelo JBN e os ventos alísios; 2) um cavado de níveis médios que pode ou não estar associado a um sistema frontal próximo do Sudeste do Brasil; 3) em altos níveis, a AB e o cavado do Nordeste, com este último podendo ou não apresentar vórtice desprendido associado; 4) é necessário que a divergência negativa em baixos níveis, o ômega negativo em médios níveis e a divergência positiva em altos níveis estejam espacialmente em fase.

\subsubsection{Forçantes e Variabilidade da ZCAS}

Os mecanismos que dão origem e manutenção à ZCAS não estão totalmente esclarecidos ainda hoje. Entretanto, estudos observacionais e numéricos apontam que este fenômeno sofre influências tanto remotas quanto locais. Casarin e Kousky (1986) sugeriram a existência de um mecanismo de propagação do tipo oscilação de 30-60 dias na região da Zona de Convergência do Pacífico Sul (ZCPS), pois, uma vez estabelecida convecção naquela região, a ZCAS se intensifica sobre a AS. A relação entre a intensidade da ZCAS, sua posição e as anomalias da temperatura da superfície do mar (TSM) do oceano Atlântico Sul foram discutidas em muitos estudos (Lenters e Cook, 1999, Robertson e Mechoso, 2000; Barreiro e Saravanan, 2002; Carvalho et al., 2004). Robertson e Mechoso (2000) mostraram que uma intensificação da ZCAS em escala interanual coincide com anomalias negativas (positivas) de TSM ao norte (sul) de $40^{\circ} \mathrm{S}$. Chaves e Nobre (2004) identificaram que anomalias de TSM positivas (negativas) são capazes de intensificar (enfraquecer) a ZCAS em um modelo de circulação geral atmosférica.

Figueroa et al. (1995) mostraram com experimento numérico que o posicionamento adequado da ZCAS depende da inclusão da topografia da Cordilheira dos Andes nas simulações. Entretanto, simulações sem a inserção dos Andes Gandu e Geisler, 1991; Figueroa et al., 1995; Kalnay et al., 1986) conseguiram reproduzir um padrão de divergência (convergência) em altos (baixos) níveis, com orientação semelhante à da ZCAS. Desta forma, embora os Andes não exerçam um papel fundamental na gênese da ZCAS, podem atuar na intensificação e direcionamento do escoamento em baixos níveis. Estudos numéricos também apontaram que o aquecimento diabático na Bacia Amazônica durante o verão induz uma circulação troposférica regional que apoia a convergência em baixos 
níveis que, por sua vez, mantém o componente continental da ZCAS Figueroa et al. 1995; Gandu e Silva Dias, 1998b)

Tanto o SMAS quanto a ZCAS apresentam variabilidades espaciais e temporais, pois seu desenvolvimento é dependente de uma ampla gama de escalas (Carvalho et al., 2002; Carvalho, 2002), como: oscilação diurna, via JBN (Herdies et al., 2002); mesoescala, por meio de vórtices ciclônicos de mesoescala (Quadro et al., 2012); sinótica, por meio da atuação de sistemas frontais (Siqueira e Machado, 2004), intra-sazonal (Nogués-Paegle e Mo, 1997; Liebmann et al., 1999; Carvalho et al., 2002; Jones e Carvalho, 2002; Ferraz e Grimm, 2004; Carvalho et al., 2004) e decadal (Carvalho et al., 2011).

A variabilidade da ZCAS e sua extensão em direção ao Oceano Atlântico promovem subsidência compensatória no sul do Brasil, Nordeste da Argentina e Uruguai (Figueroa et al., 1995; Nogués-Paegle e Mo, 1997; Gandu e Silva Dias, 1998; Liebmann et al., 1999). Vários destes estudos mostraram que a ZCAS varia como parte de um dipolo, sendo que sua intensificação se mostra associada a uma anomalia positiva de OLR centrada sobre o Uruguai e estendendo-se para a Argentina.

\subsubsection{Transporte de Umidade Associado à ZCAS}

Os primeiros trabalhos que identificaram a existência da ZCAS observaram a presença de um corredor onde atua um intenso transporte de umidade entre a região amazônica e o Sudeste do Brasil. Uma pesquisa focada no mecanismo responsável por este transporte foi feita por Herdies et al. (2002), ao analisar o balanço de umidade em diversas regiões do Brasil durante períodos de ZCAS e de não ZCAS, entre janeiro e fevereiro de 1999. Os autores verificaram que, durante os eventos de ZCAS, é observada uma forte convergência de umidade sobre a Bacia Amazônica, leste do Centro-Oeste e Região Sudeste do Brasil. Em contrapartida, é observada divergência sobre o oeste do Sul do Brasil, norte da Argentina e Paraguai. Mostram ainda que, durante a fase ativa da ZCAS (quando a atividade convectiva está mais intensa e a precipitação mais frequente durante o dia), um intenso fluxo de umidade proveniente do Oceano Atlântico tropical entra no continente pelo norte da AS e Nordeste do Brasil e dirige-se para o Sudeste brasileiro.

Utilizando do método de Funções Ortogonais Empíricas (EOFs, em Inglês) com dados de precipitação, temperatura, umidade e vento, e remoção do ciclo anual, Carvalho et al. (2011) mostraram que o transporte de umidade durante a fase úmida do SMAS e casos 
de ZCAS filtrados com o "Large-scale Index for the South American Monsoon" (LISAM) apresentou anomalia positiva entre a região norte da AS e o Sudeste do Brasil, ocorrendo em conjunto com o transporte de umidade com origem no oceano Atlântico Tropical.

Quadro et al. (2012) mostraram o avanço das análises na reprodução da precipitação observada durante eventos de ZCAS. Além disso, também evidenciaram que o Oceano Atlântico tropical tem grande importância no transporte de umidade para o Sudeste do Brasil, já que a convergência do fluxo de umidade entre a região amazônica e os alísios de nordeste é o que melhor explica a precipitação gerada durante a ZCAS.

\subsection{O Jato de Baixos Níveis (JBN)}

Por definição, o JBN representa um máximo na magnitude da velocidade do vento na baixa troposfera, cercado por regiões de grande cisalhamento vertical do vento horizontal (Bonner, 1968; Bonner e Paegle, 1970). Pode-se dizer que o principal papel do JBN é transportar calor e umidade de regiões tropicais para latitudes médias e altas (Stensrud, 1996).

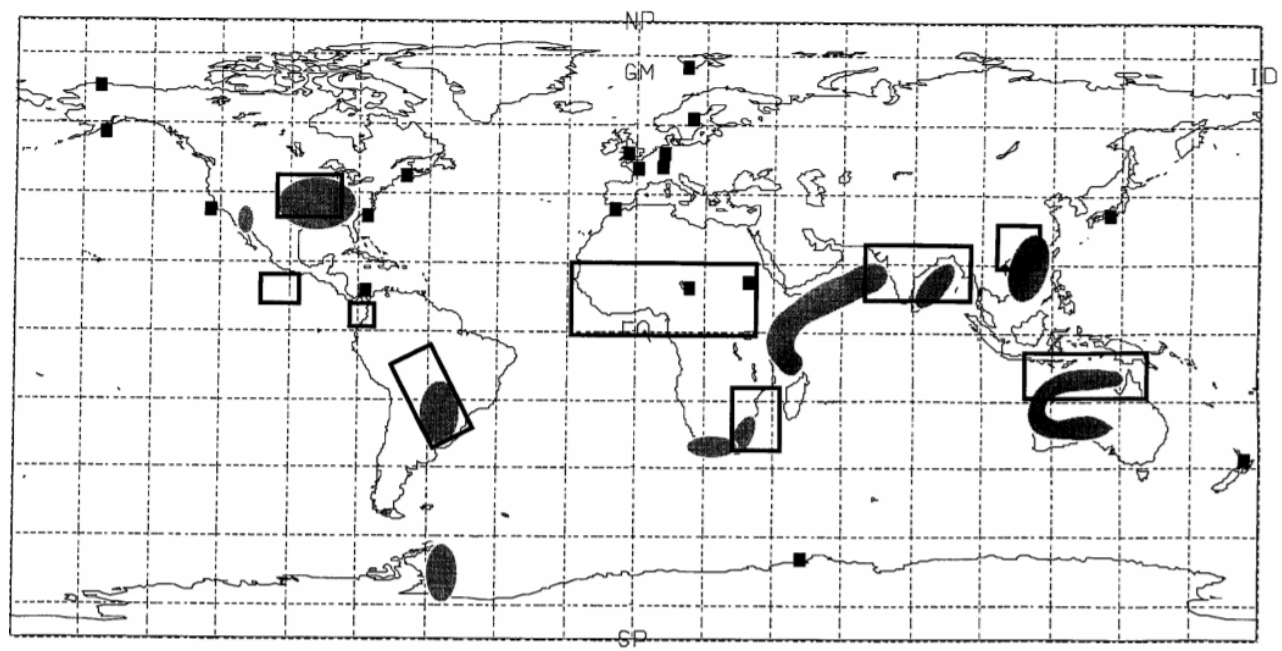

Figura 2.2: Regiões onde JBNs são conhecidos ou suspeitos de ocorrerem com alguma regularidade (sombreado) e onde complexos convectivos ocorrem frequentemente durante o verão (caixas abertas). Os quadrados denotam locais onde JBNs foram observados. Fonte: Stensrud (1996)

As primeiras pesquisas sobre JBNs datam da década de 1930, quando Goualt (1938) (apud Blackadar (1957)) e Farquharson (1939) descobriram a existência dos JBNs africanos. O JBN pode ser observado em diversas regiões do planeta, como na América do Norte 
(AN), AS, África, Ásia, Oceania e Antártica (Stensrud, 1996). A Figura 2.2, extraída de Stensrud (1996), mostra a distribuição espacial desses JBNs ao redor do globo. Blackadar (1957), Bonner (1968) e Uccellini e Johnson (1979) realizaram uma extensa pesquisa sobre a formação, evolução, distribuição e estrutura dos JBNs, bem como as relações com outros fenômenos meteorológicos e climáticos na AN. Da mesma forma, Findlater (1969, 1977) elaborou uma série de análises observacionais sobre as características do JBN e sua relação com a chuva de monções de verão no oeste da Índia.

Na AS, o JBN recebe o nome de JBNAS e embora seja observado ao longo de todo o ano (Marengo et al., 2004), é um dos principais sistemas atmosféricos que compõe o SMAS (Gandu e Geisler, 1991). Devido à sua importância nos sistemas precipitantes da AS, o JBNAS foi vastamente abordado na literatura científica nos últimos anos e será tratado à parte, na seção a seguir.

\subsubsection{O JBN da América do Sul (JBNAS)}

O JBNAS corresponde a um máximo relativo na magnitude do vento que ocorre entre 1 e $2 \mathrm{~km}$ de altitude, posicionado a leste da Cordilheira do Andes (Marengo et al., 2004). Ele desempenha um papel fundamental no transporte de calor e umidade, sendo um dos principais responsáveis pela ocorrência de atividade convectiva no Sul e Sudeste do Brasil, norte da Argentina, Uruguai e Paraguai (Virji, 1981, Velasco e Fritsch, 1987; Berri e Inzunza, 1993; Salio et al., 2007).

A Figura 2.3 ilustra um modelo conceitual de JBNAS, onde os alísios de nordeste, provenientes do Oceano Atlântico equatorial, são carregados de umidade causada pela intensa evapotranspiração da floresta amazônica. Ao serem barrados pela Cordilheira dos Andes, adquirem uma componente meridional de norte e são defletidos em direção à Bacia do Prata. Ao adquirir esta componente meridional, o vento sofre aceleração a fim de conservar sua vorticidade potencial, sendo este um dos mecanismos de formação dos JBNs (Stensrud, 1996), explicado no Apêndice A.2. Desta forma, a barreira orográfica definida pela presença dos Andes mostra-se um elemento fundamental para a existência do JBNAS, como comprovado em simulações numéricas feitas por Kleeman (1989), Gandu e Geisler (1991) e Campetella e Vera (2002). 


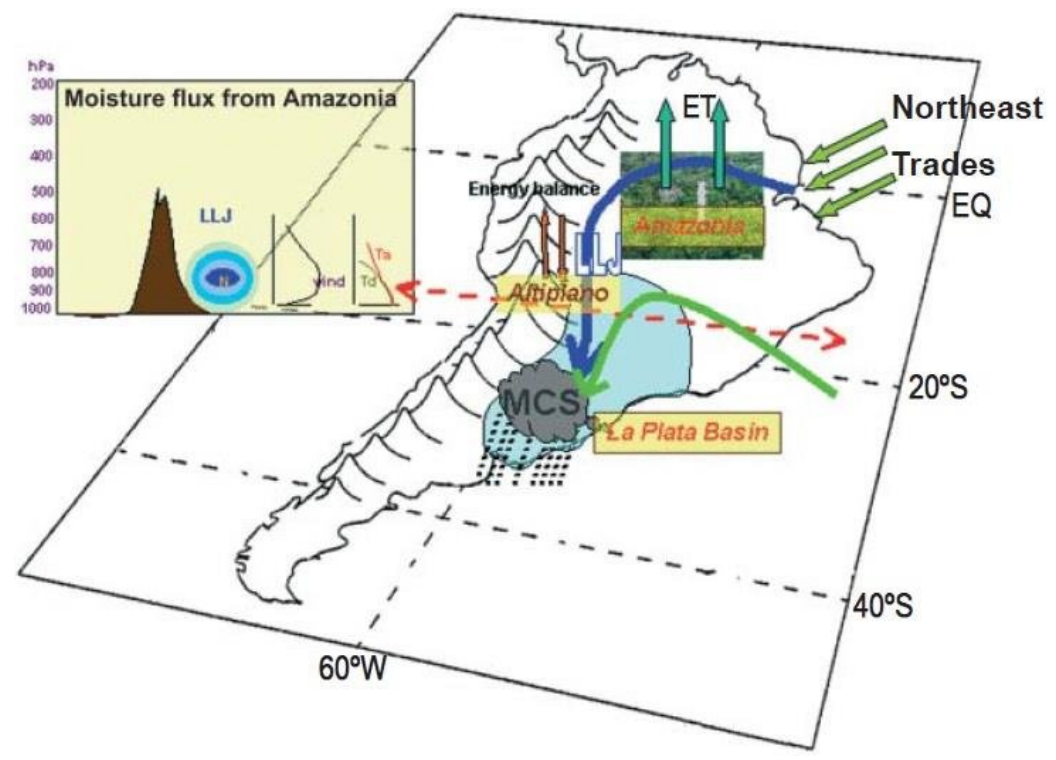

Figura 2.3: Esquema do JBNAS (LLJ na figura). A seta azul (verde) representa o transporte de umidade da Bacia Amazônica (do Atlântico Sul) em direção à Bacia do Prata, indicada em sombreado azul. O quadro menor é uma seção vertical esquematizando o fluxo meridional de umidade pelo JBNAS. MCS denota Sistemas Convectivos de Mesoescala (SCMs); ET é evapotranspiração na Amazônia. Fonte: Vera et al. (2006)

Em relação ao ciclo sazonal, vale ressaltar que, no verão, o vínculo entre o JBNAS e a Bacia Amazônica é maior que no inverno. Devido aos alísios de nordeste na região norte do Brasil serem mais fortes no verão, a deflexão para sul deste escoamento ao atingir os Andes também é mais intensa (Gandu e Geisler, 1991). Já no inverno, com o enfraquecimento dos alísios, a deflexão dos mesmos para sul diminui. Ademais, a alta subtropical do Atlântico sul, durante o inverno, adentra o Brasil central, fazendo com que o escoamento a leste dos Andes em baixos níveis se conecte ao seu flanco oeste (Montini et al., 2018).

A distribuição temporal do JBNAS depende de fatores como a proximidade com a Cordilheira do Andes, latitude e circulações atmosféricas predominantes em cada região. Segundo os resultados encontrados por Marengo et al. (2004), nas latitudes mais baixas (altas), a frequência de ocorrência de JBNAS é maior no verão (inverno). Isto indica a atuação de diferentes mecanismos de formação de JBNs, sendo que no inverno, por exemplo, a maior frequência e intensidade dos sistemas sinóticos extra e subtropicais é a principal forçante de formação do JBNAS (Marengo et al., 2004). Estudos mais recentes, como dos Santos e Reboita (2018) e Oliveira et al. (2018), encontraram que o JBNAS é mais frequente durante os meses de inverno. Por outro lado, Montini et al. (2018) mostraram que o JBNAS ocorre com praticamente a mesma frequência ao longo de todo ano, apesar 
de serem mais intensos no inverno.

Ainda em relação à variabilidade temporal, Marengo et al. (2004) encontraram que, em geral, o horário preferencial de ocorrência do JBNAS no verão é à noite, enquanto no inverno a ocorrência do sistema não parece mostrar um horário preferencial. Mais uma vez, os diferentes mecanismos de formação de JBNs explicam esta diferença, sendo a oscilação inercial (Apêndice A.1) e a variação diurna do gradiente horizontal de temperatura em terrenos inclinados (Apêndice A.2) mecanismos que explicam os máximos noturnos, enquanto as forçantes sinóticas (Apêndice A.3) são mais relevantes no inverno.

Climatologicamente, a área de maior frequência de ocorrência do JBNAS é o norte do Paraguai/Altiplano Boliviano (Marengo et al., 2004; Vera et al., 2006). Entretanto, outros trabalhos identificam JBNs em diversas áreas da AS, como na Bacia Amazônica, litoral do Brasil e Venezuela (Greco et al., 1992; Saulo et al., 2000; Rife et al., 2010), no sul do Brasil (Corrêa et al., 2007; de Campos e dos Santos, 2007) e Sudeste do Brasil e oceano Atlântico Sudoeste (Sugahara e Rocha, 1996; dos Santos e Reboita, 2018). É interessante o fato de que não existe um consenso sobre se os JBNs que ocorrem nestas regiões pertencem ou não ao grupo dos JBNsAS.

Sugahara e Rocha (1996), ao estudarem a relação entre os JBNs e a ZCAS durante os verões de 1980 a 1987, identificaram um máximo secundário de ocorrência de JBNs no sudeste do Brasil estendendo-se até o oceano Atlântico, que acontecem especialmente nos dias em que não é detectada a ocorrência do JBNAS direcionado à região sudeste da AS. Saulo et al. (2000) e Rife et al. (2010) também identificaram JBNs próximos a esta região, porém apenas no setor continental.

Seluchi e Marengo (2000) mostraram que o transporte de umidade entre os trópicos e os extratrópicos no HS é intenso devido à Cordilheira dos Andes, em adição ao fato de que este transporte ocorre em duas regiões preferenciais: 1) Nas latitudes tropicais entre $20^{\mathrm{O}} \mathrm{e}$ $30^{\circ} \mathrm{S}$, perto dos Andes e 2) associado ao estabelecimento da ZCAS. Herdies et al. (2002), ao analisar o transporte de umidade entre os trópicos e subtrópicos na circulação de verão da AS, concluíram que este transporte ocorre por dois caminhos principais: 1) em direção à região da Bacia do Prata (sudeste da AS) e 2) ao longo da região de ocorrência da ZCAS. Wang e Fu (2004) observaram variações em escala sazonal e sinótica do JBN a leste dos Andes e suas análises mostraram grandes relações entre casos de JBN com a precipitação sobre a AS e a intensidade da ZCAS. 


\subsubsection{Critérios de Identificação dos JBNS}

Em um trabalho hoje considerado clássico, Bonner (1968) examinou dois anos de dados de vento em baixos níveis em diversos pontos dos Estados Unidos e elaborou um conjunto de critérios quantitativos que definem a identificação de JBNs entre a superfície e 1500 $m$ de altitude em função de diferentes valores de cisalhamento vertical e de máximo de velocidade do vento. Foram criadas 3 categorias para classificação:

Categoria 1 - Velocidade máxima no núcleo do jato de vento de, no mínimo, $12 \mathrm{~m} / \mathrm{s}$ e cisalhamento vertical do vento horizontal de, no mínimo, $6 \mathrm{~m} / \mathrm{s}$ até $3 \mathrm{~km}$ de altitude;

Categoria 2 - Velocidade máxima do vento no núcleo do jato de, no mínimo, $16 \mathrm{~m} / \mathrm{s}$ e cisalhamento vertical do vento horizontal de, no mínimo, $8 \mathrm{~m} / \mathrm{s}$ até $3 \mathrm{~km}$ de altitude;

Categoria 3 - Velocidade máxima do vento no núcleo do jato superior ou igual a 20 $\mathrm{m} / \mathrm{s}$ e cisalhamento de, no mínimo, $10 \mathrm{~m} / \mathrm{s}$ até $3 \mathrm{~km}$ de altitude.

Posteriormente, outros trabalhos propuseram ajustes na classificação de JBN de Bonner (1968). Whiteman et al. (1997) modificou a definição original, adicionando mais um tipo de JBN, sendo este caracterizado por intensidade do vento igual ou superior a $10 \mathrm{~m} / \mathrm{s}$ no nível de máxima intensidade da velocidade do vento, com um cisalhamento de pelo menos $5 \mathrm{~m} / \mathrm{s}$ acima deste nível e abaixo de $3000 \mathrm{~m}$ de altura. Walters e Winkler (2001), utilizando critérios semelhantes a Bonner (1968), classificaram os JBNs em uma única categoria, com máximos de velocidade a partir de $8 \mathrm{~m} / \mathrm{s}$, contanto que superassem em mais de $4 \mathrm{~m} / \mathrm{s}$ os ventos em superfície. Além disto, o núcleo poderia ocorrer até 700 hPa e apresentar um cisalhamento de no mínimo $4 \mathrm{~m} / \mathrm{s}$ até o nível de menor intensidade acima do JBN. Rife et al. (2010) elaboraram um índice para identificar exclusivamente JBNs que fossem mais intensos no período noturno.

Na América do Sul, versões adaptadas da categoria 1 de Bonner (1968) foram utilizadas em muitos trabalhos que abordaram a climatologia dos JBNs e sua influência nos sistemas precipitantes (Saulo et al., 2000; Salio et al., 2002; Marengo et al., 2004; Nascimento et al., 2016). Recentemente, Oliveira et al. (2018) e Montini et al. (2018) mostraram que existem situações em que os critérios de Bonner (1968) falham em detectar JBNs, especialmente na região da Bacia do Prata. Desta forma, ambos propuseram novos e diferentes critérios para suas respectivas classificações de JBN.

Operacionalmente, o nível de $850 \mathrm{hPa}$ costuma ser utilizado para a identificação de 
JBN, dado que o máximo de magnitude do vento do mesmo é verificado entre 1 e $2 \mathrm{~km}$ de altitude e que neste nível já não é mais observada a influência da superfície. Entretanto, o nível e máxima magnitude do vento pode não ocorrer exatamente no nível de $850 \mathrm{hPa}$ (Marengo et al., 2004, Oliveira et al., 2018). 
Capítulo 3

\section{Dados e Metodologia}

Para alcançar os objetivos propostos neste trabalho, são efetuadas análises diagnósticas sobre variados conjuntos de dados meteorológicos e metodologias, descritos a seguir.

\subsection{Caso Selecionado}

O caso selecionado para suporte ao desenvolvimento deste trabalho foi a ZCAS observada entre os dias 11 e 18 de janeiro de 2016. Este evento é considerado de especial interesse para a pesquisa, pois causou grande quantidade de chuva no Sudeste brasileiro, sendo responsável por desastres naturais em diversas cidades, como já relatado no Capítulo 1. Em adição, o sistema atmosférico apresentou um fluxo de massa de noroeste em baixos níveis, com uma intensidade elevada, bem configurado e direcionado para a região Sudeste brasileira durante grande parte do seu ciclo de vida. Desta forma, este caso em específico se mostra adequado para a compreensão da funcionalidade e quantificação do transporte de umidade durante um episódio de ZCAS e sua contribuição para a precipitação em superfície. Ademais, é também apropriado para uma verificação da forma como os modelos atmosféricos regionais reproduzem os fenômenos associados a uma ZCAS em sua parte continental, propiciando ainda uma análise do efeito do aumento da resolução espacial das grades numéricas sobre os campos atmosféricos simulados.

\subsection{Dados}

\subsubsection{Análises CFSv2}

O Climate Forecast System Reanalysis (CFSR) e o Climate Forecast System Version 2 (CFSv2) do NCEP são conjuntos de dados que utilizam um modelo atmosférico global com 
com espaçamento horizontal aproximada de $38 \mathrm{~km}$ entre os pontos de grade e 64 níveis verticais. Ambas as análises são elaboradas a partir de um mesmo núcleo dinâmico, sendo ele altamente acoplado, com interações entre atmosfera, oceano, terra e gelo da superfície do mar (Saha et al. 2010, 2014), onde as variáveis oceânicas são calculadas pelo modelo Modular Ocean Model (MOM) (Griffies et al., 2004).

Neste trabalho, o conjunto de dados do CFSv2 foi utilizado tanto para a inicialização e estabelecimento das condições de fronteira do modelo WRF, quanto para análises das condições atmosféricas de escala sinótica durante a atuação do sistema. Esta escolha foi baseada nos resultados apresentados em Quadro et al. (2012), que verificou que o CFV2 tem melhor desempenho quanto às características físicas de eventos de ZCAS.

Do CFSv2, foram utilizadas variáveis em níveis de pressão entre os níveis de 1000 e 200 $\mathrm{hPa}(*)$, de superfície $(* *)$ e solo $(* * *)$, sendo elas:

- Altura geopotencial [gpm]*

- Umidade relativa [porcentagem] *

- Umidade específica $[\mathrm{kg} / \mathrm{kg}] *$

- Componente zonal do vento $[\mathrm{m} / \mathrm{s}] *$

- Componente meridional do vento $[\mathrm{m} / \mathrm{s}]$ *

- Velocidade vertical em nível de pressão $[\mathrm{Pa} / \mathrm{s}] *$

- Pressão em superfície $[\mathrm{Pa}]$ **

- Temperatura a $2 \mathrm{~m}$ da superfície $[\mathrm{K}] * *$

- Altura geopotencial na superfície [gpm] **

- Componente zonal do vento a $10 \mathrm{~m}$ da superfície $[\mathrm{m} / \mathrm{s}]$ **

- Componente meridional do vento a $10 \mathrm{~m}$ da superfície $[\mathrm{m} / \mathrm{s}]$ **

- Solo coberto por gelo $* * *$

- Cobertura do solo $[0=\text { mar, } 1=\text { terra }]^{* * *}$

- Conteúdo de água no solo nas camadas entre a superfície e $40 \mathrm{~cm}, 40 \mathrm{~cm}$ e $100 \mathrm{~cm}$, $100 \mathrm{~cm}$ e $200 \mathrm{~cm}$ e abaixo de $200 \mathrm{~cm}$ [Fração] ***

- Temperatura do solo nas camadas entre a superfície e $40 \mathrm{~cm}, 40 \mathrm{~cm}$ e 100cm, $100 \mathrm{~cm}$ e $200 \mathrm{~cm}$ e abaixo de $200 \mathrm{~cm}[\mathrm{~K}]$ ***

- Água equivalente à superfície da neve acumulada $\left[\mathrm{km} / \mathrm{m}^{2}\right] * * *$

O dado de velocidade vertical do vento $\omega(\mathrm{Pa} / \mathrm{s})$ foi transformado em $\mathrm{W}(\mathrm{m} / \mathrm{s})$ para poderem ser comparados com os dados das simulações numéricas. Para isso foi utilizada 
a equação 3.1, onde $\mathrm{P}$ é a pressão em Pascal, g a gravidade em $\mathrm{m} / \mathrm{s}^{2}, R_{\text {gas }}$ a contante universal dos gases em $\frac{J}{k g * k}$ e $\mathrm{T}$ a temperatura em Kelvin.

$$
W=-\frac{\omega}{\frac{P g}{R_{\text {gas }} T}}
$$

\subsubsection{Imagens de Satélite}

Imagens do satélite GOES13 no canal infravermelho com temperatura realçada por cores foram utilizadas para análise da banda de nebulosidade e atividade convectiva durante toda a atuação da ZCAS selecionada. O produto está disponível no acervo de imagens de satélite da Divisão de Satélites e Sistemas Ambientais do Centro de Previsão do Tempo e Estudos Climáticos (DSA - CPTEC), no link: http://satelite.cptec.inpe.br/acervo.

\subsubsection{Precipitação pelo MERGE}

O Centro de Previsão do Tempo e Estudos Climáticos do Instituto Nacional de Pesquisas Espaciais (CPTEC-INPE) disponibiliza operacionalmente um produto que combina estimativas de precipitação por satélite e mais de 1500 estações pluviométricas distribuídas pelo Brasil, numa resolução espacial de 5 km e duas escalas temporais:

- acumulados diários (entre 12 UTC do dia D-1 e 12 UTC do dia D);

- acumulados horários.

O produto é elaborado conforme a metodologia descrita por Rozante et al. (2010). A combinação entre os dados de estimativa de precipitação por satélite e os dados observados é efetuada por meio do método de análise objetiva de Barnes (Barnes, 1973), onde são dados pesos às estações de superfície em um determinado raio de influência com centro na estação. Em seguida, é aplicado um termo de correção de 0,3, valor encontrado após testes realizados durante um ano. Para a composição do MERGE, conforme descrito em Rozante et al. (2010), inicialmente foram usadas as estimativas de precipitação por satélite do The Tropical Rainfall Measuring Mission (TRMM) Multisatellite Precipitation Analysis (TMPA) (Huffman et al., 2007). Contudo, com a descontinuidade deste conjunto de dados, passou-se a usar o Global Precipitation Measurement (GPM) Integrated MultisatellitE Retrievals for GPM (IMERG) (Huffman et al., 2015, 2017) como estimativa de precipitação por satélite. 


\subsubsection{Sondagens Atmosféricas}

Os estudos de casos de JBN, assim como quaisquer outros que necessitem de uma medição em diferentes níveis da atmosfera, sofrem com a escassez de dados. O principal método de medição é efetuado por meio da utilização de radiossondagens elevadas por balões atmosféricos, que são, em geral, lançados 2 vezes ao dia: às 0000 e 1200 UTC. Este tipo de medição é realizada somente em alguns pontos do planeta, sendo bastante distante um ponto de medição do outro, principalmente em países menos desenvolvidos. No Brasil, as sondagens são realizadas nos principais aeroportos e permitem uma boa informação das características da coluna de ar local.

O Departamento de Ciências Atmosféricas da Universidade de Wyoming, nos Estados Unidos da América, tem um projeto que reúne os arquivos de sondagens atmosféricas de várias localidades ao redor do mundo e os disponibiliza publicamente no link: http://weather.uwyo.edu/upp Desta forma, os dados de radiossondagem utilizados neste trabalho são provenientes deste site. Os pontos de amostragem do perfil vertical escolhidos para esta análise são os do Aeródromo do Campo de Marte, na cidade de São Paulo; o Aeroporto de Confins, na cidade de Belo Horizonte; o Aeroporto de Galeão, na cidade de Rio de Janeiro; além das estações localizadas nos Aeroportos de Campo Grande, Cuiabá, Curitiba, Londrina e Vitória (Figura 3.2).

\subsection{Simulações Numéricas}

\subsubsection{Modelo WRF}

Modelos regionais possibilitam a realização de pesquisas e previsões em centros operacionais ao redor do mundo, por sua alta flexibilidade na instalação e configuração. Proporcionam uma vasta quantidade de variáveis meteorológicas de ar, superfície e solo resultantes. Estas características permitem a utilização desta ferramenta em diversas situações, com resultados que facilitam a análise dos processos envolvidos no evento modelado e uma resolução espacial superior aos modelos de previsão e reanálises globais.

Para as simulações numéricas deste trabalho foi utilizado o núcleo não hidrostático e compressível denominado Advanced Research WRF (ARW) do modelo Weather, Research and Forecasting (WRF), na sua versão 4.0 (Skamarock e Klemp, 2008), desenvolvido e atualizado por centros como NCAR e NCEP. O modelo em questão foi rodado num cluster 
LINUX do Laboratório de Meteorologia de Mesoescala (LMM) do DCA/IAG/USP, com 96 nodes disponíveis em processamento paralelo, propiciando o aninhamento de até três grades nesta pesquisa.

O WRF-ARW resolve as equações diferenciais prognósticas em formato de fluxo, utilizando o método numérico de Runge-Kutta de terceira ordem, o que garante baixa propagação de erros devido às características do método numérico e à conservação de massa e momento. Os níveis verticais do modelo estão em coordenada $\eta$, que acompanham o terreno e variam de 1.0 (superfície) até 0.0 (topo do modelo).

\subsubsection{Parametrizações de Processos Subgrade no WRF}

$\mathrm{Na}$ atmosfera, processos físicos de diferentes escalas atuam em conjunto, de forma que sistemas de grande escala influenciam e são influenciados por outros de menor escala. Os modelos atmosféricos atuam com a finalidade de resolver equações numéricas que traduzem e preveem estes processos físicos. Contudo, sempre há processos físicos que não podem ser resolvidos explicitamente pelos modelos em seus pontos de grade devido à sua pequena escala espacial. Por serem de escalas inferiores à resolução espacial propiciada pelo espaçamento da grade, são chamados de processos de subgrade.

Os processos de subgrade são calculados com base em soluções numéricas que aproximam o efeito físico de um fenômeno sobre as variáveis atmosféricas de interesse. Estes modelos físicos são chamados de parametrizações. As equações numéricas das parametrizações são baseadas em ponderações feitas por meio de variáveis já explicitamente conhecidas na solução da parte dinâmica do modelo (Stensrud, 2009). As parametrizações são constantemente usadas para o cálculo de processos físicos importantes na atmosfera real, sendo que os mais comuns são: os processos radiativos, a turbulência na Camada Limite Planetária (CLP), os fluxos verticais entre a atmosfera e a superfície, a microfísica de nuvens e os processos de convecção.

Os processos de convecção úmida são representados pelas chamadas parametrizações cúmulos. Estas parametrizações são aquelas que mais afetam o ambiente, produzindo precipitação à superfície, respondendo pela liberação de calor latente na coluna vertical de ar, distribuindo calor e umidade entre os níveis verticais e gerando ainda correntes verticais ascendentes e descendentes (Yamamoto, 2016). As parametrizações cúmulos foram elaboradas para domínios numéricos com espaçamento de grade superiores 9 ou $10 \mathrm{~km}$ na 
horizontal, segundo Warner (2010). Entretanto, a alteração da parametrização cúmulos nas grades de menores resoluções afeta os resultados obtidos pela grade de alta resolução espacial, onde as nuvens cúmulos são resolvidas explicitamente (Jankov et al., 2005). Esta interação entre grades aninhadas será abordada neste trabalho no capítulo de resultados.

\subsubsection{Configurações do Modelo}

A inicialização do WRF e as atualizações das condições de fronteira são realizadas com a análise do CFSv2, disponibilizado pelo NCEP, com resolução espacial de 0,5 grau e resolução temporal de 6 horas. Desta forma, definiu-se a área total de integração do modelo conforme mostrado na Figura 3.1. A grade 1 (27 km de espaçamento de grade horizontal) abrange uma área que se estende de $20^{\circ} \mathrm{N}$ à $55^{\mathrm{O}} \mathrm{S}$ e de $100^{\mathrm{O}} \mathrm{W}$ à $15^{\mathrm{O}} \mathrm{W}$, englobando grande parte do Oceano Atlântico sul, subtropical e tropical, possibilitando ao modelo regional a simulação de sistemas de escala sinótica, como cristas e cavados de níveis médios e altos, ciclones extratropicais, frentes frias, Alta da Bolívia e o VCAN do Nordeste. Além disso, toda a Cordilheira dos Andes está dentro deste domínio, fazendo com que a representação da interação da atmosfera com esta cadeia de montanhas seja possível no WRF.

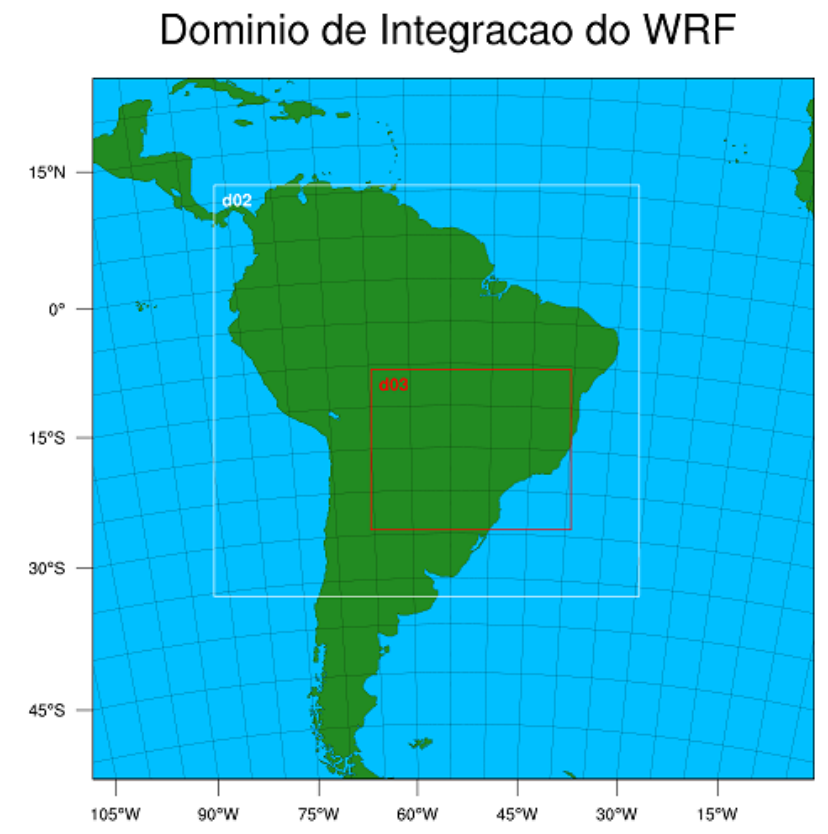

Figura 3.1: Região de integração do modelo WRF. Grades de $27 \mathrm{~km}, 9 \mathrm{~km}$ e $3 \mathrm{~km}$.

A grade 2 (9 km de espaçamento entre os pontos de grade na horizontal) abrange todo 
o território onde climatologicamente ocorrem o JBN e a ZCAS. Ressalta-se que boa parte da Cordilheira dos Andes está dentro desta área de integração, de forma que o cálculo das equações meteorológicas é efetuado sobre uma superfície de maior detalhamento. A grade 3 (3 km de espaçamento horizontal) foi cuidadosamente posicionada na região de atuação da ZCAS de maior interesse para esta pesquisa, permitindo que esta área com maior resolução espacial resolva os principais processos físicos envolvidos no ciclo de vida do fenômeno. As especificações das simulações e geometria de grade são mostradas na Tabela 3.1 .

Tabela 3.1 - Principais configurações do WRF utilizadas nas simulações.

\begin{tabular}{c|ccc}
\hline \hline Especificação & Grade 1 & Grade 2 & Grade 3 \\
\hline \hline Espaçamento de grade & $27 \mathrm{~km}$ & $9 \mathrm{~km}$ & $3 \mathrm{~km}$ \\
\hline Resolução temporal & 6 horas & 6 horas & 1 hora \\
\hline Passo de tempo & $60 \mathrm{~s}$ & $20 \mathrm{~s}$ & $6,66 \mathrm{~s}$ \\
\hline Pontos na orientação Leste-Oeste & 352 & 622 & 877 \\
\hline Pontos na orientação Norte-Sul & 342 & 601 & 703 \\
\hline Níveis Verticais & 65 & 65 & 65 \\
\hline Topo do Modelo & $50 \mathrm{hPa}$ & $50 \mathrm{hPa}$ & $50 \mathrm{hPa}$ \\
\hline Níveis de Solo & 4 & 4 & 4 \\
\hline
\end{tabular}

O primeiro experimento numérico, com a configuração básica de geometria de grade e parametrizações físicas iniciais (Tabela 3.2), forma a simulação controle (CTRL), baseandose no trabalho de da Silva (2018). Outro ponto importante foi a utilização do nudging espectral, uma vez que da Silva (2018) mostra que a filtragem de ondas curtas no comprimento de onda de $2000 \mathrm{~km}$ é o que gera melhores resultados para simulações de ZCAS. Esta ferramenta é aplicada para a temperatura do ar, vento zonal, vento meridional e altura geopotencial acima da CLP, de forma que as interações entre a superfície e atmosfera são regidas pela física do modelo regional. A parametrização cúmulos é ativada somente nas grades de 27 e $9 \mathrm{~km}$ de espaçamento horizontal e é mantida inativa na grade de 3 $\mathrm{km}$, enquanto o tratamento da água em suas três fases é totalmente deixado a cargo da parametrização de microfísica de nuvens nesta alta resolução espacial.

A grade 1 foi executada durante toda a atuação do sistema, enquanto as grades 2 e 3 foram utilizadas somente durante o período de maior intensidade do fluxo de umidade, 
por limitações de espaço em disco físico para os arquivos gerados pelas simulações. Para garantir que o período de spin-up do modelo numérico não afetasse diretamente os horários de análise, a grade 1 foi iniciada no dia 07/01/2016 às 0000 UTC, de forma que, no dia 09/01/2016 às 0000 UTC, quando é feita a inicialização da grade 2, o modelo já não apresenta oscilações espúrias de alta frequência no interior das grades. Finalmente, no dia 10/01/2016 às 0000 UTC, após a grade 2 rodar por 24 horas, inicializa-se a grade 3.

Tabela 3.2 - Principais parametrizações físicas utilizadas nas simulações com o WRF.

\begin{tabular}{|c|c|c|}
\hline Parametrização & Esquema Usado & Referência \\
\hline Microfísica de Nuvens & WSM 6-class & (Hong e Lim, 2006) \\
\hline Radiação de Onda Curta & RRTMG & Iacono et al. 2008) \\
\hline Radiação de Onda Longa & RRTMG & (Iacono et al. 2008) \\
\hline Camada Limite & Yonsei University Scheme & Hong et al. 2006$)$ \\
\hline Camada Superficial & MM5 & (Zhang e Anthes, 1982) \\
\hline Modelo de Superfície & Noah MP & (Niu et al. 2011$)$ \\
\hline
\end{tabular}

Foram feitas duas simulações variando-se a parametrização cúmulos, com o intuito de verificar os impactos nos resultados obtidos. A primeira simulação é chamada de controle (CTRL), que aciona a parametrização cúmulos de Kain-Fritsch (Kain, 2004), que fornece os melhores resultados segundo da Silva (2018). A segunda é a simulação Grell-Freitas (GF), que utiliza a parametrização cúmulos de mesmo nome e pertence à nova geração de parametrizações (Grell e Freitas, 2014). A descrição de ambas as parametrizações é apresentada nas próximas subseções.

\subsubsection{Parametrização Cúmulos de Kain-Fritsch}

A parametrização de Kain-Fritsch (Kain, 2004) é derivada da metodologia proposta por Fritsch e Chappell (1980), utilizando valores médios de variáveis dinâmicas e termodinâmicas, como velocidade vertical, umidade e temperatura do ar, em camadas de $60 \mathrm{hPa}$ entre a superfície e $300 \mathrm{hPa}$ acima dela. O modelo físico em questão simula o levantamento de uma parcela de ar com tais condições até o Nível de Condensação por Levantamento (NCL) e a compara com as condições do ambiente neste nível. Como forçante para o levantamento da parcela até o NCL, é feita uma perturbação na temperatura da mesma. Caso a temperatura perturbada da parcela no nível do NCL seja maior que o ambiente ao 
seu redor e a profundidade da nuvem superior a um mínimo pré estabelecido, é formada a nuvem (o mesmo teste é realizado camada a camada acima). O desenvolvimento da nuvem depende dos fluxos verticais de calor e umidade, além de considerar entranhamento e desentranhamento ao longo de todo o perfil vertical da nuvem. Por conta da estabilização do ambiente, durante o processo de convecção é efetuada uma redução de $90 \%$ da Energia Potencial Disponível para Convecção (em inglês, CAPE) (Kain, 2004, Cassol, 2019).

\subsubsection{Parametrização Cúmulos de Grell-Freitas}

Com o avanço computacional, modelos usados tanto operacionalmente quanto em pesquisas científicas passaram a utilizar um menor espaçamento de grade, atuando na chamada gray zone, que varia entre 10 e $4 \mathrm{~km}$, onde as parametrizações cúmulos mais antigas geram resultados indesejados. Neste contexto, a parametrização Grell-Freitas (Grell e Freitas, 2014) foi desenvolvida aprimorando algumas funcionalidades das versões anteriores, discutidas adiante.

Como discutido em (Grell, 1993; Grell e Dévényi, 2002), a principal modificação foi quanto ao movimento de subsidência compensatório. Nos esquemas cúmulos mais antigos, este movimento gerava a inibição da convecção na área de atuação. A solução proposta no esquema Grell-Freitas é distribuir este movimento de subsidência para os pontos de grade vizinhos aonde ocorre a convecção, diminuindo a sua influência na coluna de ar do ponto em questão (Grell e Freitas, 2014) e evitando, desta forma que a corrente subsidente de compensação acabe por inibir o movimento ascendente que mantém as células convectivas ativas.

No esquema Grell-Freitas a inicialização da convecção se dá em função de valores assumidos pelas variáveis termodinâmicas, perturbando-se a temperatura e a umidade com base nos fluxos de calor sensível e latente na base da nuvem, respectivamente Grell e Freitas, 2014). O entranhamento e o desentranhamento acontecem ao longo de toda a nuvem, e não somente na base e no topo, como na versão inicial do esquema (Grell, 1993). Além disso, utiliza-se a técnica de ensemble nos fluxos de massa, tanto para o tratamento da convecção quanto no fechamento da parametrização, fornecendo uma melhor representatividade dos efeitos gerados pela convecção. 


\subsection{Métodos de Análise dos Dados}

\subsubsection{Características Sinóticas da ZCAS}

Em eventos de ZCAS, algumas características sinóticas que mantêm a constante e organizada convecção do sistema são frequentemente observadas. Estas características são bem descritas na nota técnica "Zona de Convergência do Atlântico Sul (ZCAS): critério de detecção para uso em centros operacionais de previsão de tempo", elaborada pelo Dr. Gustavo Carlos Juan Escobar, disponível no link: http://urlib.net/8JMKD3MGP3W34R/3SGMUDP.

Os campos plotados para uma primeira identificação da ZCAS foram feitos com médias diárias entre 0000 UTC e 2300 UTC do dia analisado. O primeiro campo foi o de vento horizontal e convergência de massa em $850 \mathrm{hPa}$, o segundo mostra a altura geopotencial e o movimento ascendente em 500 hPa e para os altos níveis foi usado um terceiro campo, com linhas de corrente e divergência de massa no nível de 200 hPa. Como complemento, foram elaborados campos mostrando a quantidade de água precipitável entre a superfície e o nível de 200 hPa e o transporte do fluxo de umidade entre os níveis de 900 e 700 hPa. Estas variáveis são calculadas de acordo com a metodologia explicada com mais detalhes na próxima subseção. Estes campos permitem visualizar a interação entre os diferentes níveis da atmosfera e o fornecimento de umidade gerado pelos processos de convecção local e transporte de umidade pelo escoamento no sentido noroeste-sudeste entre a região amazônica e o Sudeste brasileiro.

\subsubsection{Estimativa das Contribuições Físicas do JBN}

Para realizar uma primeira verificação da posição de atuação do JBN, foram plotados campos de magnitude do vento em $850 \mathrm{hPa}$ superior a $10 \mathrm{~m} / \mathrm{s}$ utilizando a análise do CFSv2 e também ambas as simulações [com parametrização cúmulos de Kain-Fritsh (CTRL) e experimento com Grell-Freitas (GF)). Posteriormente, para comprovar a atuação do JBN, foram elaborados gráficos do perfil vertical da intensidade do vento em pontos de lançamento de radiossondagens próximos às áreas de maior intensidade da circulação entre a região amazônica e o Sudeste brasileiro.

Uma interpolação bilinear dos dados observados para os mesmos níveis do conjunto de dados do CFSv2 e das simulações numéricas com o modelo WRF foi efetuada, tornando possível uma comparação direta da magnitude do vento entre todos os conjuntos de dados. 
Desta forma, analisou-se o perfil vertical para verificar a presença ou não do JBN em cada ponto.

A análise do transporte de umidade pelo JBN durante este caso de ZCAS é o principal objetivo deste trabalho. Desta forma, foram feitos campos que permitem avaliar a intensidade e região de atuação do fluxo de umidade ao longo do dia. Sendo assim, o primeiro passo realizado foi o cálculo do campo de transporte de umidade por meio da equação:

$$
\vec{Q}=\frac{1}{g} \int_{\text {sup }}^{900} q \vec{V} d p-\frac{1}{g} \int_{\text {sup }}^{700} q \vec{V} d p
$$

O vetor fluxo $(\vec{Q})$ pode ser expresso pelas suas componentes zonal e meridional:

$$
\begin{aligned}
& Q_{x}=\frac{1}{g} \int_{\text {sup }}^{900} q u d p-\frac{1}{g} \int_{\text {sup }}^{700} q u d p \\
& Q_{y}=\frac{1}{g} \int_{\text {sup }}^{900} q v d p-\frac{1}{g} \int_{\text {sup }}^{700} q v d p
\end{aligned}
$$

Nas equações acima, $q$ é a umidade específica, $u$ e $v$ são, respectivamente, as componentes zonal e meridional do vento $\vec{V}$ e $g$ é a aceleração da gravidade. Os limites superiores de integração de cada integral são os níveis isobáricos de $900 \mathrm{hPa}$ e $700 \mathrm{hPa}$, objetivando-se obter a estimativa da contribuição específica da camada atmosférica onde tipicamente se encontra o JBN, eliminando, assim, contribuições de outros níveis no escoamento de massa. Para evitar erro na integração em locais onde a pressão em superfície é inferior a 900 hPa, foi feita uma subtração entre o fluxo integrado entre a superfície e $700 \mathrm{hPa}$ e o calculado entre a superfície e o nível de $900 \mathrm{hPa}$, garantindo que não fossem utilizados dados que se encontram "abaixo da superfície".

Outra grandeza que possibilita uma boa análise da quantidade de umidade na atmosfera é a água precipitável (PW), calculada a partir da expressão:

$$
P W=\frac{1}{\rho_{l} g} \int_{\text {sup }}^{200} q(p) d p
$$

onde $g$ é a aceleração da gravidade, $q(p)$ é a umidade específica no nível vertical $p$ de pressão e $\rho_{l}$ é a densidade da água líquida. Os limites de integração sup e 200 são, respectivamente, a superfície e o nível de $200 \mathrm{hPa}$.

Os campos gerados mostram o transporte do fluxo de umidade médio diário entre 900 e 700 hPa em cada um dos dias de atuação do sistema. Em seguida, nos dias de 
maior intensidade deste transporte, foram efetuados cortes verticais. O primeiro foi feito de forma paralela à região com maior intensidade do vento em baixos níveis, mostrando a magnitude do vento, enquanto o segundo mostra magnitude e direção do vento e o transporte de umidade ao longo da região de maior intensidade do mesmo (Figura 3.2). Desta forma, estes dois campos permitem analisar o núcleo de maior intensidade do JBN e do fluxo de umidade.
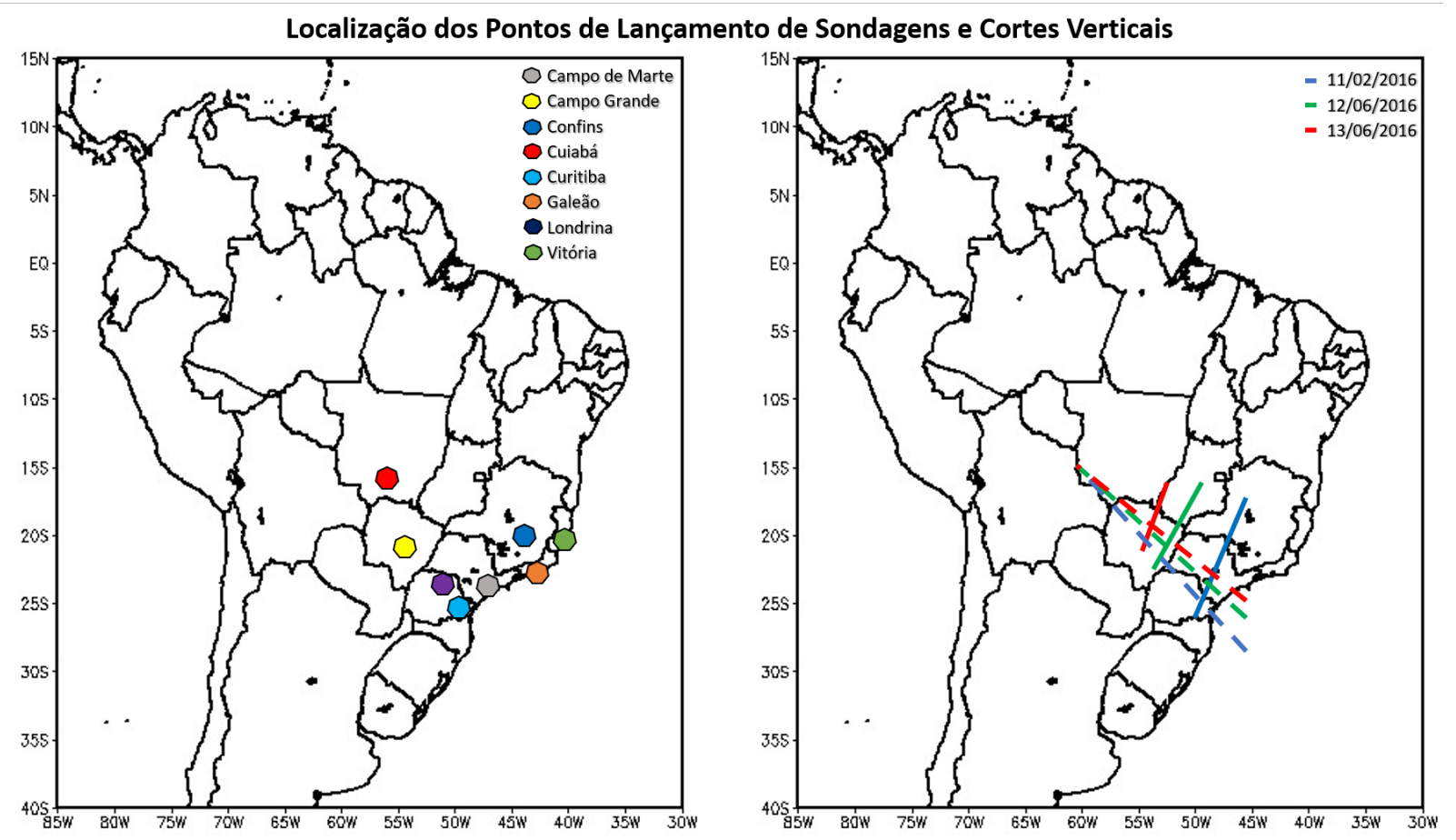

Figura 3.2: A esquerda são exibidos os pontos de lançamento das sondagens que coletaram os dados utilizados para análise do perfil vertical do vento. A direita é possível notar o posicionamento do corte vertical realizados tanto nos dados de magnitude do vento (linhas continuas) quanto do fluxo de umidade (linhas tracejadas).

\subsubsection{Análise da Precipitação}

As estimativas de precipitação utilizadas para a análise deste trabalho são resultados do produto MERGE com resolução horária, disponibilizado no banco de dados do CPTECINPE.

Foram plotados campos diários de precipitação acumulada, de forma que é possível analisar as alterações do sistema com o passar do tempo. Além disso, também foi elaborado um campo de precipitação acumulada durante todo o ciclo de vida do sistema, onde é determinada a região em que a chuva acumulada é maior. 


\subsubsection{Análise de Séries Temporais}

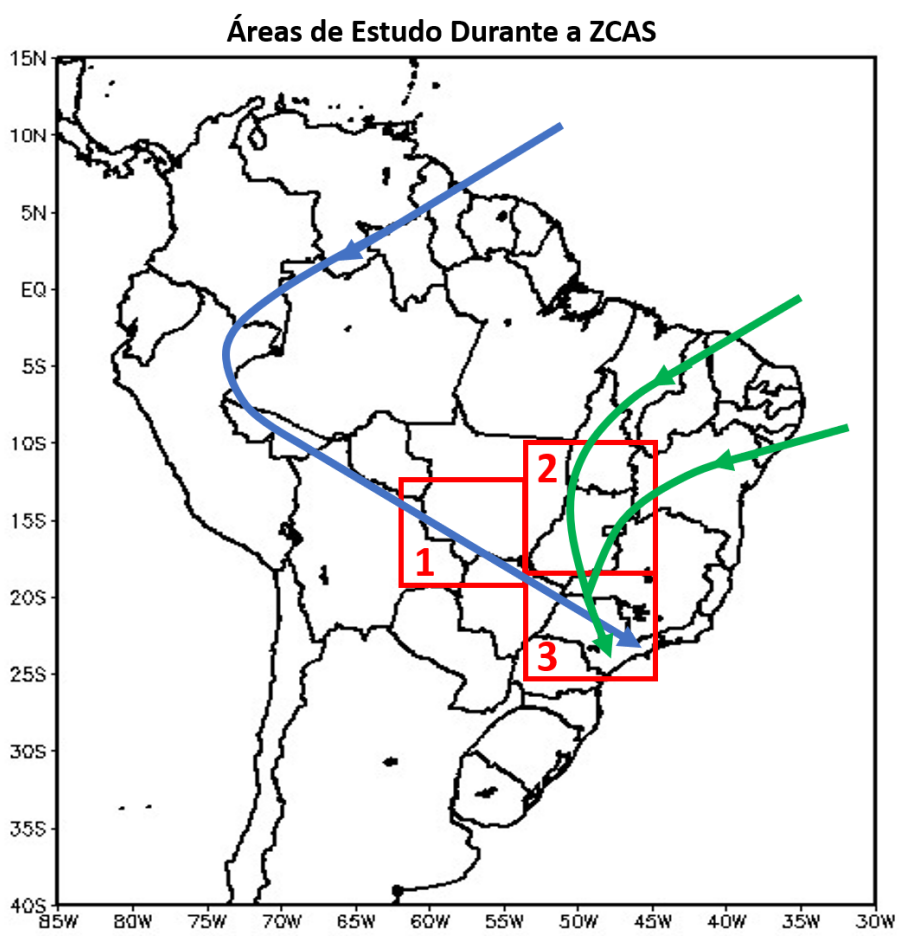

Figura 3.3: Áreas de análise do fluxo de umidade e precipitação. A área 1 abrange parte do corredor de umidade entre a região amazônica e o Sudeste do Brasil (seta azul). A área 2 exibe amostras da região sob efeito das circulações dos alísios de nordeste e da ASAS, que entram pelo Nordeste do Brasil e seguem em direção ao Sudeste brasileiro (setas verdes). A área 3 abrange o Sudeste do Brasil e parte norte do estado do Paraná, afetada por ambas as circulações.

Para uma análise do comportamento do fluxo de umidade ao longo da atuação do sistema, foram selecionadas 3 regiões que podem ser vistas na Figura 3.3, sendo elas:

1) Ao longo da região de maior intensidade do JBN e fluxo de umidade;

2) Na região do fluxo de umidade proveniente da circulação da ASAS;

3) Abrangendo a área com maior acumulado de precipitação durante o sistema, majoritariamente localizada sobre o Sudeste do Brasil mais a parte norte do estado do Paraná.

Nestas áreas realizou-se médias do fluxo de umidade, que posteriormente foram plotados em forma de séries temporais. Para isto, utilizou-se os dados do CFSv2 e os resultados do WRF das grades 1 e 3 de ambas as simulações, uma vez que a grade 1 fornece uma visão durante toda a atuação do sistema, enquanto a grade 3, com maior resolução temporal, proporciona uma melhor visualização da comportamento desta variável ao longo do dia. 
O mesmo processo foi realizado para os dados de precipitação, porém foram utilizados o MERGE (acumulado por 6 horas) e a grade 1 dos experimentos numéricos. Esta escolha deve-se ao fato de que o MERGE apresenta toda a precipitação das últimas 6 horas, não o valor momentâneo, como no fluxo de umidade.

\subsubsection{Validação dos Resultados de Precipitação}

Para a verificação da assertividade das simulações, foram elaborados gráficos de dispersão e calculados erros estatísticos na série temporal de precipitação de cada uma das áreas em destaque na Figura 3.3 . Foram utilizados dois erros estatísticos complementares descritos no trabalho de Hallak e Pereira Filho (2011), sendo eles:

i. O viés (BIAS, em inglês), que pode ser explicado como sendo o erro médio entre o conjunto de dados simulados e o observado pelo MERGE. Este teste não é o melhor para quantificar o erro do modelo, uma vez que valores positivos e negativos de mesma intensidade se anulam, mas é utilizado para indicar tendências de sub ou superestimativa por parte do experimento;

ii. A Raiz do Erro Médio Quadrático (RMSE, em inglês), é obtido através da raiz quadrada da média do quadrado do erro entre o simulado e o observado. Este método exclui a possibilidade de anulação entre valores de sinais opostos e de mesma magnitude, por isto resulta em uma melhor indicação do erro do experimento, apesar de não indicar o sinal do mesmo.

Estes erros foram calculados usando-se somente os resultados da grade 1 de ambas as simulações, primeiramente para todo o período de atuação do sistema e, posteriormente, para o período onde a grade 3 do modelo regional foi ativada, com a finalidade de quantificar a melhor representação da ZCAS nos momentos onde os processos de formação de chuva são resolvidos explicitamente. 
Capítulo 4

\section{Resultados e Discussões}

\subsection{Análise Sinótica}

\subsubsection{Características Gerais do Caso}

Durante toda a atuação do sistema, a circulação média nos baixos níveis ( $850 \mathrm{hPa})$ é direcionada no sentido noroeste-sudeste entre o sul da região amazônica e o norte de SP, sul de MG e Oceano Atlântico subtropical. Neste último, nota-se a confluência dos ventos próximos à superfície, o que indica a presença de uma frente fria, que auxilia na organização desse escoamento, como pode ser visto nos campos da Figura 4.1. Além disso, nota-se a presença de uma região de convergência de massa espacialmente em fase com a circulação mencionada anteriormente. As simulações CTRL e GF (Figura 4.1 (b) e (c), respectivamente) mostraram uma circulação média muito próxima do apresentado pela análise do CFSv2 (Figura 4.1 (a)), indicando que, numa análise sinótica inicial, as simulações capturam o campo observado pela análise. Os alísios de nordeste adentram o território brasileiro pelo litoral oeste da Região Norte e litoral norte da Região Nordeste, avançando em direção ao centro da América do Sul. Os alísios de nordeste transportam umidade que precipita na região Amazônica, reflete nos Andes, capta vapor d'água proveniente da evapotranspiração da floresta amazônica e se direciona para o Sudeste brasileiro. Além disso, a Figura 4.1 mostra uma circulação com giro ciclônico sobre o sul de MS e leste de SP. O encontro dessas duas circulações gera uma região de convergência de massa, que, associada ao fluxo de noroeste, favorece o levantamento de ar quente e úmido.

Em $500 \mathrm{hPa}$, o campo médio de altura geopotencial e velocidade vertical durante o cilco de vida do sistema (Figura 4.2) mostra um cavado no Oceano Atlântico subtropical próximo ao litoral sudeste do Brasil, com o eixo a oeste da confluência do vento em 850 

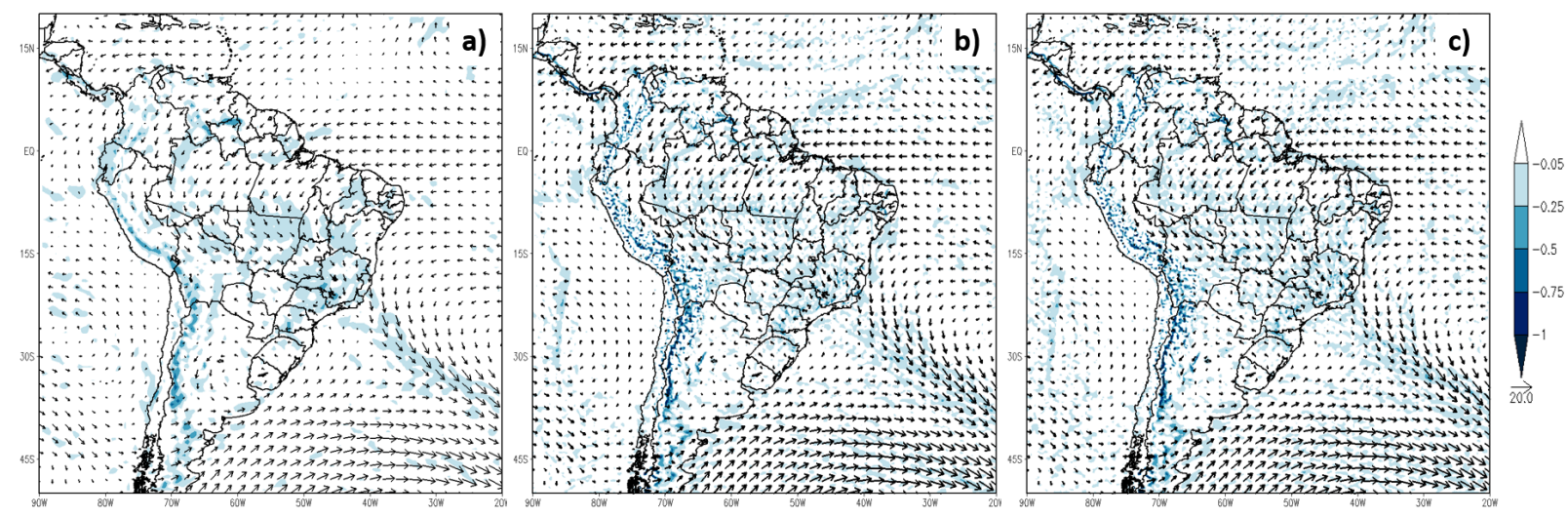

Figura 4.1: Médias do vento horizontal (vetores) e convergência de massa $\left[10^{-5} \mathrm{~s}^{-1}\right]$ (sombreado) no nível de $850 \mathrm{hPa}$ entre os dias 11 e 18 de janeiro de 2016 para (a) análises do CFSv2; (b) simulação CTRL; (c) simulação GF.
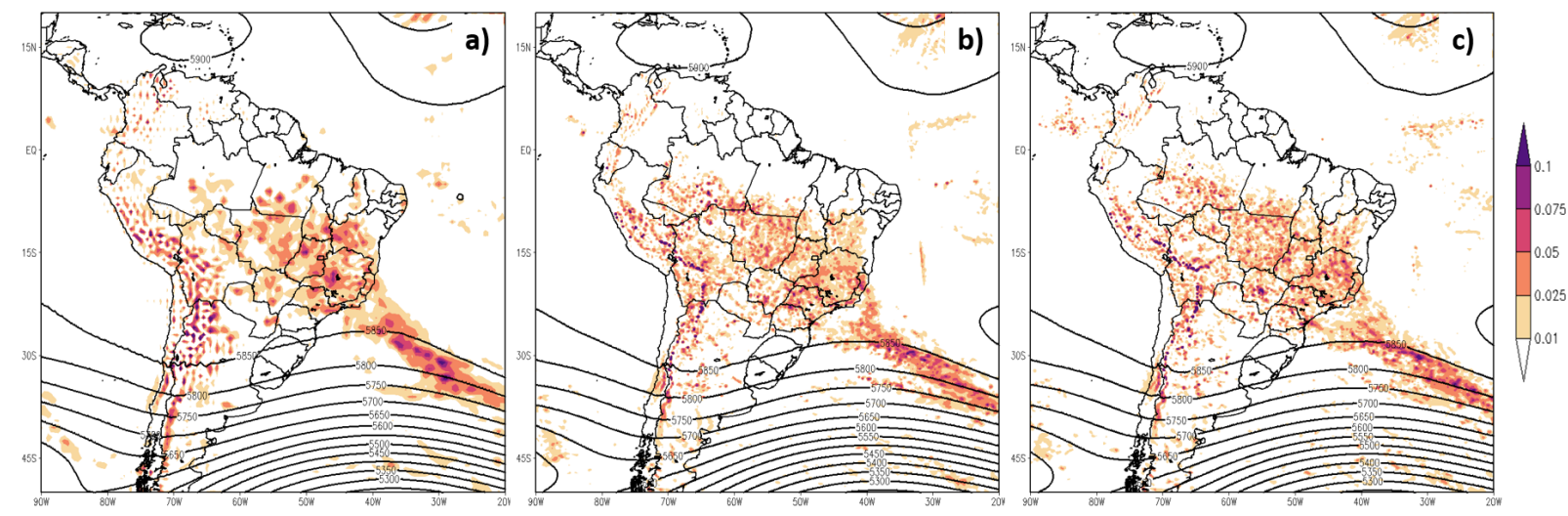

Figura 4.2: Médias altura geopotencial [m] (linhas de contorno) e movimento vertical ascendente $\left[\mathrm{m} \mathrm{s}^{-1}\right]$ (sombreado) em $500 \mathrm{hPa}$ entre os dias 11 e 18 de janeiro de 2016 para (a) análises do CFSv2; (b) simulação CTRL; (c) simulação GF.

hPa. Na região central e parte do Sudeste do Brasil, movimento ascendente atua na mesma posição da convergência de massa em baixos níveis. As simulações CTRL e GF (Figura 4.2 (b) e (c), respectivamente) mostram o mesmo padrão exibido pela análise 4.2 (a)). Contudo, a intensidade do movimento vertical é simulada de forma menos intensa quando comparada à análise.

Em altos níveis (200 hPa) o campo de circulação e divergência do vento médio durante a atuação do sistema (Figura 4.3) mostra a presença da Alta da Bolívia (AB) com centro em aproximadamente $20^{\circ} \mathrm{S}$ e $58^{\circ} \mathrm{W}$, do Vórtice Ciclônico de Altos Níveis (VCAN) no Nordeste $\left(16^{\circ} \mathrm{S}\right.$ e $\left.24^{\circ} \mathrm{W}\right)$ e uma zona de divergência de massa entre essas duas circulações, 

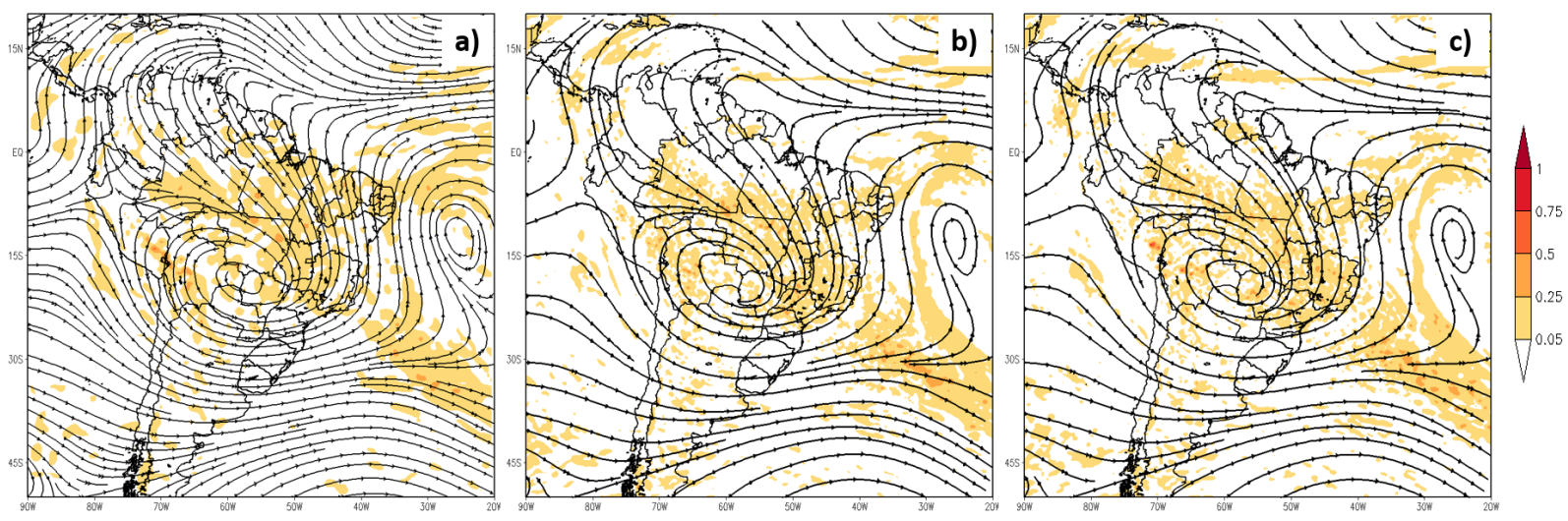

Figura 4.3: Médias do vento horizontal (linhas de corrente) e divergência de massa $\left[10^{-5}\right.$ $s^{-1}$ ] (sombreado mostrando apenas valores positivos) no nível de $200 \mathrm{hPa}$ entre os dias $11 \mathrm{e}$ 18 de janeiro de 2016 para (a) análises do CFSv2; (b) simulação CTRL; (c) simulação GF.

espacialmente em fase com a convergência em baixos níveis e o movimento vertical em 500 hPa. Tanto a simulação CTRL 4.3 (b)) quanto a GF 4.3 (c)) capturam a AB e o VCAN nas mesmas posições da análise do CFSv2 $4.3(\mathrm{a})$ ), entretanto, no norte das regiões Norte e Nordeste do Brasil a divergência de massa simulada pelo modelo WRF em ambos os experimentos apresenta intensidade inferior a análise do CFSv2.

\subsubsection{Evolução Diária}

Os campos médios para os baixos, médios e altos níveis da atmosfera durante o dia 11/01/2016 são mostrados na Figura 4.4. Tanto nas análises do CFSv2 quanto nas simulações CTRL e GF (respectivamente, Figuras 4.4 (a), (b) e (c)), existem dois principais fluxos em direção ao Sudeste brasileiro. O primeiro, é proveniente do sul da região amazônica e o segundo, refere-se à circulação da ASAS, que penetra o continente pelo norte da região Nordeste e passa pela região central do Brasil. Estes fluxos convergem próximo da divisa entre SP, MG, GO e MS, gerando uma região com intensa convergência de massa. Nesta área de convergência, ambas as simulações do WRF mostram valores inferiores ao apresentado pelo CFSv2. No sul de RO, o CFSv2 mostra um núcleo de intensa convergência de massa, valores que foram subestimados por ambas as simulações.

Ainda no dia 11/01/2016, em médios níveis, existe um cavado sobre o Oceano Atlântico adjacente ao litoral do PR e SC. As simulações (Figuras 4.4 (e) e (f)) representam esta perturbação de forma menos intensa do que o CFSv2 4.4 (d)). Consequentemente, o 

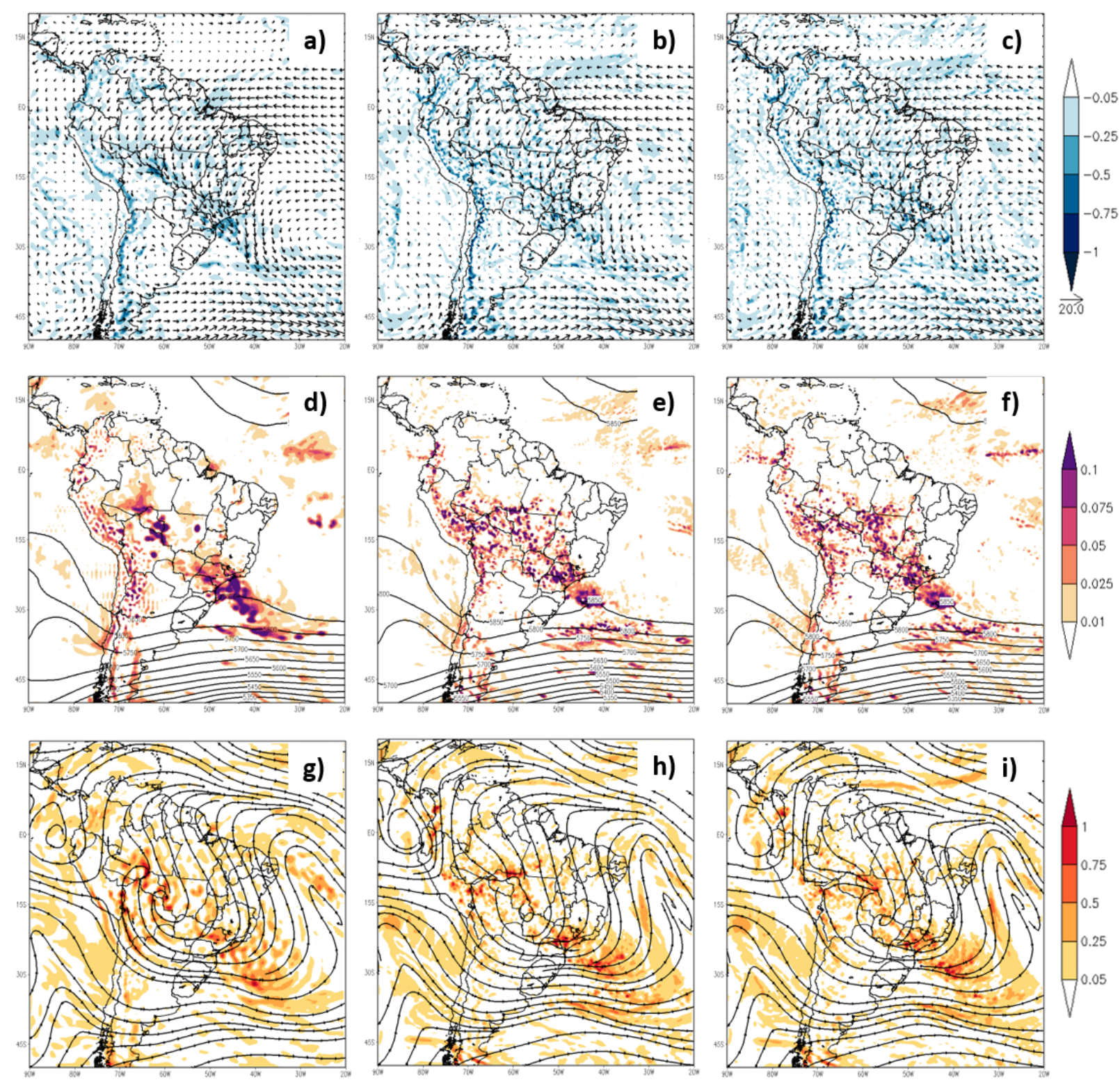

Figura 4.4: Campos do dia 11 de janeiro de 2016, mostrando: Vento horizontal (vetores) e convergência de massa $\left[10^{-5} s^{-1}\right]$ (sombreado) no nível de $850 \mathrm{hPa}$ para (a) análises CFSv2, (b) simulação CTRL e (c) simulação GF. Altura geopotencial [m] (linhas de contorno) e movimento vertical ascendente $\left[\mathrm{m} \mathrm{s}^{-1}\right]$ em $500 \mathrm{hPa}$ para (d) análises CFSv2, (e) simulação CTRL e (f) simulação GF. Vento horizontal (linhas de corrente) e divergência de massa $\left[10^{-5}\right.$ $s^{-1}$ ] (sombreado) no nível de $200 \mathrm{hPa}$ para (g) análises CFSv2, (h) simulação CTRL e (i) simulação GF.

movimento ascendente em $500 \mathrm{hPa}$ a leste do eixo deste cavado também é menos intenso nas simulações. Na divisa entre SP e PR existe um núcleo de intenso movimento ascendente, representado de forma similar por todos os conjuntos de dados, localizado sobre uma região de intensa convergência de massa em baixos níveis. No sul de RO, na 
mesma posição onde as simulações divergem do CFSv2 ao representar uma região de convergência de massa, as mesmas mostraram movimento ascendente menos intenso quando comparado a análise. Pela menor intensidade das circulações simuladas e mostradas nas Figuras 4.4 (a) a (f), portanto, obtém-se indicações de que os processos físicos simulados para a Camada Limite Planetária podem ter influência sobre o resultado.

Em altos níveis, a $\mathrm{AB}$ e o VCAN do Nordeste aparecem bem configurados, tanto nas análises (Figura 4.4 (g)) quanto nas simulações CTRL e GF (Figuras 4.4 (h) e (i), respectivamente). $\mathrm{O}$ centro da $\mathrm{AB}$ está localizado na mesma região em que o CFSv2 mostra uma convergência em baixos níveis e movimento vertical intenso em níveis médios. Uma prolongada área de divergência entre o sul do AM e o Sudeste brasileiro acompanha a região de atuação do fluxo em baixos níveis e o movimento ascendente em $500 \mathrm{hPa}$. No centro-sul do estado de São Paulo, os 3 conjuntos de dados mostram um centro de intensa divergência de massa, espacialmente em fase com a convergência em $850 \mathrm{hPa}$ e o movimento ascendente em $500 \mathrm{hPa}$. Estas características indicam o intenso acoplamento vertical observado durante o dia 11/01/2016, como esperado durante eventos de ZCAS.
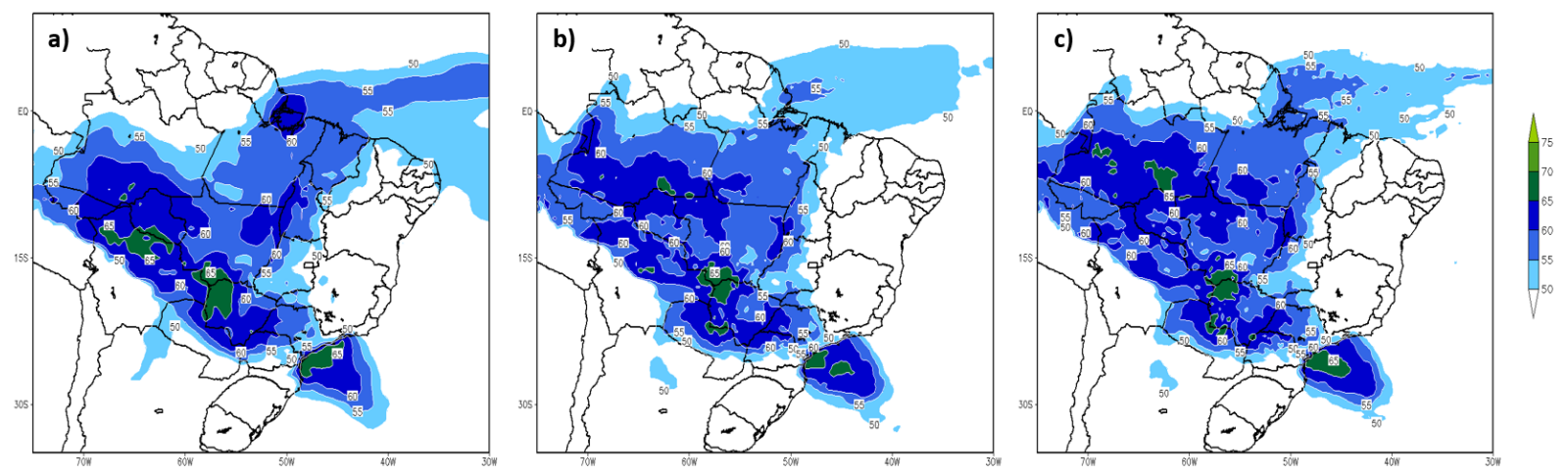

Figura 4.5: Campos de água precipitável [mm] (sombreado) do dia 11 de janeiro de 2016 para (a) análises CFSv2, (b) CTRL e (c) GF).

A quantidade média de água disponível para precipitação durante o dia 11/01/2016 é exibida na Figura 4.5, mostrando que, além da instabilidade atmosférica repreenta pelos campos anteriores, também verifica-se alta disponibilidade de vapor d'água na coluna atmosférica. Tanto a análise quanto as simulações CTRL e GF (respectivamente, Figuras 4.5 (a), (b) e (c)) mostram valores superiores a $50 \mathrm{~mm}$ em praticamente nas Regiões Norte e Centro-Oeste do Brasil, estendendo-se a SP e centro-norte do PR. As regiões com valores superiores a $60 \mathrm{~mm}$ ocorrem espacialmente em fase com a circulação de baixos níveis entre 
o sul do AM e a divisa entre SP, PR e MS. Os centros de máximas são mais extensos no CFSv2 do que nas simulações, que mostram centros de máxima de valores equivalentes ao CFSv2, mas em porções isoladas se comparadas aos centros verificados nas análises. O CFSv2 mostra 3 núcleos com valores superiores à $65 \mathrm{~mm}$, sendo eles a fronteira entre Bolívia e RO, divisa oeste entre MT e MS e Oceano Atlântico adjacente ao litoral do PR e SP. No Norte do Brasil, as simulações mostram valores superiores a $65 \mathrm{~mm}$ no norte de RO.
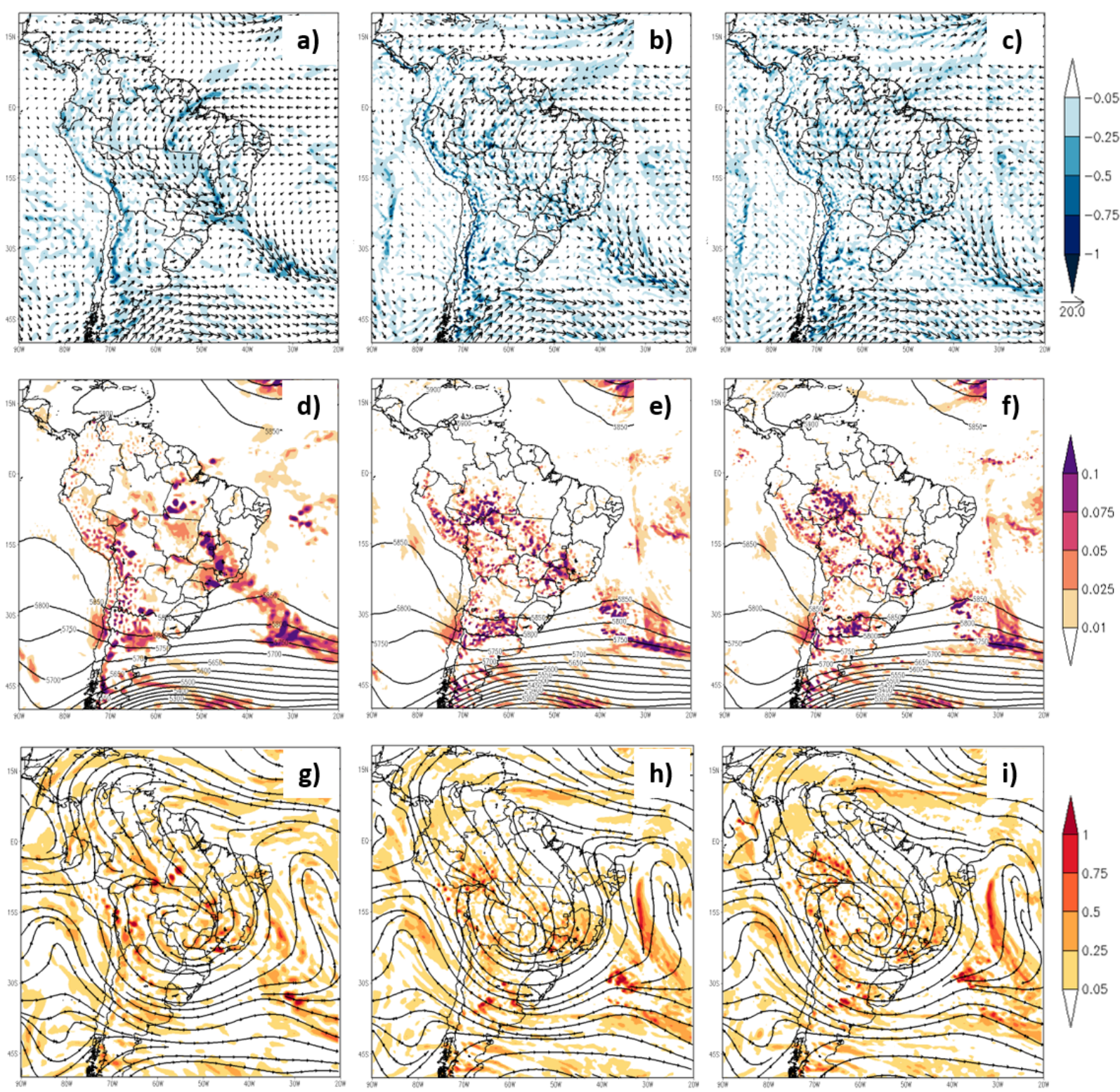

Figura 4.6: Mesmos campos da Figura 4.4 porém para o dia 12/01/2016.

No dia 12 (Figura 4.6), o campo médio em 850 hPa mostra a circulação noroeste-sudeste 
permanecendo sobre o estado de SP, tanto no CFSv2 (Figura 4.6 (a)) quanto nas simulações CTRL (Figura 4.6 (b)) e GF (Figura 4.6 (c)). Assim como no dia 11/01/2016, existe uma convergência de massa posicionada sobre esta região de fluxo mais intenso, que também é bem representada pelas simulações numéricas. Uma faixa com intensa convergência entre o norte de GO e o sul de MG é mostrada pela análise do CFSv2, enquanto nas simulações este padrão não existe.

Em médios níveis, a análise do CFSv2 (Figura 4.6 (d)) mostra um deslocamento do cavado para leste em relação ao dia anterior, com o movimento ascendente intenso sobre o leste de São Paulo e acompanhando a região de convergência em baixos níveis. Tanto a simulação CTRL quanto a GF (respectivamente, Figuras 4.6 (e) e (f)) apresentam posição e amplitude do cavado semelhantes à análise, com a região de movimento ascendente mais intenso ocorrendo ao longo do fluxo de noroeste-sudeste, e não entre o norte de GO e sul de MG, como no CFSv2.

A AB e o VCAN do Nordeste continuam a ser observados nos campos médios em $200 \mathrm{hPa}$. Os 3 conjuntos de dados mostram a divergência espacialmente em fase com a convergência em $850 \mathrm{hPa}$ e o movimento ascendente em $500 \mathrm{hPa}$, de forma que as regiões de maior intensidade diferem entre a análise (Figura 4.6 (g)) e as simulações (Figuras 4.6 (h) e (i)). Além disso, existe um cavado que acompanha todo o litoral norte da América do Sul, com intensidade e posições similares nos campos do CFSv2 e da simulação CTRL, enquanto a simulação GF (Figura 4.6 (i)) mostra este cavado mais acentuado e dentro do continente.
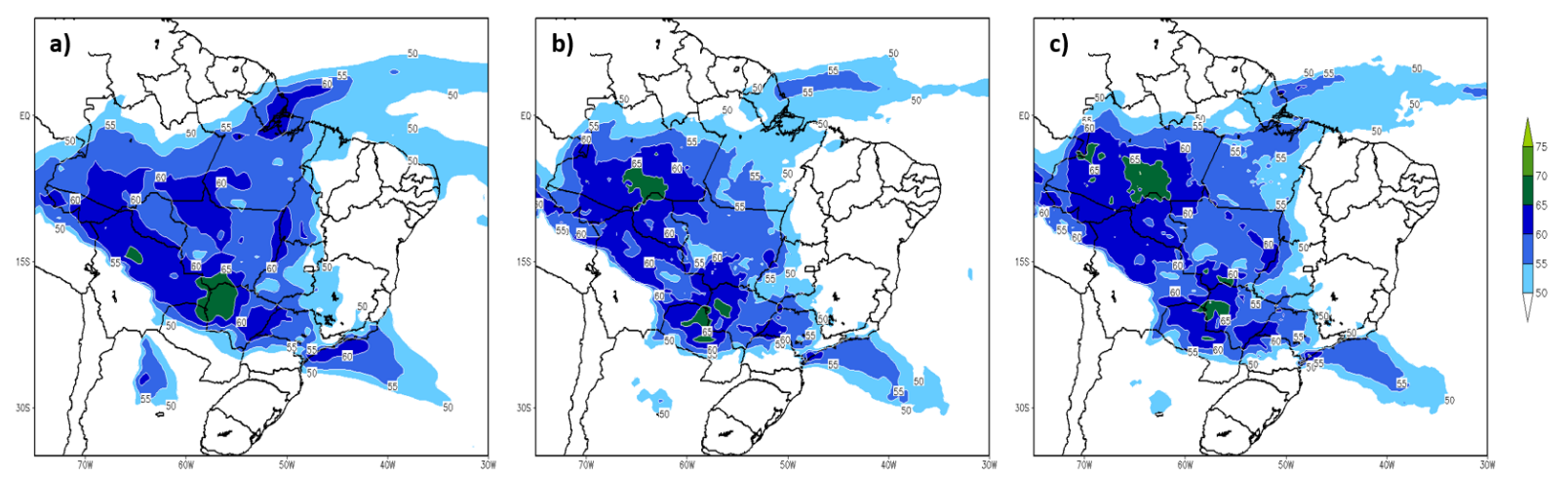

Figura 4.7: Mesmos campos da Figura 4.5, porém para o dia 12/01/2016.

A quantidade de água precipitável durante o dia 12/01/2016 apresenta uma redução 
em área dos núcleos de máximos valores em relação ao dia anterior, como pode ser visto na Figura 4.7. Nos 3 conjuntos de dados, as regiões com valores superiores a $50 \mathrm{~mm}$ permanecem as mesmas do dia 11/01/2016, com exceção do norte do PR, onde é observada uma leve redução e do litoral de SP. Ao longo da circulação entre o sul da região amazônica e o Sudeste brasileiro, as simulações CTRL e GF (Figuras 4.7 (b) e (c)) continuam subestimando os valores apresentados pela análise (Figura 4.7 (a)). O mesmo acontece com o núcleo posicionado no noroeste de $\mathrm{MS}$, onde a região com valores superiores a $65 \mathrm{~mm}$ apresentada pelas simulações tem área reduzida ao exibido pela análise, sendo disponibilizada uma menor quantidade de vapor d'água para o levantamento do ar impulsionado pela AB, com núcleo posicionado sobre esta região. Na região Norte do Brasil, as simulações mostram uma superestimativa do valor de água precipitável, com um núcleo de $65 \mathrm{~mm}$.
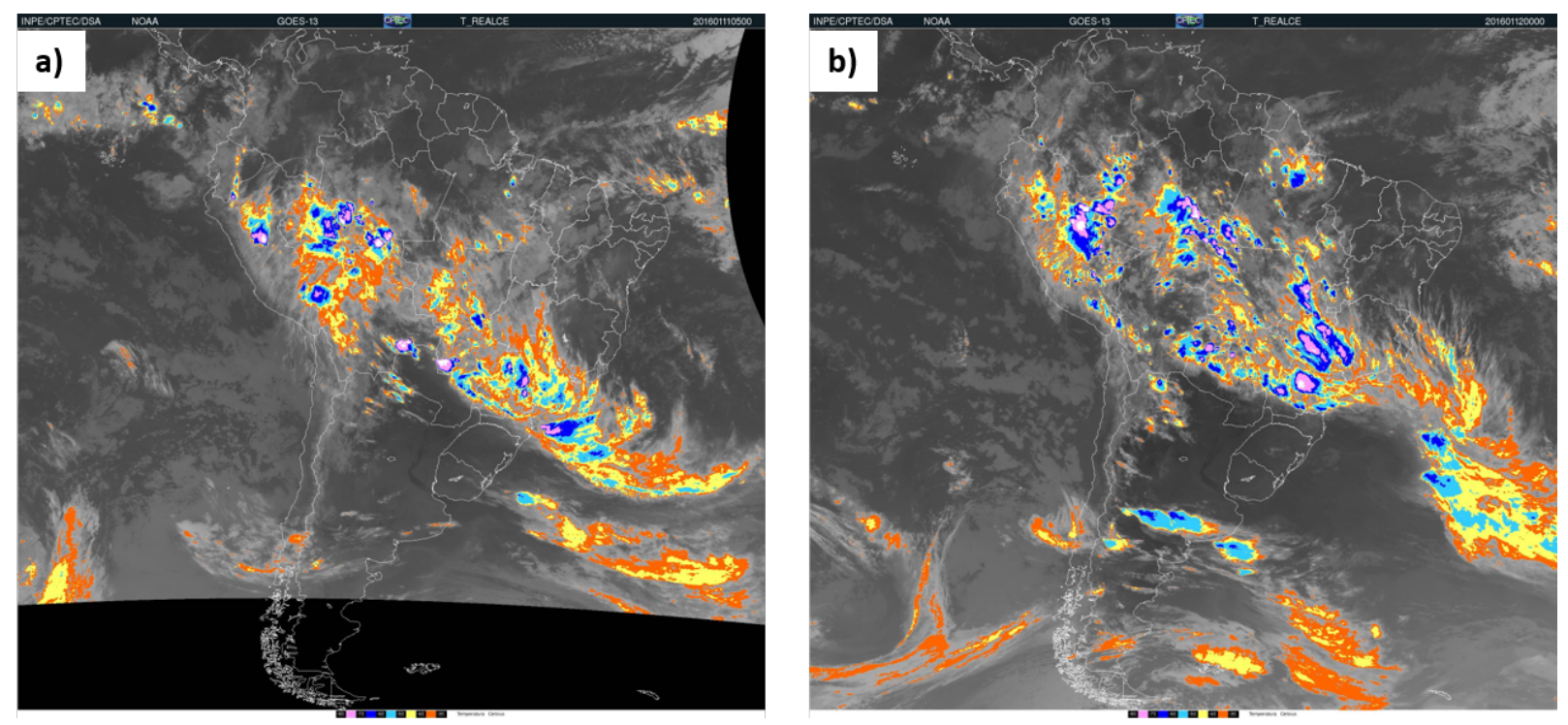

Figura 4.8: Imagem de satélite geostacionário GOES-13 no canal infravermelho, com temperatura realçada por cores, para os dias: (a) 11/01/2016; (b) 12/01/2016. Fonte: DSA-CPTEC

Os dias 11 e 12 de janeiro de 2016 foram marcados por uma circulação de baixos níveis intensa e direcionada para o Sudeste brasileiro, principalmente para o norte do PR, SP e sul de MG. Associado a esta circulação e um intenso acoplamento vertical, é observada uma banda de nuvens organizada no sentido noroeste-sudeste. A imagem de satélite do dia 11/01/2016 (Figura 4.8 (a)) mostra um aglomerado de nuvens sobre parte do Sul e Sudeste brasileiro, região com intenso levantamento do ar, como verificado na Figura 4.4. No dia 12/01/2016, a imagem de satélite (Figura 4.8 (b)) mostra nuvens com menor temperatura de topo tanto nas regiões ao sul do estado de SP, como entre o norte de GO e sul de 
MG, regiões que apresentam intenso acoplamento vertical da atmosfera durante o dia em questão, como pode ser visto na Figura 4.6 .
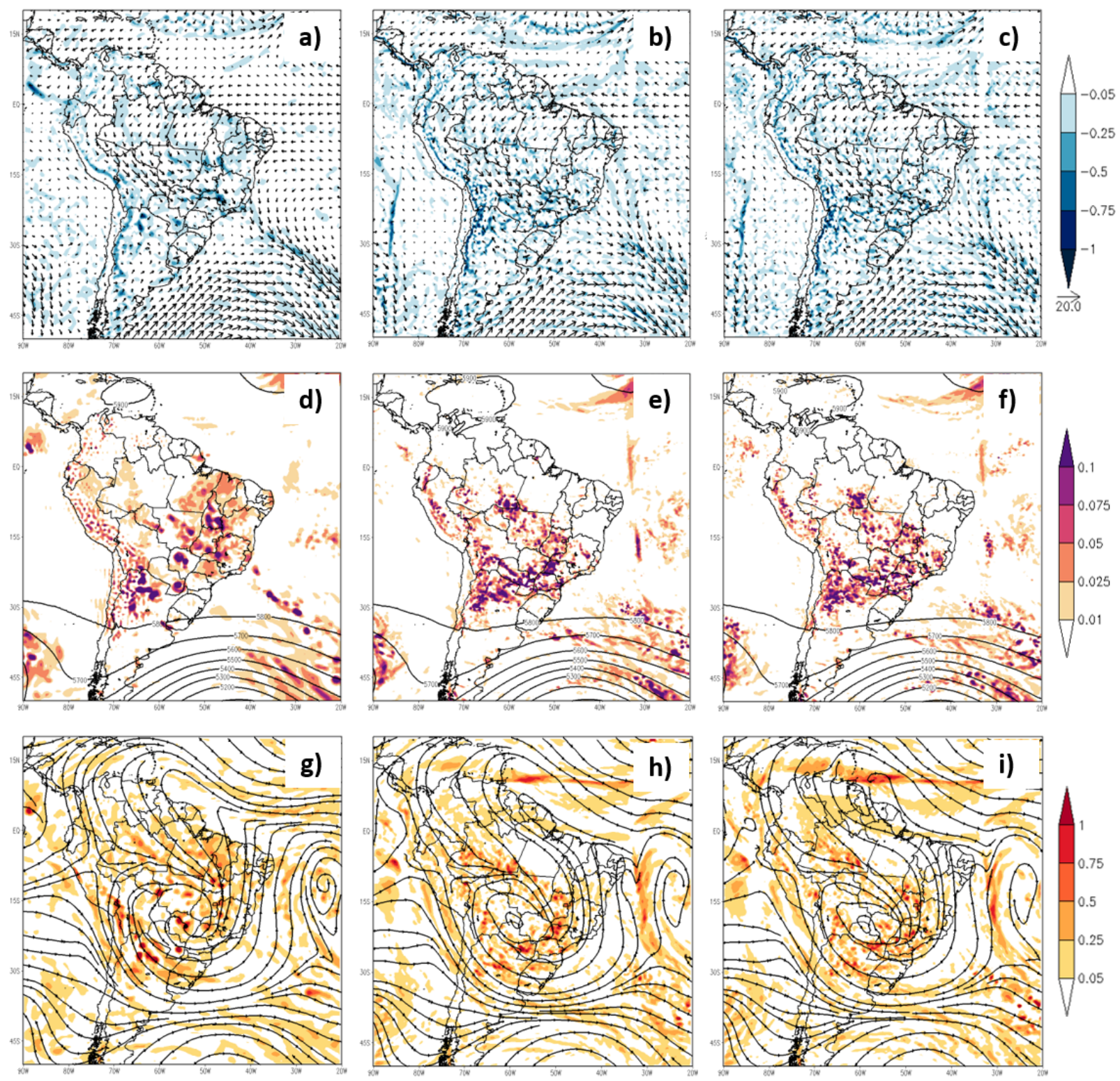

Figura 4.9: Mesmos campos da Figura 4.4. porém para o dia 13/01/2016.

No dia 13/01/2016, a análise do CFSv2 mostra, em baixos níveis (Figura 4.9 (a)), um deslocamento para norte do fluxo posicionado entre o sul da Amazônia e o Sudeste brasileiro, com a circulação ficando praticamente zonal entre o leste de MS e o centrosul de MG. As Figuras 4.9 (b) e (c) mostram, respectivamente, os campos referentes à circulação de baixos níveis das simulações CTR e GF, onde é possível notar que o padrão apresentado pela análise não foi capturado pelas simulações do modelo WRF, uma vez que 
ambas representam este deslocamento do fluxo de forma menos intensa, fazendo com que ele ainda atue sobre o estado de SP. Além disso, a análise mostra uma região de intensa convergência de umidade entre o sul de TO e o sudoeste de MG, enquanto as simulações apresentam a maior intensidade da convergência de massa entre o norte da Argentina e extremo oeste de MG, com maior intensidade na simulação CTRL.

O campo da análise para médios níveis (Figura 4.9 (d)) mostra o cavado no Atlântico perdendo amplitude e o movimento ascendente aparecendo entre o norte da Argentina, centro-oeste de MG e TO. As simulações CTRL (Figura 4.9 (e)) e GF (Figura 4.9 (f)) representam bem a desintensificação do cavado. No entanto, as regiões de maior intensidade do movimento ascendente diferem ao mostrado pela análise. Toda a região entre o oeste do Pará (PA), sul do TO e Piauí (PI) não apresenta movimento ascendente, diferentemente do conjunto de dados do CFSv2. Além disso, a variável é representada de forma mais intensa em duas outras regiões, sendo elas entre o oeste de SP e norte do PR, e entre o sudeste do AM e oeste de MG.

Ainda no dia 13/01/2016, em altos níveis, a análise do CFSv2 (Figura $4.9(\mathrm{~g})$ ), mostra a atuação da $\mathrm{AB}$ e do VCAN do Nordeste, mantendo uma área de divergência entre os dois sistemas. Neste dia, as simulações (Figuras 4.9 (h) e (i)) representam a AB deslocada cerca de $4^{\mathrm{o}}$ a oeste em relação à análise. Outra diferença é o cavado posicionado no litoral norte da AS, uma vez que a análise o representa com uma amplitude próxima à do dia anterior, porém deslocado em direção ao Oceano Atlântico tropical, enquanto as simulações mostram esta perturbação com uma amplitude superior e com formato deformado, principalmente na simulação GF.
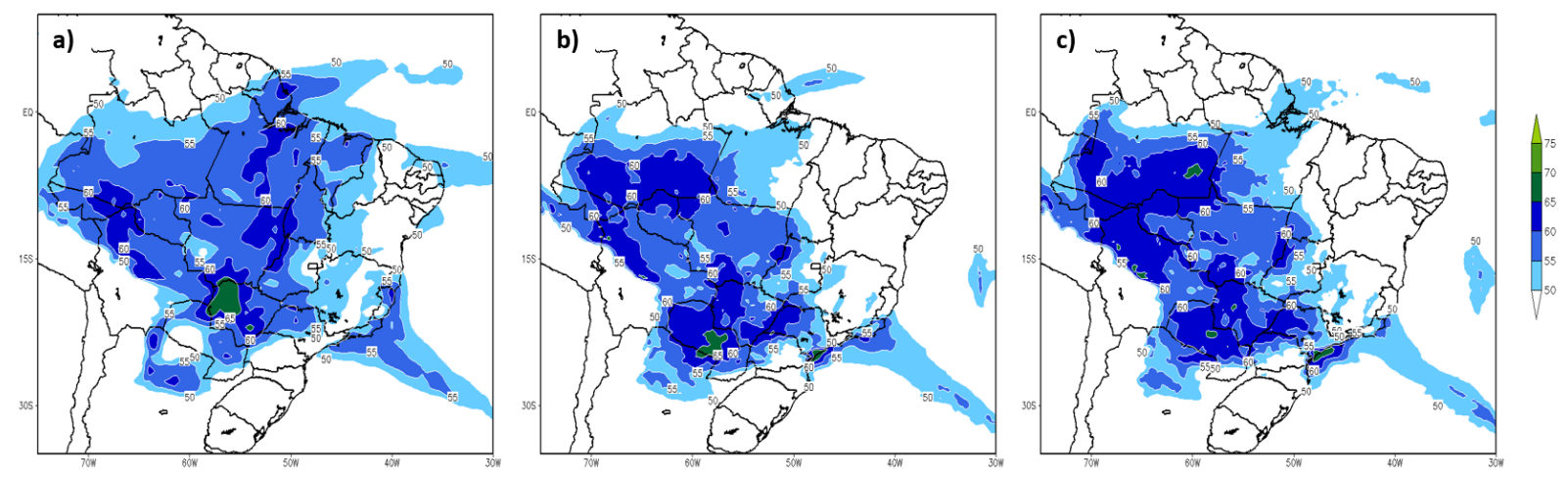

Figura 4.10: Mesmos campos da Figura 4.5, porém para o dia 13/01/2016. 
Durante o dia 13/01/2016, a quantidade de água disponível para a precipitação é inferior aos dois primeiros dias de atuação da ZCAS, como pode ser visto na Figura 4.10. Segundo o CFSv2 (Figura 4.10 (a)), as regiões com valores superiores à $50 \mathrm{~mm}$ e $55 \mathrm{~mm}$ continuam as mesmas do dia 12/01/2016, entretanto, áreas com mais de $60 \mathrm{~mm}$ ocorrem de forma esparsa em grande parte do território brasileiro e o núcleo com mais de $65 \mathrm{~mm}$ de água precipitável permanece somente no noroeste de MS. A redução da quantidade de água precipitável em relação ao dia anterior apresentada pelas simulações CTRL e GF (Figuras 4.10 (b) e (c), respectivamente) foi menor do que mostrado pela análise, especialmente nas regiões com valores superiores à $60 \mathrm{~mm}$, ocorrendo em áreas com maior extensão, principalmente na região Norte do Brasil. Por outro lado, o núcleo de maior intensidade no Centro-Oeste do Brasil é subestimado em ambas as simulações, sendo inexistente no experimento GF e menos extenso e deslocado para o sul na simulação CTRL.

No dia 14/01/2016, o campo de análise do CFSv2 em baixos níveis (Figura 4.11 (a)) exibe, assim como no dia 13/01/2016, o fluxo de noroeste-sudeste sendo desviado e ficando praticamente zonal entre o sul de MT e oeste de MG. Ao sul deste fluxo, mais precisamente sobre MS e oeste de SP, existe uma circulação com giro ciclônico, que surge pela baixa pressão originada em médios níveis pela liberação de calor latente devido à precipitação naquela área. Esta circulação ciclônica é então responsável por manter o fluxo praticamente zonal no Centro-Oeste do Brasil. A convergência de massa é bem espalhada pelo território brasileiro, mas existem núcleos de maior intensidade nos estados de MG, TO e PA. As simulações (Figuras 4.11 (b) e (c)) mostram um escoamento menos intenso e organizado comparado à análise, porém as regiões de convergência são próximas e também existe uma circulação ciclônica em parte do Centro-Oeste brasileiro.

Em médios níveis, o cavado sobre o Oceano Atlântico volta a se intensificar, como pode ser visto no campo do CFSv2 exibido na Figura 4.11(d). As simulações do modelo regional WRF (Figuras 4.11 (e) e (f)), concordaram com a análise quanto à posição e intensidade deste cavado. A análise do CFsv2 também mostra um alinhamento no movimento ascendente entre a Bolívia e o oeste do PR, além de núcleos em todo o Sudeste, Centro-Oeste e Nordeste do Brasil. Quanto ao movimento ascendente simulado, foram observadas diferenças em relação à análise, com a área de alinhamento do movimento ascendente sendo mostrada levemente deslocada ao norte da posição do CFSv2. As simulações também diferem da análise ao representarem um intenso movimento ascendente no litoral do PR. 

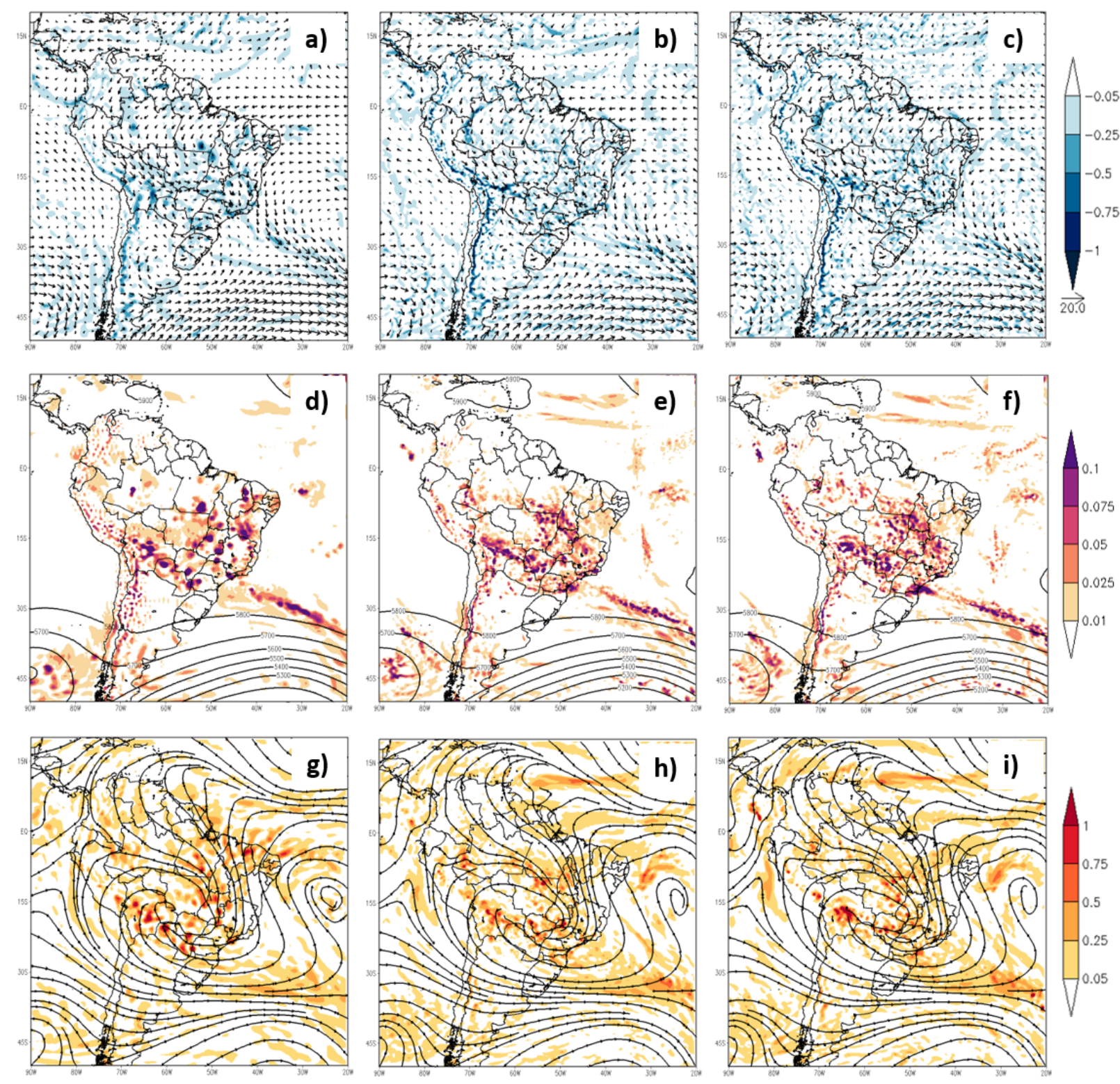

Figura 4.11: Mesmos campos da Figura 4.4 porém para o dia 14/01/2016.

Nos altos níveis da atmosfera, durante o dia 14/01/2016, a análise do CFSv2 (Figura $4.11(\mathrm{~g}))$ mostra a AB com centro próximo de $17^{\mathrm{O}} \mathrm{S}$ e $52^{\mathrm{O}} \mathrm{W}$, o VCAN do Nordeste em $14^{\mathrm{O}} \mathrm{S}$ e $22^{\mathrm{O}} \mathrm{W}$ e o cavado no litoral norte da AS deslocado para norte, assim como no dia anterior. Tanto a simulação CTRL (Figura 4.11 (h)) quanto a GF (Figura 4.11(i)) mostram a AB e o VCAN do Nordeste nas mesmas posições da análise, porém o cavado no norte da AS permanece com intensidade e padrão distintos ao CFSv2. As áreas de divergência estão espacialmente em fase com a convergência em baixos níveis e o movimento ascendente em níveis médios, em cada um dos conjuntos de dados. 

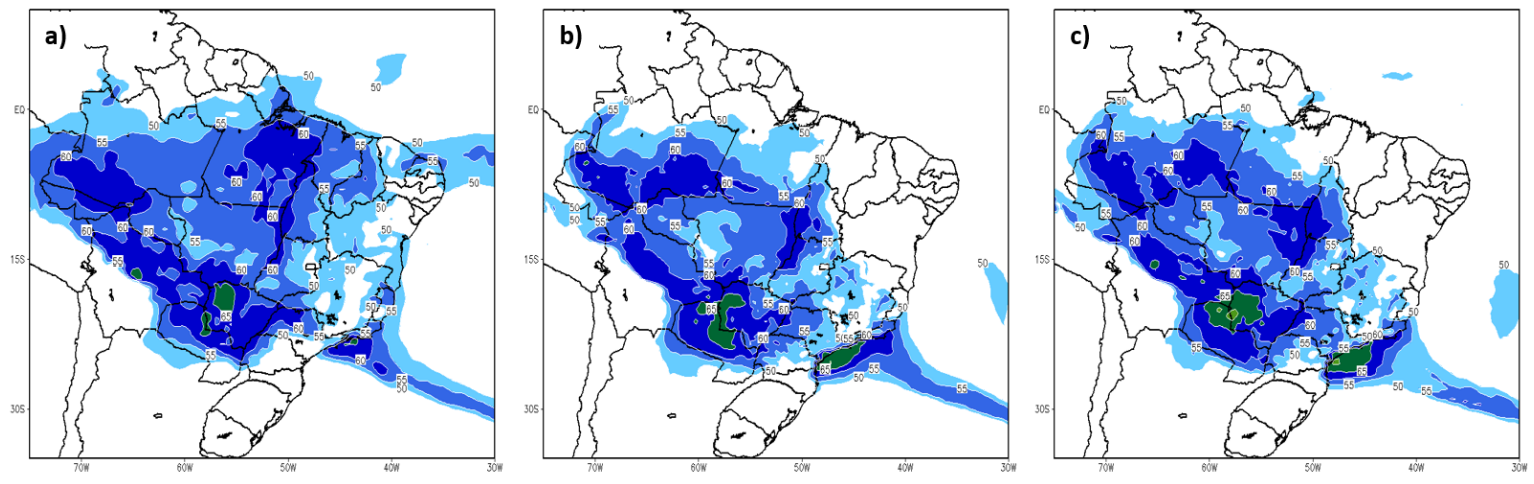

Figura 4.12: Mesmos campos da Figura 4.5, porém para o dia 14/01/2016.

A água precipitável média durante o dia 14/01/2016 é mostrada na Figura 4.12. O CFSv2 (Figura 4.12 (a)) continua apresentando um núcleo de valores superiores à $65 \mathrm{~mm}$ no oeste de MS, sendo representado de forma similar pelas simulações CTRL (Figura 4.12 (b)) e GF (Figura 4.12 (b)). Existem outras duas áreas onde experimentos e a análise diferem, a primeira é no litoral de SP, onde a área com mais de $65 \mathrm{~mm}$ é mais extensa nas simulações, e a segunda no nordeste do PA, com os experimentos numéricos subestimando em, no mínimo, $10 \mathrm{~mm}$ os valores da análise.
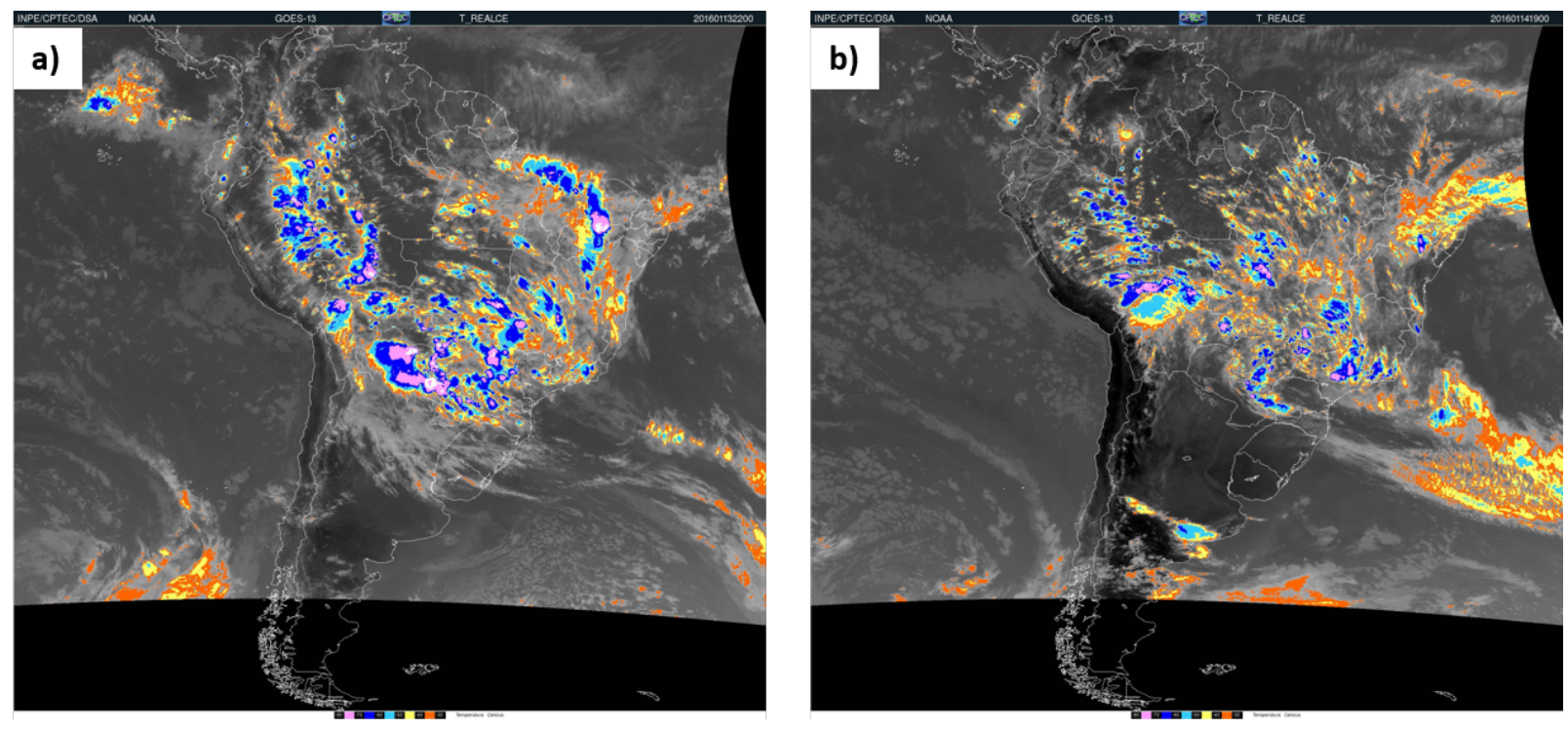

Figura 4.13: Imagem de satélite no canal de temperatura realçada para os dias: (a) 13/01/2016; (b) 14/01/2016. Fonte: DSA-CPTEC

A imagem de satélite no canal de temperatura realçada para os dias 13/01/2016 e 14/01/2016 (respectivamente, Figuras 4.13 (a) e (b)) mostram uma quebra no padrão 
de nebulosidade observado nos dias anteriores. As nuvens aparecem em grande parte do Brasil, de forma que os núcleos com maior desenvolvimento vertical concordam com as regiões verticalmente acopladas nos campos sinóticos de ambos os dias. O padrão circular das nuvens sobre MS e parte de SP, em ambos os dias, coincidem com a circulação ciclônica observada nos campos em baixos níveis do dia 14/01/2016 (Figuras 4.11 (a), (b) e (c), indicando a presença de tal perturbação durante o sistema.

No dia 15/01/2016 o campo de circulação média em baixos níveis segundo a análise do CFSv2 é mostrado na Figura 4.14 (a), onde se nota que o fluxo de noroeste que chega ao Sudeste brasileiro volta a ficar retilíneo, sem os desvios observados nos dias 13/01/2016 e 14/01/2016, uma vez que a circulação ciclônica sobre o MS e SP perde intensidade. As simulações (Figuras 4.14 (b) e (c)), por outro lado, mostram a circulação entre o sul da Amazônia e o Sudeste do Brasil menos organizada e com um desvio próximo ao observado no dia anterior, com o giro ciclônico representado com intensidade superior à análise, devido à precipitação simulada em contraste à ausência de precipitação na análises. As regiões com intensa convergência de massa acontecem na divisa entre o nordeste de SP e o sul de MG, oeste de GO e centro-sul de MT, sendo que as simulações mostram somente a área localizada entre SP e MG, enquanto as outras regiões não são simuladas de forma correta pelos experimentos.

No campo de médios níveis do CFSv2 (Figura 4.14 (d)), observa-se uma melhor definição espacial do sistema, com uma região de movimento ascendente que acompanha o fluxo noroeste-sudeste em baixos níveis, com alguns núcleos isolados em parte do Norte e Nordeste brasileiro. A simulação CTRL (Figura 4.14 (e)) subestima o movimento ascendente em grande parte do Brasil, principalmente no estado de SP. Por outro lado, a simulação GF (Figura 4.14 (f)) apresenta padrões e valores mais próximos à análise, mesmo estando levemente deslocados. As linhas de altura geopotencial revelam a ausência de um cavado próximo da região Sudeste do Brasil, porém a linha de 5800 m mostra uma leve curvatura próximo do litoral do Rio Grande do Sul (RS), tanto na análise como nas simulações.

Assim como o movimento ascendente em médios níveis, a região de divergência em 200 hPa do CFSv2 (Figura 4.14 (g)) concorda com a convergência em 850 hPa. Além disso, também está presente a AB, o VCAN do Nordeste e, alinhado a este, o cavado no litoral norte do Brasil. Estas características também são representadas pelas simulação CTRL 
(Figura $4.14(\mathrm{~h})$ ) e GF (Figura $4.14(\mathrm{i})$ ). Entretanto, a intensidade da divergência é inferior à apresentada pela análise, assim como ocorre no movimento ascendente em 500 hPa.
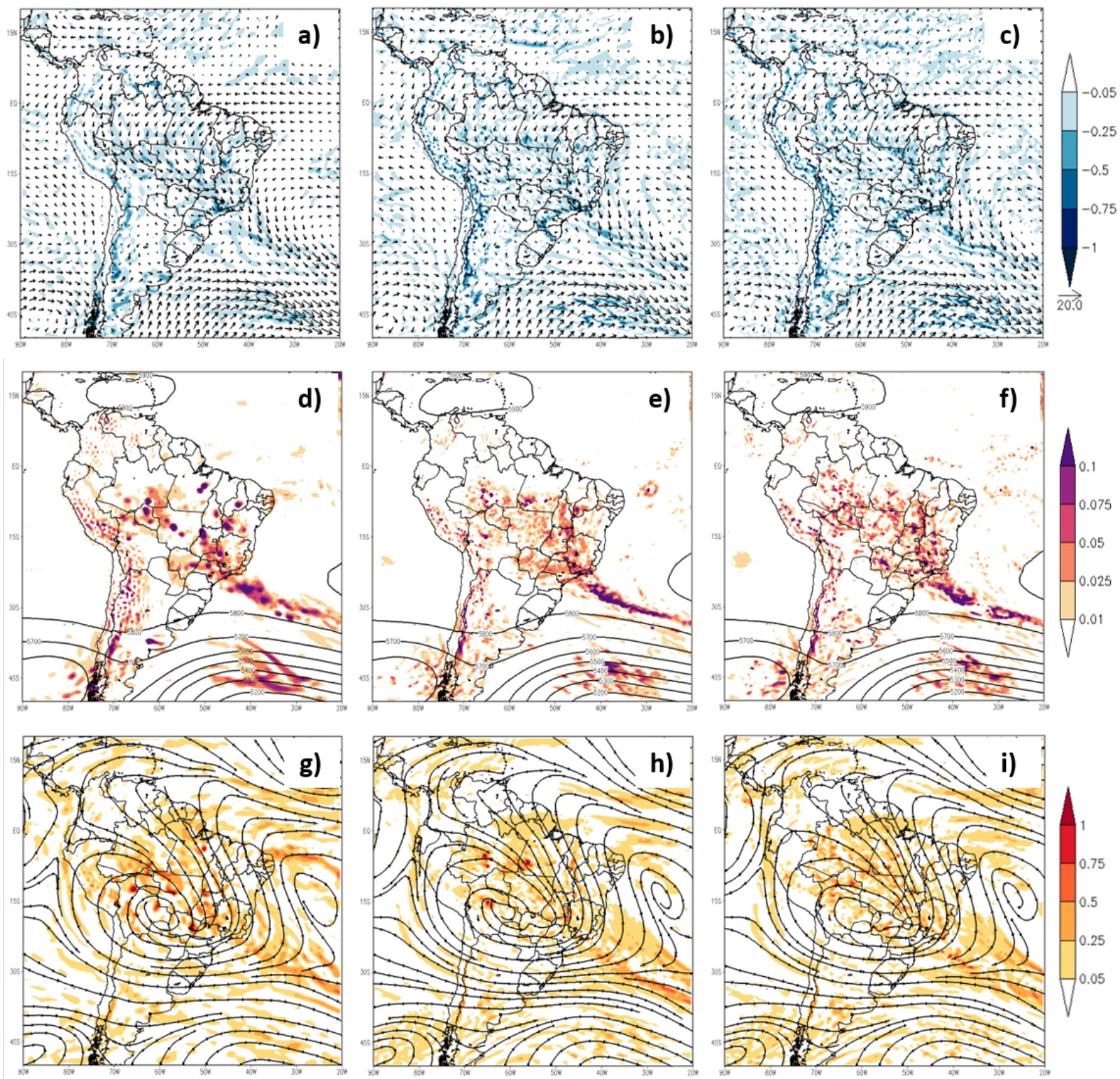

Figura 4.14: Mesmos campos da Figura 4.4. porém para o dia 15/01/2016.

A quantidade de água precipitável durante o dia 15/01/2016 é mostrada nos campos da Figura 4.15. O CFSv2 apresenta um núcleo de valores superiores à $65 \mathrm{~mm}$ no oeste do MS, enquanto no Oceano Atlântico adjacente ao Sudeste brasileiro é observado um aumento na quantidade de água precipitável em relação ao dia anterior. As simulações CTRL e GF (Figuras 4.15 (b) e (c), respectivamente) diferem da análise em alguns pontos, sendo os principais a subestimação no oeste do MS, região Norte do Brasil e noroeste do Nordeste 
brasileiro, e a superestimação no Oceano Atlântico próximo de SP e RJ.
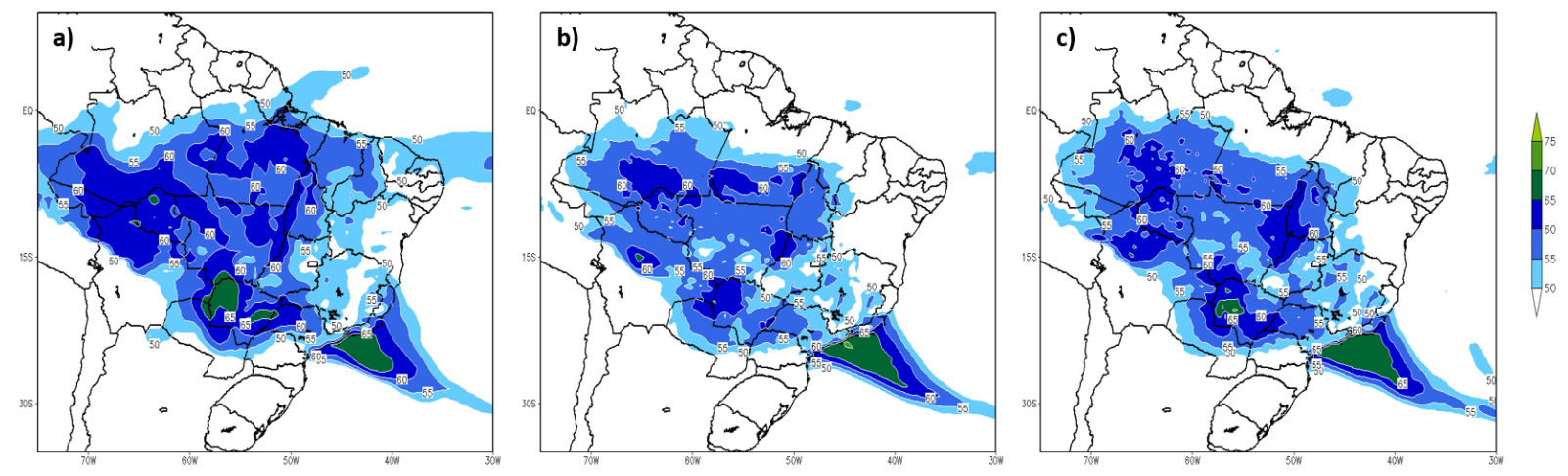

Figura 4.15: Mesmos campos da Figura 4.5, porém para o dia 15/01/2016.

A imagem de satélite no canal de temperatura realçada do dia 15/01/2016 (Figura 4.18 (a)) mostra as nuvens de forma esparsa, porém com uma organização que converge com as características mostradas pelos campos sinóticos da Figura 4.14. A região de atuação da circulação ciclônica em baixos níveis e a AB são praticamente as mesmas, podendo explicar a formação de nuvens com elevado desenvolvimento vertical sobre o oeste do MS.

Durante o dia 16/01/2016, a circulação ciclônica no Centro-Oeste brasileiro aparece de forma mais intensa que a do dia anterior, como pode ser visto no campo de vento médio do CFSv2 em 850 hPa (Figura 4.16 (a)). Esta circulação está localizada na face sul do fluxo orientado de noroeste a sudeste, fazendo com que o mesmo adquira esta curvatura ciclônica entre o oeste de MT e o norte do Rio de Janeiro (RJ). As regiões que possuem intensa convergência do vento são o sul de MG, nordeste de MT e oeste da Bahia (BA). A circulação em baixos níveis das simulações CTRL e GF são mostradas nas Figuras 4.16(b) e (c), respectivamente, onde, comparando-se às análises, verifica-se a circulação ciclônica e o fluxo de noroeste na mesma posição e intensidade, sendo que o mesmo acontece sobreposto à convergência de massa em baixos níveis.

Em médios níveis, os dados da análise (Figura 4.16 (d)) exibem o cavado em níveis médios mais intenso em relação ao dia anterior. As regiões com movimento ascendente intenso são observadas de forma esparsa, e nos mesmos locais onde existe convergência de massa em $850 \mathrm{hPa}$. Os campos das simulações CTRL e GF (Figuras 4.16 (e) e (f), respectivamente) representam de forma similar o padrão apresentado pela análise, porém a intensidade do movimento ascendente é inferior. 

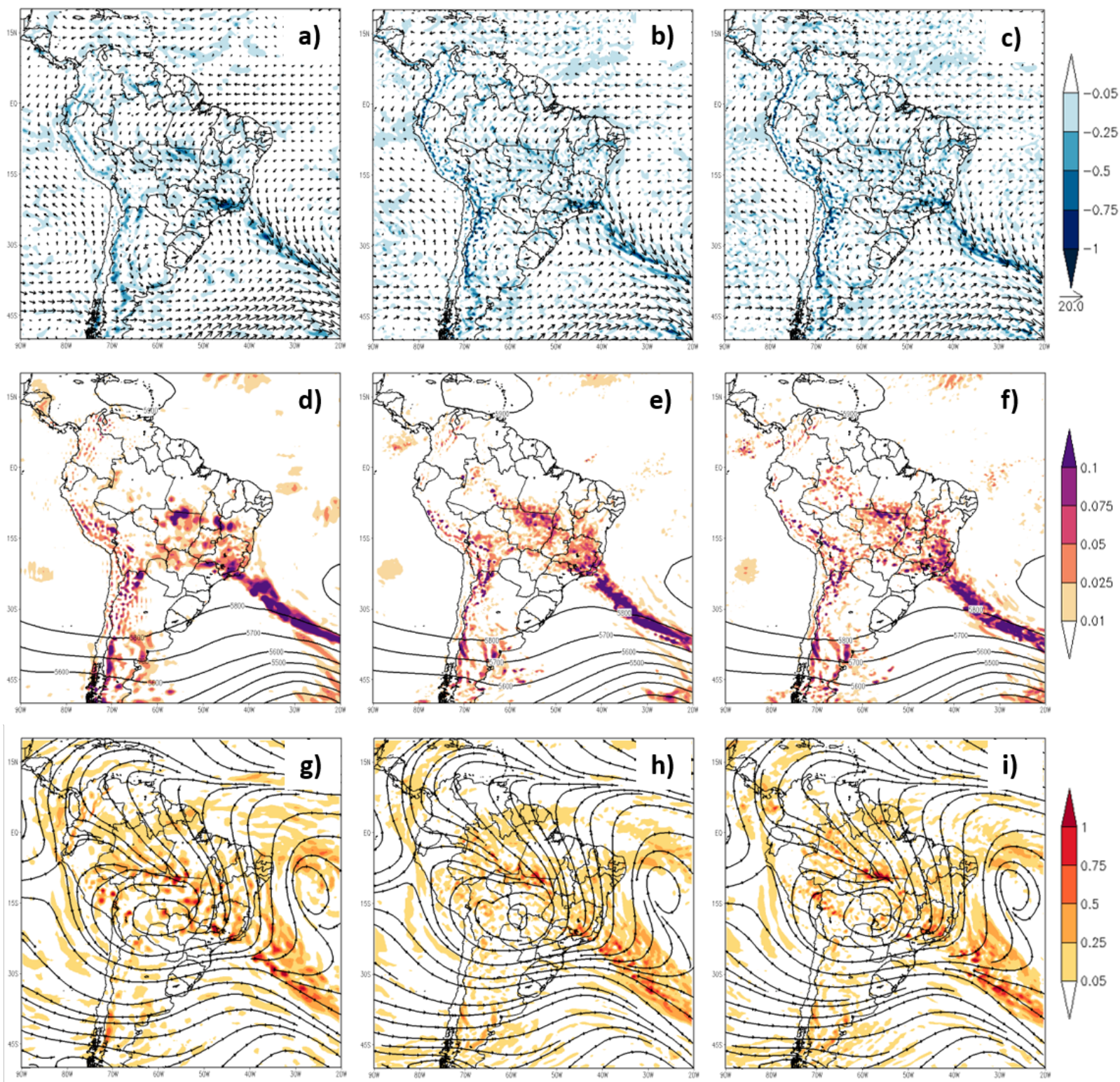

Figura 4.16: Mesmos campos da Figura 4.4, porém para o dia 16/01/2016.

Em altos níveis, o CFSv2 (Figura $4.16(\mathrm{~g})$ ) exibe a AB e o VCAN do Nordeste ainda configurados e a divergência de massa posicionada entre estas duas circulações, onde os pontos de maior intensidade acontecem em fase com a convergência em baixos níveis e o movimento vertical em $500 \mathrm{hPa}$. As simulações (Figuras 4.16 (h) e (i)) representam a AB e o VCAN do Nordeste nas mesmas posições da análise, com a divergência ocorrendo nas mesmas regiões, porém com intensidade inferior, assim como no movimento vertical em $500 \mathrm{hPa}$. 

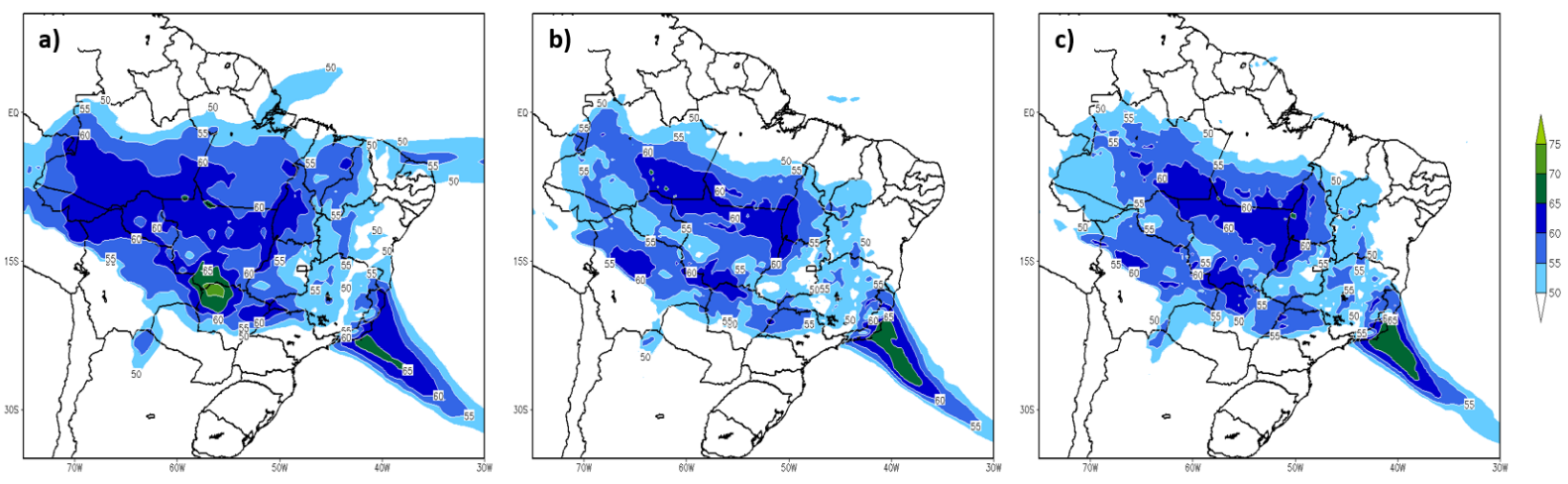

Figura 4.17: Mesmos campos da Figura 4.5, porém para o dia 16/01/2016.

Ainda no dia 16/01/2016, as regiões com água precipitável superior à $50 \mathrm{~mm}$ se deslocam para norte da posição do dia anterior, e somente o noroeste de SP mantém tais níveis de disponibilidade de vapor d'água. A análise (Figura 4.17 (a)) continua a mostrar grandes valores de água precipitável no noroeste de MS, chegando a $70 \mathrm{~mm}$ no núcleo de maior intensidade, região de atuação do vórtice ciclônico em baixos níveis e a AB em 200 $\mathrm{hPa}$ (respectivamente, Figuras 4.16 (a) e (g)). Além disso, também houve um aumento na disponibilidade de vapor d'água para precipitação no Nordeste brasileiro, e uma redução da mesma variável no Oceano Atlântico próximo ao litoral do RJ. Ambas as simulações (Figuras 4.17 (b) e (c)) subestimam a quantidade de água precipitável exibida pela a análise em todo o Brasil, de forma que somente no Oceano Atlântico adjacente ao Sudeste brasileiro os valores foram superiores ao CFSv2.

Da mesma forma que no dia anterior, a imagem de satélite do dia 16/01/2016 (Figura 4.18 (b)) mostra um padrão de nebulosidade coerente com a circulação apresentada pelos campos médios do dia (Figura 4.16). As nuvens com maior desenvolvimento vertical estão próximas das regiões com intenso acoplamento da atmosfera, incluindo a área sob atuação da circulação ciclônica em 850 hPa e a AB em 200 hPa.

No dia 17/01/2016, em baixos níveis, a circulação ciclônica na região central do Brasil continua sendo observada, posicionada logo ao sul do fluxo entre o sul do AM e o leste de MG, como pode ser visto na Figura 4.19 (a). Nas simulações (Figuras 4.19 (b) e (c)) o vórtice ciclônico na região central do Brasil é menos intenso. Por outro lado, as áreas de máxima convergência de massa acontecem com intensidade e em regiões similares às observadas na análise. 

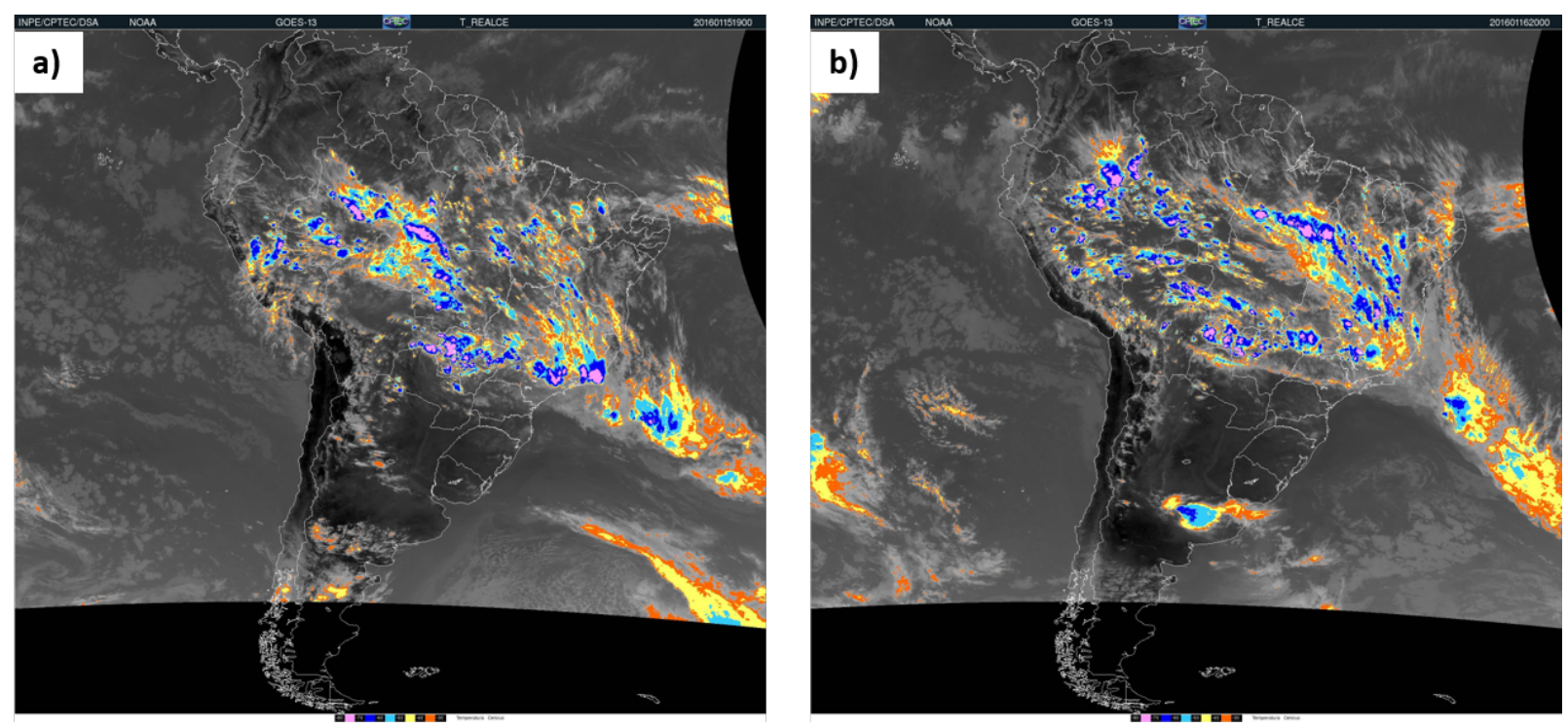

Figura 4.18: Imagem de satélite no canal de temperatura realçada para os dias: (a) 15/01/2016; (b) 16/01/2016. Fonte: DSA-CPTEC

Em níveis médios, o CFsv2 (Figura 4.19 (d)) mostra que o cavado sobre o Oceano Atlântico subtropical ganha amplitude, como pode ser visto na isolinha de $5850 \mathrm{~m}$, que se posiciona mais a norte do que em dias anteriores. Tanto a simulação CTRL (Figura 4.19 (e)) quanto a simulação GF (Figura 4.19 (f)) representam o eixo do cavado ligeiramente a sul do apresentado pela análise. Comparado à análise, o movimento vertical das simulações acontece na mesma região, mas com intensidade inferior, principalmente no experimento GF.

No nível de 200 hPa do CFSv2 4.19 (g)), a AB continua presente e intensa, porém o VCAN do Nordeste se distancia do continente e da AB. Tanto a simulação CTRL (Figura 4.19 (h)) quanto a GF (Figura 4.19 (i)) representam a AB e o VCAN do Nordeste nas mesmas posições da análise. A divergência de massa de ambas as simulação é menos intensa do que o apresentado pelo CFSv2, principalmente no Nordeste brasileiro.

A quantidade de água precipitável média durante o dia 17/01/2016 é mostrada na Figura 4.20. O CFSv2 (Figura 4.20 (a), mostra um aumento na disponibilidade de vapor d'água no Nordeste do Brasil, além da presença de um núcleo com $70 \mathrm{~mm}$ no noroeste de MS e uma diminuição nos valores sobre o Oceano Atlântico adjacente ao Sudeste brasileiro, em relação ao dia anterior. Ambas as simulações (Figuras 4.20 (b) e (c), respectivamente simulações CTRL e GF) subestimam a análise, sendo que os menores valores são observados na Simulação GF. Somente sobre o Oceano Atlântico, próximo ao litoral do Espírito Santo 
(ES), a simulação CTRL apresenta valores de água precipitável superior a análise.

Na imagem de satélite do dia 17/01/2016 (Figura 4.23 (a)), existem nuvens com elevado desenvolvimento vertical próximo da fronteira entre MG e MS, divisa entre MG e GO e entre MG e BA, concordando com as regiões de intenso acoplamento vertical atmosférico observados nas análises numéricas. Existem pequenos núcleos de baixa temperatura de topo espalhados ao longo da circulação entre o sul da Amazônia e o leste da Bahia, concordando com o aumento de água precipitável nessa região.
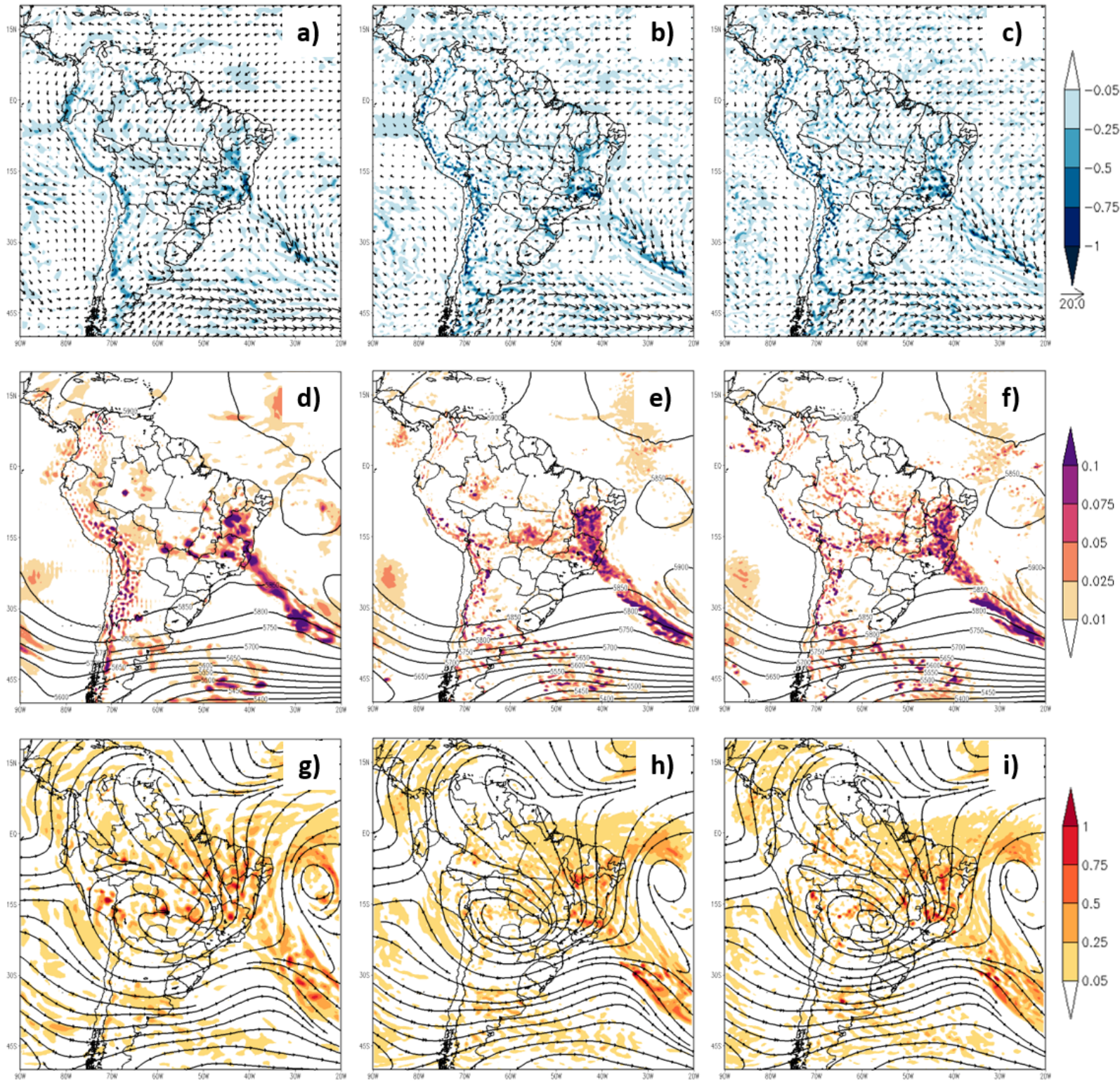

Figura 4.19: Mesmos campos da Figura 4.4 porém para o dia 17/01/2016. 

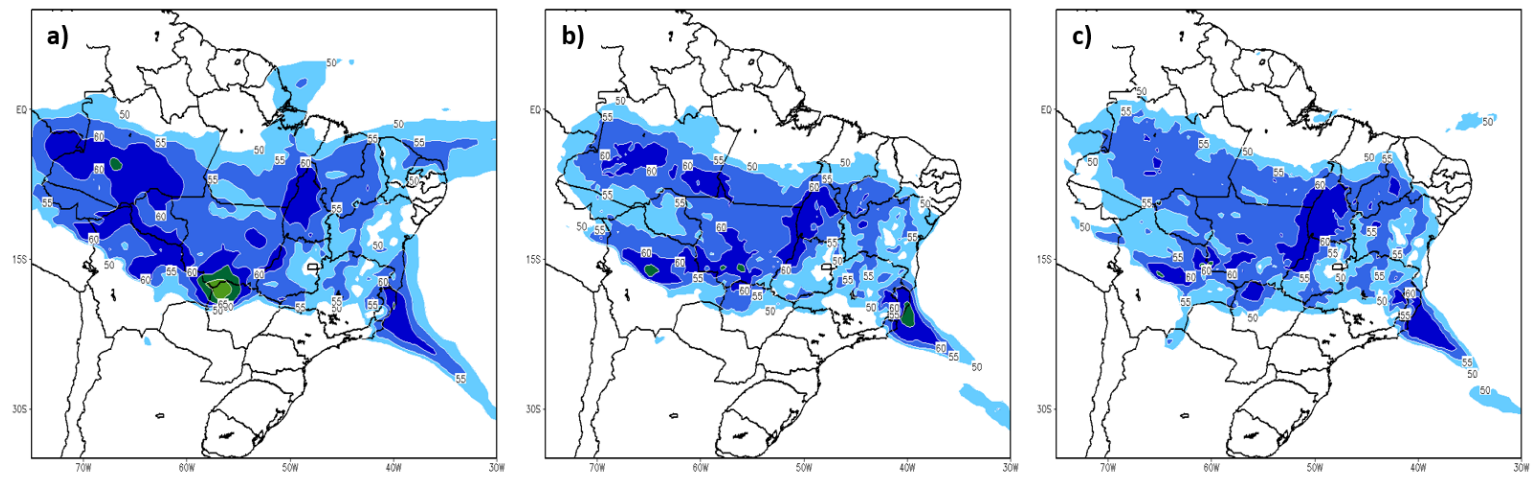

Figura 4.20: Mesmos campos da Figura 4.5. porém para o dia 17/01/2016.

No dia 18/01/2016, o campo em 850 hPa do CFSv2 (Figura 4.21(a)) mostra a circulação ciclônica ainda presente, porém enfraquecida, enquanto o fluxo entre o sul da Amazônia e o Sudeste brasileiro aparece menos intenso e ocorrendo basicamente devido à circulação ciclônica no Centro-Oeste brasileiro. As simulações CTRL e GF (Figura 4.21 (b) e (c)) representam o vórtice ciclônico com intensidade inferior à apresentada pela análise, sendo que tal enfraquecimento também ocorre com o fluxo noroeste-sudeste. Por outro lado, a convergência de massa representada pelas simulações acontece em regiões similares ao CFSv2.

Em médios níveis (Figura 4.21(d)), a análise representa o cavado ainda intenso e com o eixo permanecendo sobre o Oceano Atlântico subtropical. Tanto a simulação CTRL quanto a GF (Figura 4.21 (e) e (f), respectivamente) mostram o movimento ascendente ocorrendo nas mesmas regiões da análise, porém sem os núcleos de maior intensidade. Além disso, o cavado sobre o Oceano Atlântico também é observado, porém localizado mais a sul, assim como no dia anterior.

Em 200 hPa (Figura 4.21 (g)), a AB e o VCAN do Nordeste ainda atuam, porém a $\mathrm{AB}$ se desloca para sudoeste e o VCAN se distancia do continente, fazendo com que os dois sistemas fiquem mais distantes entre si e com que a região com divergência de massa ocorra de forma mais abrangente sobre o centro-norte do Brasil. As regiões com intenso acoplamento entre baixos, médios e altos níveis atmosféricos aparecem em forma de núcleos esparsados e com tamanho reduzido em relação aos dias anteriores. As simulações (Figura 4.21 (h) e (i)) representam a $\mathrm{AB}$ e o VCAN do Nordeste posicionados nas mesmas regiões do CFSv2, porém com a divergência do vento subestimada. 

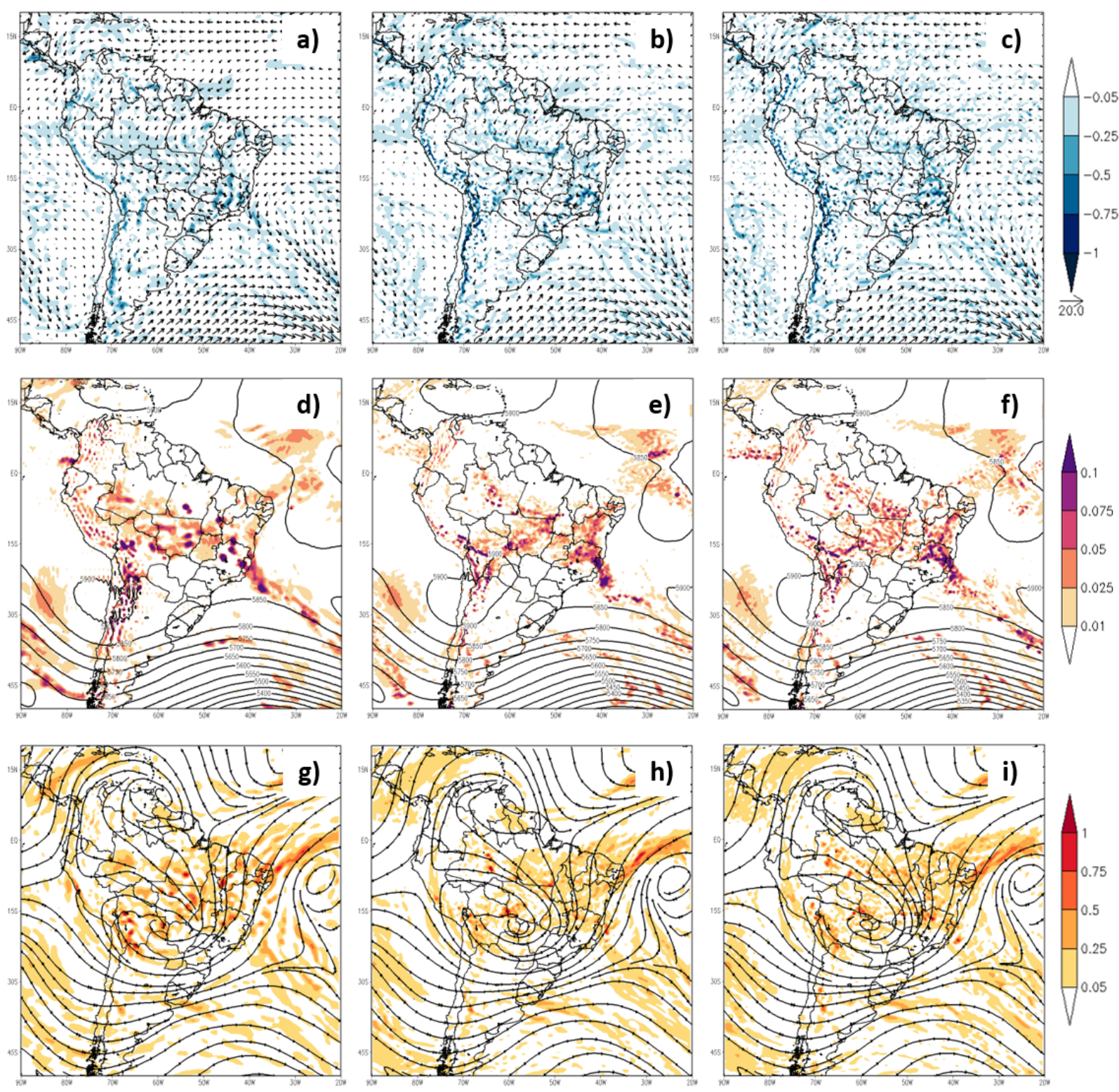

Figura 4.21: Mesmos campos da Figura 4.4 porém para o dia 18/01/2016.

A quantidade de água precipitável do dia 18/01/2016 se mantém constante em relação ao dia anterior somente no sul da região Norte brasileira, oeste do Nordeste do Brasil e MT, como mostrado na Figura 4.22. No sul de MT, onde a análise (Figura 4.22 (a)) mostra valores superiores a $65 \mathrm{~mm}$, existe uma subestimação por parte das simulações, principalmente pelo experimento CTRL (Figura 4.22 (b)). Na região Norte do Brasil, os experimentos continuam subestimando a quantidade de água precipitável e os menores valores são observados no campo da simulação GF (Figura 4.22 (c)). 

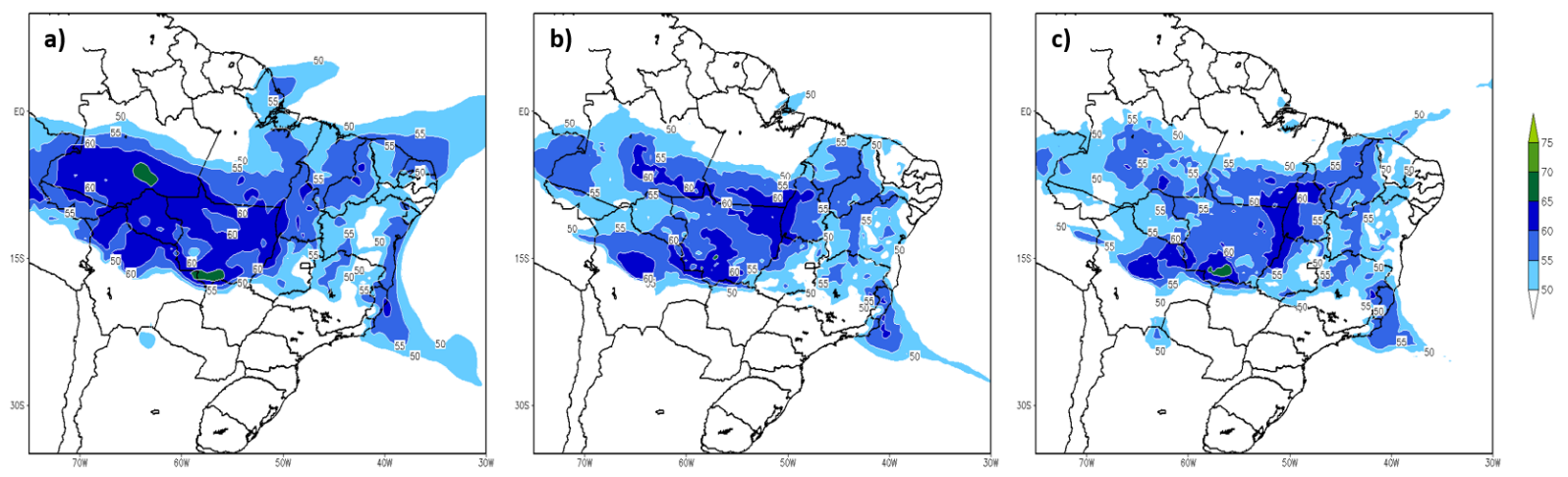

Figura 4.22: Mesmos campos da Figura 4.5, porém para o dia 18/01/2016.
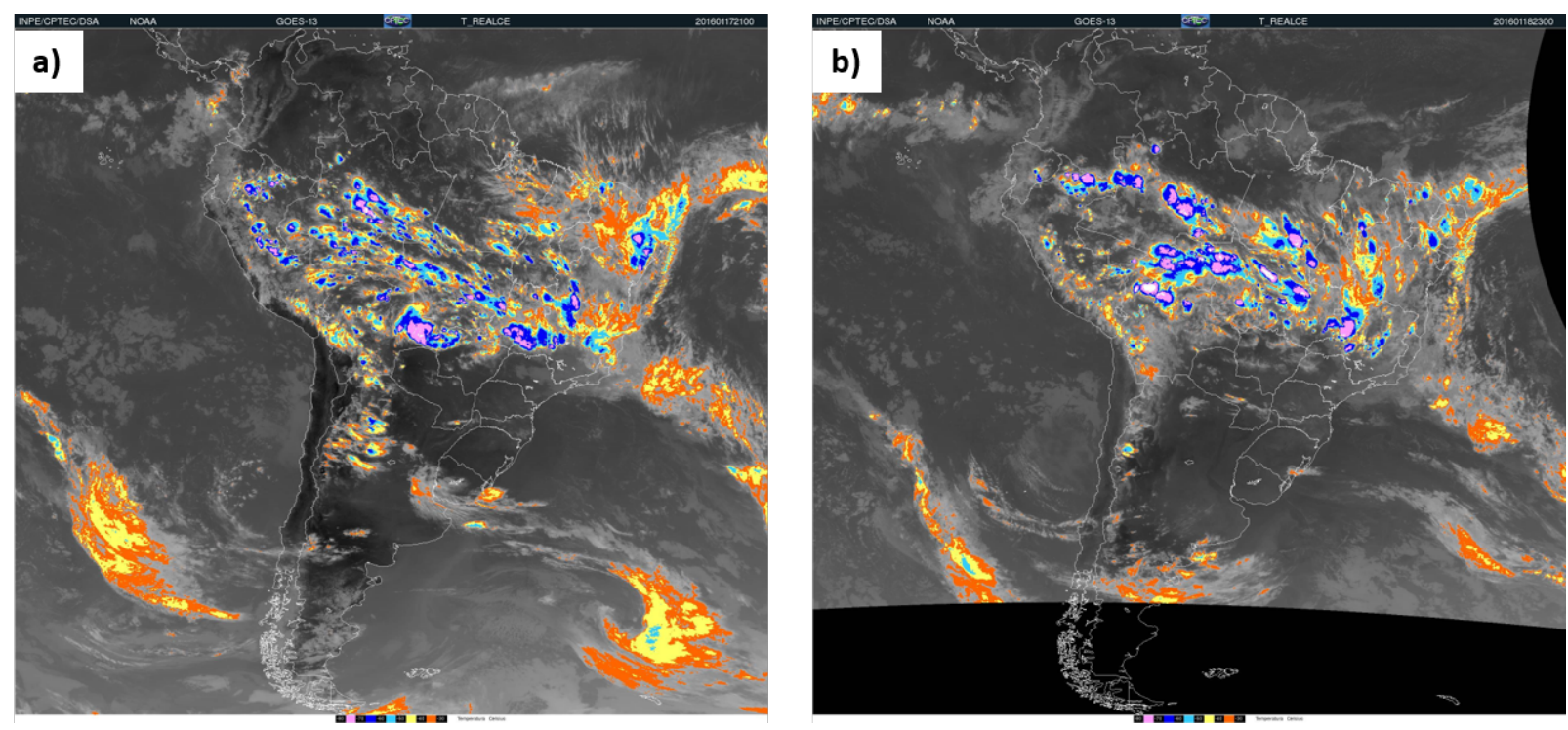

Figura 4.23: Imagem de satélite no canal de temperatura realçada para os dias: (a) 17/01/2016; (b) 18/01/2016. Fonte: DSA-CPTEC

A imagem de satélite no canal de temperatura realçada para o dia 18/01/016 (Figura 4.23 (b)) mostra os maiores conglomerados de nuvens com elevado desenvolvimento vertical acontecendo no sul da região Amazônica. Enquanto isso, no Sudeste e Nordeste do Brasil, os núcleos são mais esparsos e com temperatura do topo da nuvem mais elevada, indicando a presença de nuvens com desenvolvimento vertical reduzido, associadas à fase de dissipação da ZCAS.

Os campos médios durante toda a atuação do sistema mostram que as características sinóticas do caso de ZCAS em análise foram bem capturadas pelas simulações, acontecendo nas mesmas posições apresentadas pela análise do CFSv2. Porém, tanto a convergência 
de massa em baixos níveis quanto o movimento ascendente em médios níveis foram representados com intensidade inferior ao observado nos campos das análises CFSv2. A análise diária dos campos de massa mostram que esta subestimativa ocorreu, majoritariamente, após o dia 13, momento em que a grade 3 - onde os processos convectivos são resolvidos explicitamente - está desativada. O mesmo acontece com a quantidade de água precipitável, sendo uma boa representação da análise até o dia 13/01/2016 e, após esse dia, apresentando uma subestimativa por parte dos experimentos numéricos, principalmente na região Amazônica.

\subsection{Jato de Baixos Níveis}

\subsubsection{Campos Espaciais}

Embora não seja a forma correta de se verificar a atuação de um JBN, o campo de vento em $850 \mathrm{hPa}$ fornece uma noção de quais região estão sob a possível influência deste sistema. Segundo Bonner (1968) e Whiteman et al. (1997), o JBN de menor intensidade apresenta velocidade do vento mínima de $10 \mathrm{~m} / \mathrm{s}$ em seu núcleo, por isso regiões em 850 hPa com essa característica podem estar sob a influencia de um JBN.
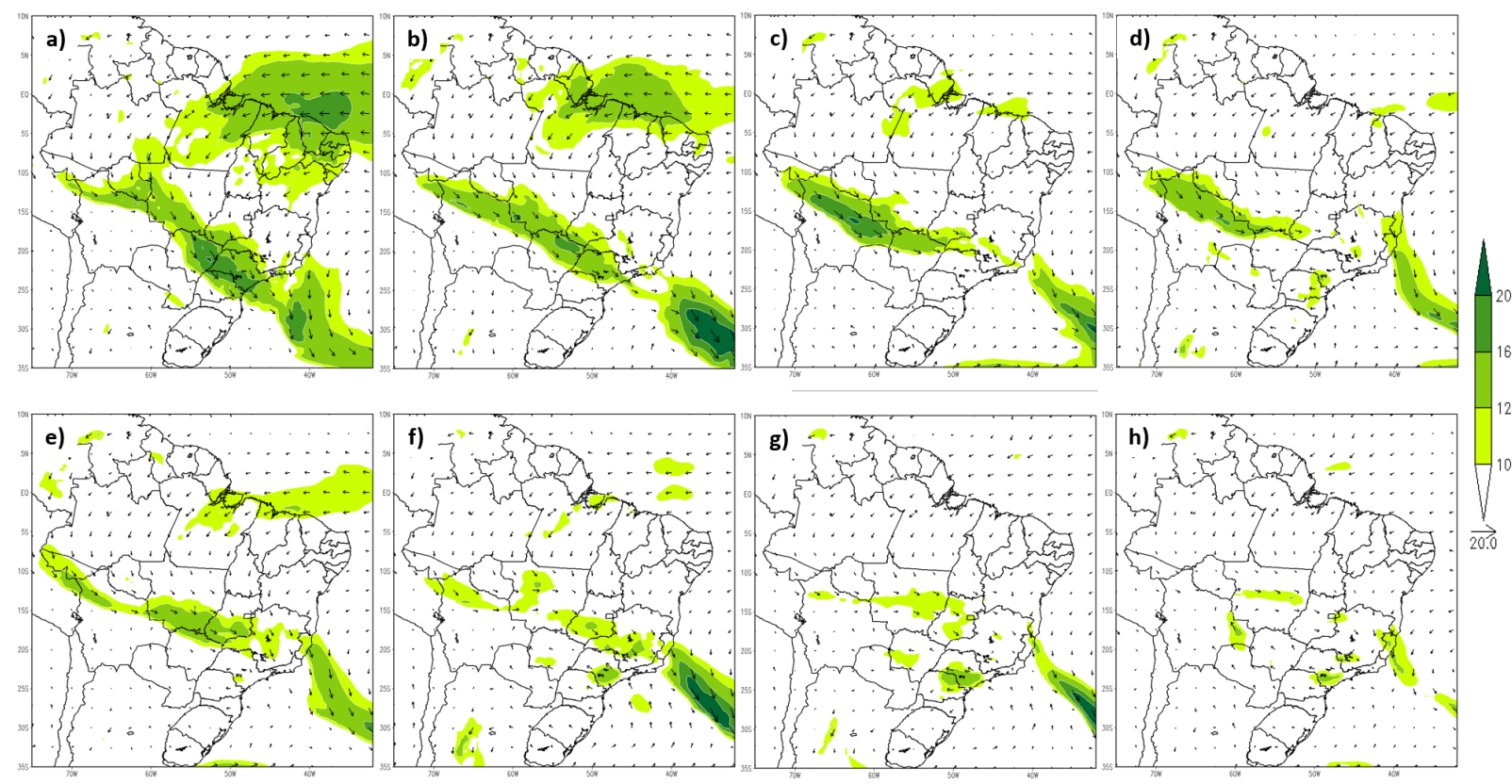

Figura 4.24: Média da magnitude e direção do vento (sombreado $[\mathrm{m} / \mathrm{s}]$ e vetor, respectivamente) em $850 \mathrm{hPa}$ pelos dados do CFSv2 durante janeiro de 2016, para os dias: a) 11; b) 12 ; c) 13 ; d) 14 ; e) 15 ; f) 16 ; g) 17 ; e h) 18 . 
Os campos da Figura 4.24 apresentam a magnitude e direção do vento em 850 hPa pela análise do CFSv2. No dia 11/01/2016 (Figura 4.24 (a)) existem duas regiões principais com magnitude do vento superior a $10 \mathrm{~m} / \mathrm{s}$, a primeira é no Oceano Atlântico tropical, enquanto a segunda é entre o sul da região amazônica e a divisa entre SP e PR, onde os valores ultrapassam $16 \mathrm{~m} / \mathrm{s}$. No dia 12/01/2016 (Figura 4.24 (b)), as regiões com possível atuação do JBN são as mesmas do dia anterior, porém a intensidade do vento é inferior, chegando a $16 \mathrm{~m} / \mathrm{s}$ somente no noroeste do MS. No dia 13/01/2016 (Figura 4.24 (c)), a magnitude do vento perde ainda mais intensidade, e valores superiores a $10 \mathrm{~m} / \mathrm{s}$ praticamente não são observados no Oceano Atlântico tropical. No fluxo noroeste-sudeste, a região de possível atuação do JBN não chega até o Sudeste brasileiro, ficando restrita ao Centro-Oeste do Brasil e a Bolívia. O padrão para o dia 14/01/2016 (Figura 4.24 (d)) é o mesmo do dia anterior, porém é observado um enfraquecimento na magnitude do vento em baixos níveis. Entretanto, no dia 15/01/2016 (Figura 4.24 (e)), este volta a se intensificar no Centro-Oeste brasileiro, sul de MT e GO. Entre os dias 16/01/2016 e 18/01/2016 (Figuras 4.24 (f), (g) e (h)), é observada uma desintensificação da velocidade do vento em baixos níveis, sendo que, no dia 18/01/2016, praticamente não existem regiões com magnitude do vento superior a $10 \mathrm{~m} / \mathrm{s}$.
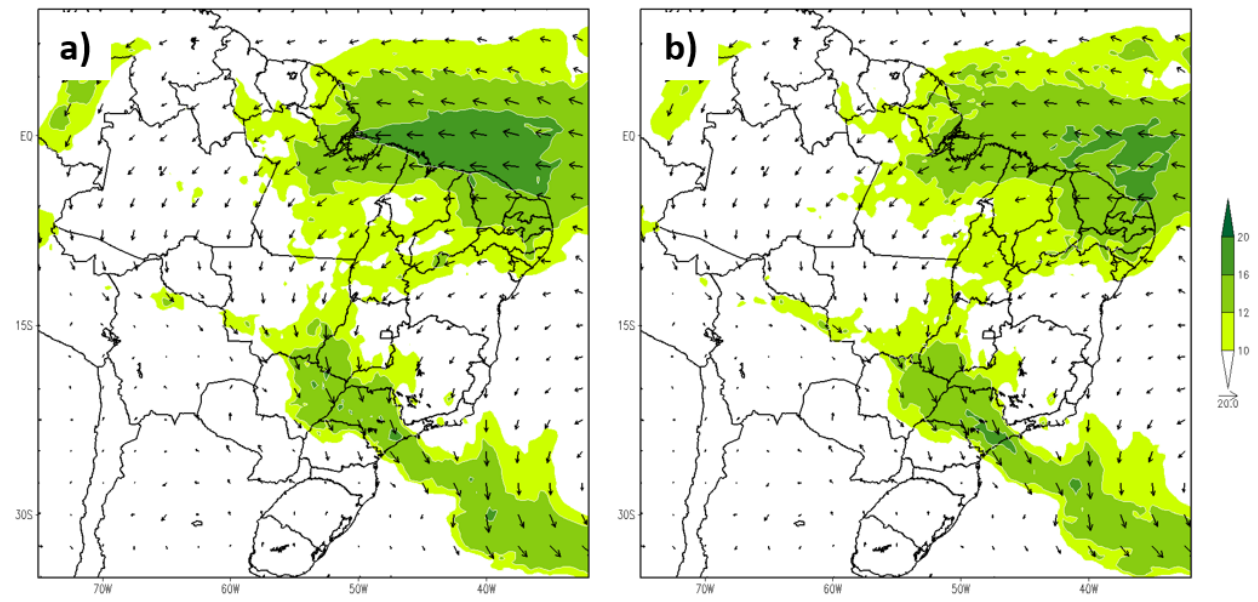

Figura 4.25: Média diária da magnitude do vento em $850 \mathrm{hPa}$ (sombreado $[\mathrm{m} / \mathrm{s}]$ e vetor) para 11 de janeiro de 2016 pelas simulações: a) CTRL; b) GF.

Os campos da Figura 4.24 mostram que, nos dias 11, 12 e 13 de janeiro de 2016, o JBN é mais intenso. Assim, estes dias foram selecionados para realizar as análises com os experimentos do modelo atmosférico com mais detalhes, como mostrado nas Figuras 4.25 . 
4.26 e 4.27, respectivamente.

No dia 11/01/2016, as simulações CTRL (Figura 4.25 (a)) e GF (Figura 4.25 (b)) mostram padrões semelhantes, com regiões de magnitude do vento superiores à $10 \mathrm{~m} / \mathrm{s}$ no Oceano Atlântico tropical e entre o sudeste de MT e o litoral de SP, sendo que na simulação CTRL estes valores são superiores aos da simulação GF. Ainda, verifica-se que a simulação GF se aproxima mais à análise (Figura 4.24 (a)). Em ambas as simulações, no Sudeste e Centro-Oeste brasileiro, a região de atuação da circulação noroeste-sudeste ocorre mais ao norte, enquanto no sul da região amazônica e Nordeste do Brasil, os valores de magnitude do vento são, respectivamente, inferiores e superiores, quando comparadas ao CFSv2.
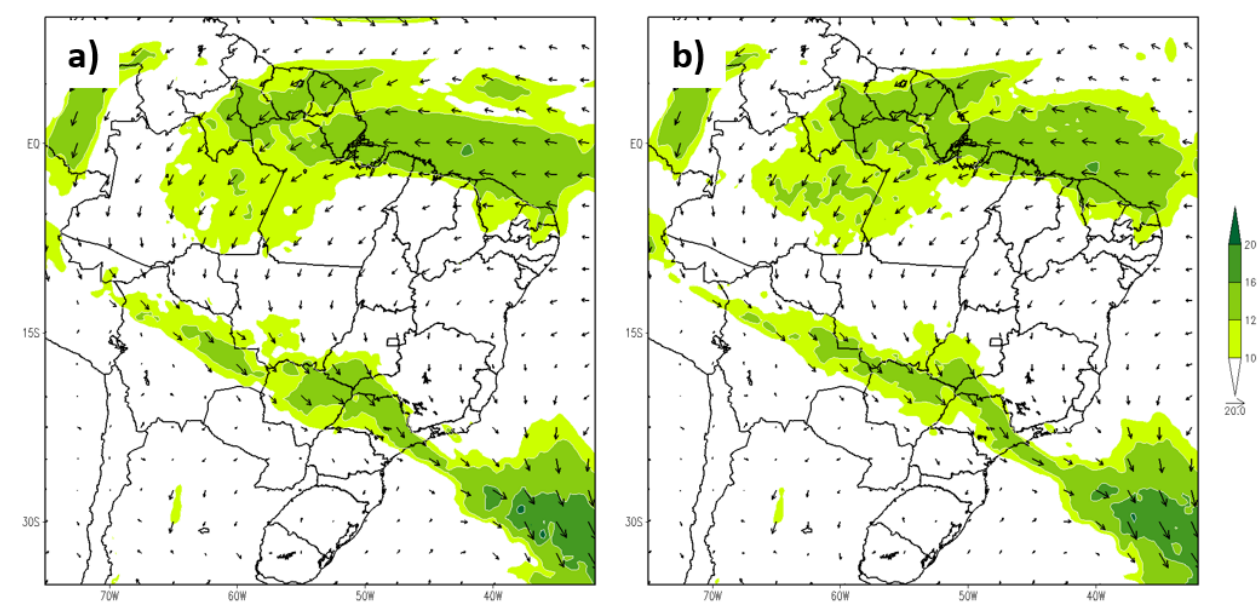

Figura 4.26: Idem à Figura 4.25 porém para o dia 12/01/2016.

Para o dia 12/01/2016, as simulações CTRL e GF (Figuras 4.26 (a) e (b)) novamente apresentam resultados semelhantes a análise do CFSv2 (Figura 4.24 (b)), entretanto, a magnitude do vento no Oceano Atlântico Tropical é mais intensa e consegue adentrar de forma mais acentuada no continente. Entre o sul da Amazônia e o Sudeste brasileiro, a região de maior intensidade do vento em baixos níveis mais uma vez ocorre a norte do exibido pela análise, além de ser menos intensa e organizada.

Durante o dia 13/01/2016, as simulações diferem da análise em alguns aspectos. A simulação CTRL (Figura 4.27 (a)) é a que apresenta maiores valores de magnitude do vento no Oceano Atlântico Tropical, enquanto a simulação GF (Figura 4.27(b)) tem menor intensidade nesta mesma região, porém ainda sendo superior à análise (Figura 4.24 (c)). Nos dois experimentos, a circulação noroeste-sudeste está ao sul da posição apresentada 
na análise, ocorrendo na região central da Bolívia e norte do Paraguai, enquanto o CFSv2 mostra a região com maior intensidade posicionada no noroeste da Bolívia.
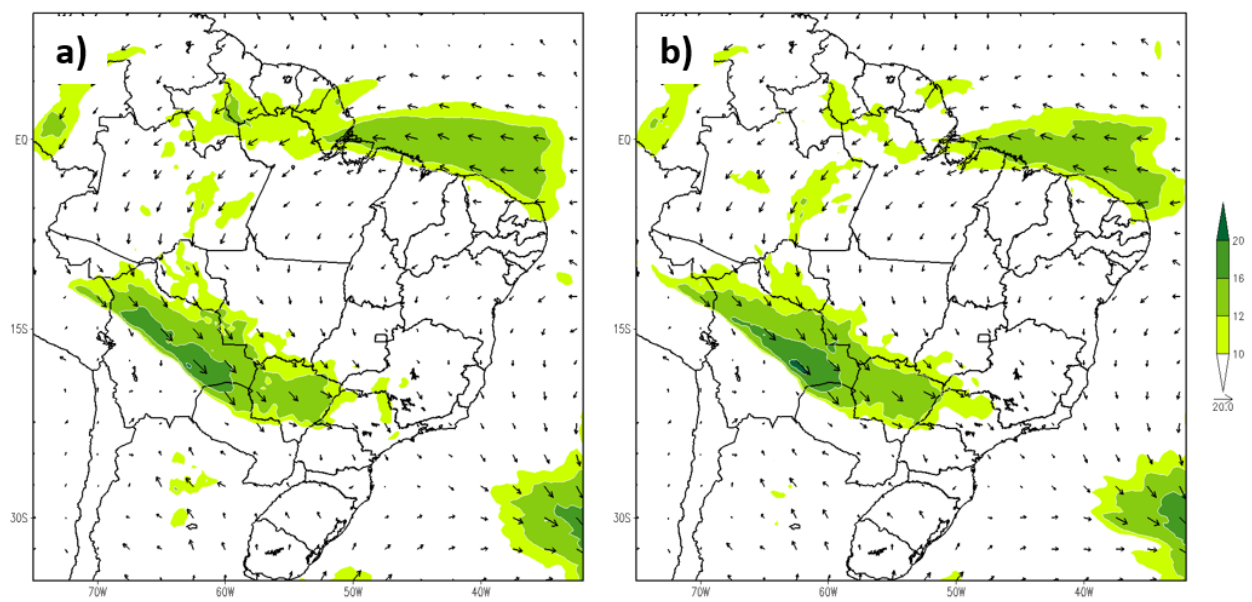

Figura 4.27: Idem à Figura 4.25 porém para o dia 13/01/2016.

Durante os dias de maior intensidade do vento em $850 \mathrm{hPa}$, em ambas as simulações a magnitude do vento é superior à análise do CFsv2 no Oceano Atlântico tropical. Já o fluxo entre o sul da região amazônica e o Sudeste do Brasil é menos intenso nos experimentos numéricos, além de apresentarem divergências quanto ao posicionamento.

\subsubsection{Perfis Verticais do Vento}

Os campos espaciais da magnitude do vento em $850 \mathrm{hPa}$ da seção anterior auxiliaram na determinação dos pontos de lançamento de radiossondagem em que seria válida a verificação do perfil vertical do vento. Como os dias de maior intensidade do vento foram 11, 12 e 13/01/2016, somente estes foram analisados em detalhes.

Na Figura 4.28 é mostrada uma comparação entre o perfil vertical do vento observado por meio de radiossondagens, o conjunto de dados da análise do CFSv2 e as simulações CTRL e GF para o dia 11/01/2016 às 0000 UTC. No Campo de Marte (Figura 4.28(a)), existe uma pequena divergência na magnitude do vento nos níveis mais baixos da atmosfera. Em aproximadamente $850 \mathrm{hPa}$, a radiossondagem mostra um máximo de $12 \mathrm{~m} / \mathrm{s}$, enquanto a análise não exibe esse mesmo padrão, apresentando, ao invés, uma intensificação na magnitude do vento praticamente linear entre 900 e $600 \mathrm{hPa}$. As simulações mostram o valor da magnitude do vento em baixos níveis mais próximo ao observado, porém acima 
de $900 \mathrm{hPa}$ este segue constante ao redor de $11 \mathrm{~m} / \mathrm{s}$ até o nível de $750 \mathrm{hPa}$, o que não se observa na radiossondagem, que mostra intensificação dos ventos entre 800 e 650 hPa, atingindo $15 \mathrm{~m} / \mathrm{s}$ neste nível.
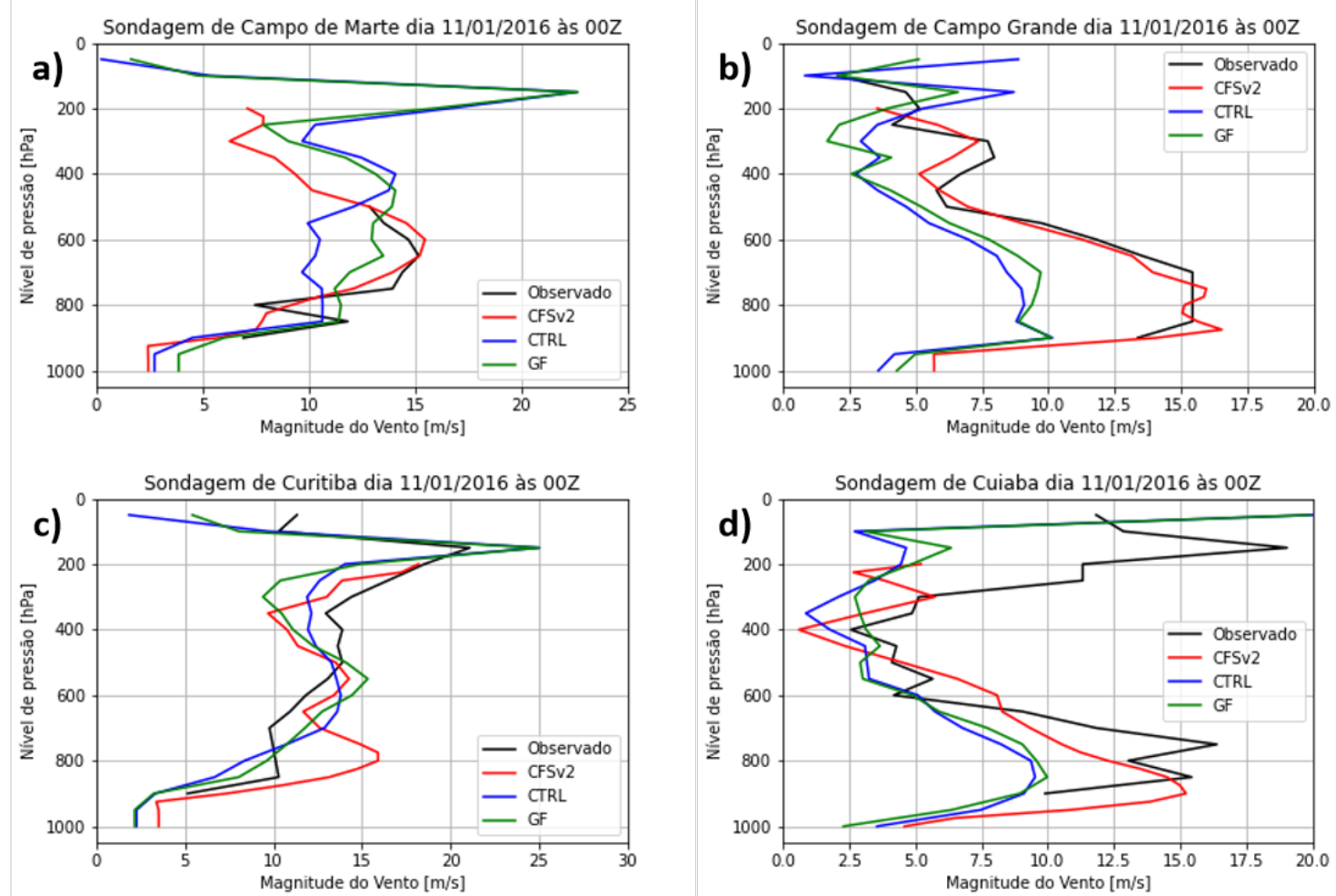

Figura 4.28: Comparação do perfil vertical entre as medidas de radiossondagens (linha preta), análise do CFSv2 (linha vermelha), simulação CTRL (linha azul), simulação GF (linha verde) em 11 de janeiro de 2016 às 0000 UTC, nos aeroportos de: a) Campo de Marte, na cidade de São Paulo; b) Campo Grande; c) Curitiba; d) Cuiabá.

No aeroporto de Campo Grande (Figuras 4.28(b)), a análise segue a tendência e intensidade do dado aferido, mostrando um pico de aproximadamente $15 \mathrm{~m} / \mathrm{s}$ entre os níveis de 850 e $700 \mathrm{hPa}$, com um intenso gradiente acima e abaixo dos mesmos, indicando a presença de um JBN. Por outro lado, mesmo com as simulações mostrando um padrão de aceleração dos ventos nesses mesmos níveis similar ao observado, a intensidade do vento é inferior, chegando somente a $10 \mathrm{~m} / \mathrm{s}$. Em Cuiabá (Figura 4.28(d)), o observado mostra um pico na intensidade do vento que ultrapassa $15 \mathrm{~m} / \mathrm{s}$ próximo de $750 \mathrm{hPa}$, com um acentuado gradiente nos níveis superiores e inferiores, indicando a presença de um JBN na região. Comparada ao observado, a análise do CFSv2 representa tanto a intensidade quanto o padrão do perfil vertical do vento próximo ao observado, enquanto as simulações apresentam um padrão similar ao observado, porém com menor intensidade, e pico sendo 
inferior a $10 \mathrm{~m} / \mathrm{s}$. As diferenças no perfil vertical da magnitude do vento entre simulações WRF e observações ou análise CFSv2 devem ser objeto de análise em trabalhos futuros.

Em Curitiba (Figura 4.28(c)), a sondagem mostra que o máximo de intensidade do vento em baixos níveis ocorre em $850 \mathrm{hPa}$, com magnitude de $10 \mathrm{~m} / \mathrm{s}$, porém não existe cisalhamento vertical intenso acima deste nível, o que não configura um caso de JBN. As simulações apresentam um padrão próximo à radiossondagem. Entretanto, o pico de 10 m/s em $850 \mathrm{hPa}$ observado não é visto devido a um aumento contínuo da velocidade do vento simulado entre a superfície e $550 \mathrm{hPa}$. A análise do CFSv2 mostra o JBN com máximo de aproximadamente $16 \mathrm{~m} / \mathrm{s}$ em $850 \mathrm{hPa}$, que não encontra contrapartida na sondagem.
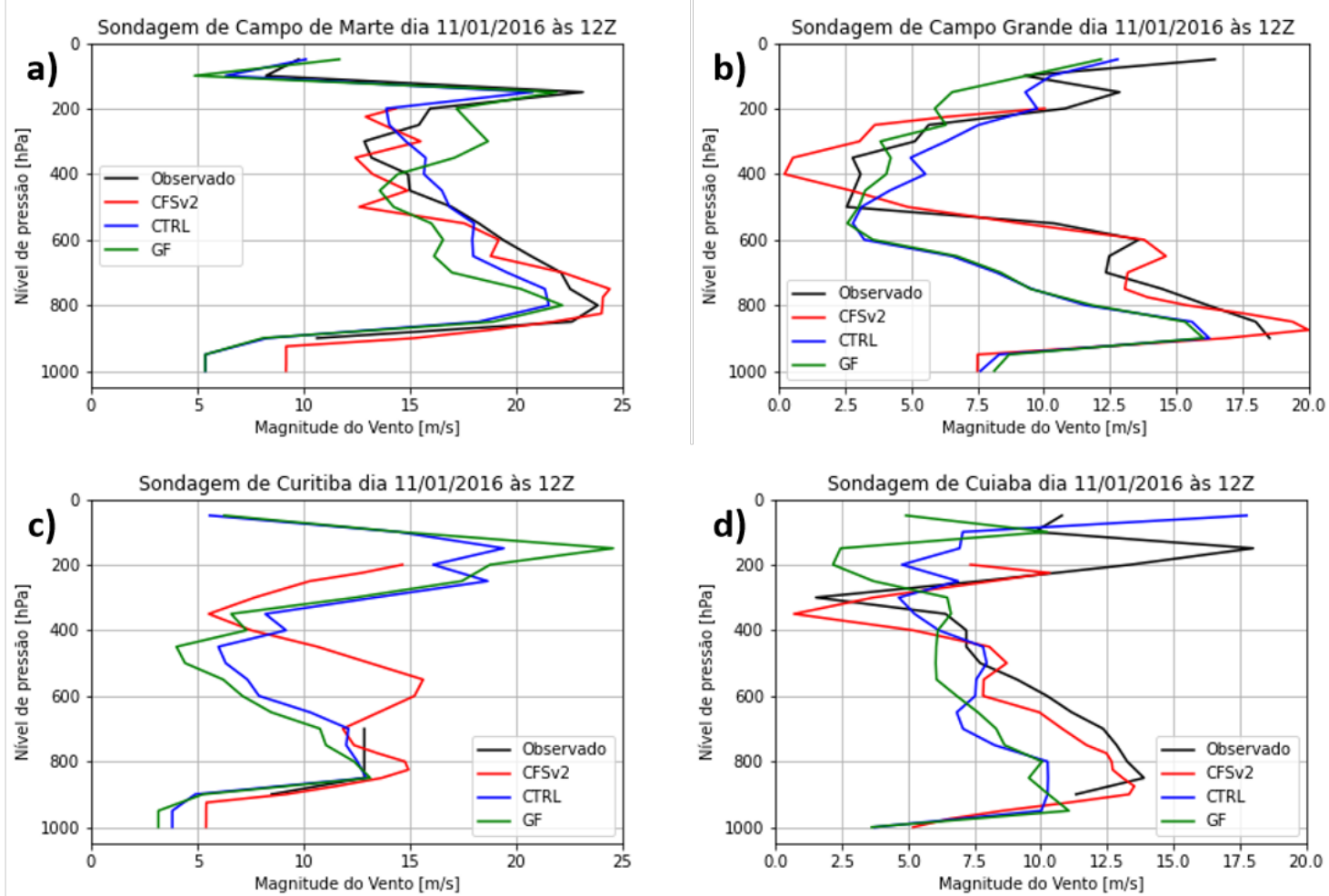

Figura 4.29: Comparação do perfil vertical entre as medidas de radiossondagens (linha preta), análise do CFSv2 (linha vermelha), simulação CTRL (linha azul), simulação GF (linha verde) em 11 de janeiro de 2016 às 1200 UTC, nos aeroportos de: a) Campo de Marte, na cidade de São Paulo; b) Campo Grande; c) Curitiba; d) Cuiabá.

Para o horário das 1200 UTC do dia 11/01/2016 (Figura 4.29), todas as sondagens lançadas nos aeroportos selecionados apresentam um padrão que remete à presença do JBN. Em Campo de Marte (Figura 4.29(a)), o dado observado mostra que a intensidade do vento é superior a $20 \mathrm{~m} / \mathrm{s}$ entre $850 \mathrm{hPa}$ e $600 \mathrm{hPa}$, com intenso gradiente nos níveis periféricos. 
Neste local, tanto a análise quanto as simulações apresentam um padrão próximo ao dado observado, com exceção de que, nos experimentos numéricos, há uma subestimação na intensidade do vento em níveis abaixo dos $600 \mathrm{hPa}$.

No aeroporto de Campo Grande (Figura 4.29(b)), a radiossonda não capturou dados abaixo de 900 hPa. Na primeira medição da radiossondagem, a magnitude do vento aferida fica próxima a $18 \mathrm{~m} / \mathrm{s}$ em $850 \mathrm{hPa}$, sendo esse o máximo de intensidade nos baixos níveis, indicando a atuação do JBN nesse local. O CFSv2 apresenta perfil vertical próximo ao observado, enquanto as simulações subestimam a magnitude do vento em aproximadamente $5 \mathrm{~m} / \mathrm{s}$ nos níveis de atuação do JBN até aproximadamente $500 \mathrm{hPa}$.
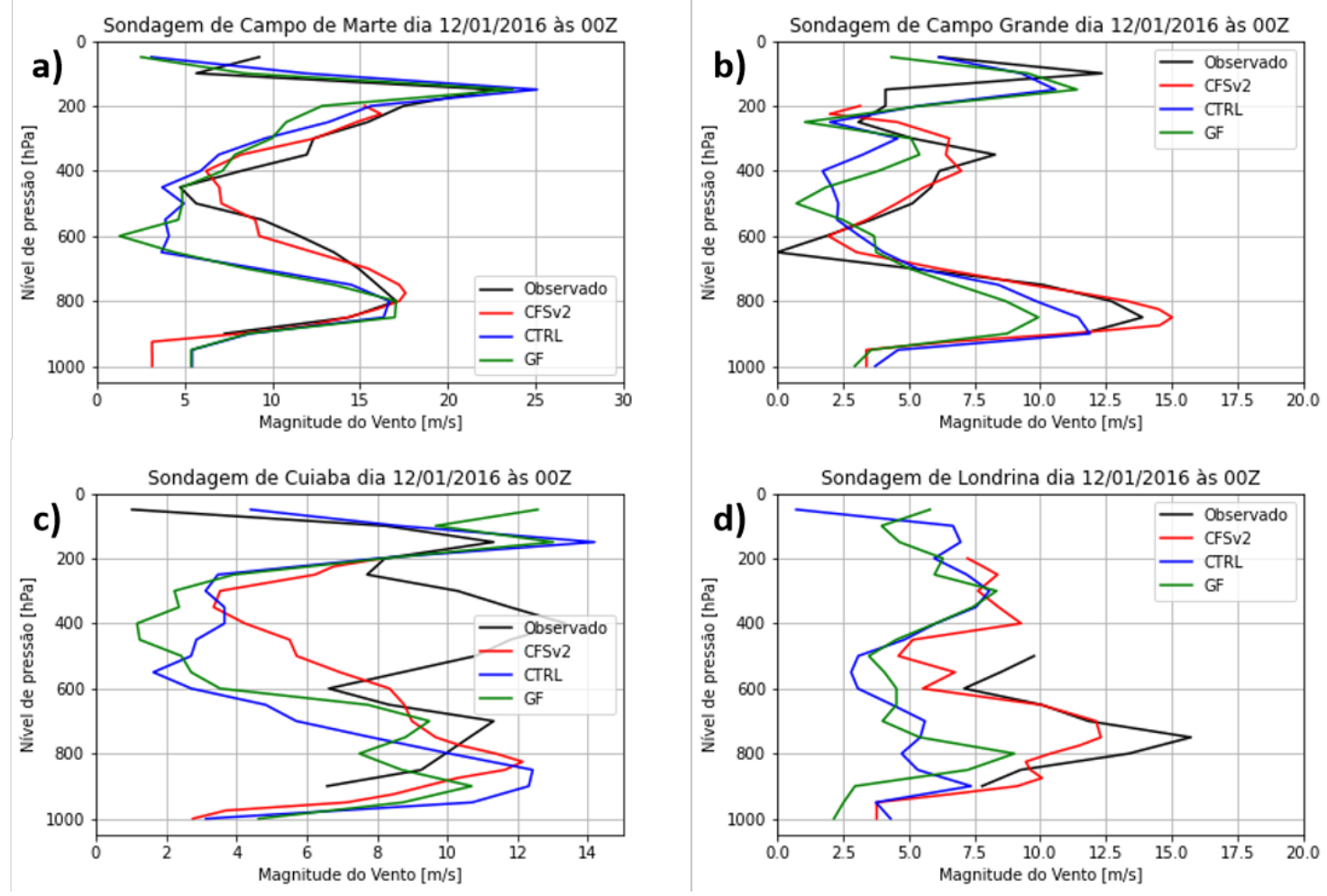

Figura 4.30: Comparação do perfil vertical entre as medidas de radiossondagens (linha preta), análise do CFSv2 (linha vermelha), simulação CTRL (linha azul), simulação GF (linha verde) em 12 de janeiro de 2016 às 0000 UTC, nos aeroportos de: a) Campo de Marte, na cidade de São Paulo; b) Campo Grande; c) Cuiabá; d) Londrina.

Ainda às 1200 UTC do dia 11/01/2016, no aeroporto de Curitiba (Figura 4.29(c)) a radiossondagem apresentou problemas e a quantidade de dados disponíveis é pequena, impossibilitando uma melhor comparação e gerando desconfiança quanto aos dados oferecidos pelo aparelho. Os dados do CFSv2 para este aeroporto apresentam um máximo de aproximadamente $13 \mathrm{~m} / \mathrm{s}$ na magnitude do vento em $800 \mathrm{hPa}$ e intenso gradiente vertical nos 
níveis próximos, que podem caracterizar um JBN. As simulações subestimam a intensidade do vento em baixos níveis, demonstrando um erro do tipo sistemático nesta variável, assim como mostrado nos campos da Figura 4.25 .
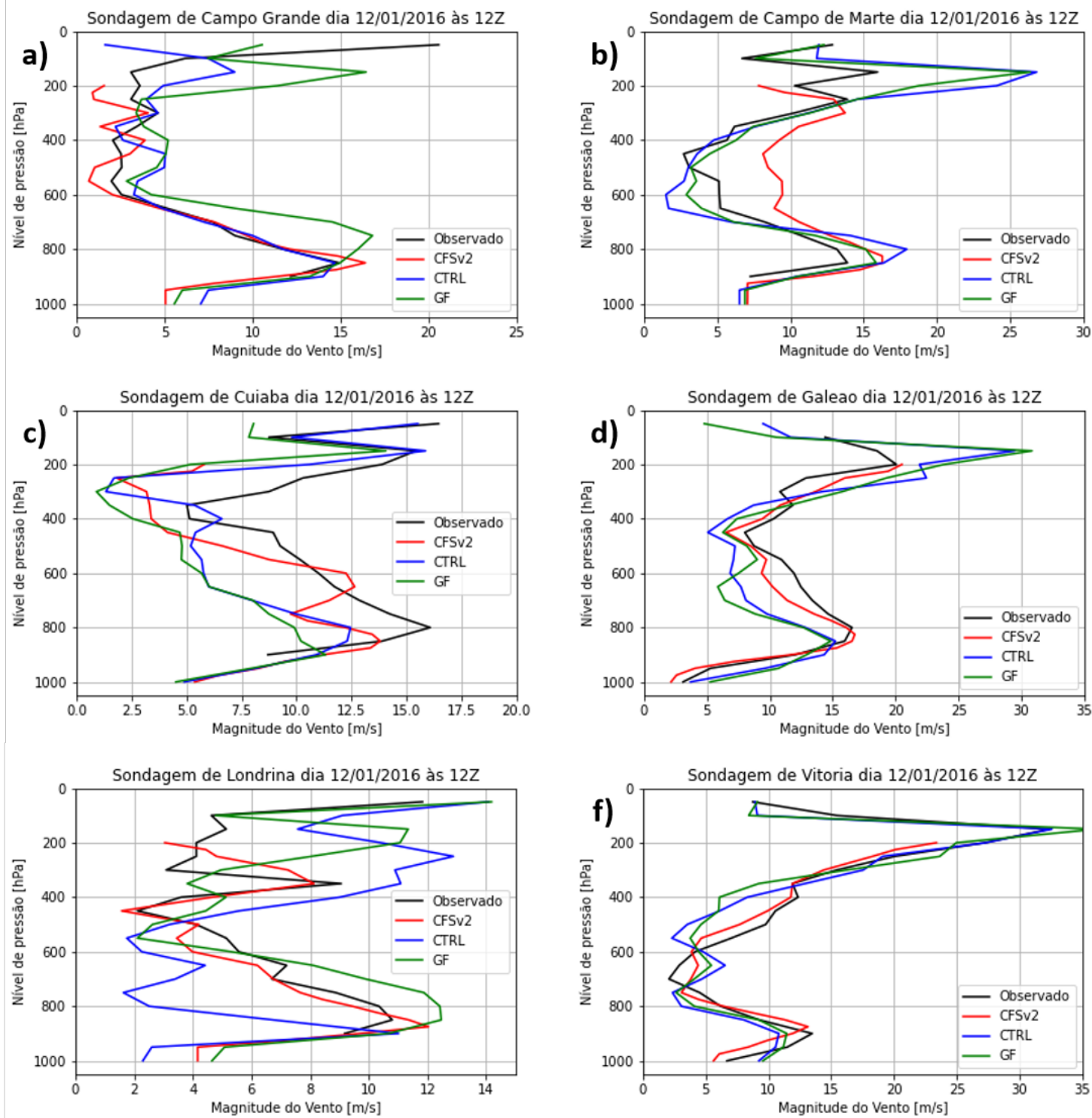

Figura 4.31: Comparação do perfil vertical entre as medidas de radiossondagens (linha preta), análise do CFSv2 (linha vermelha), simulação CTRL (linha azul), simulação GF (linha verde) em 12 de janeiro de 2016 às 1200 UTC, nos aeroportos de: a) Campo de Marte, na cidade de São Paulo; b) Campo Grande; c) Cuiabá; d) Galeão, no Rio de Janeiro; e) Londrina; f) Vitória.

$\mathrm{Na}$ sondagem do aeroporto de Cuiabá (Figura 4.29(d)), a intensidade máxima do vento foi inferior em relação às demais localidades, sendo próxima a $13 \mathrm{~m} / \mathrm{s}$ em $850 \mathrm{hPa}$, com a presença de gradiente na intensidade do vento nos níveis superiores e inferiores. Novamente, 
a representação do perfil vertical do vento pela análise CFSv2 é coerente ao observado, enquanto as simulações mostram valores da magnitude do vento em baixos níveis inferiores ao mesmo.

O perfil vertical do vento às 0000 UTC do dia 12/01/2016 (Figura 4.30) mostra que, em todos os aeroportos analisados, as sondagens possuem máximos de vento em baixos níveis com magnitude superior a $10 \mathrm{~m} / \mathrm{s}$ a até $15 \mathrm{~m} / \mathrm{s}$, com intenso gradiente acima e abaixo do ponto de máximo, corroborando que, neste horário, o JBN estava presente nas regiões próximas aos aeroportos em questão. No Campo de Marte (Figura 4.30(a)), tanto a análise quanto as simulações reproduzem de forma correta o observado pela sondagem, com o ponto de máxima intensidade do vento de aproximadamente $17 \mathrm{~m} / \mathrm{s} \mathrm{em} 800 \mathrm{hPa}$. Em relação ao gradiente acima desse nível, uma ligeira divergência de valores é observada entre as simulações e os demais dados, sendo evidente a maior intensidade nos experimentos numéricos. No aeroporto de Campo Grande (Figura 4.30(b)), o pico de máxima intensidade do vento é de aproximadamente $14 \mathrm{~m} / \mathrm{s}$ e ocorre no nível de $850 \mathrm{hPa}$. O padrão apresentado pela análise (simulações) é próximo do observado, divergindo somente nos baixos níveis, onde é superestimado (subestimado).

No perfil vertical do aeroporto de Cuiabá (Figura 4.30(c)), vê-se uma defasagem tanto espacial quanto na magnitude do vento. Enquanto a observação mostra um máximo de aproximadamente $11 \mathrm{~m} / \mathrm{s}$ em $700 \mathrm{hPa}$, a análise do CFSv2 e a simulação CTRL mostram $12 \mathrm{~m} / \mathrm{s}$ em $800 \mathrm{hPa}$ e a simulação GF apresenta 10,5 m/s em $900 \mathrm{hPa}$.

Em Londrina (Figura $4.30(\mathrm{~d})$ ), houve problemas na radiossonda e os dados foram coletados somente entre 900 e 500 hPa, notando-se a atuação do JBN com máximo de magnitude do vento de $15 \mathrm{~m} / \mathrm{s}$ em $750 \mathrm{hPa}$. A análise, por outro lado, mostra esse máximo entre 750 e $700 \mathrm{hPa}$, com valores próximos a $12 \mathrm{~m} / \mathrm{s}$, subestimando o dado observado, enquanto as simulações mostram esse pico com magnitude inferior a $10 \mathrm{~m} / \mathrm{s}$, não caracterizando um JBN, apesar de apresentarem cisalhamento vertical.

Às 1200 UTC do dia 12/01/2016 (Figura 4.31), os perfis verticais das sondagens mostram a ocorrência do JBN em vários aeroportos da região Sudeste, Centro-Oeste e no aeroporto de Londrina. Em Campo Grande (Figura 4.31(a)), o CFSv2 e a simulação CTRL são coerentes ao dado observado, apresentando o mesmo comportamento, com valor absoluto de $15 \mathrm{~m} / \mathrm{s}$ em $850 \mathrm{hPa}$ e intenso gradiente acima e abaixo deste nível. Por outro lado, a simulação GF representou o máximo na intensidade do vento com cerca de 
$16 \mathrm{~m} / \mathrm{s}$ em $750 \mathrm{hPa}$, superestimando a magnitude e deslocando para níveis superiores este ponto de máxima intensidade.

No Campo de Marte (Figura 4.31(b)), verifica-se um máximo na magnitude do vento em $850 \mathrm{hPa}$, chegando a $13 \mathrm{~m} / \mathrm{s}$ pelo dado observado e a $16 \mathrm{~m} / \mathrm{s}$ pelo CFSv2 e simulação GF, enquanto a simulação CTRL mostra este pico em 800 hPa, com magnitude máxima próxima a $18 \mathrm{~m} / \mathrm{s}$. Estes valores mostram que, tanto a análise quanto os experimentos numéricos, superestimam os valores de magnitude do vento em baixos níveis observado pela radiossondagem.

No aeroporto de Cuiabá (Figura 4.31(c)), existe uma divergência de valores entre a sondagem e os demais dados. O máximo observado é superior a $15 \mathrm{~m} / \mathrm{s} \mathrm{em} 800 \mathrm{hPa}$, enquanto no CFSv2 ocorre em $850 \mathrm{hPa}$, com magnitude do vento próxima a $13 \mathrm{~m} / \mathrm{s}$. Em relação às simulações, o experimento CTRL apresenta o ponto de máxima intensidade com 12,5 m/s em 800 hPa, enquanto no GF, o máximo é de 11 m/s em 900 hPa. Sendo assim, fica explícito que o CFSv2 e os experimentos numéricos subestimam a magnitude do vento em baixos níveis e também deslocam o pico de máxima intensidade do JBN para níveis inferiores ao observado.

No aeroporto de Galeão, no Rio de Janeiro (Figura 4.31(d)), a análise representa bem a realidade do dado observado, acompanhando-o durante todo o perfil vertical, inclusive no nível de $800 \mathrm{hPa}$, onde existe o máximo de magnitude do vento em baixos níveis, com magnitude próxima a $16 \mathrm{~m} / \mathrm{s}$ e forte cisalhamento acima e abaixo deste nível. As simulações também reproduzem o padrão observado, porém a intensidade no nível de atuação do JBN é inferior $(15 \mathrm{~m} / \mathrm{s})$ e acontece $850 \mathrm{hPa}$, ligeiramente abaixo do que o observado.

No aeroporto de Londrina (Figura 4.31(e)), o máximo de magnitude do vento em baixos níveis é menor quando comparada aos outros aeroportos, chegando a $10 \mathrm{~m} / \mathrm{s}$ e ocorrendo em $850 \mathrm{hPa}$, com gradiente superior e inferior que indicam a atuação do JBN nessa região. Estas características indicam que, nesse horário do dia, a circulação proveniente da região amazônica ainda chegava nesta latitude, diferente do mostrado pelos campos das Figuras 4.24 (b) e 4.26. O CFSv2 representou esse perfil vertical de forma satisfatória, enquanto as simulações divergiram tanto na altitude quanto na intensidade do JBN.

No aeroporto de Vitória (Figura 4.31(f)), a intensidade máxima do vento observado em baixos níveis chega a aproximadamente $12 \mathrm{~m} / \mathrm{s}$ e apresenta intenso gradiente em torno desse núcleo. Nesse aeroporto, a representação da sondagem pela análise do CFSv2 mostrou-se 
assertiva, tanto para a magnitude quanto para a tendência do perfil vertical do vento. As simulações também foram eficazes na representação do perfil vertical do vento observado, porém a intensidade do JBN é ligeiramente subestimada.
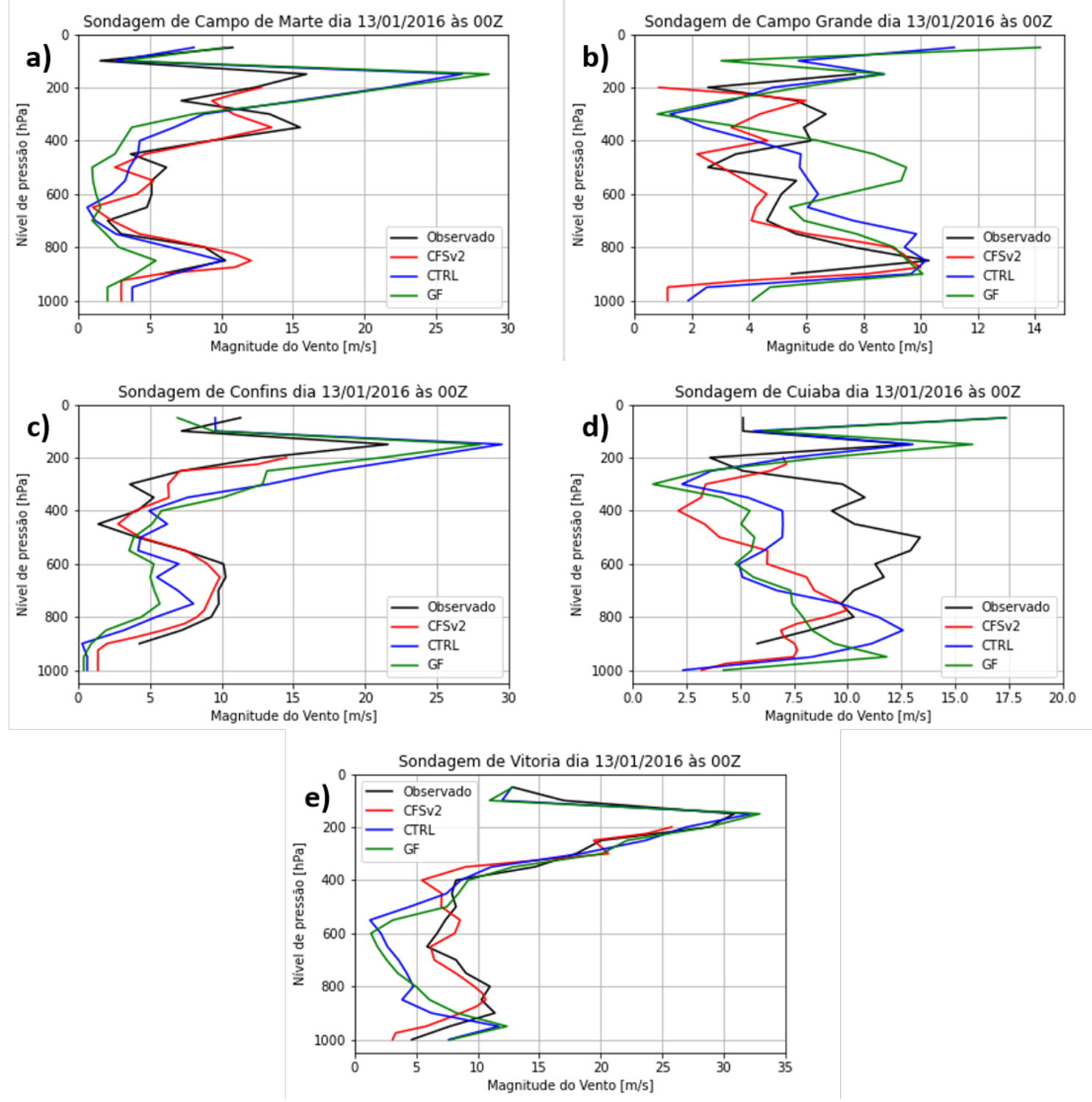

Figura 4.32: Comparação do perfil vertical entre as medidas de radiossondagens (linha preta), análise do CFSv2 (linha vermelha), simulação CTRL (linha azul), simulação GF (linha verde) em 13 de janeiro de 2016 às 0000 UTC, nos aeroportos de: a) Campo de Marte, na cidade de São Paulo; b) Campo Grande; c) Confins, em Belo Horizonte; d) Cuiabá; e) Vitória.

No dia 13/01/2016, como visto nas Figuras 4.24(c) e 4.27, o fluxo de noroeste-sudeste é menos intenso e deslocado para norte quando comparado aos dias anteriores. Este enfraquecimento e deslocamento podem ser confirmados nas sondagens do dia 13/01/2016 às 0000 UTC (Figura 4.32), uma vez que entre os pontos de observação analisados, somente 
no aeroporto de Vitória a magnitude do vento supera os $10 \mathrm{~m} / \mathrm{s}$ nos primeiros níveis da atmosfera. No Campo de Marte, em São Paulo (Figura 4.32(a)), nota-se que o dado observado tem um ponto com magnitude máxima do vento de $10 \mathrm{~m} / \mathrm{s}$ em $850 \mathrm{hPa}$ e intenso gradiente acima e abaixo do mesmo. Este padrão foi capturado pela simulação CTRL, enquanto a análise do CFSv2 mostra este pico sendo um pouco mais intenso do que o observado, com intensidade aproximada de $12 \mathrm{~m} / \mathrm{s}$. A simulação GF, por sua vez, mostra uma intensidade muito inferior, com $5 \mathrm{~m} / \mathrm{s}$ e um gradiente pouco intenso.

No Aeroporto de Campo Grande (Figura 4.32(b)) o dado observado mostra um máximo de $10 \mathrm{~m} / \mathrm{s}$ em $850 \mathrm{hPa}$, com intenso gradiente em torno deste máximo. Tanto o CFSv2 quanto as simulações mostram magnitude e gradiente nos níveis superiores e inferiores da atmosfera próximos do observado. Mais a norte, no aeroporto de Confins, na cidade de Belo Horizonte (Figura 4.32(c)), vemos que não existe um nível de máxima magnitude do vento nos baixos níveis da atmosfera, mas sim uma constante intensificação até 500 hPa, mostrando que nesse horário não havia a atuação de um JBN nesse ponto. Tanto o padrão quanto a intensidade do vento nos dados observados foram bem representados pela análise do CFSv2, enquanto as simulações, mesmo apresentando um padrão próximo do observado, exibem uma intensidade do vento inferior em todo o perfil vertical.

Na cidade de Cuiabá (Figura 4.32(d)), acima de 750 hPa existe uma divergência de valores entre o observado e os demais conjuntos de dados. O observado mostra uma intensificação na magnitude do vento entre $750 \mathrm{hPa}$ e $500 \mathrm{hPa}$, seguido de um enfraquecimento até $200 \mathrm{hPa}$. Em contrapartida, a análise mostra uma desintensificação na velocidade do vento entre $750 \mathrm{hPa}$ e $400 \mathrm{hPa}$, seguida de um aumento até $200 \mathrm{hPa}$. Entre a superfície e $750 \mathrm{hPa}$, onde os valores convergem para o mesmo comportamento e a velocidade do vento chega a $10 \mathrm{~m} / \mathrm{s}$. A ausência de gradiente vertical nos dados da radiossondagem desqualifica o evento como um JBN sobre esta região, enquanto o padrão apresentado pelo CFSv2 indica a atuação de um JBN em 750 hPa, devido à existência de cisalhamento vertical do vento tanto acima quanto abaixo do ponto de máxima intensidade. As simulações divergem de ambos os dados comentados anteriormente, mostrando a magnitude do vento superior a 12 m/s em 950 hPa na simulação GF e 850 hPa na simulação CTRL, ambas com intenso gradiente nos níveis periféricos, indicando a atuação do JBN mais intenso e em níveis inferiores ao apresentado pela análise.

Em Vitória (Figura 4.32(e)), a análise do CFSv2 apresenta boa semelhança às medidas 
da radiossondagem lançada no aeroporto da cidade. Ambas mostram a possível atuação do JBN sobre o ponto de observação, uma vez que a magnitude máxima nos baixos níveis da atmosfera chega a $10 \mathrm{~m} / \mathrm{s}$ entre 850 e $800 \mathrm{hPa}$, com gradiente em torno deste nível sendo intenso o suficiente para classifica-lo como JBN. As simulações também mostram a atuação do JBN, porém com o máximo de velocidade do vento próximo a $12 \mathrm{~m} / \mathrm{s}$ em 950 hPa e um intenso gradiente nos níveis próximos.
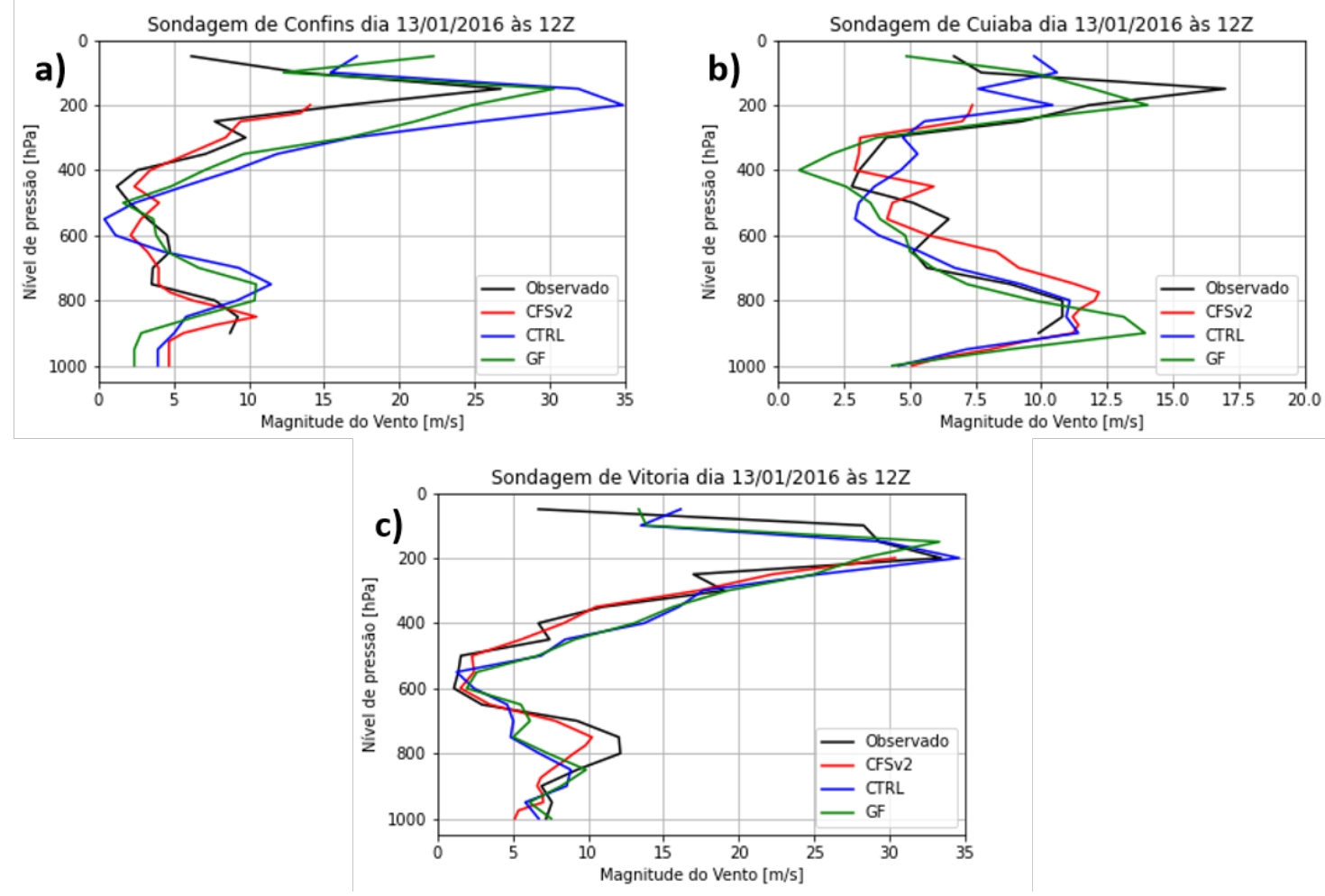

Figura 4.33: Comparação do perfil vertical entre as medidas de radiossondagens (linha preta), análise do CFSv2 (linha vermelha), simulação CTRL (linha azul), simulação GF (linha verde) em 13 de janeiro de 2016 às 1200 UTC, nos aeroportos de: a) Confins, na cidade de Belo Horizonte; b) Cuiabá; c) Vitória.

Na Figura 4.33 são mostrados os perfis verticais da magnitude do vento às 1200 UTC do dia 13/01/16. No aeroporto de Confins, na cidade de Belo Horizonte 4.33(a)), nota-se uma boa concordância entre o observado e a análise do CFSv2. Entretanto, enquanto o dado observado apresenta valores inferiores a $10 \mathrm{~m} / \mathrm{s}$, o que não caracteriza a atuação do JBN, o CFSv2 mostra magnitude do vento em baixos níveis superior a $10 \mathrm{~m} / \mathrm{s}$ e com intenso cisalhamento vertical nos níveis próximos, indicando a atuação do JBN. As simulações apresentam magnitude igual ou superior a $10 \mathrm{~m} / \mathrm{s}$ em $750 \mathrm{hPa}$ e o gradiente necessário para classificação como JBN, representando esse sistema de forma superestimada e em 
níveis superiores aos dados anteriores.

No aeroporto de Cuiabá (Figura 4.33(b)), a magnitude máxima do vento ocorre em $800 \mathrm{hPa}$, com intensidade de $10 \mathrm{~m} / \mathrm{s}$, conforme observado pela radiossondagem, e $12 \mathrm{~m} / \mathrm{s}$, conforme a análise, ambos com um gradiente vertical da magnitude do vento que indica a atuação de um JBN. A simulação CTRL apresenta valores e padrão similares ao observado, enquanto a simulação GF tem a magnitude do vento superior a 13 m/s em $900 \mathrm{hPa}$, simulando o ponto de máxima intensidade do JBN de forma mais intensa e em menor altitude do que o observado.

No Aeroporto de Vitória 4.33(c)), a observação mostra a atuação do JBN com um pico de intensidade do vento entre 800 e $750 \mathrm{hPa}$ e magnitude de $12 \mathrm{~m} / \mathrm{s}$, com intenso gradiente nos níveis periféricos. De forma similar, o CFSv2 apresenta o mesmo padrão, mas com intensidade máxima de $10 \mathrm{~m} / \mathrm{s}$. As simulações diferem desses dois perfis, simulando o máximo do vento em $850 \mathrm{hPa}$ e com intensidade inferior a $10 \mathrm{~m} / \mathrm{s}$, sendo insuficiente para classificar este evento como um JBN segundo os critérios adotados neste trabalho.

Em suma, os perfis verticais da magnitude do vento durante o dia 13/01/2016 comprovaram o enfraquecimento do vento nos baixos níveis da atmosfera. Os aeroportos do Sudeste do Brasil mostraram menores magnitude do vento, enquanto as estações localizadas no Centro-Oeste brasileiro indicaram a atuação do JBN de forma mais intensa.

Um compilado da velocidade máxima do vento em baixos níveis nos pontos de lançamento citados anteriormente entre os dias 11 e 13/01/2016 pode ser visto na Figura C.1 do Apêndice C. Nela nota-se que o Centro-Oeste do Brasil esteve sob atuação de um JBN durante os 3 primeiros dias de atuação da ZCAS, já que nos pontos de lançamento de sondagem de Cuiabá (MT) e Campo Grande (MS) o vento permaneceu com intensidade superior à $10 \mathrm{~m} / \mathrm{s}$ no nível de máxima intensidade e elevado cisalhamento vertical do vento nos níveis adjacentes. Este comportamento foi verificado nos campos espaciais da subseção anterior e comprovado nos gráficos de perfil vertical analisados.

No Sudeste do Brasil, as radiossondas lançadas nos pontos de São Paulo (Campo de Marte), Rio de Janeiro (Galeão) e Vitória exibem a atuação do JBN durante a maior parte do tempo analisado, sendo que no Galeão e no Campo de Marte nota-se, no dia 13/01/2016, um enfraquecimento na velocidade do vento em baixos níveis. Já no aeroporto de Confins (MG), a intensidade do vento é menor e somente nos dias 11 e 13/01/2016 o perfil vertical apresenta características suficientes para que seja comprovado um JBN. 
Esta maior ocorrência do JBN em pontos mais próximos ao litoral pode ser explicada pela posição do cavado em médios níveis e a frente fria associada a ele, que atuam sobre o Oceano Atlântico Subtropical Oeste. Nos pontos de lançamento de radiossondas do Sul do Brasil (Londrina e Curitiba, ambas no Paraná) existe um sinal claro do avanço da ZCAS para o norte, isto porque a intensidade do vento sofre uma forte redução a partir do dia 12/01/2016, indicando a atuação da alta pós frontal e a subsidência gerada pela convecção na região da ZCAS.

A Figura C.1 ainda explicita que tanto a análise do CFSv2 quanto as simulações CTRL e GF apresentam os máximos da velocidade do vento em níveis semelhantes ao observado. Porém, as simulações possuem uma tendência de subestimar os valores aferidos pelas radiossondas. Estes resultados representam o estado da coluna atmosférica na posição de lançamento do equipamento, e para uma melhor verificação desta possível tendência foram feitos cortes verticais perpendiculares a região de atuação do JBN, que podem ser vistos na subseção a seguir.

\subsubsection{Cortes Verticais}

Com o intuito de visualizar espacialmente o núcleo e desenvolvimento vertical do JBN, foram efetuados cortes verticais perpendiculares à região de atuação do sistema entre o sul da Amazônia e o Sudeste brasileiro nos horários das 0000 e das 1200 UTC de 11 a 13/01/2016. Os resultados são apresentados nas Figuras 4.34, 4.35 e 4.36 e discutidos adiante.

Como visto nos campos da Figura 4.24, o dia 11/01/2016 foi o que apresentou maior intensidade do vento nas regiões Sudeste e Centro-Oeste, o que também é observado nos campos de corte vertical entre os pontos $\left(27^{\underline{0}} \mathrm{~S} ; 51^{\mathrm{o}} \mathrm{W}\right)$ e $\left(16^{\mathrm{o}} \mathrm{S} ; 46^{\underline{\mathrm{O}}} \mathrm{W}\right)$ para o mesmo dia, expostos na Figura 4.34. Às 0000 UTC, o CFSv2 (Figura 4.34 (a)) apresenta ventos com magnitude superior a $12 \mathrm{~m} / \mathrm{s}$ nos baixos níveis da atmosfera em praticamente toda a extensão do corte. Na porção sul (esquerda), a região com magnitude do vento superior a $12 \mathrm{~m} / \mathrm{s}$ acorre em praticamente toda a extensão vertical da atmosfera, com um centro mais intenso de 16 m/s observado entre 800 e 500 hPa. Na parte norte do campo (direita), o vento com intensidade superior a $10 \mathrm{~m} / \mathrm{s}$ é verificado apenas entre 850 e 700 hPa. Para o mesmo horário, as simulações CTRL e GF (respectivamente, Figuras 4.34 (c) e 4.34 (e)) apresentam um padrão similar, uma vez que na região sul do campo a área com maior 
intensidade do vento ocorre em toda a extensão vertical da atmosfera, enquanto na região norte o mesmo se restringe aos baixos níveis. Um ponto importante a ser verificado é a intensidade do vento nas simulações, que apresenta intensidade inferior ao apresentado pela análise, principalmente na simulação CTRL.

00 UTC
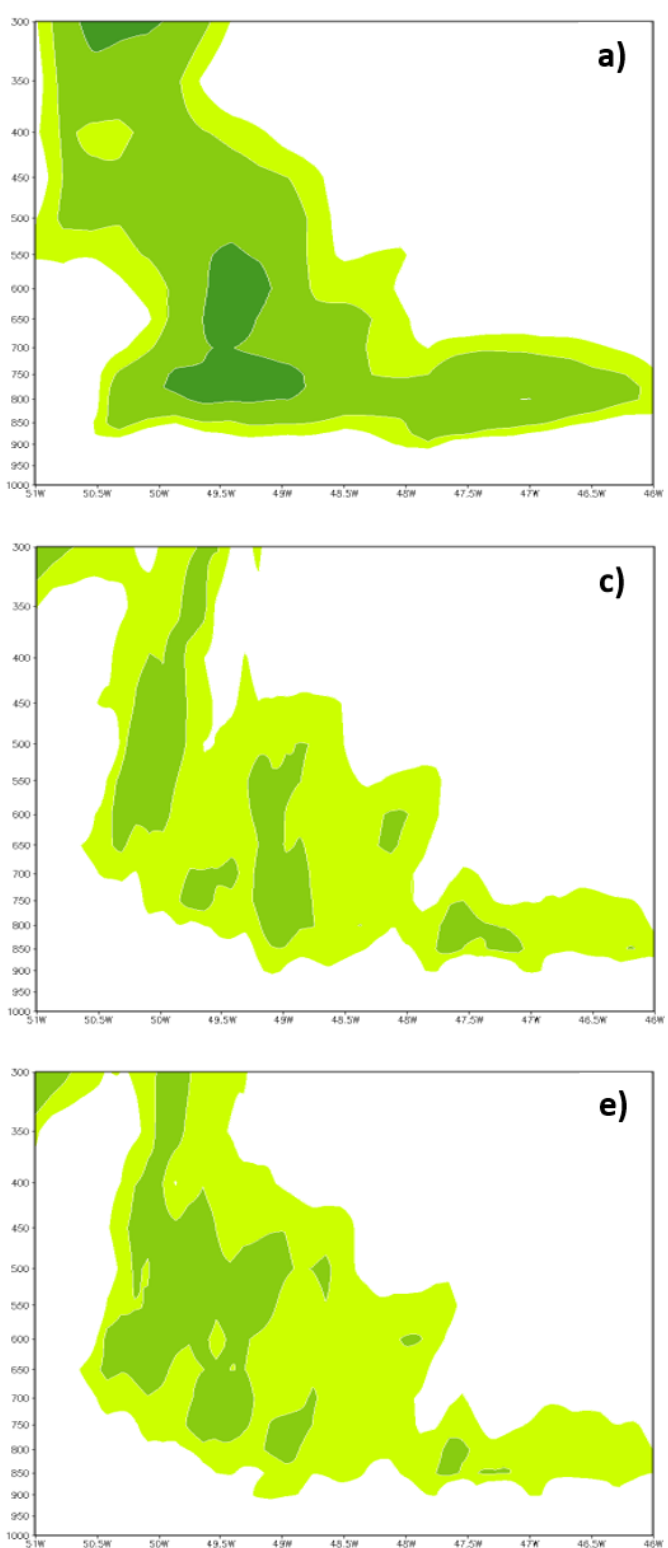

12 UTC
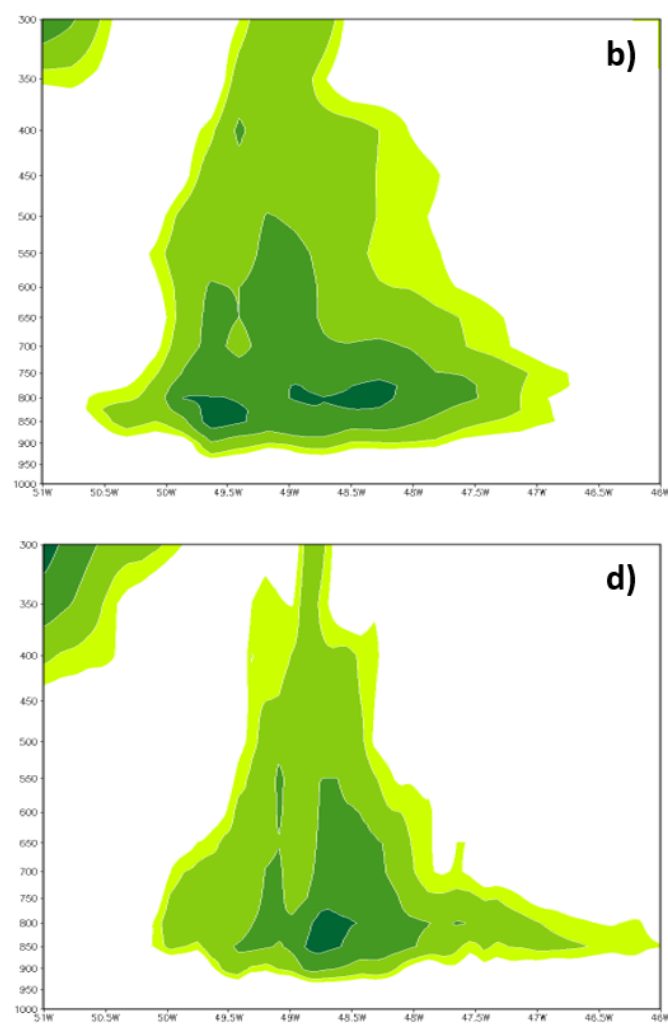

f)

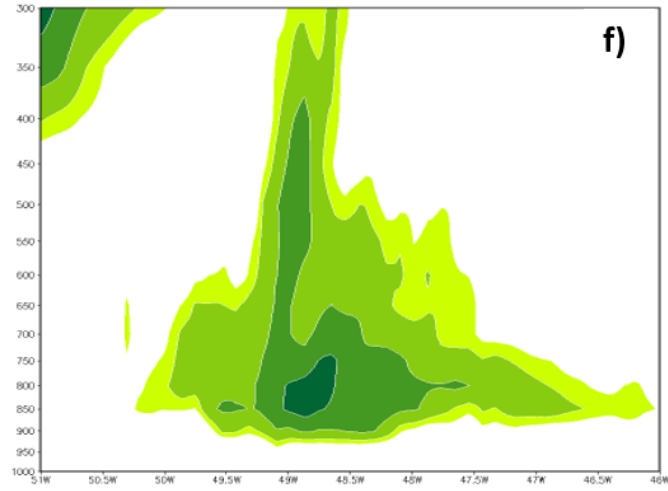

Figura 4.34: Cortes verticais da magnitude do vento (sombreado, $[\mathrm{m} / \mathrm{s}]$ ) entre os pontos $\left(27^{\mathrm{O}}\right.$ $\left.\mathrm{S} ; 51^{\mathrm{O}} \mathrm{W}\right)$ e $\left(16^{\mathrm{o}} \mathrm{S} ; 46^{\mathrm{O}} \mathrm{W}\right)$ no dia 11/01/2016 às 000 UTC ((a) CFSv2; (c) Simulação CTRL; (e) Simulação GF) e 1200 UTC ((b) CFSv2; (d) Simulação CTRL; (f) Simulação GF).

Às 1200 UTC do dia 11/01/2016, o campo do CFSv2 (Figura 4.34 (b)) mostra que a magnitude do vento em baixos níveis da atmosfera se intensifica em relação ao horário 
anterior, apresentando dois núcleos com intensidade superior a $20 \mathrm{~m} / \mathrm{s}$, um em 49,5ํㅡㄴ $\mathrm{W}$ e o outro em 59,5ำ W, ambos entre 850 e 800 hPa. Esta região com vento mais intenso se estende até os altos níveis da atmosfera com valores de $12 \mathrm{~m} / \mathrm{s}$. As duas simulações mostram que o núcleo de máxima intensidade da magnitude do vento atua de forma mais estreita e ao norte em relação a análise. Os dois experimentos apresentam padrões semelhantes, uma única região com intensidade superior a $20 \mathrm{~m} / \mathrm{s}$ (aproximadamente em 48,75ำ $\mathrm{W}$ e entre 800 e $850 \mathrm{hPa}$ ), com um decaimento nos níveis superiores e inferiores a este. A divergência entre as simulações está na abrangência vertical da região com ventos superiores a $16 \mathrm{~m} / \mathrm{s}$, uma vez que a simulação CTRL (Figura 4.34 (d)) mostra o ponto máximo acontecendo em 48, $5^{\mathrm{O}} \mathrm{W}$ até $550 \mathrm{hPa}$, e a simulação GF (Figura 4.34 (f)) em $49^{\mathrm{O}} \mathrm{W}$ até $400 \mathrm{hPa}$.

No dia 12/01/2016, o corte vertical perpendicular à região de ventos intensos em 850 hPa resulta nos campos da Figura 4.35. Às 0000 UTC, o CFSv2 (Figura 4.35 (a)) mostra que somente entre $54^{\mathrm{O}} \mathrm{W}$ e $51,9^{\mathrm{O}} \mathrm{W}$ a magnitude do vento superou $10 \mathrm{~m} / \mathrm{s}$ entre os níveis de 950 e 750 hPa. Neste dia, o vento ocorreu de forma menos intensa em relação ao mesmo horário do dia anterior. A simulação CTRL (Figura 4.35 (c)) teve um comportamento divergente da análise, com a região de maior intensidade do vento ocorrendo mais a norte (à direita na figura) e com um maior desenvolvimento vertical, chegando até $550 \mathrm{hPa}$ com magnitude do vento superior a 10 m/s. A simulação GF (Figura 4.35 (e)) diverge dos conjuntos de dados anteriores, apresentando velocidade do vento com valores inferiores, porém abrangendo regiões similares à simulação CTRL. O núcleo de maior intensidade do vento no experimento GF dá-se em 51,9º W no nível de 850 hPa, superando a análise e a simulação CTRL com velocidade do vento acima de $16 \mathrm{~m} / \mathrm{s}$. Contudo, a extensão meridional do JBN é inferior ao observado nos demais campos.

Às 1200 UTC do dia 12/01/2016, o CFsv2 (Figura 4.35(b)) mostra uma intensificação do vento em baixos níveis. A região com maior intensidade do vento é observada em torno de $52,8^{\mathrm{O}} \mathrm{W}$, com valores superiores a $16 \mathrm{~m} / \mathrm{s}$ em $850 \mathrm{hPa}$, enquanto a região com magnitude do vento superior a $10 \mathrm{~m} / \mathrm{s}$ ocorre entre $57^{\mathrm{O}} \mathrm{W}$ e $51,3^{\mathrm{O}} \mathrm{W}$, estendendo-se desde 900 a 550 hPa. Assim como às 0000 UTC, neste horário ambas as simulações subestimaram a magnitude do vento. Comparada à análise, a simulação CTRL (Figura 4.35 (d)) mostra a região com valores acima de $10 \mathrm{~m} / \mathrm{s}$ transcorrendo de forma mais horizontalmente abrangente, porém com um desenvolvimento vertical inferior, além da área com ventos superiores a 16 m/s ser reduzida. A simulação GF (Figura 4.35 (f)), assim como o experimento CTRL, 
apresentou uma área de atuação de ventos superiores a $10 \mathrm{~m} / \mathrm{s}$ horizontalmente maior que a análise. Ainda no experimento GF, o desenvolvimento vertical desta região com ventos mais intensos é menor do que o exibido pela simulação CTRL. Entretanto, a região com ventos superiores a $16 \mathrm{~m} / \mathrm{s}$ está mais próximo do apresentado pelo CFSv2.

00 UTC
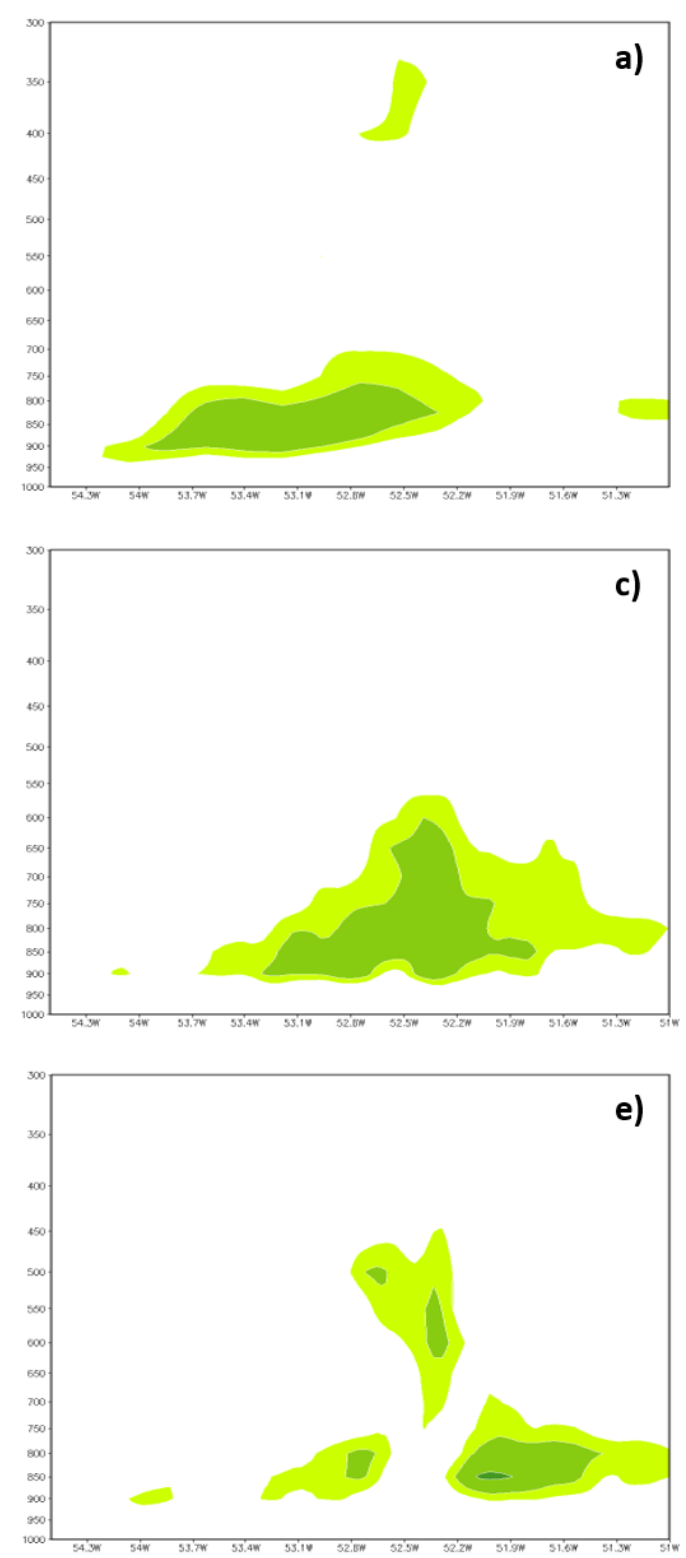

12 UTC

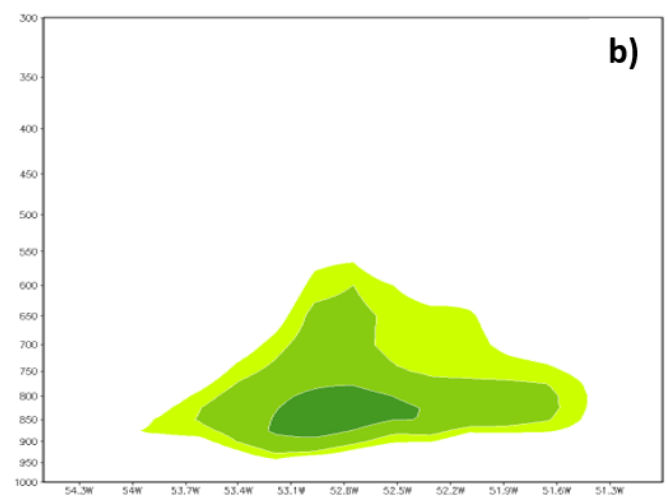

d)

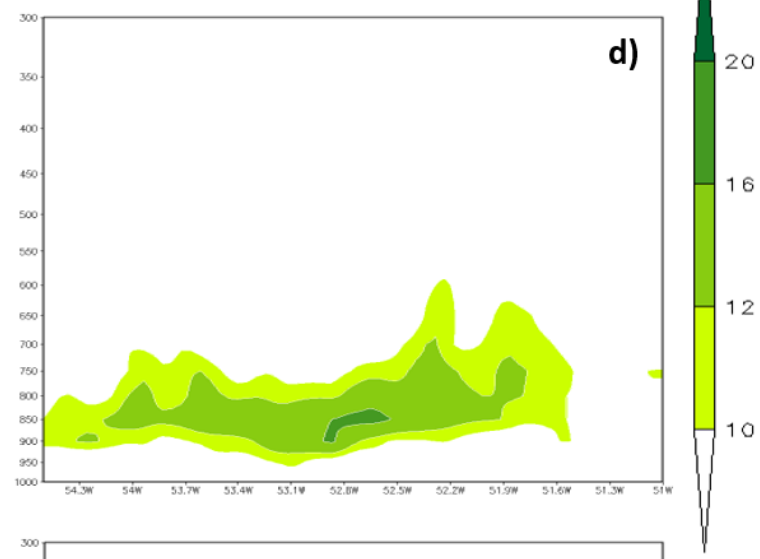

f)

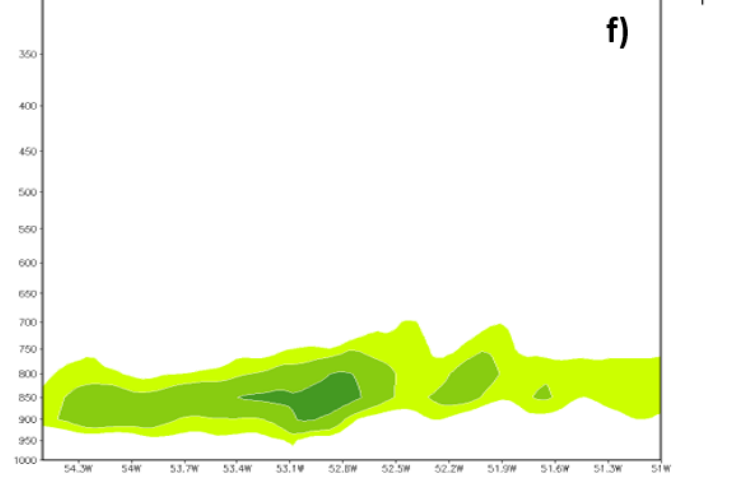

Figura 4.35: Cortes verticais da magnitude do vento (sombreado, $[\mathrm{m} / \mathrm{s}]$ ) entre os pontos $\left(23^{\mathrm{O}}\right.$ $\left.\mathrm{S} ; 54,5^{\mathrm{O}} \mathrm{W}\right)$ e $\left(15^{\mathrm{O}} \mathrm{S} ; 51^{\mathrm{O}} \mathrm{W}\right)$ no dia 12/01/2016 às 0000 UTC ((a) CFSv2; (c) Simulação CTRL; (e) Simulação GF) e 1200 UTC ((b) CFSv2; (d) Simulação CTRL; (f) Simulação $\mathrm{GF})$.

No dia 13/01/2016, a Figura 4.24 mostra uma desintensificação do vento na circulação 
entre o sul da Amazônia e o Sudeste brasileiro, com a região de maior intensidade acontecendo na Bolívia. A Figura 4.36 apresenta campos resultantes de um corte vertical transversal à região de maior intensidade do vento em baixos níveis dentro do território brasileiro, onde pode ser notada este enfraquecimento em relação aos dias anteriores. O corte vertical para o horário das 0000 UTC, utilizando a análise, pode ser visto na Figura 4.36 (a), onde os valores de máxima magnitude do vento ficam próximos a $12 \mathrm{~m} / \mathrm{s}$. A simulação CTRL (Figura 4.36 (c)) mostra valores inferiores à análise, onde a magnitude do vento não chega a $12 \mathrm{~m} / \mathrm{s}$, e valores superiores a $10 \mathrm{~m} / \mathrm{s}$ são observados somente em alguns pontos esparsos. A simulação GF (Figura 4.36 (e)) apresenta valores superiores aos dois conjuntos de dados descritos anteriormente, ultrapassando $12 \mathrm{~m} / \mathrm{s}$. O posicionamento desta região com vento mais intenso no experimento GF coincide com o apresentado pela análise, porém abrange uma área mais extensa.

Às 1200 UTC do dia 13/01/2016, assim como nos dias anteriores, é observada uma intensificação na velocidade do vento em relação às 0000 UTC, indicando a existência de um ciclo diurno na intensidade do vento em baixos níveis. A análise do CFSv2 (Figura 4.36 (b)) apresenta, em 55,4⿳⺈ $\mathrm{W}$, um núcleo com valores superiores a $20 \mathrm{~m} / \mathrm{s}$ em $900 \mathrm{hPa}$ e decaimento da magnitude do vento nas regiões vizinhas. Em níveis mais elevados, de 650 a 300 hPa, existe uma outra região com ventos intensos, porém o núcleo de máxima intensidade com $16 \mathrm{~m} / \mathrm{s}$ ocorre em $450 \mathrm{hPa}$, não se classificando como JBN devido ao nível vertical deste máximo.

Em virtude do que foi constatado nos campos das Figuras 4.24 e 4.27, as simulações mostram a região com magnitude do vento superior a $10 \mathrm{~m} / \mathrm{s}$ a sul do apresentado pela análise. A simulação CTRL (Figura 4.36 (d)), por exemplo, desenvolve o núcleo de maior intensidade com valores superiores a $16 \mathrm{~m} / \mathrm{s}$ em 55,4º W no nível de 850 hPa. Nos níveis superiores e inferiores a este núcleo, existe uma gradiente intenso na velocidade do vento, indicando a presença do JBN. Ainda no experimento CTRL, é importante ressaltar que a região com magnitude do vento superior a $10 \mathrm{~m} / \mathrm{s}$ se estende verticalmente até $450 \mathrm{hPa}$ na longitude 55, $7^{\mathrm{O}} \mathrm{W}$. A simulação GF (Figura 4.36(f)), por sua vez, apresenta valores de magnitude do vento em baixos níveis superiores a $10 \mathrm{~m} / \mathrm{s}$ em praticamente todo o domínio do corte, com o núcleo de maior intensidade em 55,4 $\mathrm{W}$ com magnitude superior a 20 m/s, na mesma posição da análise. Assim como o experimento CTRL, o desenvolvimento vertical também ocorre de forma diferente da análise, posicionado ligeiramente a sul e 
estendendo-se até $500 \mathrm{hPa}$, sem a formação de um novo núcleo como no CFSv2.

Durante o dia 13/01/2016, apesar das simulações divergirem, a análise quanto à posição da região com ventos superiores a $10 \mathrm{~m} / \mathrm{s}$, a localização do JBN foi representada de forma coerente, principalmente pelo experimento GF, o qual mostra inclusive a magnitude do vento no núcleo próxima ao CFSv2.

00 UTC
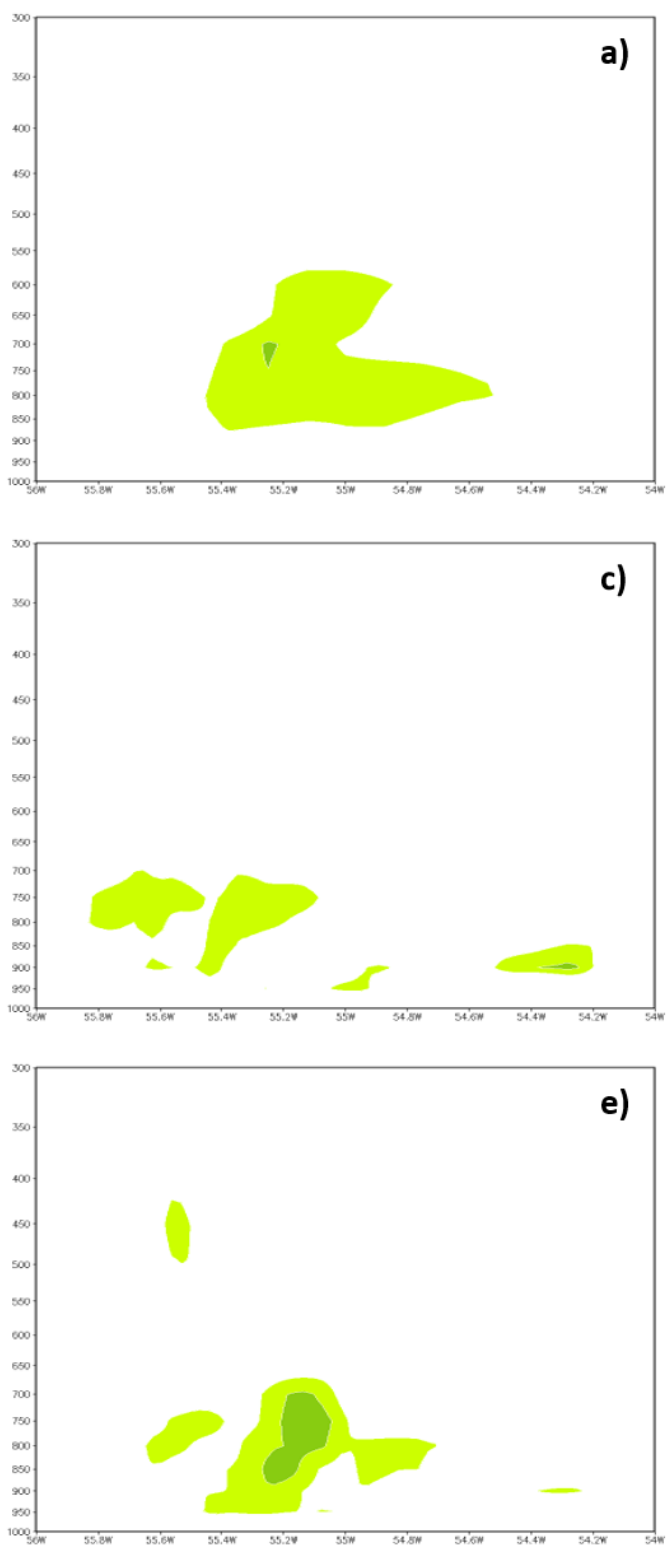

12 UTC
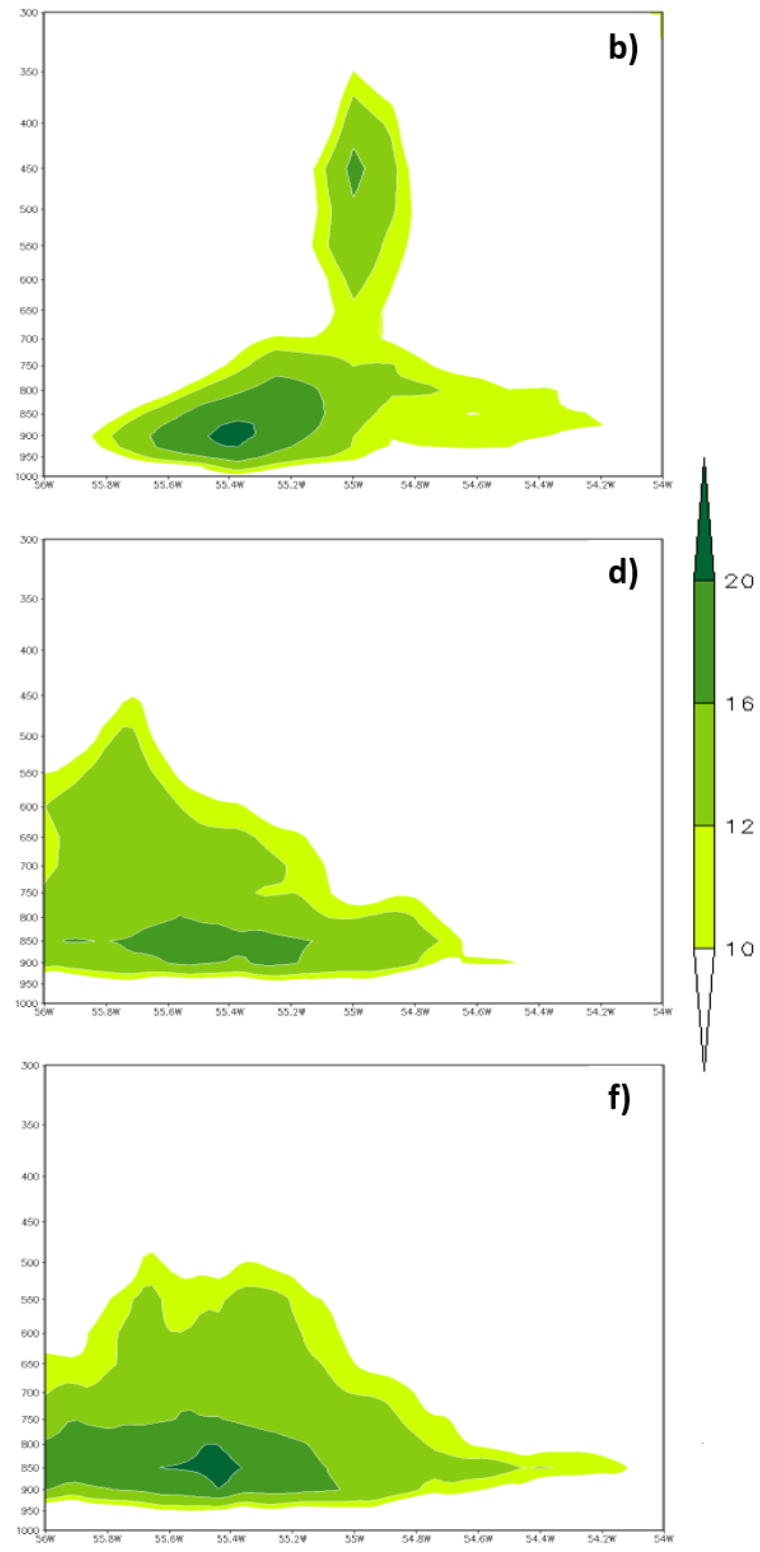

Figura 4.36: Cortes verticais da magnitude do vento (sombreado, $[\mathrm{m} / \mathrm{s}]$ ) entre os pontos $\left(22^{\mathrm{O}} \mathrm{S} ; 56^{\mathrm{O}} \mathrm{W}\right)$ e $\left(14^{\mathrm{O}} \mathrm{S} ; 54^{\mathrm{O}} \mathrm{W}\right)$ no dia 13/01/2016 às 0000 UTC ((a) CFSv2; (c) Simulação CTRL; (e) Simulação GF) e 1200 UTC ((b) CFSv2; (d) Simulação CTRL; (f) Simulação GF). 
Estes campos mostram que as simulações representam o vento em baixos níveis sempre com menor intensidade se comparadas às análises do CFSv2, confirmando o observado nos campos espaciais e no perfil vertical do vento apresentado nos capítulos anteriores. Além disso, fica claro que a intensidade do vento é maior às 1200 UTC do que às 0000 UTC, possivelmente ligado ao fato de que a intensificação e formação do JBN devido a oscilação inercial acontece durante a noite.

As simulações representaram os núcleos de máxima intensidade do vento de forma similar a análise do CFSv2, principalmente a simulação GF, uma vez que são observados nas mesmas posições e com intensidade próxima. Porém, o posicionamento do vento com intensidade superior a $10 \mathrm{~m} / \mathrm{s}$ e periférico a este núcleo apresenta uma defasagem espacial em relação ao CFSv2, acontecendo em uma área mais estreita no dia 11/01/2016 e deslocado ligeiramente para o sul nos dias 12 e 13/01/2016. As simulações mostram uma maior intensidade do vento entrando do Oceano Atlântico Tropical para o norte da AS, o que pode explicar este fluxo no Norte para o Sudeste do Brasil um pouco mais a Sul.

Tanto a verificação da velocidade do vento em $850 \mathrm{hPa}$ quanto o perfil vertical do mesmo indicam a presença do JBN na maior parte da região sob influência da ZCAS, como definida pela análise sinótica da seção 4.1. O primeiro dia de atuação do sistema é o que apresenta maior intensidade do vento em baixos níveis, tanto no limite entre o Oceano Atlântico Tropical e o Norte e Nordeste da América do Sul quanto entre o Sul da região amazônica e o sul do Sudeste brasileiro. A partir do segundo dia ocorre um enfraquecimento da magnitude do vento em ambas as regiões, exceto no dia 15/01/2016, quando há uma intensificação dos valores observados em ambas as áreas.

\subsection{Fluxo de Umidade}

\subsubsection{Campos Espaciais}

A Figura 4.37 mostra o fluxo de umidade médio diário entre os níveis de 900 a 700 hPa para o período de dias entre 11 e 18 de janeiro de 2016 pelas análises do CFSv2. No geral, esta sequência de figuras mostra que o escoamento úmido proveniente do Oceano Atlântico tropical foi essencial para explicar o ciclo de vida da banda associada à ZCAS. De fato, a partir do terceiro dia (Figura 4.37 (c)) verifica-se a desintensificação do transporte de umidade pelos alísios de nordeste, bem visível nos dois dias anteriores, e que, a partir de 
então, o transporte do fluxo de umidade pela banda associada à ZCAS desintensifica-se dia a dia.

No dia 11/01/2016 (Figura 4.37(a)), é observado um fluxo de umidade intenso proveniente do Oceano Atlântico tropical, passando pelo Norte e Nordeste do Brasil e convergindo para o corredor de umidade entre o norte da Bolívia e o litoral dos estados de SP e PR, sendo que a região com maior intensidade do transporte de umidade acontece em aproximadamente $23^{\mathrm{O}} \mathrm{S}$ e $52^{\mathrm{O}} \mathrm{W}$. No dia $12 / 01 / 2016$ (Figura 4.37 (b)), tanto a intensidade do fluxo de umidade proveniente do Atlântico tropical quanto o corredor de umidade da região amazônica diminuem. Entretanto, a localização permanece a mesma. Durante esse dia, o núcleo de maior intensidade é próximo de $18^{\mathrm{O}} \mathrm{S}$ e $55^{\mathrm{O}} \mathrm{W}$.

Dia 13/01/2016 (Figura 4.37 (c)), ocorre um deslocamento do corredor de umidade para norte, além de uma desintensificação e quebra no fluxo próximo a região sul de MG, juntamente a uma forte redução no fluxo de umidade proveniente do Oceano Atlântico tropical. Neste dia, os maiores valores de fluxo de umidade acontecem no nordeste da Bolívia, próximo da fronteira com o Brasil, no estado de MT, em $16^{\underline{\mathrm{O}}} \mathrm{S}$ e $62^{\mathrm{O}} \mathrm{W}$. Em 14/01/2016 (Figura 4.37(d)), percebe-se que o padrão do fluxo de umidade do dia anterior se mantém, apresentando intensidade, em geral, inferior à do dia anterior. Entre o norte da Bolívia e o sul de GO, a intensidade é mais moderada, com enfraquecimento na região sul de MG. A Figura 4.37 (e) mostra que o fluxo de umidade no dia 15/01/2016 se manteve na mesma localização do dia anterior, porém, com intensidade reduzida no Centro-Oeste do Brasil e sem quebra do transporte de vapor d'água na região sul de MG. Nos dias 16/01/2016, 17/01/2016 e 18/01/2016 (respectivamente, Figuras 4.37(f), (g), (h)) o fluxo de umidade se desintensifica a cada dia e a localização se mantém a mesma, atuando sobre MT, TO e MG.

Sendo assim, os dias 11/01/2016, 12/01/2016 e 13/01/2016 foram, dentro os dias de atuação do sistema, os que tiveram o fluxo de umidade mais intenso, bem configurado e direcionado para o Sudeste brasileiro, concordando com o período de maior intensidade do vento em $850 \mathrm{hPa}$ (Figura 4.24). Desta forma, estes foram os dias selecionados para uma analise mais detalhada do fluxo de umidade simulado pelos experimentos numéricos do modelo regional WRF, como pode ser visto nas Figuras 4.38, 4.39 e 4.40. 


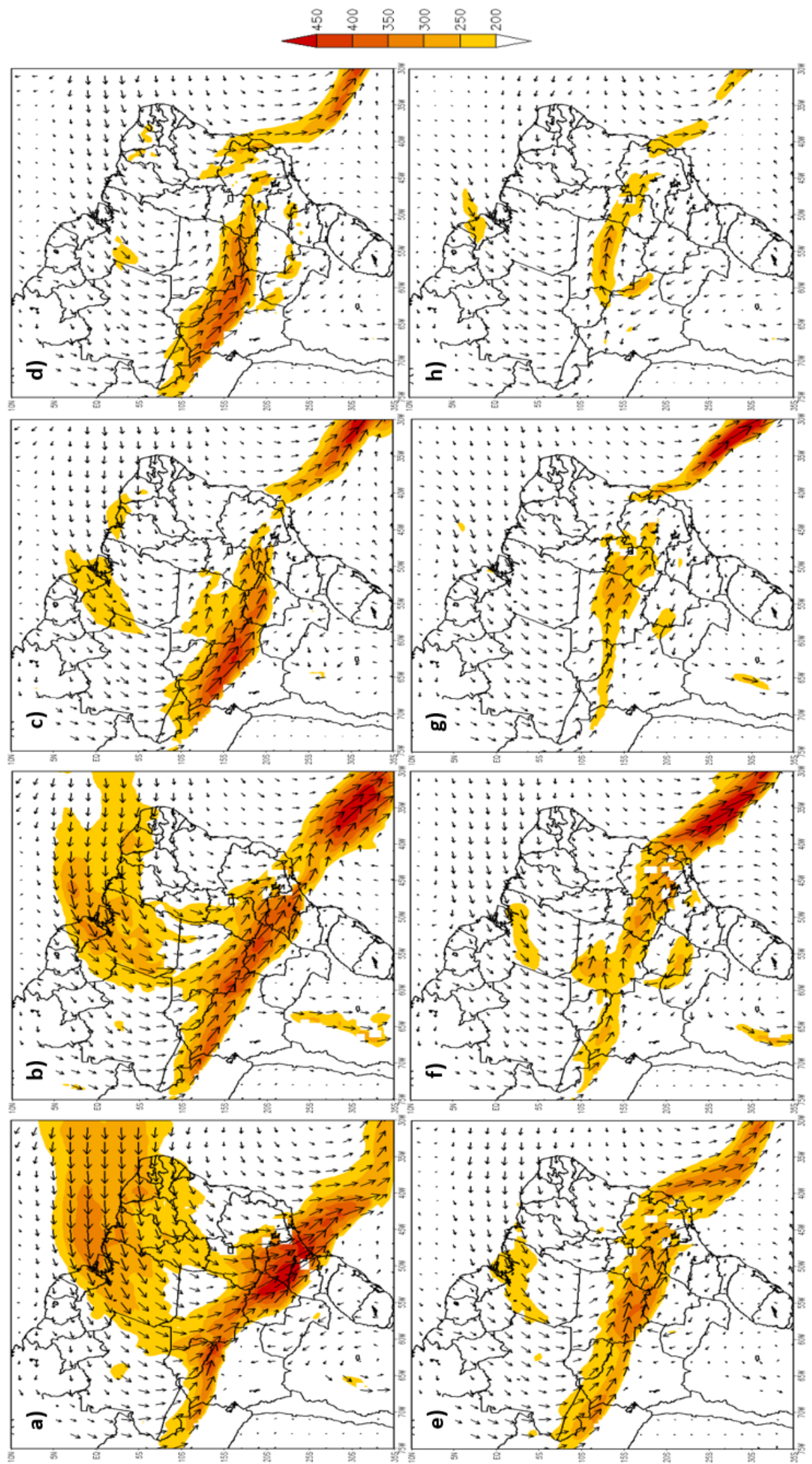

Figura 4.37: Transporte de umidade $\left[\mathrm{kgm}^{-1} \mathrm{~s}^{-1}\right]$ médio diário pelo CFSv2 para os dias: a) 11 de janeiro de 2016; b) 12 de janeiro de 2016; c) 13 de janeiro de 2016; d) 14 de janeiro de 2016; e) 15 de janeiro de 2016; f) 16 de janeiro de 2016; g) 17 de janeiro de 2016; h) 18 de janeiro de 2016. 

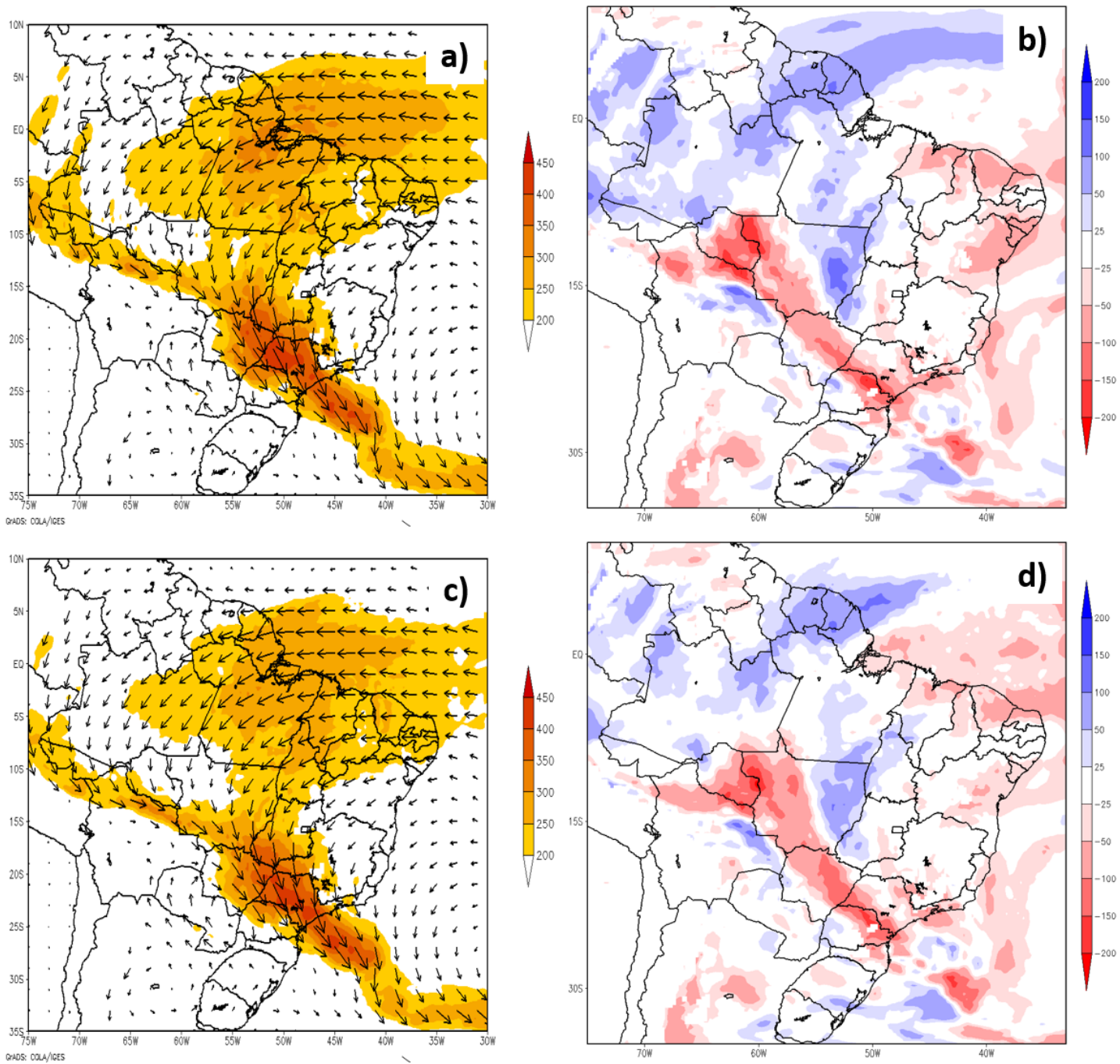

Figura 4.38: Campos de fluxo de umidade $\left[\mathrm{kg}_{\mathrm{g}} \mathrm{m}^{-1} \cdot \mathrm{s}^{-1}\right]$ do dia 11 de janeiro de 2016. (a) Simulação CTRL; (b) diferença de fluxo de umidade entre a simulação CTRL e o CFSv2 (CTRL - CFSv2); (c) simulação GF; (d) diferença de fluxo de umidade entre a simulação GF e o CFSv2 (GF - CFSv2).

Tanto a simulação CTRL quanto a GF apresentam, para o dia 11/01/2016 (Figura 4.38 (a) e (c), respectivamente), um padrão semelhante ao observado no CFSv2. Entretanto, como pode ser visto nos campos de diferença entre o CFSv2 e os experimentos (Figuras 4.38 (b) e (d)), a região entre o sul da Amazônia e o Sudeste brasileiro apresenta valores negativos, indicando que ambos os experimentos subestimam o transporte de umidade pelo JBN em relação à análise. Em contrapartida, em toda a Região Norte do Brasil e nordeste de MT, as simulações mostram valores de transporte de umidade mais intenso do que o CFSv2, sendo que o experimento CTRL apresenta os maiores valores. Esse padrão indica um maior transporte de umidade do Oceano Atlântico tropical para a região 
amazônica, porém uma maior porção desta umidade permanece no Norte do Brasil e não é transportada para o Sudeste, como na análise do CFSv2.

O enfraquecimento do transporte de umidade para o Sudeste do Brasil durante o dia 12/01/2016, apresentado pelo CFSv2 na Figura 4.37 (b), também pode ser visto nos campos de média diária das simulações CTRL e GF (respectivamente, Figuras 4.39 (a) e (c)). O campo de diferença entre as simulações e o CFsv2 deixa clara algumas divergências quanto ao representado pelos experimentos e a análise quanto à fase ou posicionamento do fluxo sobre a região central do Brasil e Sudeste, identificado pelo par de faixas positivas e negativas em paralelo nas figuras de diferenças. Na Figura 4.39 (b), a diferença entre a simulação CTRL e o CFSv2 explicita a superestimativa do experimento no transporte de vapor d'água entre o Oceano Atlântico tropical e a região amazônica. Enquanto isso, entre o sul da Amazônia e o Sudeste brasileiro, nota-se a presença de valores negativos no norte da Bolívia, sul de RO, sudeste de MT, norte de MS e oeste de SP, com valores positivos logo a sul. Este padrão indica uma defasagem quanto ao posicionamento da região de maior intensidade do transporte de umidade, com a simulação posicionando o JBN pouco mais ao sul. O mesmo é observado na simulação GF (ver Figura 4.39 (d)). Porém, a diferença na magnitude do fluxo de umidade em ambas as regiões ocorre de forma menos intensa quando comparada ao experimento CTRL.

Durante o dia 13/01/2016, as simulações ainda apresentam o JBN mais ao sul do que na análise. Em relação ao dia anterior, tanto o experimento CTRL (Figura 4.40 (a)) quanto o GF (Figura 4.40 (c)) simulam uma redução na quantidade de vapor d'água que chega tanto ao Sudeste brasileiro quanto ao que penetra na região amazônica pelo norte do continente. Quando comparada a análise do CFSv2, a simulação CTRL (Figura 4.40 (b)) mostra o núcleo de maior intensidade ao longo do JBN ocorrendo mais a sul, concordando com as discussões do capítulo 4.2. Além da defasagem espacial, a intensidade do fluxo de umidade também diverge da análise. Enquanto a simulação apresenta núcleo com intensidade superior a $450 \mathrm{~kg} / \mathrm{m} / \mathrm{s}$, a análise exibe valores entre 400 e $450 \mathrm{~kg} / \mathrm{m} / \mathrm{s}$, mostrando que o experimento numérico superestimou o fluxo de umidade, comportamento também encontrado no norte da AS. O comparativo da análise com a simulação GF (Figura 4.40 (d)) segue o mesmo padrão do experimento CTRL, apresentando diferenças somente no norte da AS, onde os valores simulados são menos intensos aos representados pela simulação CTRL, porém ainda superiores à análise. Diferente do dia 11/01/2016, no dia 13/01/2016 
o maior transporte de umidade do Oceano Atlântico tropical para a região amazônica por parte das simulações reflete-se na maior quantidade de vapor d'água transportada para o Centro-Oeste e Sudeste do Brasil.
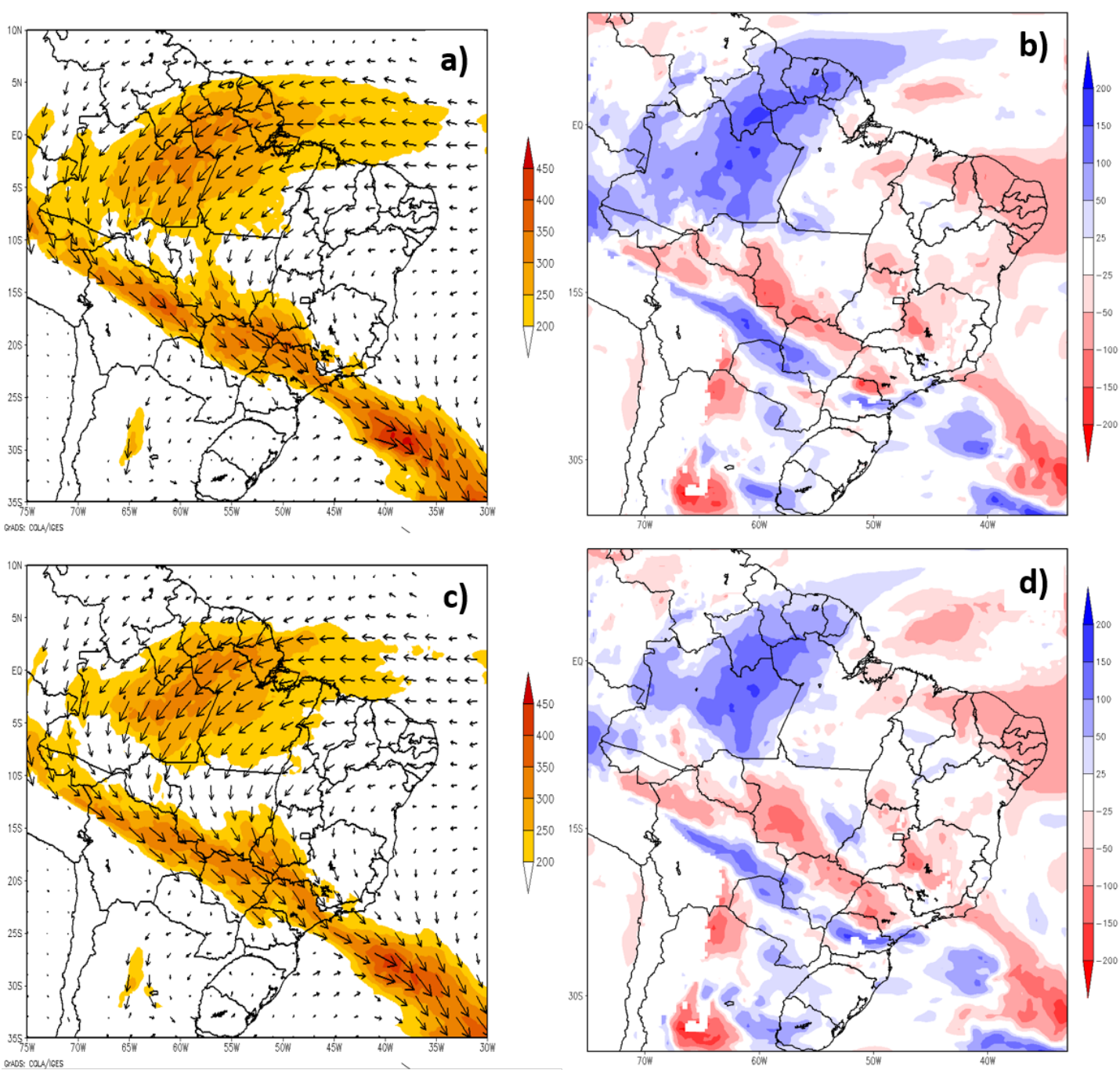

Figura 4.39: Mesmos campos da Figura 4.38 porém para o dia 12/01/2016.

Em suma, os campos analisados nesta seção explicitam que a região de maior intensidade do fluxo de umidade concorda com a máxima intensidade do vento em baixos níveis. Apesar de apresentarem algumas diferenças entre os experimentos e a análise, os resultados mostram a destreza do WRF em simular o JBN quanto ao transporte do fluxo de umidade, apresentando intensidades e padrões relativamente próximos ao mostrado nas análises CFSv2. A partir do dia 14/01/2016, a intensidade do transporte de umidade diminui. Em termos computacionais, as grades 2 e 3 são desativadas e os processos convectivos passam a ser resolvidos somente pelas parametrizações cúmulos referentes a cada 
um dos experimentos.

Os campos do fluxo de umidade médio diário entre 14/01/2016 e 18/01/2016 das simulações CTRL e GF podem ser vistos no apêndice B (respectivamente, Figuras B.1 e B.2. No dia 14/01/2016, ambas as simulações subestimam a umidade que é transportada para o centro-leste do Brasil e exibem valores acima da análise na parte sul do vórtice ciclônico na fronteira entre Brasil, Paraguai e Bolívia. Na média do dia 15/01/2016, as simulações mostram o mesmo padrão de alteração mostrado pelo CFSv2, porém a intensidade continua inferior na área ocupada pelo JBN e superior ao sul do vórtice. Entre os dias 16 e 18 de janeiro de 2016, os experimentos mostram resultados muito próximos ao fluxo de umidade mostrado pela análise, sendo que a simulação GF se assemelha mais ao CFSv2.
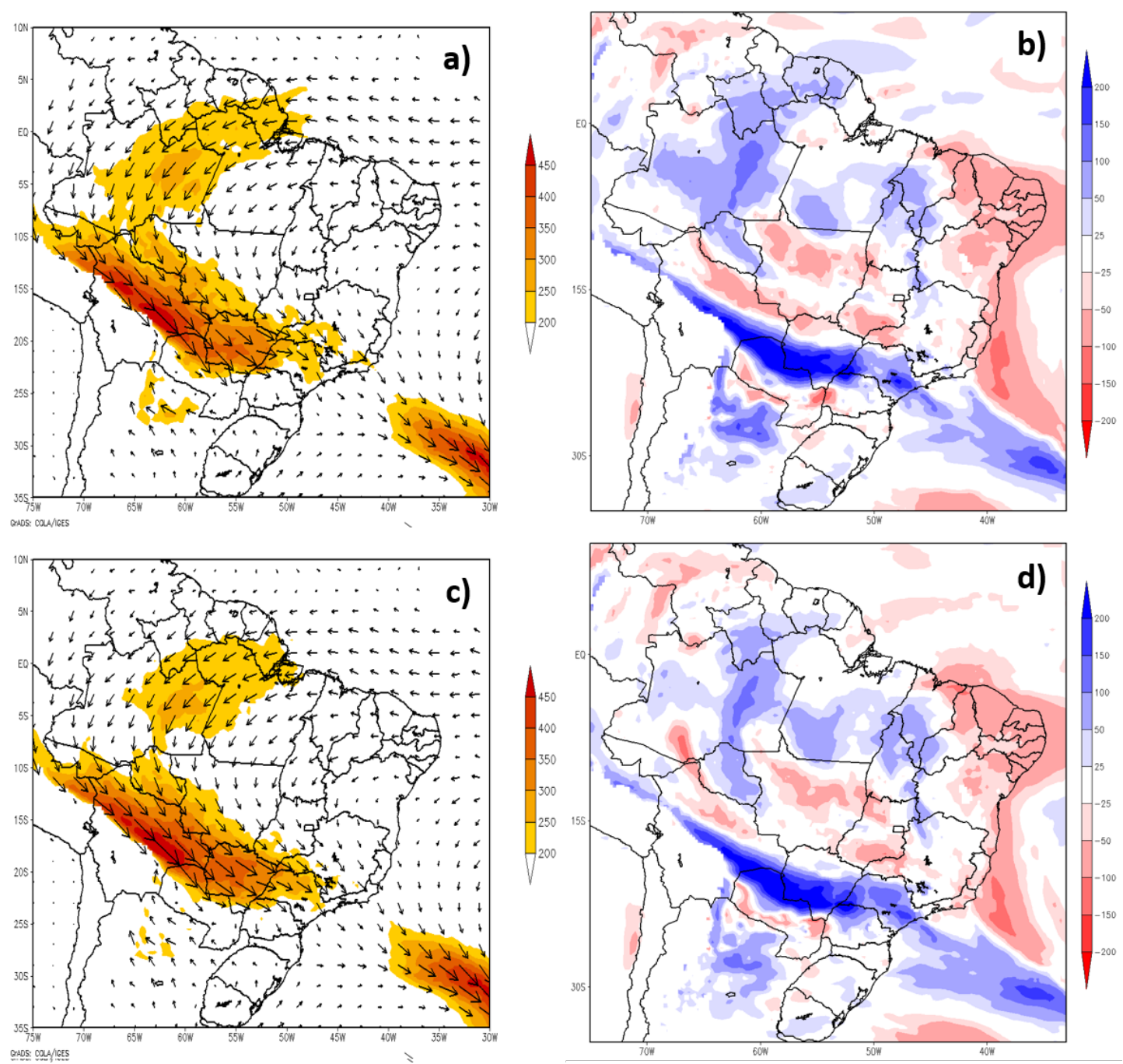

Figura 4.40: Mesmos campos da Figura 4.38 porém para o dia 13/01/2016. 
Por fim, observa-se que estes campos indicam que a intensidade do fluxo de umidade da Região Norte para o Sudeste do Brasil têm uma relação direta com a quantidade de vapor d'água do Oceano Atlântico tropical que adentra o continente pelo seu norte. Assim, nos mesmos dias em que há uma intensificação/desintensificação no fluxo de umidade entre o Oceano Atlântico tropical e o Norte da AS, o mesmo ocorre no transporte do fluxo de vapor d'água na região de atuação do JBN, ressaltando a importância do Oceano Atlântico tropical como fonte de umidade durante casos de ZCAS, já destacado em Quadro et al. (2012).

\subsubsection{Cortes Verticais}

Um corte vertical entre os pontos $\left(15^{\mathrm{o}} \mathrm{S}, 60^{\mathrm{O}} \mathrm{W}\right)$ e $\left(25^{\mathrm{o}} \mathrm{S}, 45^{\mathrm{O}} \mathrm{W}\right)$, na região do fluxo de umidade mais intenso durante o dia 11/01/2016, deu origem aos campos da Figura 4.41.

Tanto às 0000 UTC quanto às 1200 UTC, no CFSv2 (Figuras 4.41 (a) e (b), respectivamente), a região de maior intensidade do fluxo de umidade fica em torno de $53^{\mathrm{o}} \mathrm{W}$, na mesma região de maior magnitude do vento horizontal, superando $20 \mathrm{~m} / \mathrm{s} \mathrm{em} 850 \mathrm{hPa}$, com um intenso gradiente nos níveis superiores e inferiores. Comparado às 1200 UTC, no campo das 0000 UTC o fluxo de umidade é mais extenso e atinge com maior intensidade latitudes mais elevadas, confirmando a atuação do JBN no transporte de umidade entre a região amazônica e o Sudeste brasileiro. Além disso, entre $54^{\mathrm{O}} \mathrm{W}$ e $51^{\mathrm{o}} \mathrm{W}$, este conjunto de dados representa um intenso transporte de vapor d'água se estendendo até aproximadamente $600 \mathrm{hPa}$ durante os dois horários exibidos. Ambas as simulações foram uma boa representação do CFSv2, acontecendo nas mesmas posições e com o mesmo padrão. A subestimativa observada no campos espaciais também é visível neste corte vertical, sendo que os valores não ultrapassam $0,25 \mathrm{~kg} / \mathrm{m} / \mathrm{s}$ nos experimentos e são superiores $0,3 \mathrm{~kg} / \mathrm{m} / \mathrm{s}$ na análise.

No campo das simulações às 1200 UTC (Figuras 4.41(d) e (f), respectivamente CTRL e GF), as diferenças quanto ao CFSv2 continuam, com ambos os experimentos apresentando menor desenvolvimento vertical e abrangência horizontal do fluxo de umidade. Neste horário, aparecem divergências nos valores entre as simulações, onde a posição da região de maior intensidade é a mesma, entre $53,5^{\mathrm{O}} \mathrm{W}$ e $51,5^{\mathrm{O}} \mathrm{W}$, porém a simulação CTRL apresenta valores superiores à simulação GF. Em relação à intensidade do vento, nesse horário as simulações o representam de forma próxima à análise, com magnitude maior ou 
igual a $20 \mathrm{~m} / \mathrm{s}$ na mesma posição de máxima intensidade do fluxo de umidade, além de um elevado cisalhamento vertical do vento.
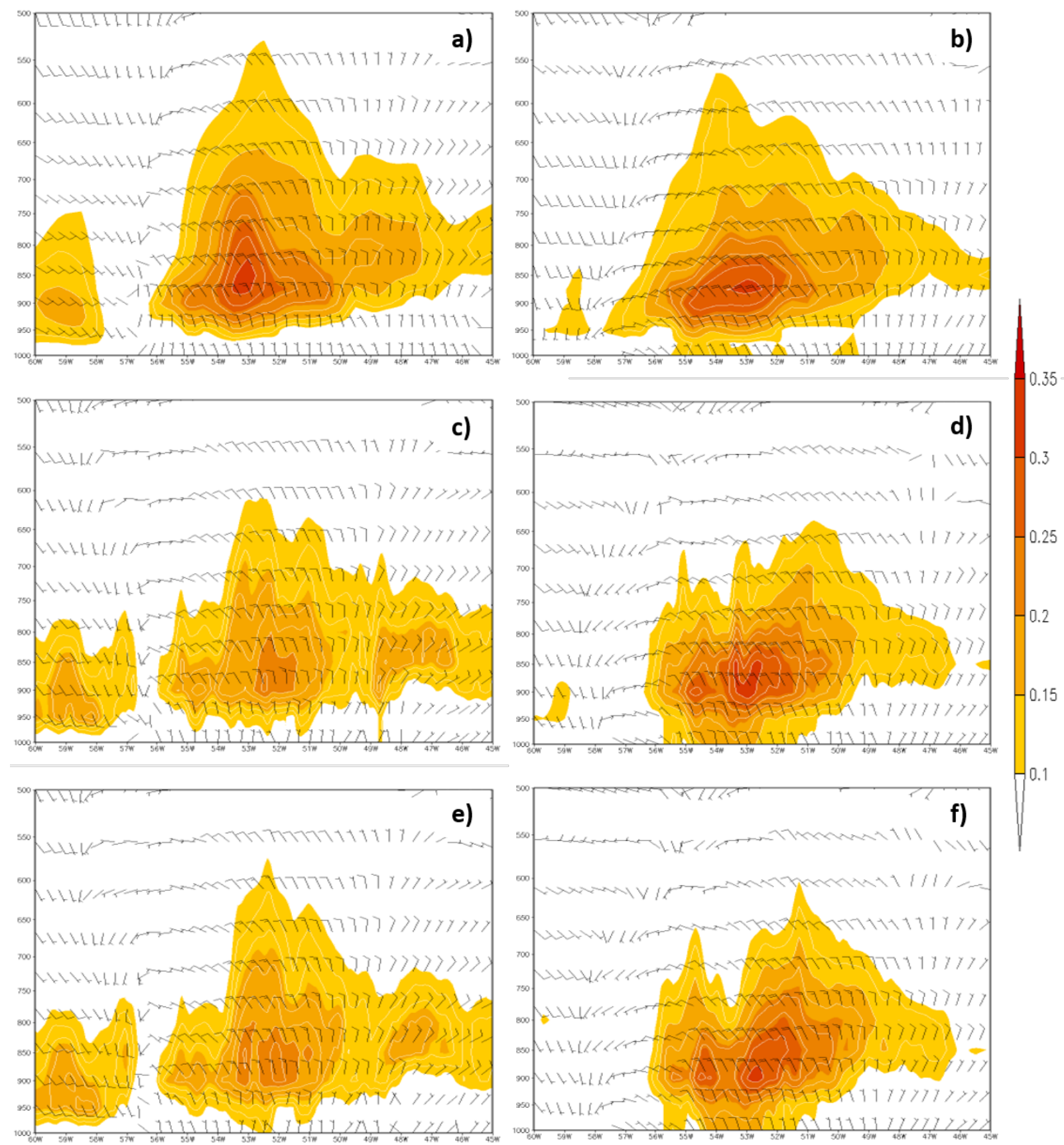

Figura 4.41: Cortes verticais do vento horizontal (barbelas), magnitude do vento horizontal (linhas de contorno, $[\mathrm{m} / \mathrm{s}]$ ) e fluxo de umidade (sombreado $\left[\mathrm{kg} \cdot \mathrm{m}^{-1} \cdot \mathrm{s}^{-1}\right]$ ) entre os pontos $\left(15^{\mathrm{o}} \mathrm{S} ; 60^{\mathrm{O}} \mathrm{W}\right)$ e $\left(25^{\mathrm{o}} \mathrm{S} ; 45^{\mathrm{O}} \mathrm{W}\right)$ no dia 11/01/2016 às $0000 \mathrm{UTC}$ ((a) CFSv2; (c) Simulação Controle; (e) Simulação Grell Freitas) e 1200 UTC ((b) CFSv2; (d) Simulação Controle; (f) Simulação Grell Freitas).

Durante o dia 12/01/2016, o corte vertical na região de maior intensidade do fluxo 
de umidade média diária resulta nos campos expostos na Figura 4.42. Às 0000 UTC, o CFSv2 (Figura 4.42 (a)) mostra uma região com valores elevados entre $55^{\mathrm{O}} \mathrm{W}$ e $47^{\mathrm{O}}$ W, com o núcleo de maior intensidade de 900 a $800 \mathrm{hPa}$ e $53^{\mathrm{O}} \mathrm{W}$ a $54^{\mathrm{O}} \mathrm{W}$. Entre $55^{\mathrm{O}}$ $\mathrm{W}$ e $50^{\mathrm{O}} \mathrm{W}$, nota-se que a intensidade do vento ultrapassa $10 \mathrm{~m} / \mathrm{s}$ próximo do nível de $850 \mathrm{hPa}$, com intenso gradiente acima e abaixo deste nível, indicando a presença do JBN nesta região. Tanto a extensão vertical como a horizontal deste fluxo são inferiores ao dia anterior (Figura 4.41), concordando com os campos espaciais expostos na seção anterior.

A simulação CTRL (Figura 4.42 (c)) apresenta um padrão espacial próximo da análise (Figura 4.35 (a)), porém o núcleo de maior intensidade do fluxo de umidade tem valores superiores, ocorrendo entre $51^{\mathrm{O}} \mathrm{W}$ e $50^{\mathrm{O}} \mathrm{W}$. A magnitude do vento horizontal também é superior a da análise, sendo maior ou igual a $20 \mathrm{~m} / \mathrm{s}$ na região de maior intensidade, enquanto a análise tem valores inferiores a $20 \mathrm{~m} / \mathrm{s}$. Por sua vez, a simulação GF (Figura 4.42 (e)) apresenta valores inferiores aos outros dois conjuntos de dados, tanto para o fluxo de umidade (inferior a $0,2 \mathrm{~kg} / \mathrm{m} / \mathrm{s}$ ) quanto para magnitude do vento (inferior a $15 \mathrm{~m} / \mathrm{s}$ ). A área de atuação do fluxo de umidade mais intenso também é menor em relação à análise e a simulação CTRL, confirmando que o fluxo de umidade é subestimado nesse experimento.

Às 1200 UTC, o CFSv2 (Figura 4.42 (b)) mostra uma intensificação do fluxo de umidade, além de um aumento na área de atuação do mesmo, chegando até o Oceano Atlântico adjacente ao estado de SP, em $45^{\mathrm{O}} \mathrm{W}$. A velocidade do vento também é superior a apresentada no horário anterior, sendo maior ou igual a $20 \mathrm{~m} / \mathrm{s}$ entre $54^{\mathrm{O}} \mathrm{W}$ e $58^{\mathrm{O}} \mathrm{W}$. As simulações numéricas apresentam padrões semelhantes, que divergem em relação à análise. A região com fluxo de umidade mais intenso ocorre em latitudes mais altas do que o mostrado pelo CFSv2, posicionada entre $57^{\circ} \mathrm{W}$ e $48^{\circ} \mathrm{W}$. Os valores de fluxo de umidade e magnitude do vento apresentados pelas simulações são inferiores à análise, não ultrapassando 0,25 $\mathrm{kg} / \mathrm{m} / \mathrm{s}$ e $15 \mathrm{~m} / \mathrm{s}$, respectivamente. A direção do vento na região de atuação do JBN é outro fator que diverge entre análise e simulações, com a primeira sendo totalmente zonal e a segunda, direcionada no sentido noroeste-sudeste.

No dia 13/01/2016, às 0000 UTC, a configuração vertical da intensidade do fluxo de umidade mostrada pelo CFSv2 (Figura 4.43 (a)) evidencia uma desintensificação no transporte de vapor d'água em comparação aos primeiros dias do evento. O núcleo com maior intensidade acontece de 900 à $850 \mathrm{hPa}$ e entre $57^{\mathrm{O}} \mathrm{W}$ e $53^{\mathrm{O}} \mathrm{W}$, com valores inferiores ao dia anterior. A magnitude do vento também é menor em relação ao dia 12/01/2016, não 
ultrapassando $10 \mathrm{~m} / \mathrm{s}$. Esta diminuição pode ser explicada pelo deslocamento da região final do fluxo de umidade para norte, fazendo com que o gradiente de temperatura entre a entrada e a saída do JBN diminuam, além de que uma menor variação da latitude resulta numa menor aceleração do vento por conservação de vorticidade potencial.
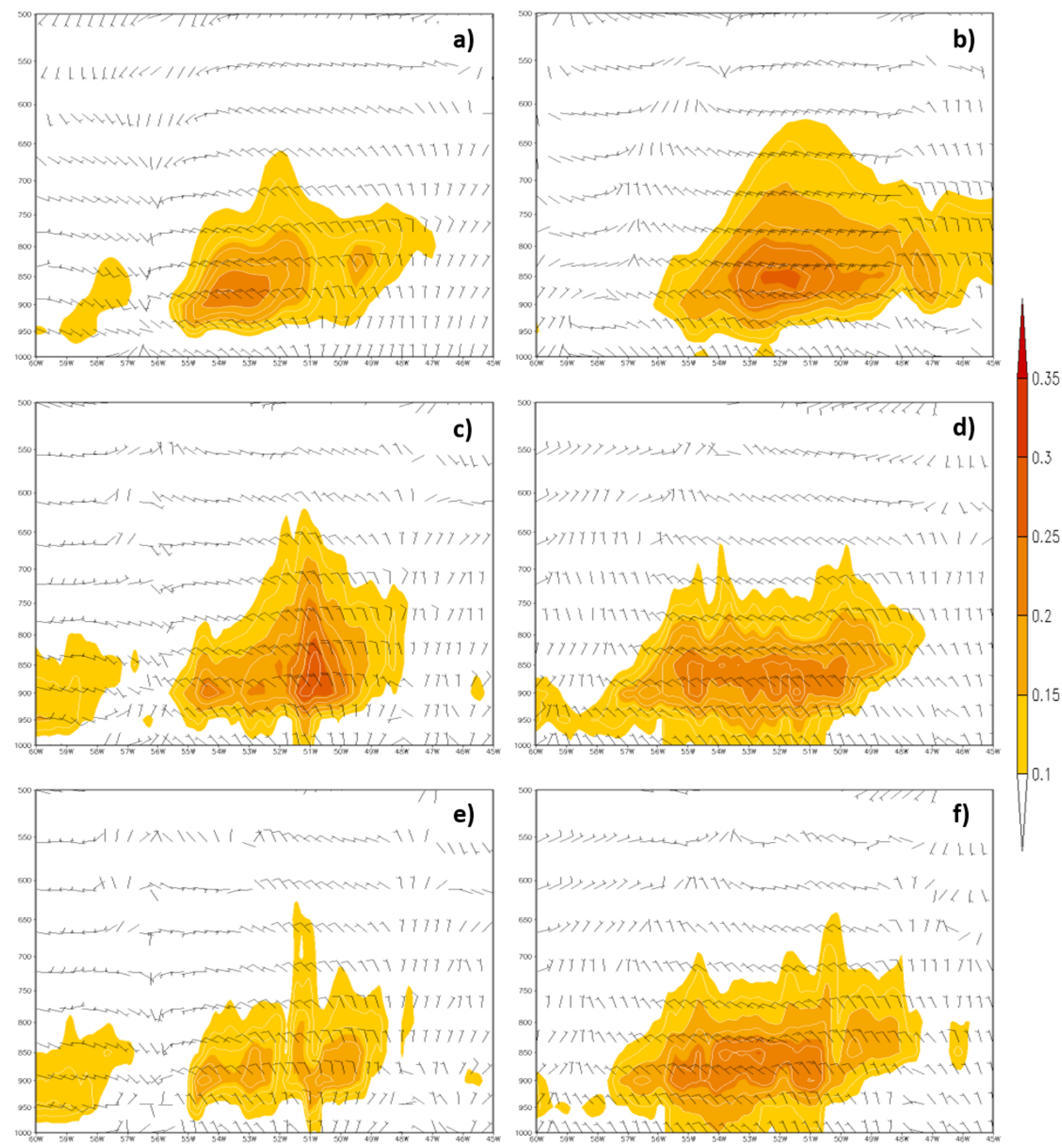

Figura 4.42: Cortes verticais do vento horizontal (barbelas), magnitude do vento horizontal

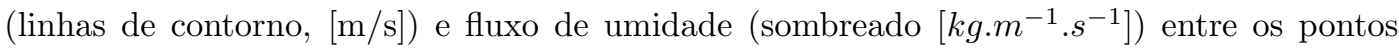
$\left(15^{\mathrm{O}} \mathrm{S} ; 60^{\mathrm{O}} \mathrm{W}\right)$ e $\left(25^{\mathrm{O}} \mathrm{S} ; 45^{\mathrm{O}} \mathrm{W}\right)$ no dia 12/01/2016 às 0000 UTC ((a) CFSv2; (c) Simulação Controle; (e) Simulação Grell Freitas) e 1200 UTC ((b) CFSv2; (d) Simulação Controle; (f) Simulação Grell Freitas). 

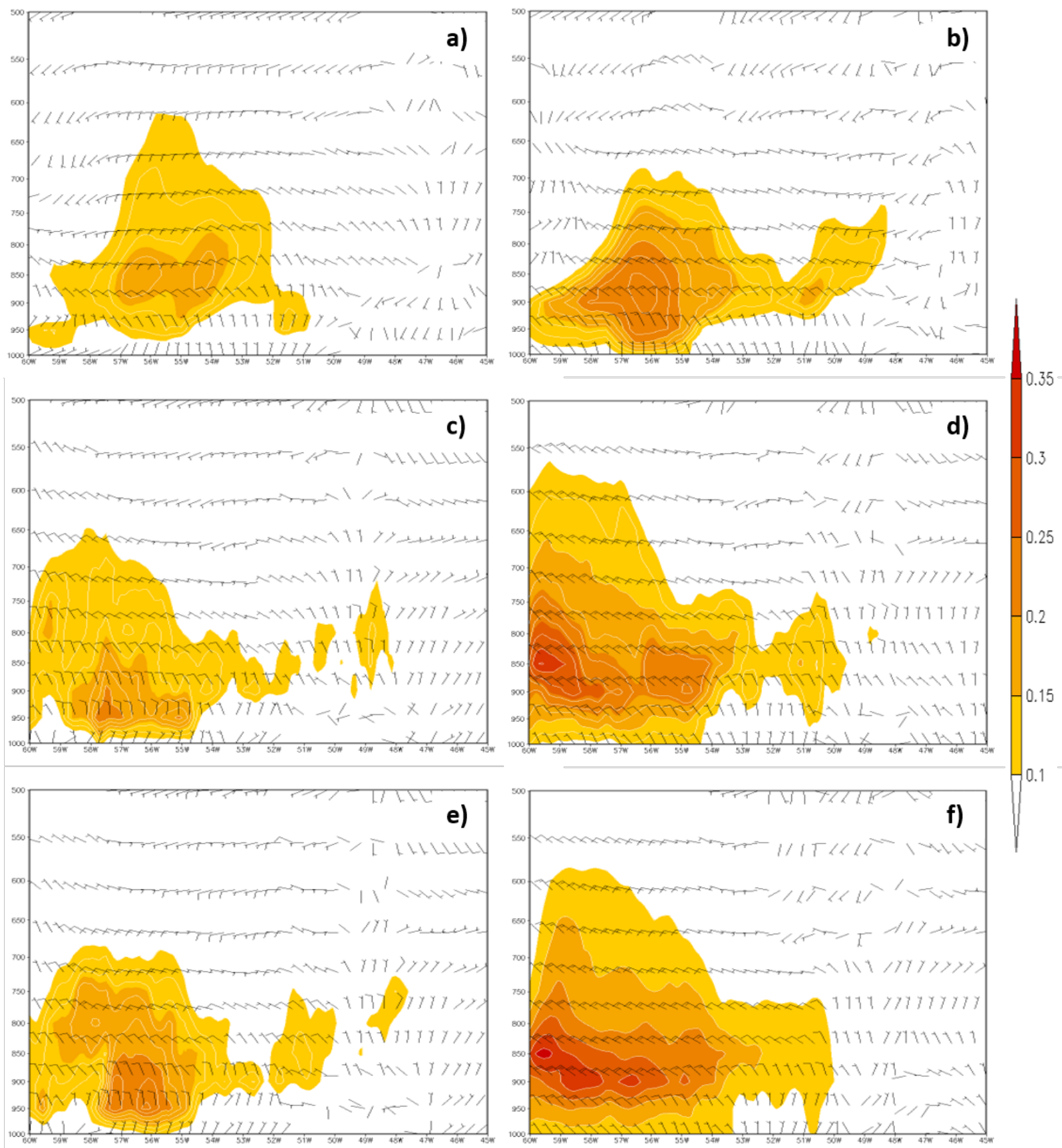

Figura 4.43: Cortes verticais do vento horizontal (barbelas), magnitude do vento horizontal [linhas de contorno, $(\mathrm{m} / \mathrm{s})]$ e fluxo de umidade (sombreado $\left[\mathrm{kg}_{\mathrm{m}} \mathrm{m}^{-1} \cdot \mathrm{s}^{-1}\right]$ ) entre os pontos $\left(15^{\mathrm{o}} \mathrm{S} ; 60^{\mathrm{O}} \mathrm{W}\right)$ e $\left(24^{\mathrm{o}} \mathrm{S} ; 45^{\mathrm{o}} \mathrm{W}\right)$ no dia 13/01/2016 às 0000 UTC ((a) CFSv2; (c) Simulação Controle; (e) Simulação Grell Freitas) e 1200 UTC ((b) CFSv2; (d) Simulação Controle; (f) Simulação Grell Freitas).

Às 0000 UTC do dia 13/01/2016, os experimentos CTRL (Figura 4.43 (c)) e GF (Figura 4.43 (e)) apresentam padrões semelhantes entre si, diferindo da análise no posicionamento e intensidade do fluxo de umidade. A região com valores superiores a $1 \mathrm{~kg} / \mathrm{m} / \mathrm{s}$ nas 
simulações é posicionada a sul da posição no CFSv2, entre $53^{\circ} \mathrm{W}$ e $60^{\mathrm{O}} \mathrm{W}$. O núcleo de maior intensidade está posicionado em torno de $57^{\mathrm{O}} \mathrm{W}$, entre 950 e $900 \mathrm{hPa}$ e com magnitude variando de 0,2 a $0,25 \mathrm{~kg} / \mathrm{m} / \mathrm{s}$, sendo mais intenso a oeste e em menor altitude do que o apresentado pela análise.

Analisando a Figura 4.43 (b) composta pelo corte vertical na região de maior intensidade do fluxo de umidade, nota-se que, às 1200 UTC do dia 13/01/2016, o mesmo é menos intenso quando comparado ao mesmo horário dos dias anteriores. O núcleo de maior intensidade acontece entre $55^{\mathrm{O}} \mathrm{W}$ e $58^{\mathrm{O}} \mathrm{W}$ e em torno de $900 \mathrm{hPa}$. A magnitude do vento em baixos níveis apresenta valores superiores a $15 \mathrm{~m} / \mathrm{s}$ no núcleo de maior intensidade do fluxo de umidade, perdendo intensidade corrente abaixo. As simulações CTRL (Figura 4.43 (d)) e GF (Figura 4.43 (f)) apresentam este núcleo com magnitude e longitudes superiores à análise. Estes resultados concordam com os campos exibidos na Figura 4.40, mostrando que o fluxo de umidade simulado em ambos os experimentos é mais intenso do que o apresentado pela análise.

Estes resultados mostram que o transporte de umidade nesta região acontece da mesma forma que o JBN, a sua maior intensidade acontece em baixos níveis da atmosfera e em forma de núcleo, com um decaimento na magnitude nos níveis superiores e inferiores. Os maiores valores de fluxo de umidade acontecem sobre o Centro-Oeste do Brasil, região em que tanto os campos horizontal quanto o perfil vertical da magnitude do vento apresentaram uma maior permanência da atuação do JBN, ressaltando uma relação direta entre a atuação do JBN e a quantidade de vapor d'água transportada para latitudes mais altas durante um evento de ZCAS.

As diferenças existentes entre os resultados obtidos em acada uma das simulações e a análise do CFSv2 acontecem, principalmente, no posicionamento das regiões com intenso fluxo de umidade, uma vez que os valores obtidos são bem próximos. Os experimentos numéricos com o modelo regional WRF representam o fluxo de umidade sobre o Sudeste do Brasil menos intenso durante estes dias analisados.

\subsubsection{Séries Temporais}

Utilizando caixas estrategicamente posicionadas nas regiões de maior intensidade do transporte de umidade durante a atuação da ZCAS, foram feitas médias espaciais desta variável utilizando tanto os dados do CFSv2 quanto das simulações CTRL e GF. 

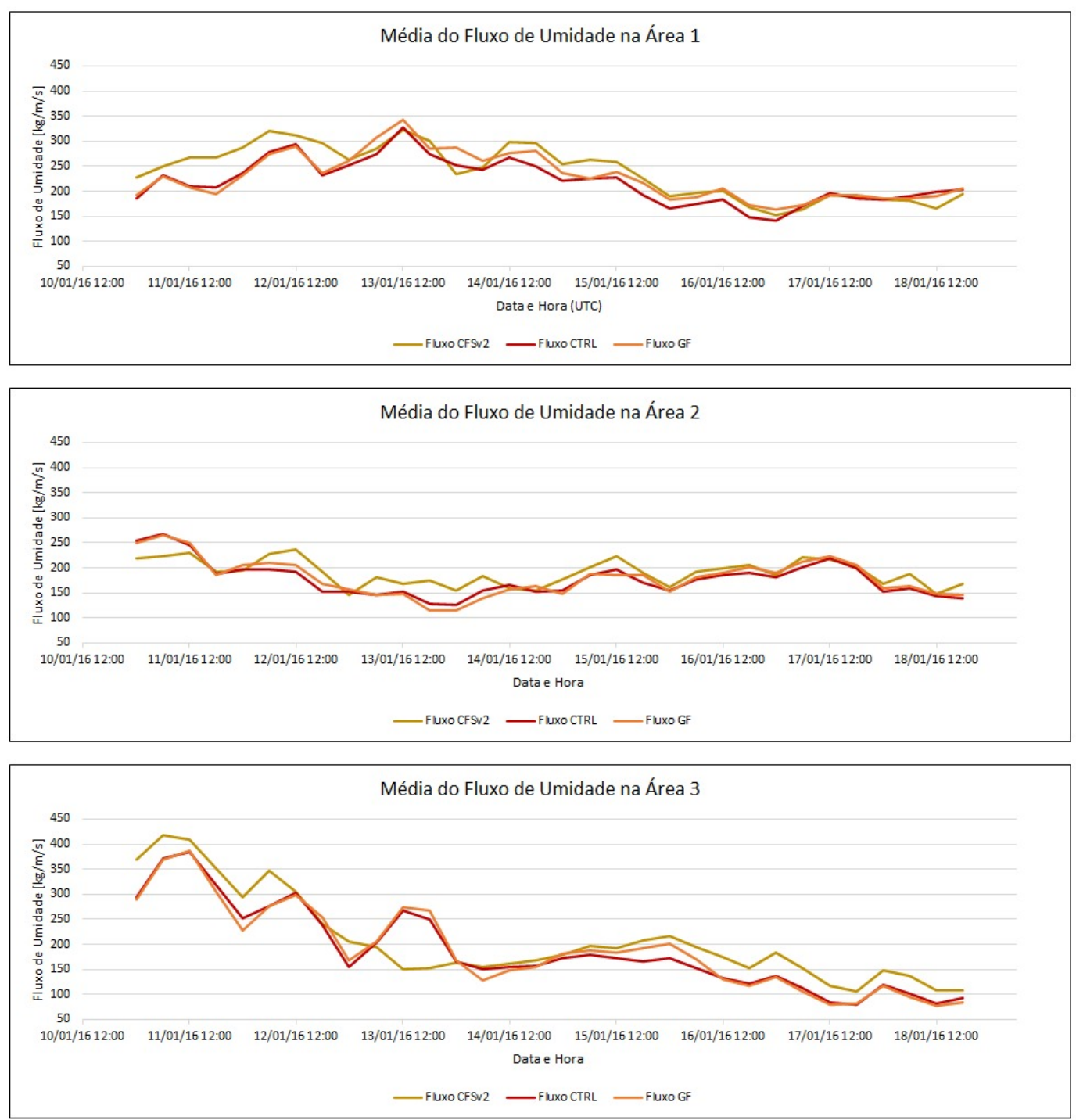

Figura 4.44: Série temporal da média de fluxo de umidade nas áreas, utilizando os dados do CFSv2, CTRL e GF na grade 1.

A Figura 4.44 apresenta a média entre os dias 11 e 18 de janeiro de 2016, utilizando a análise e os resultados da grade 1 de ambas as simulações numéricas. No início da atuação do sistema, a maior intensidade do fluxo de umidade é observado na área 3, posicionada na região Sudeste do Brasil. Nesta mesma área, é visível uma redução na intensidade do fluxo de umidade, passando de aproximadamente $350 \mathrm{~kg} / \mathrm{m} / \mathrm{s}$ pelo CFSv2 e $300 \mathrm{~kg} / \mathrm{m} / \mathrm{s}$ pelas simulações para valores em torno de $100 \mathrm{~kg} / \mathrm{m} / \mathrm{s}$ no dia 18/01/2016 às 1800 UTC, em todos os conjuntos de dados.

Ainda na área 3, é observada uma proximidade entre os resultados das simulações. Entre os experimentos e a análise existem algumas pequenas divergências quanto à in- 
tensidade, porém o comportamento ao longo da atuação da ZCAS foi bem representado. Durante os dois primeiros dias de atuação do sistema, ambas as simulações subestimam os valores apresentados pela análise. Já durante o período diurno do dia 13/01/2016, existe uma superestimativa de $100 \mathrm{~kg} / \mathrm{m} / \mathrm{s}$ por parte de ambos os experimentos. Nos dias 14/01/2016 e 15/01/2016, todos os conjuntos de dados apresentam valores de transporte de vapor d'água semelhantes, enquanto a partir do dia 16/01/2016, os experimentos voltam a subestimar os valores exibidos pela análise.

A área 2 abrange o fluxo de umidade gerado pela circulação proveniente da atuação da ASAS e dos alísios que entram pelo Nordeste brasileiro e avançam em direção ao Sudeste. Esta área apresenta, às 0000 UTC de 11/01/2016, fluxo de umidade médio de 200 $\mathrm{kg} / \mathrm{m} / \mathrm{s}$ nas simulações e $225 \mathrm{~kg} / \mathrm{m} / \mathrm{s}$ pela análise, enfraquecendo até o dia 13/01/2016 às 1200 UTC. Ainda na área 2, entre às 1200 UTC do dia 13/01/2016 e às 1200 UTC do dia 17/01/2017, existe uma leve intensificação do transporte de umidade médio na área, chegando a valores superiores a $200 \mathrm{~kg} / \mathrm{m} / \mathrm{s}$, com posterior enfraquecimento até o fim da atuação do sistema. Nota-se também que a diferença entre os experimentos é mínima e a similaridade entre a análise e as simulações é grande. As maiores diferenças acontecem entre às 0600 UTC do dia 12/01/2016 e 1200 UTC do dia 15/01/2016, sendo mais intensa durante o dia 13/01/2016. Em todo este período, comparado à análise, as simulações subestimam a magnitude do fluxo de umidade.

Entre o sul da Amazônia e o norte do Pantanal (área 1), é observada uma amplificação da média de quantidade de vapor d'água transportada pelo JBN entre as 0000 UTC do dia 11/01/2016 e 1200 UTC do dia 13/01/2016, com permanência de uma derivada negativa até o último dia de atuação do sistema. Os resultados das simulações numéricas são próximos entre si. Porém, apesar do comportamento durante o sistema ser bem representado, estes subestimam a magnitude do fluxo de umidade ao longo dos dois primeiros dias. Já entre os dias 13 e 18 de janeiro de 2016, os valores mostrados por ambas as simulações assemelhamse à análise, tanto na magnitude quanto na variação da intensidade do transporte de umidade.

A Figura 4.45 mostra a média espacial do transporte de umidade resultado da grade 3 de ambos os experimentos durante os dias 11, 12 e 13 de janeiro de 2016. Esta grade, por ser a mais refinada, possui resolução temporal superior, facilitando a visualização das flutuações na intensidade da variável em questão. Os dois experimentos não apresentam 
grandes diferenças entre si, com a divergência máxima entre eles sendo de aproximadamente $25 \mathrm{~kg} / \mathrm{m} / \mathrm{s}$ em cada umas das áreas.

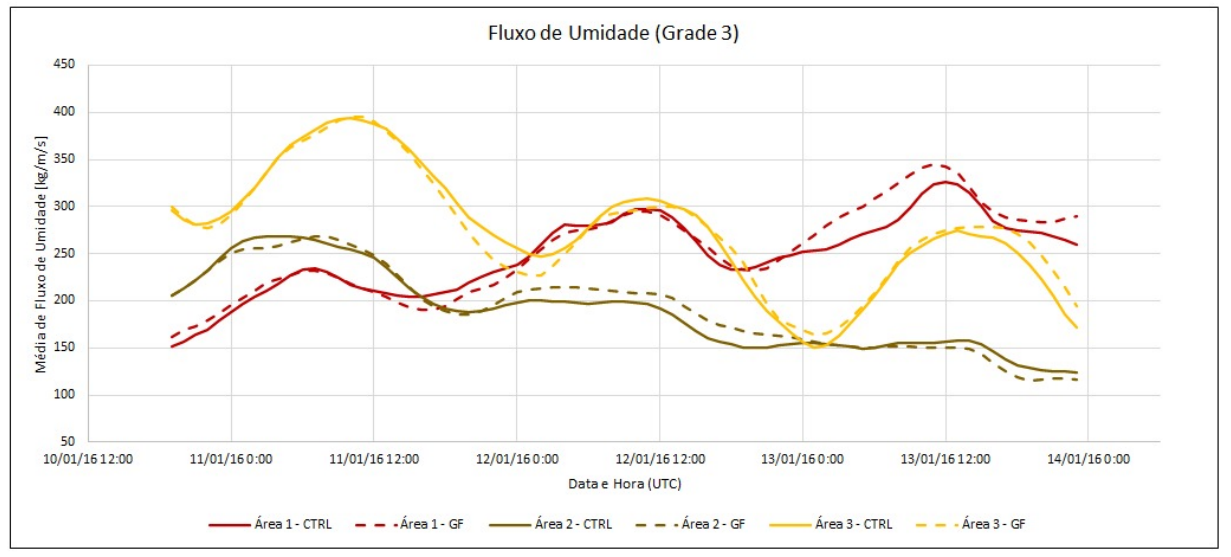

Figura 4.45: Série temporal da média de fluxo de umidade nas áreas 1, 2 e 3, utilizando os dados das simulações CTRL e GF na grade 3 .

Na área 1, o padrão de intensificação durante os primeiros dias observado na Figura 4.44 é apresentado de forma mais detalhada, partindo de $150 \mathrm{~kg} / \mathrm{m} / \mathrm{s}$ às 0000 UTC do dia 11/01/2016 para o valor máximo de $350 \mathrm{~kg} / \mathrm{m} / \mathrm{s}$ na simulação GF e $325 \mathrm{~kg} / \mathrm{m} / \mathrm{s}$ na simulação CTRL, ambos às 1200 UTC do dia 13/01/2016. É exibido um padrão de ciclo diurno na intensidade do transporte de umidade nesta região, com os maiores (menores) valores acontecendo de madrugada e início da manhã (início da tarde). Diferente da região anterior, os valores médios de magnitude do fluxo de umidade na área 2 não apresentam um ciclo diurno bem definido e acontecem com intensidade praticamente constante durante todo o dia.

A média na área 3 mostra uma desintensificação do fluxo de umidade durante os 3 primeiros dias, concordando com os resultados da grade 1 (Figura 4.44). Ambos os gráficos explicitam um ciclo diurno bem definido, com as intensidades máximas ocorrendo às 1200 UTC e as mínimas próximo de 0000 UTC, e variação de aproximadamente $150 \mathrm{~kg} / \mathrm{m} / \mathrm{s}$ entre estes pontos.

A presença de um ciclo diurno nas áreas 1 e 3 e ausência na área 2 ocorre devido ao fato de que o sistema que impulsiona este transporte de umidade é diferente nesta região. As áreas 1 e 3 têm o fluxo de umidade gerado e intensificado pela atuação do JBN, que por si só possui um ciclo diurno, uma vez que a oscilação inercial (ver Apêndice A.1) acontece 
durante o período da noite, sendo este o momento de intensificação observado nos gráficos. Na área 2, o sistema responsável pelo transporte de umidade é a circulação da ASAS e os alísios que adentram o Nordeste brasileiro. Estes sistemas não possuem um ciclo diurno bem definido, o que se reflete no padrão observado no gráfico.

Apesar da quantidade de vapor d'água advectada pelo JBN tanto no Centro-Oeste quanto no Sudeste do Brasil (áreas 1 e 3, respectivamente) apresentar máximos de intensidade, também ocorrem momentos de mínimos. Por outro lado, o fluxo de umidade gerado pela circulação da ASAS e dos alísios que entram pelo Nordeste (área 2) tem um comportamento mais linear e com intensidade que pouco varia, sendo uma fonte de umidade constante durante a ZCAS.

\subsection{Análise da Precipitação}

\subsubsection{Acumulado Total}

As análises efetuadas até aqui mostram que a ZCAS em questão apresentou forte acoplamento vertical entre os campos sinóticos de massa, com transporte de umidade pelo JBN, o qual se reflete na quantidade de água precipitável disponível no Sudeste brasileiro. O resultado da atuação destes mecanismos pode ser visto nos campos de precipitação acumulada durante todo o sistema mostrados na Figura 4.46, onde as regiões de maior influência destes elementos também apresentam os maiores acumulados de chuva. O melhor exemplo desta correspondência é a região que se estende entre o norte do PR e o norte de MG, com acumulados que pontualmente ultrapassam $300 \mathrm{~mm}$ tanto no MERGE quanto nos experimentos CTRL e GF.

O MERGE (Figura 4.46 (a)) apresenta valores acima de $50 \mathrm{~mm}$ em praticamente todo o território dos estados de SP, MG, RJ e GO, superando 100 mm no norte de SP e grande parte de MG. Pontos com acumulados superiores a $300 \mathrm{~mm}$ são observados no centronorte de SP, nordeste de GO e no Oceano Atlântico subtropical. Em relação ao MERGE, as simulações CTRL e GF (respectivamente, Figuras 4.46 (b) e (c)) apresentam valores inferiores de precipitação em todo o território brasileiro.

A simulação CTRL (Figura 4.46 (b)) mostra o menor acumulado total dentre todos os conjuntos de dados, com valores acima de $100 \mathrm{~mm}$ ocorrendo em uma área menor, especificamente no oeste de SP, noroeste do PR, ES, Oceano Atlântico subtropical e pequenos 
pontos isolados no Norte e Centro-Oeste brasileiro, Peru e Bolívia. Valores de precipitação acumulada superiores a $300 \mathrm{~mm}$ são observados apenas no noroeste do PR, ES e Bolívia.
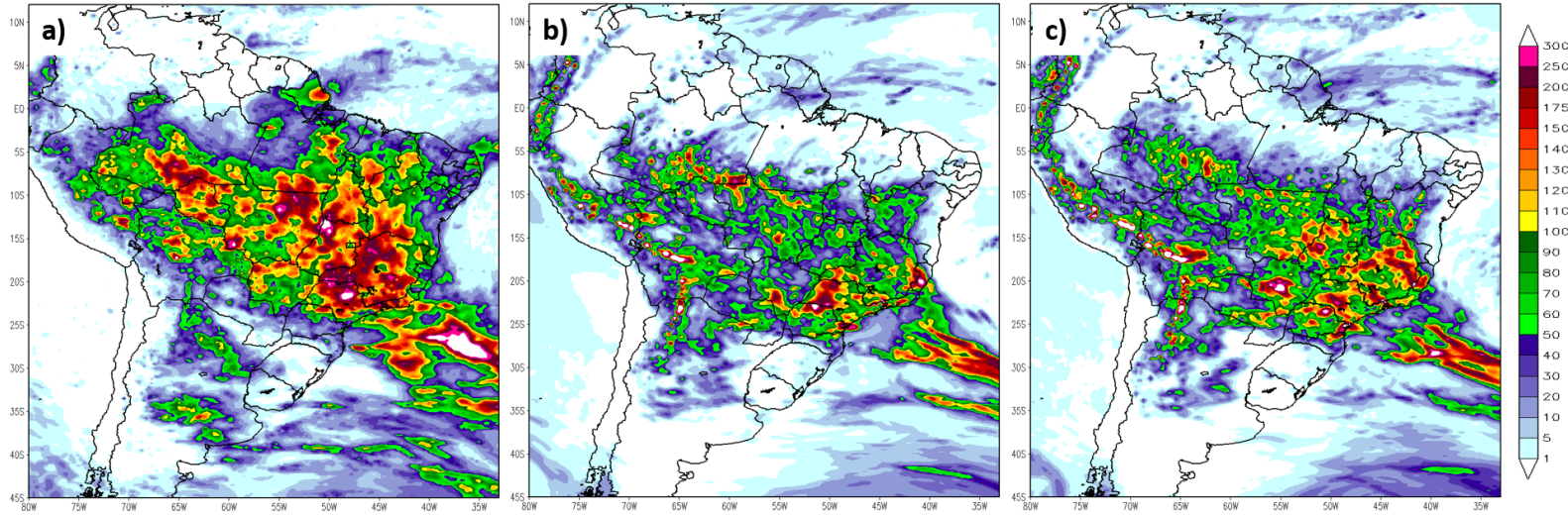

Figura 4.46: Precipitação acumulada $(\mathrm{mm})$ durante toda a atuação do sistema, pelos dados do(a) (a) MERGE; (b) simulação CTRL; (c) simulação GF.

O experimento GF (Figura 4.46 (c)), assim como o CTRL, também subestima os valores do MERGE. Porém, o acumulado durante todo o sistema ainda é superior ao representado pela simulação CTRL. As áreas com acumulados acima de $50 \mathrm{~mm}$ não aparecem de forma generalizada como no MERGE, mas ocorrem praticamente nas mesmas regiões. Neste experimento, as regiões com acumulados acima de $300 \mathrm{~mm}$ são o centro de MS, centro da Bolívia, Sul do Peru e Oceano Atlântico Subtropical.

No Nordeste brasileiro os experimentos mostram uma intensa subestimativa do acumulado total. A precipitação nesta região ocorre devido ao transporte de umidade gerado pelos alísios de nordeste e convecções locais, principalmente após o dia 13/01/2016, como mostrado na subseção a seguir.

\subsubsection{Acumulados Diários}

A precipitação acumulada durante o dia 11/01/2016 e a diferença entre os conjuntos de dados podem ser vistas na Figura 4.47. O MERGE (Figura 4.47(a)) apresenta valores superiores a $75 \mathrm{~mm}$ no sul do AM, a $100 \mathrm{~mm}$ na divisa entre PR e SP, a $125 \mathrm{~mm}$ no norte de MT e acumulados de menor valor em toda a região de atuação do JBN e fluxo de umidade mostrados nas seções anteriores. Ambos os experimentos (CTRL (Figura 4.47 (c)) e GF (Figura 4.47 (e))) representam a precipitação na divisa entre PR e SP de forma coerente ao MERGE, porém os valores da simulação CTRL são mais próximos ao observado, uma 
vez que a simulação GF apresenta um núcleo com acumulado superior a $300 \mathrm{~mm}$. No sul do AM e no norte do MT, os experimentos não mostram os altos acumulados observados no campo do MERGE.
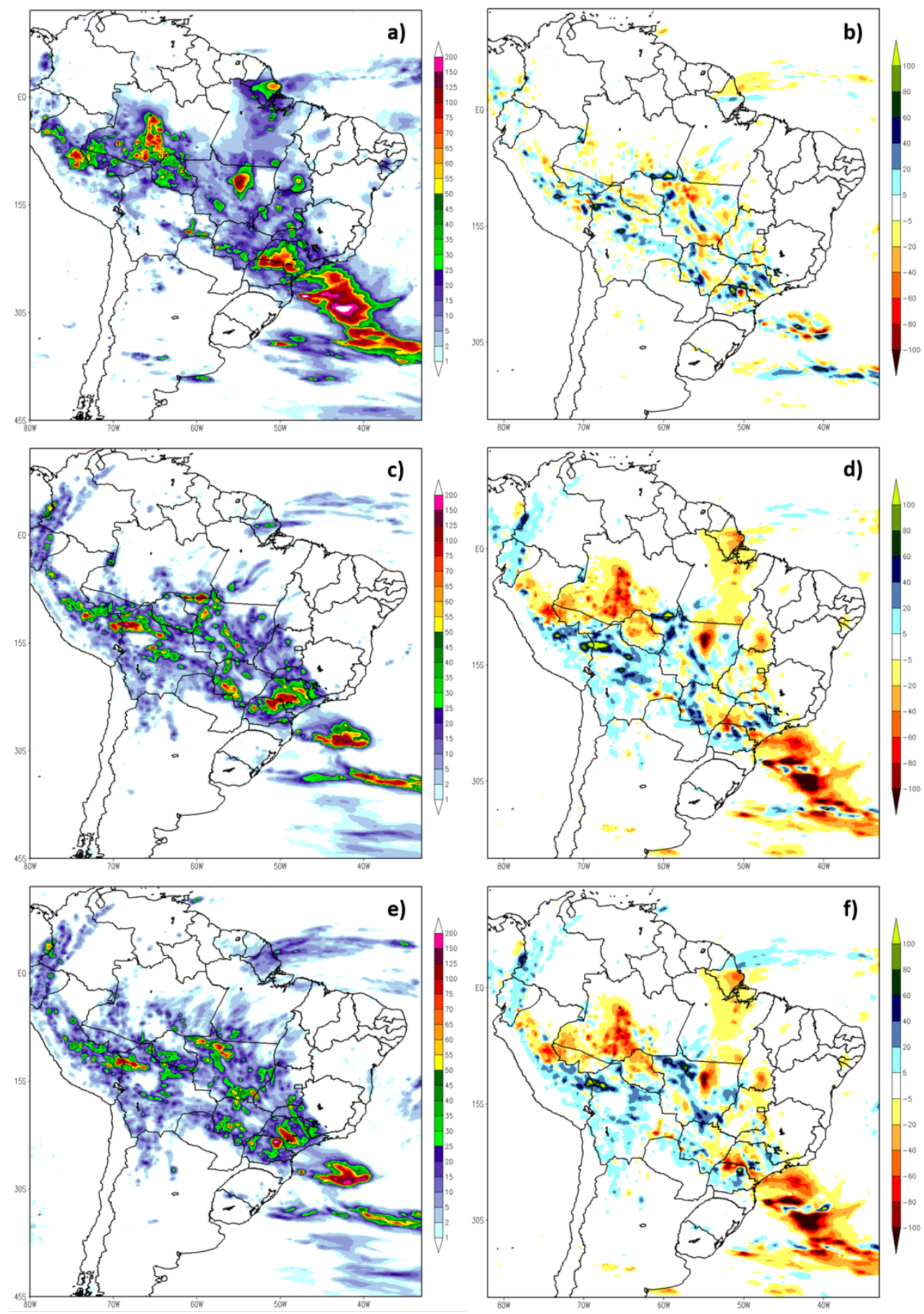

Figura 4.47: Acumulados diários de precipitação (mm) do dia 11/01/2016: a) MERGE; b) CTRL - GF; c) Simulação CTRL; d) CTRL - MERGE; e) Simulação GF; f) GF - MERGE.

O campo da diferença entre os experimentos e o MERGE (Figuras 4.47 (d) e (f), 
respectivamente CTRL e GF), confirma as divergências citadas anteriormente. Além disso, estes campos evidenciam uma defasagem na posição da chuva na região Norte, com os experimentos representando a chuva no Peru e Bolívia e não no sul do AM, concordando com as divergências na posição do JBN e fluxo de umidade entre as simulações e a análise mostradas anteriormente. O campo de diferença entre os experimentos (Figura 4.47 (b)) mostra que as simulações possuem um comportamento próximo entre si, uma vez que as diferenças aparecem somente no formato de núcleos esparsos.

A Figura 4.48 mostra a precipitação acumulada durante o dia 12/01/2016 e a diferença entre os conjuntos de dados. O MERGE (Figura 4.48 (a)) mostra os maiores valores sobre o estado de SP, com núcleos que chegam próximo a $100 \mathrm{~mm}$ e regiões com valores de aproximadamente $70 \mathrm{~mm}$ entre o oeste de MG e sudoeste do PA, mesma posição da convergência de massa mostrada pela análise do CFSv2. As simulações CTRL (Figura 4.48 (c)) e GF (Figura 4.48 (d)) apresentam um padrão que difere do observado, com precipitação intensa no sul do AM, norte de RO e oeste da divisa entre PR e SP, enquanto subestimam o acumulado de SP em aproximadamente $60 \mathrm{~mm}$.

Os campos de diferença entre as simulações e o MERGE (Figura 4.48 (d) e (f), respectivamente CTRL e GF) mostram que ambos os experimentos apresentam a chuva a sul e com valores muito abaixo do observado, exceto no sul do AM e norte de RO. Esse padrão da chuva a sul do observado, assim como no dia anterior, concorda com o JBN e fluxo de umidade das simulações acontecendo a sul da análise do CFSv2. No Norte do Brasil e oeste da divisa entre SP e PR, a superestimativa das simulações acontece na mesma região onde, no dia anterior, o MERGE mostra valores e posição similares, indicando uma possível defasagem temporal na chuva simulada pelos experimentos numéricos.

A precipitação acumulada durante o dia 13/01/2016 é mostrada na Figura 4.49, assim como o comparativo entre os conjuntos de dados. O MERGE (Figura 4.49 (a)) mostra os maiores acumulados ocorrendo em duas principais regiões, a primeira sendo na divisa oeste entre SP e MG, com valores próximos de $70 \mathrm{~mm}$, e a segunda região abrangendo o estado de TO, sul do CE e do Maranhão (MA) e leste do Pará com máximos de 75 a 100 mm. A posição destes núcleos coincidem com os mesmos pontos onde os campos sinóticos do CFSv2 mostram as regiões de máxima convergência de massa em 850 hPa, movimento ascendente em 500 hPa e divergência em 200 hPa, mas não com a área sob efeito de intenso fluxo de umidade (Figura 4.37 (c)). 

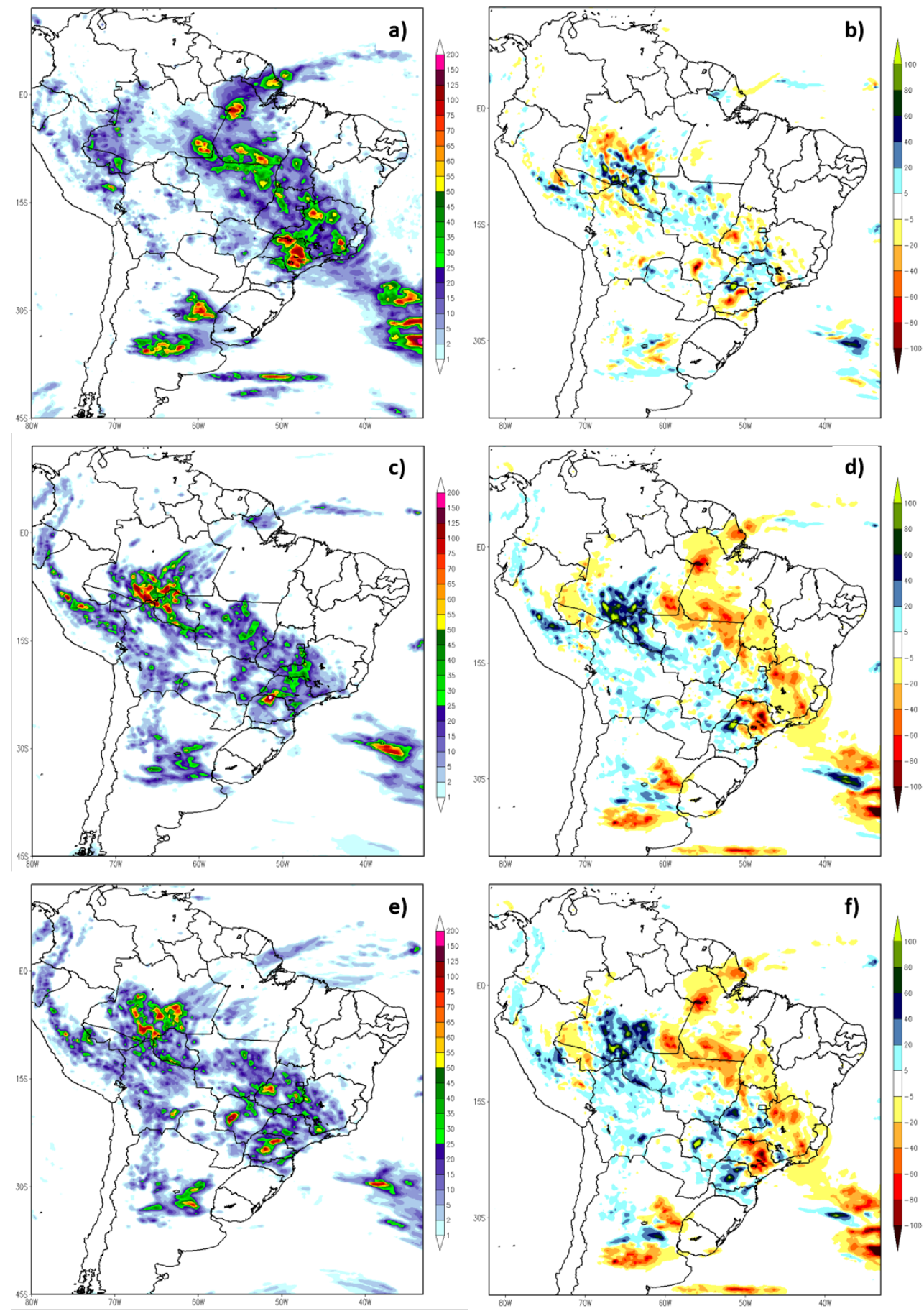

Figura 4.48: Mesmos campos da Figura 4.47 porém para o dia 12/01/2016.

A precipitação acumulada pelas simulações CTRL (Figura 4.49 (c)) e GF (Figura 4.49 (e)) divergem do mostrado pelo MERGE, com a região de máxima precipitação localizada desde o oeste de SP até o norte da Argentina e o noroeste de MT. Os máximos da simulação CTRL ficam entre 150 e 200 mm no oeste de SP, enquanto os da simulação GF em torno de $75 \mathrm{~mm}$ no noroeste do PR e Bolívia. Ambas as simulações não apresentam acopla- 
mento vertical em parte do Norte e Nordeste do Brasil, explicando a menor quantidade de precipitação em relação ao observado.
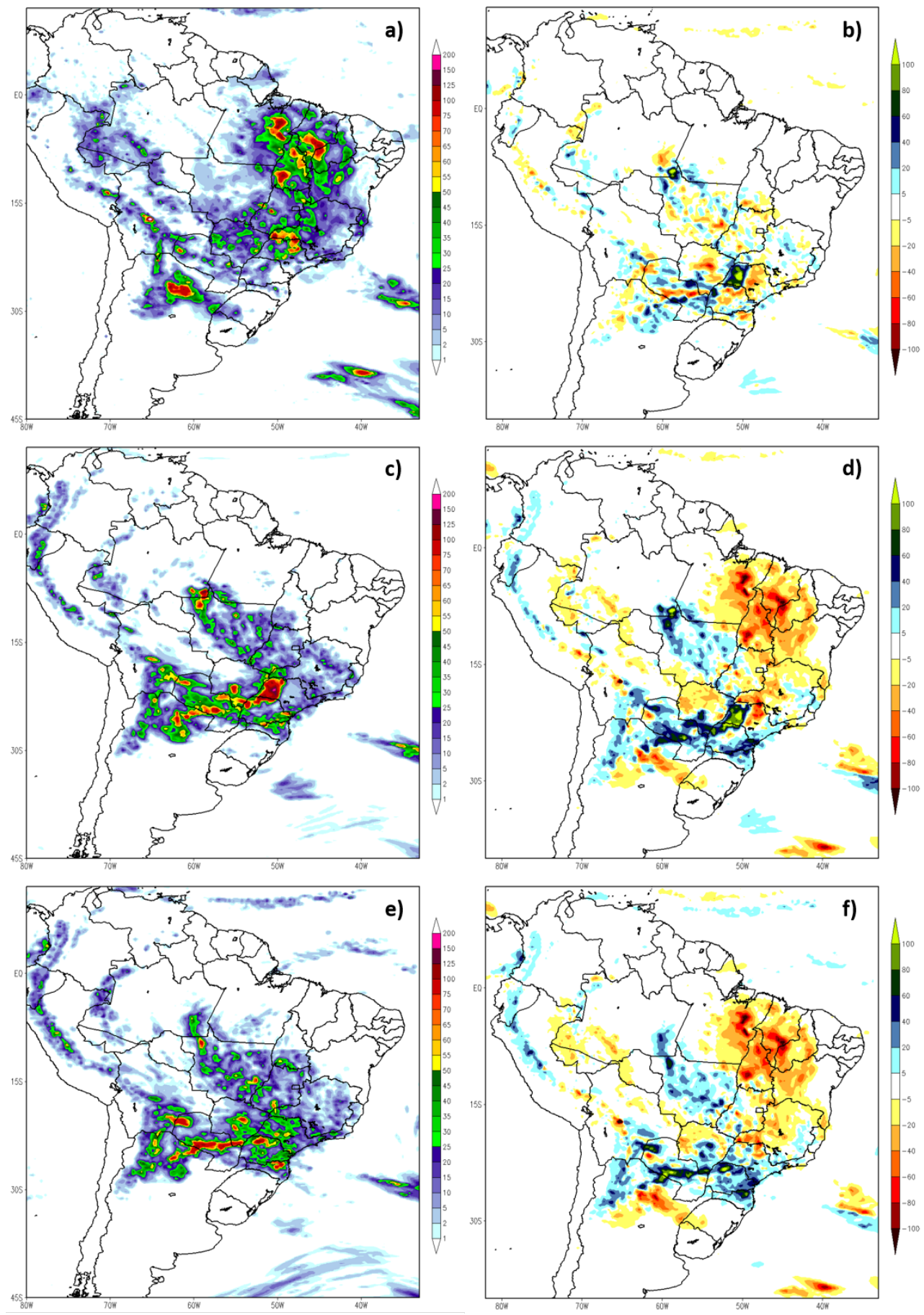

Figura 4.49: Mesmos campos da Figura 4.47 porém para o dia 13/01/2016.

A diferença entre a simulação CTRL e o MERGE (Figura 4.49 (d)) apresenta um núcleo com mais de $100 \mathrm{~mm}$ no oeste de SP e valores positivos que se estendem deste 
ponto até outras duas regiões, o norte da Argentina e o noroeste de MT, indicando que o experimento superestima a chuva nestas regiões. Valores negativos são observados no MS e entre MG e o litoral norte do Brasil, sendo que esta subestimativa pode ser explicada pelas diferenças entre as simulações e a análise do CFSv2 em relação aos campos sinóticos, área de atuação do JBN e fluxo de umidade. Isto ocorre, pois no Norte e Nordeste do Brasil não existe o intenso acoplamento vertical observado pelo CFSv2, enquanto o JBN e o fluxo de umidade acontecem a sul da posição da análise. Estas diferenças entre os campos da simulação CTRL e o CFSv2 também foram observadas no experimento GF e, por isso, a diferença na precipitação acumulada (Figura 4.49 (f)) apresenta o mesmo padrão do experimento CTRL, diferindo somente na intensidade da chuva. O campo de diferença entre as simulações (Figura 4.49 (b)) evidencia que o padrão apresentado por ambos os conjuntos é semelhante, com a maior diferença no oeste de SP, sendo que os valores superiores a $100 \mathrm{~mm}$ indicam um maior acumulado gerado pelo experimento CTRL.

Os acumulados de precipitação para o dia 14/01/2016 são exibidos na Figura 4.50. Vale salientar que a partir desta data os processos convectivos passaram a ser representados pelas parametrização de cada uma das simulações. O campo do MERGE (Figura 4.50 (a)) apresenta máximos de precipitação superiores a $150 \mathrm{~mm}$ na Bolívia e valores acima de $30 \mathrm{~mm}$ entre esta região e o nordeste de MT e noroeste de GO, com picos de $75 \mathrm{~mm}$ nessa área. Estes máximos ocorrem na mesma região da máxima intensidade do fluxo de umidade mostrado pelo CFSv2. Outros núcleos isolados são observados no Nordeste, Centro-Oeste e Sudeste do Brasil, devido à convecção local. Tanto o experimento CTRL (Figura 4.50 (C)) quanto o GF (Figura 4.50 (e)) representam a chuva de forma isolada, distribuídas preferencialmente em duas regiões: a primeira entre a Bolívia e o leste de MS e a segunda entre o nordeste do MT e o a região central de MG, convergindo com as regiões de intenso acoplamento vertical.

Os campos de diferença entre os acumulados das simulações CTRL e GF e o observado do MERGE (respectivamente, Figuras 4.50 (d) e (f)) explicitam a subestimativa dos experimentos, com valores negativos em praticamente toda a área das regiões Norte, Nordeste, Centro-Oeste e Sudeste, com somente alguns núcleos isolados apresentando valores positivos. O campo de diferença entre as simulações (Figura 4.50 (b)) mostra que os padrões representados pelos experimentos são próximos, com pequenas divergências no 
posicionamento dos núcleos isolados de precipitação.
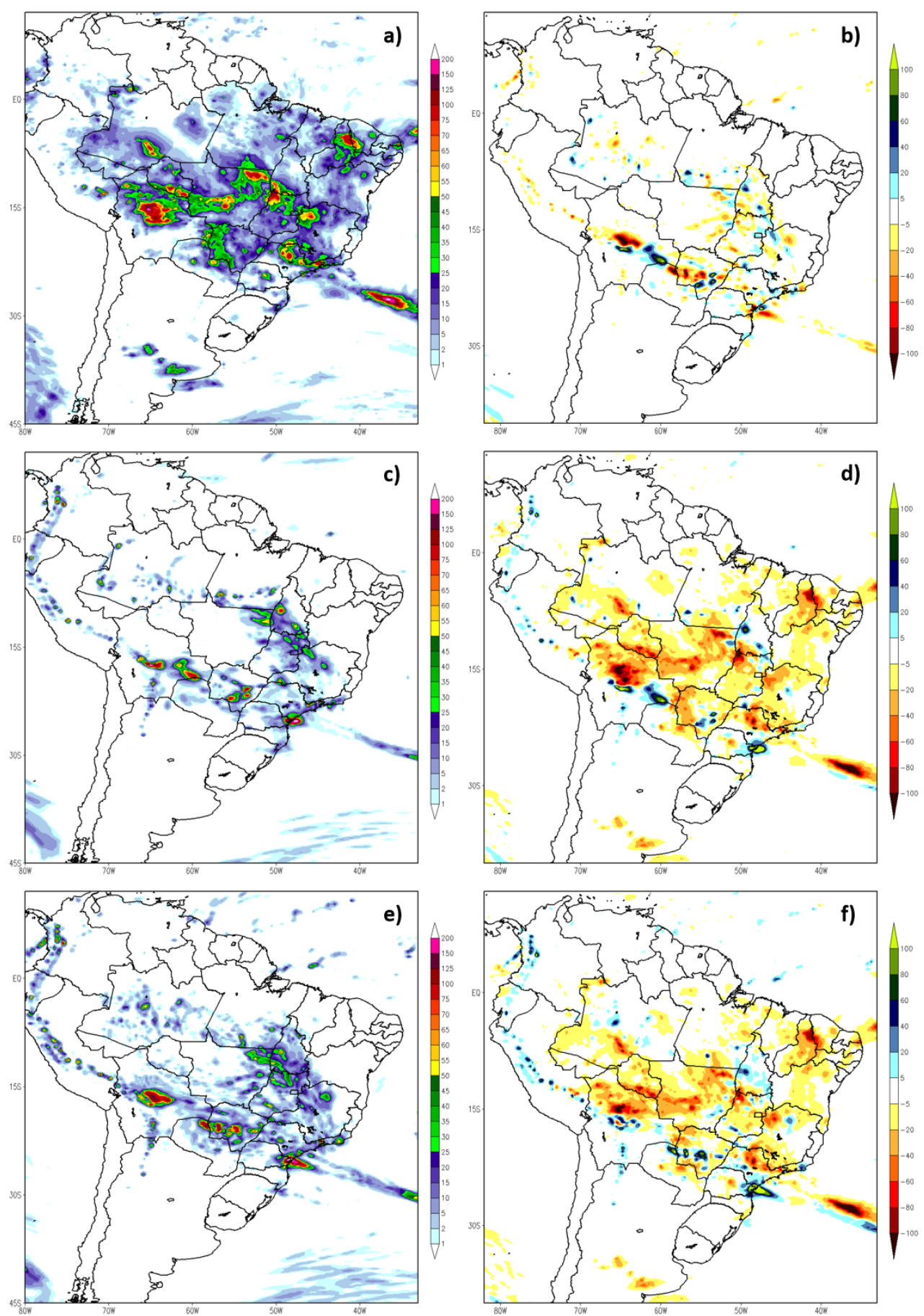

Figura 4.50: Mesmos campos da Figura 4.47 porém para o dia 14/01/2016. 

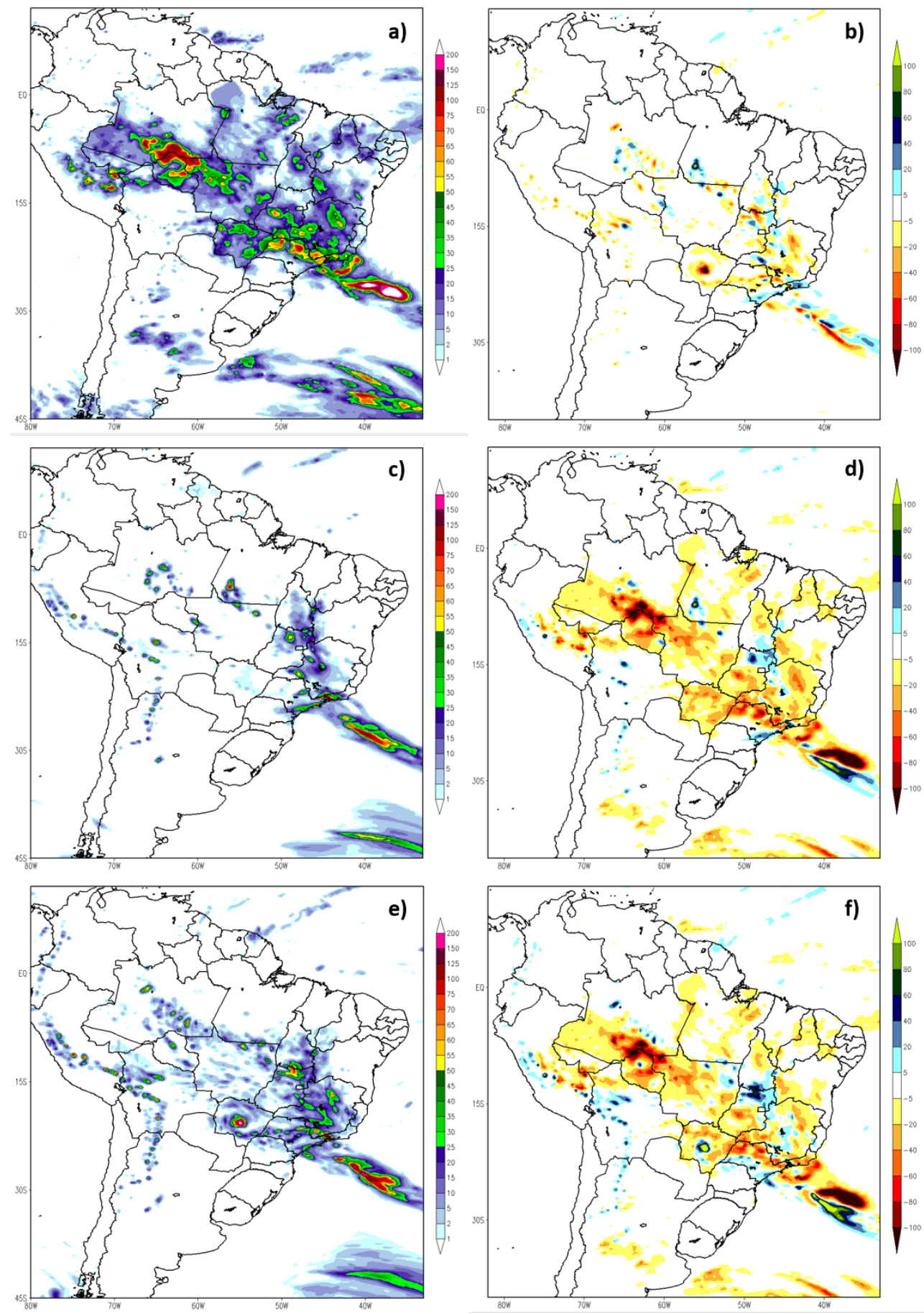

Figura 4.51: Mesmos campos da Figura 4.47. porém para o dia 15/01/2016.

No dia 15/01/2016, os campos sinóticos e o fluxo de umidade ficam bem organizados, refletindo na precipitação observada pelo MERGE (Figura 4.51 (a)). Os maiores acumulados são observados entre o sul do AM e a divisa entre SP e RJ, chegando a valores superiores a $100 \mathrm{~mm}$ na divisa entre RO e AM. Por outro lado, as simulações CTRL e GF (respectivamente, Figuras 4.51 (c) e (e)), mostram valores de precipitação acumulada 
muito inferiores, uma vez que seguem o padrão sinótico do CFSv2 somente entre o leste de SP e o nordeste de GO, onde existe uma maior concordância entre a chuva observada pelo MERGE e o simulado pelos experimentos. Esta divergência entre as simulações e o CFSv2 são confirmadas nos campos de diferenças entre os experimentos CTRL e GF e a análise (Figuras 4.51 (d) e (f), respectivamente), com valores negativos em praticamente todo o Brasil, mas ocorrendo com maior intensidade entre o sul do AM e a divisa entre SP e RJ. A Figura 4.51 (b) exibe uma pequena diferença entre os modelos, com valores negativos sobre o MS, indicando que a simulação GF tem maiores acumulados que a CTRL nesta região, onde o experimento simula o vórtice ciclônico de forma mais intensa.

O total de precipitação acumulada durante o dia 16/01/2016 e a diferença entre os conjuntos de dados é exibida nos campos da Figura 4.52. Os maiores acumulados observados pelo MERGE (Figura 4.52 (a)) localizam-se entre o nordeste do MT e o sudeste de MG, com máximos acima de $75 \mathrm{~mm}$. As simulações CTRL (Figura 4.52 (c)) e GF (Figuras 4.52 (e)), novamente subestimam os valores observados, com os maiores acumulados no sudeste chegando a $70 \mathrm{~mm}$ e valores inferiores a $25 \mathrm{~mm}$ entre esta região e o nordeste de MT. Os campos de diferença entre as simulações e o observado (Figuras 4.52 (d) e (f)) apresentam valores negativos em praticamente todo o território brasileiro, comprovando a subestimativa das simulações quanto ao observado pelo MERGE. O campo de diferença entre os experimentos (Figura 4.52 (a)), mostra pequenas variações entre as simulações, uma vez que os padrões de chuva são próximos uns dos outros e os acumulados são baixos.

Durante o dia 17/01/2016, a precipitação acumulada observada pelo MERGE (Figura 4.53 (a)) apresenta, entre o sudeste de MG e o sul do MA e PI, valores superiores a 25 mm e núcleos de $75 \mathrm{~mm}$ e, entre o sudeste de MG e o sudoeste do AM, uma área com acumulados inferiores espacialmente em fase com a região de atuação do JBN e fluxo de umidade mostrados pelo CFSv2. Os campos de precipitação acumulada das simulações CTRL (Figura 4.53 (c)) e GF (Figura 4.53 (e)) mostram divergências quanto ao observado, principalmente nas regiões Norte e Centro-Oeste do Brasil, onde a precipitação acumulada pelo experimento GF é baixa e no experimento CTRL é praticamente nula. Nas Regiões Nordeste e parte do Sudeste do Brasil, existem algumas divergências quanto à posição e intensidade da chuva, mas os padrões representados pelas simulações se aproximam do observado, devido à simulação de médios e altos níveis próxima ao apresentado pela análise do CFSv2. 

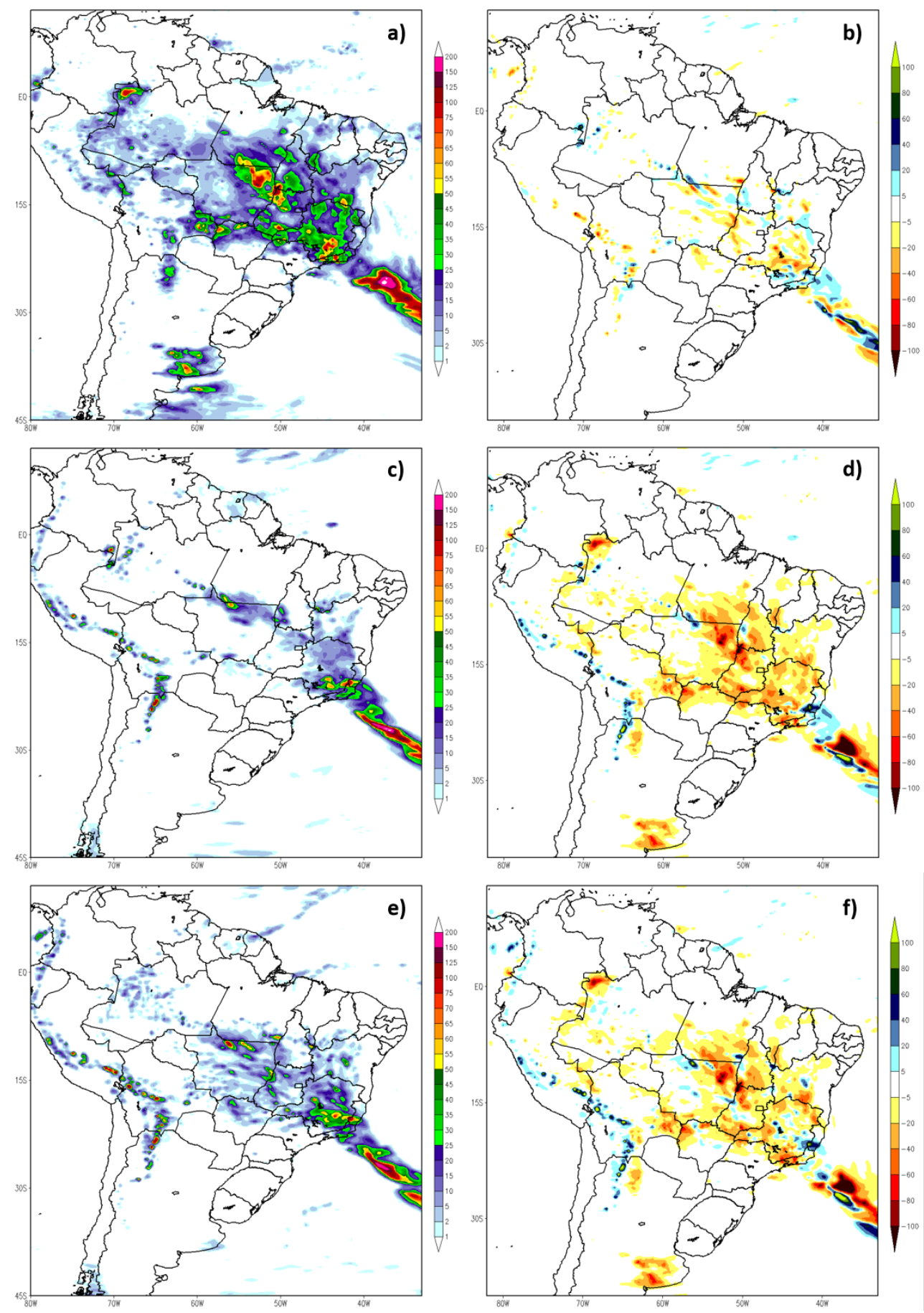

Figura 4.52: Mesmos campos da Figura 4.47 porém para o dia 16/01/2016.

A diferença entre a simulação CTRL e o MERGE (Figura 4.53 (d)) exibe valores negativos nas regiões Norte, Centro-Oeste e parte do Sudeste do Brasil e evidenciam a subestimativa do experimento quanto ao observado, sendo que valores positivos acontecem somente entre o ES e o oeste da BA, região onde os experimentos mais concordam com o observado. O campo de diferença entre a precipitação acumulada pela simulação GF 
e o MERGE (Figura 4.53 (f)) mostra o mesmo padrão da simulação CTRL, porém os valores negativos no Brasil central possuem magnitude inferior, indicando uma melhor representação do observado por parte deste experimento.
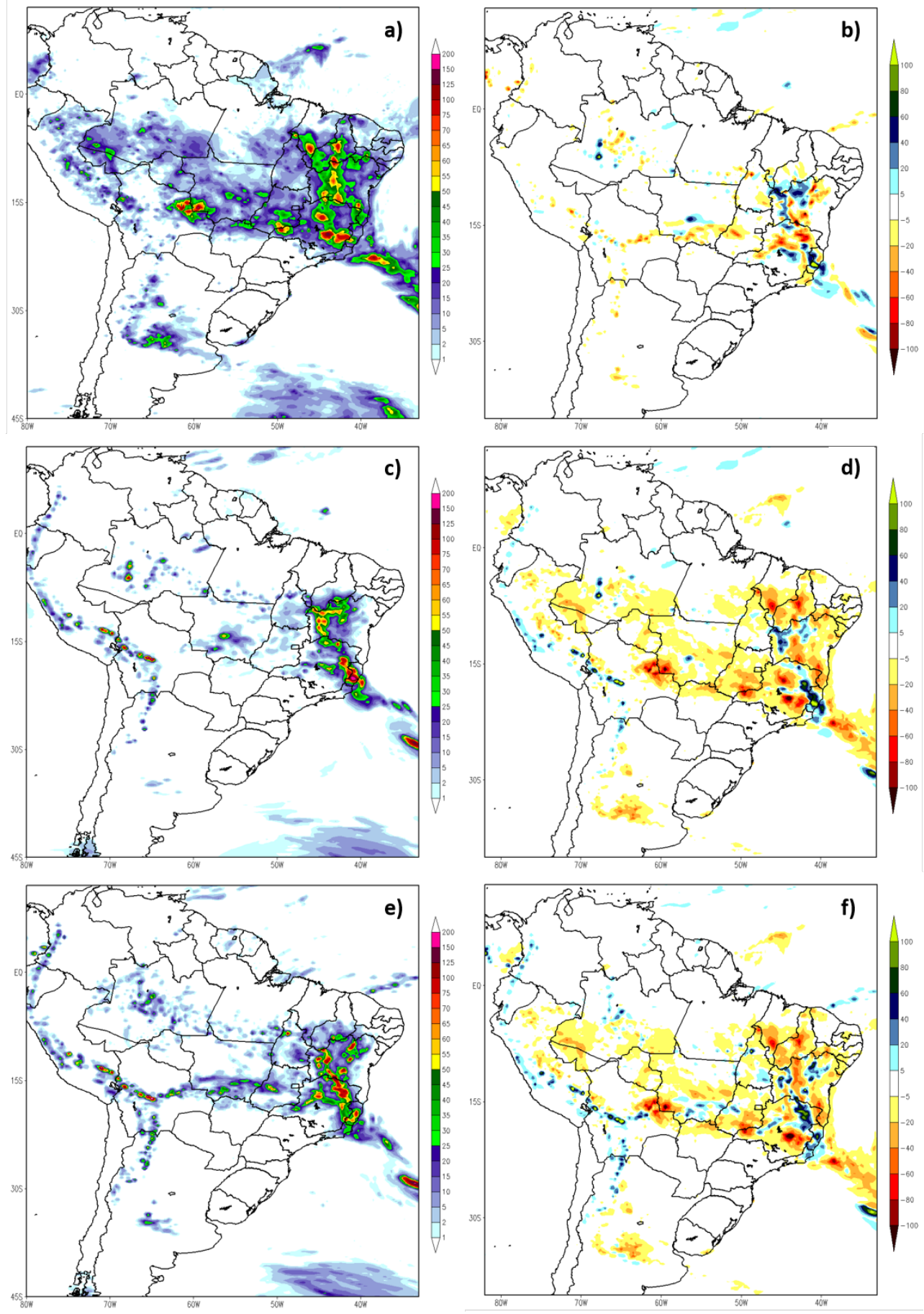

Figura 4.53: Mesmos campos da Figura 4.47 porém para o dia 17/01/2016.

A diferença entre as duas simulações (Figura 4.53 (b)) confirma, no Centro-Oeste brasi- 
leiro, maiores acumulados no experimento GF ao apresentar valores negativos. Entre o ES e o sul do PI, o padrão de chuva é similar, porém existe uma discordância na posição dos núcleos de máxima precipitação dos modelos, com valores negativos e positivos isolados.
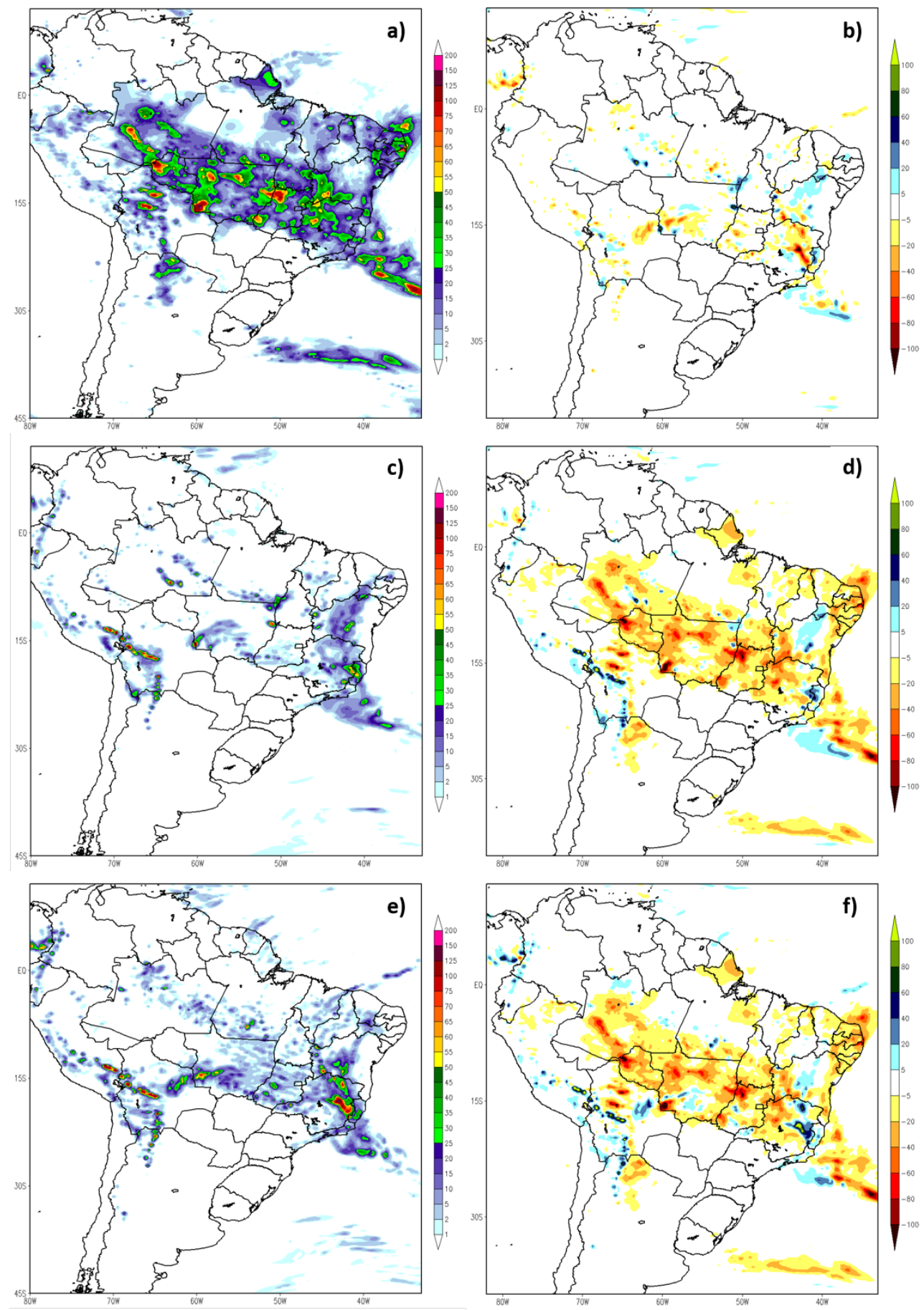

Figura 4.54: Mesmos campos da Figura 4.47 porém para o dia 18/01/2016.

A precipitação acumulada no dia 18/01/2016 é mostrada na Figura 4.54, onde os dados 
do MERGE (Figura 4.54 (a)) mostram núcleos de intensidade superior a $70 \mathrm{~mm}$ embebidos em uma área com precipitação inferior a $25 \mathrm{~mm}$ entre o ES e o oeste do AM, sendo esta a região mais dinamicamente instável segundo o CFSv2. Os campos de precipitação acumulada da simulação CTRL (Figura 4.54 (c)) e a diferença com o MERGE (Figura 4.54 (d)) mostram uma grande subestimativa em praticamente todo o território brasileiro, uma vez que acumulados superiores a $10 \mathrm{~mm}$ ocorrem somente entre o norte da BA e a região central de MG e pontos extremamente isolados em parte do Centro-Oeste e Norte do Brasil. Assim como na simulação CTRL, os campos das Figuras 4.54 (e) e (f) mostram que o experimento GF subestima a chuva observada em praticamente todo o Brasil, sendo que somente no nordeste de MG esta foi simulada acima do observado. O padrão da precipitação simulada apresenta similaridades ao MERGE, localizada entre o ES e o noroeste do AM, porém com magnitude inferior. Devido à predominância de valores negativos, a diferença entre os experimentos (Figura 4.54 (b)) indica que a simulação GF apresenta maior intensidade na chuva acumulada no dia, com valores intermediários aos demais conjuntos de dados.

Os campos de precipitação diária mostradas pelo MERGE apresentam a constante formação de precipitação tanto na região de atuação do fluxo de umidade associado ao JBN quanto no gerado pelos alísios de nordeste e a circulação da ASAS. Além disto, também é possível notar os maiores acumulados ocorrendo nas regiões onde as duas circulação se encontram, gerando convergência de massa, levantamento de ar úmido e consequente formação de precipitação.

Com exceção do dia 13/01/2016, onde as simulações não captaram o padrão de chuva observado pelo MERGE, a posição dos núcleos de precipitação dos experimentos numéricos se aproxima do observado, porém com intensidade reduzida, principalmente entre os dias 14 e 18/01/2016, período em que a convecção foi resolvida através da parametrização cúmulos respectiva de cada uma das simulações. Em uma primeira análise, a parametrização GF foi a que mais se assemelhou ao MERGE, com acumulado superior a precipitação resultante do experimento CTRL.

Os campos exibidos na análise sinótica mostram uma subestimativa no movimento ascendente em 500 hPa e na divergência de massa em $200 \mathrm{hPa}$, principalmente após o dia 13/01/2016. Uma hipótese é de que esta subestimativa aconteça devido ao movimento subsidente compensatório gerado pela atuação das parametrizações cúmulus. O amorteci- 
mento destes movimentos diminui o acoplamento vertical na região de atuação da ZCAS, fazendo com que o transporte de umidade dos níveis mais baixos para os mais altos da atmosfera seja subestimado, o que resulta numa menor formação de chuva. Este mecanismo é tratado de forma diferenciada pelas parametrizações utilizadas em cada um dos experimentos, sendo que a simulação GF ameniza este efeito distribuindo o movimento subsidente compensatório para os pontos de grade vizinhos, explicando a sua maior proximidade com o observado pelo MERGE.

\subsubsection{Séries Temporais e Testes de Erro}

Realizando uma média nas áreas previamente determinadas e plotando a série temporal dos resultados, obtém-se os gráficos da Figura 4.55, que permitem uma análise mais aprofundada do comportamento da chuva ao longo da atuação da ZCAS em cada um dos conjuntos de dados.

Na área 1, entre o dia 11/01/2016 e a manhã do dia 13/01/2016, mesmo que os experimentos estejam superestimando a precipitação acumulada, o padrão de redução apresentado pela análise é corretamente simulado pelo modelo regional, assim como o pico de precipitação às 0000 UTC do dia 13/01/2016, com 3 mm observado pelos conjuntos de dados do MERGE e simulação CTRL e 5 mm na simulação GF. Durante o dia 14/01/2016 é observada a maior diferença entre as simulações e MERGE, com os valores máximos sendo de $7 \mathrm{~mm}$ às 1200 UTC, da simulação CTRL 3 mm também às 1200 UTC e 2 mm às 0000 UTC do dia 15/01/2016 pelo experimento GF. Entre os dias 15/01/2016 e 18/01/2016 a precipitação média na área 1 apresenta um aumento de 2 para $6 \mathrm{~mm}$ com variações entre pontos de máxima intensidade ao longo do tempo, aumento representado pelos experimentos com menor intensidade e picos de máximo acumulado acontecendo somente na simulação GF.

O segundo gráfico da Figura 4.55 apresenta a série temporal na área 2, com o observado do MERGE exibindo um aumento no acumulado médio entre os dias 11/01/2016 com aproximadamente $2 \mathrm{~mm}$ e o dia 14/01/2016 com mais de $8 \mathrm{~mm}$. Entre os dias 11/01/2016 e 13/01/2016 as simulações CTRL e GF apresentam evoluções próximas do observado, porém o acumulado é inferior durante praticamente todo este período, inclusive no dia 14/01/2016, quando a diferença é maior e os experimentos subestimam em $4 \mathrm{~mm}$ o valor observado. Durante o dia 15/01/2016, como é possível notar no campo espacial, a preci- 
pitação observada nesta área diminui, e os experimentos apresentam valores próximos ao MERGE até o dia 16/01/2016, quando ocorre a chuva de maior intensidade na área, com o observado ultrapassando $10 \mathrm{~mm}$ e os experimentos com valores inferiores a $3 \mathrm{~mm}$. Como também é possível notar nos campos espaciais da seção anterior, as simulações representam a chuva nesta região de forma próxima ao observado durante o dia 17/01/2016 e voltam a subestimar no dia 18/01/2016, padrões que podem ser confirmados no gráfico em questão.
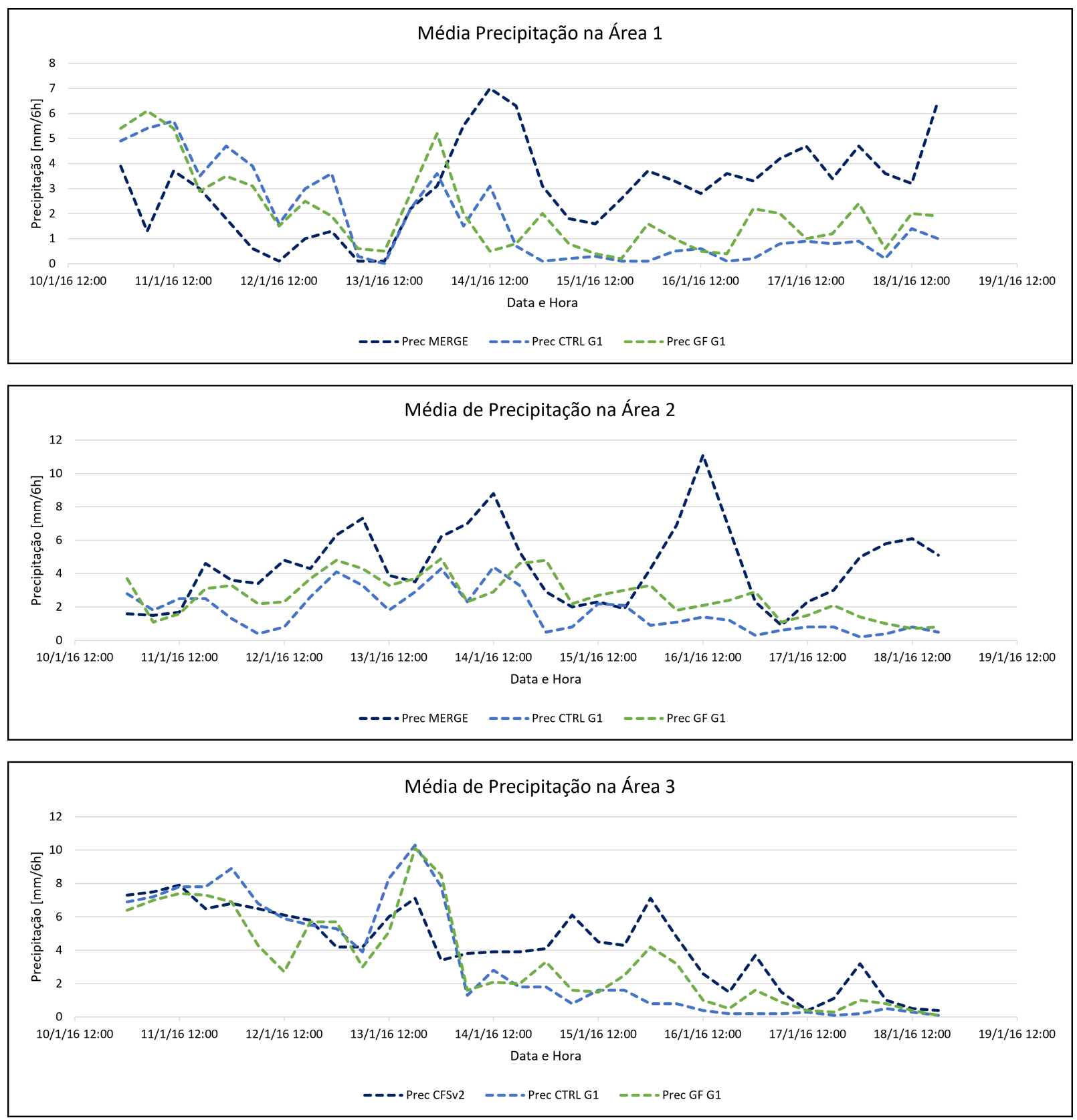

Figura 4.55: Série temporal da média de precipitação acumulada na área, utilizando os dados do CFSv2, CTRL e GF na grade 1. 


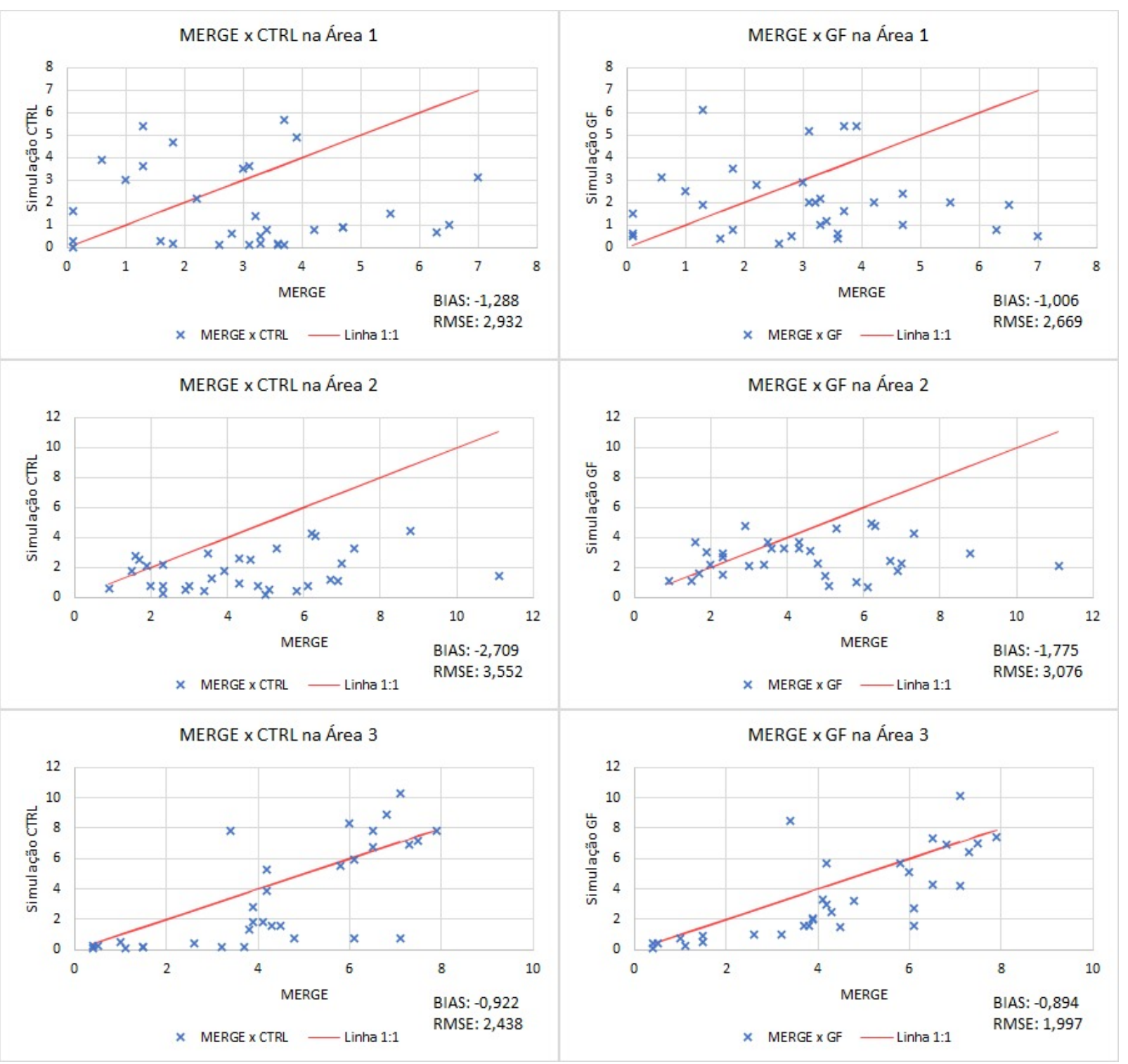

Figura 4.56: Gráfico de dispersão entre a precipitação média observada pelo MERGE e o resultado da grade 1 das simulações CTRL e GF nas áreas 1, 2 e 3.

A área 3 abrange parte do Sudeste, Centro-Oeste e norte do Sul do Brasil, e a evolução temporal da precipitação durante a atuação do sistema (Figura 4.55 responde aos campos espaciais, com os maiores acumulados acontecendo entre os dias 11 e 13 de janeiro de 2016, e posterior redução na precipitação média após esta data, devido ao deslocamento do sistema para menores latitudes. Nestes primeiros dias os experimentos são uma boa representação do observado, com valores que variam em torno do MERGE, enquanto a partir do dia 14/01/2016 a simulação GF, apesar de apresentar picos de intensificação e desintensificação coerentes, subestima o observado. A simulação CTRL, a partir do dia 14/01/2016, exibe os menores valores de precipitação, não ultrapassando 3 mm em nenhum 
momento.

Para uma verificação da assertividade dos experimentos numéricos foram feitos testes de BIAS e RMSE para a precipitação média nas 3 áreas durante toda a atuação do sistema. Estes resultados são exibidos nos gráficos de dispersão da Figura 4.56.

Na área 1, a simulação CTRL (GF) apresenta -1,287 (-1,006) de BIAS e 2,932 (2,669) de RMSE, resultados que indicam uma tendência dos experimentos subestimarem a precipitação média nos valores do RMSE, o que representa grande parte da precipitação observada, uma vez que o máximo exibido pelo MERGE foi de $7 \mathrm{~mm}$. Na área 2, a tendência é de que as simulações subestimem a chuva, uma vez que a grande maioria dos pontos no gráfico de dispersão estão abaixo da linha de máxima assertividade, com BIAS de -2,709 e -1,775 e RMSE de 3,552 e 3,076 nas simulações CTRL e GF, respectivamente. O mesmo padrão continua na área 3, com a simulação CTRL (GF) apresentando BIAS de -0,922 $(-0,894)$ e RMSE de 2,438 (1,997), os menores valores entre todas as áreas, indicando uma maior assertividade das simulações.

As séries temporais mostram que os experimentos CTRL e GF mais se aproximam do observado pelo MERGE durante os 3 primeiros dias do sistema, onde estavam ativas as 3 grades e os processos convectivos foram calculados explicitamente. Sendo assim, foram feitos testes de BIAS e RMSE somente durante estes 3 dias e os resultados são exibidos na Tabela 4.1. Na área 1, a simulação CTRL (GF) apresentou BIAS de 1,642 (1,425) indicando uma tendência de superestimativa, diferente do observado no período todo das simulações. Os valores de RMSE de 2,101 $(1,886)$, aproximadamente $0,5(0,8)$ menor que o valor obtido durante toda a atuação da ZCAS, demonstram que durante o período em que a grade 3 estava ativa a assertividade dos experimentos foi maior.

Tabela 4.1 - BIAS e RMSE da precipitação simulada por ambos os experimentos entre os dias 11 e 13/01/2016.

\begin{tabular}{c|cc|cc}
\hline \hline & \multicolumn{2}{|c}{ Sim CTRL } & \multicolumn{2}{c}{ Sim GF } \\
Áreas & BIAS & RMSE & BIAS & RMSE \\
\hline \hline Área 1 & 1,642 & 2,101 & 1,425 & 1,886 \\
Área 2 & $-1,642$ & 2,334 & $-0,783$ & 1,489 \\
Área 3 & 0,725 & 1,397 & $-0,358$ & 1,630 \\
\hline \hline
\end{tabular}

Os valores de BIAS na área 2 mostram que a tendência das simulações subestimarem o 
observado também acontece neste período, uma vez que os valores obtidos foram de -1,642 para a simulação CTRL e -0,783 para a simulação GF. O erro representado pelo RMSE nesta área, assim como na área 1, foi menor do que o simulado durante todo o período de atuação do sistema, com a simulação CTRL (GF) apresentando o valor de 2,334 $(1,489)$ nos 3 primeiros dias, uma melhora de aproximadamente 35\% (52\%). Estes resultados mostram uma melhor representação da chuva pelas simulações durante o período em que a grade com maior resolução estava ativa, com melhores resultados observados na simulação GF.

$\mathrm{Na}$ área 3 os resultados obtidos no cálculo do erro durante os 3 primeiros dias do experimento da simulação CTRL (GF) são de 0,725 (-0,358) e 1,397 (1,630) para o BIAS e RMSE, respectivamente, indicando que o experimento superestima (subestima) os valores observados. O RMSE, assim como nas áreas anteriores, mostra, neste período, valores de precipitação das simulações mais próximos ao observado, com uma melhora de aproximadamente $42 \%$ e $19 \%$ para os experimento CTRL e GF, respectivamente. 
Capítulo 5

\section{Conclusões}

\subsection{Considerações Finais}

Ao longo dos últimos anos reconheceu-se a importância do fenômeno JBNAS na formação de Complexos Convectivos de Mesoescala, que afetam principalmente o norte da Argentina, o sul do Paraguai e a parte oeste dos estados do RS e SC, com menor influência nas áreas adjacentes. Ainda, apesar de ter seus efeitos no transporte de umidade reconhecidos durante eventos de ZCAS, poucos estudos se aprofundaram no tema. Desta forma, o principal objetivo deste trabalho foi determinar a importância do vapor d'água transportado pelo JBNAS para a formação da precipitação durante um evento ZCAS. Para atingir este objetivo, foram realizados estudos por meio de análises globais e simulações regionais com o modelo WRF através de um estudo de caso do evento ZCAS observado na Região Sudeste do Brasil entre 11 e 18 de janeiro de 2016.

De forma geral, os resultados mostraram que o modelo WRF, especificamente para as configurações definidas para este estudo, simulou grande parte dos aspectos físicos encontrados nas análises do modelo global CFSv2 que, em conjunto com imagens de satélite GOES-13 e produtos de precipitação também obtidos por satélite, foram usadas como referência para a determinação das características físicas da atmosfera durante o período ZACS. Também de forma geral, as diferenças encontradas entre os campos simulados e as análises do CFSv2 devem-se principalmente ao posicionamento das células e pequenos sistemas convectivos simulados. Estas diferenças explicaram uma parte considerável da defasagem encontrada entre os campos de precipitação acumulada em superfície entre as simulações e o produto MERGE, do CPTEC/INPE.

Os resultados específicos mais importantes estão relacionados a seguir: 
1. Os campos horizontais do transporte do fluxo de umidade integrado na vertical mostraram o papel fundamental dos ventos alísios de nordeste que provêm do Oceano Atlântico tropical na intensificação do transporte de umidade pelo JBNAS em direção à Região Sudeste neste evento ZCAS. Neste sentido, verificou-se que a interrupção deste fluxo de umidade de componente meridional antecede a desintensificação do transporte de umidade pelo JBNAS.

2. Os dias com maior intensidade do JBNAS (11 a 13/01/2016) também foram os que apresentaram os maiores valores de fluxo de umidade entre a região amazônica e o Sudeste Brasileiro, complementando a conclusão apresentada no item anterior e realçando a importância do JBNAS no transporte de vapor d'água durante a atuação da ZCAS.

3. Os gráficos de série temporal da média do transporte de umidade integrado entre 900 e $700 \mathrm{hPa}$ mostraram um ciclo diurno bem pronunciado, principalmente na região de atuação do JBNAS. Este apresenta os maiores (menores) valores próximo às 1200 UTC (0000 UTC), momentos em que também se verificou uma maior (menor) intensidade do JBN pelos campos do corte vertical.

4. A série temporal da precipitação em associação com a de fluxo de umidade, ambas médias nas áreas predeterminadas, indicaram algumas associações entre as variáveis: Na área 1, a intensificação (enfraquecimento) do fluxo de umidade gerou uma diminuição (aumento) da precipitação nesta mesma região; Na área 2 o comportamento é similar ao da área 1, porém com uma menor variação da intensidade do fluxo de umidade; Na área 3 o fluxo de umidade e a intensidade da precipitação mostraram uma correspondência direta, sendo um exemplo disto o ocorrido no dia 13/01/2016, onde o fato de as simulações terem superestimado o fluxo de umidade em relação ao CFSv2 resultou em valores de precipitação acima do observado pelo MERGE.

De um modo geral, os sistemas sinóticos que compõem a ZCAS foram bem representados tanto pela simulação CTRl quanto pela simulação GF. As diferenças entre posicionamento e intensidade da AB, VCAN do Nordeste, frente fria, cavado em níveis médios e vórtice ciclônico em baixos níveis são pequenas, tanto numa comparação entre os experimentos numéricos quanto em relação a análise do CFSv2. Entretanto, numa análise 
mais aprofundada, ressaltaram-se algumas diferenças: tanto a velocidade do vento quanto o fluxo de umidade das simulações regionais com o WRF mostraram defasagens espaciais e, em alguns momentos, na intensidade em relação ao representado pelo CFSv2. Porém, entre as simulações as diferenças entre os resultados destas variáveis foram pequenas.

A velocidade vertical em 500 hPa e a divergência de massa em 200 hPa foram variáveis subestimadas pelas simulações, quando comparadas ao CFSv2. Esta diferença foi observada durante todo o período das simulações, porém aconteceu com maior intensidade a partir do dia 14/01/2016, indicando que o desligamento das grades 2 e 3 pode estar relacionado com esta variação nos resultados. As parametrizações cúmulos simulam o mecanismo de subsidência compensatória, que inibe os movimentos ascendentes nos pontos de grade onde este processo é ativado. A hipótese aqui levantada é de que esta subsidência gerada pelas parametrizações cúmulos tenham influenciado nos resultados, diminuindo o acoplamento vertical e resultando nos baixos acumulados de precipitação apresentados por ambos os experimentos numéricos. A parametrização de Grell-Freitas distribui a subsidência compensatória nos pontos de grade vizinhos onde o processo é ativado, o que explica os acumulados gerados por este experimento estarem mais próximos do observado pelo esquema MERGE. Este melhor desempenho da parametrização de Grell-Freitas durante toda a atuação do sistema é comprovada pelos valores de RMSE para a precipitação média, com a simulação GF (CTRL) apresentando os valores de 2,669 (2,932) na área 1, $3,076(3,522)$ na área 2 e 1,997 $(2,438)$ na área 3. Por conseguinte, fica evidente a importância dos resultados aqui mostrados em relação à sua possível aplicação em serviços ambientais ou de gestão de recursos hídricos.

A importância da grade 3 , com resolução horizontal de $3 \mathrm{~km}$, reside na resolução explícita dos processos convectivos pela parametrização de microfísica de nuvens. Esta grade esteve ativa somente nos 3 primeiros dias de simulação da ZCAS, durante o período ande o JBNAS e o fluxo de umidade entre o noroeste da AS e o sudeste brasileiro atuavam com maior intensidade. Neste período, a subestimativa dos movimentos ascendentes em 500 hPa e da divergência em 200 hPa foi menor em relação às grades de menor resolução espacial, o que mostra o quão essencial é o investimento em maior poder computacional e conhecimento técnico e científico de modelagem numérica de alta resolução. Para corroborar os resultados, o RMSE, em geral, foi menor para esta grade 3, com a simulação CTRL (GF) apresentando RMSE de 2,101 (1,886) na área 1, 2,334 $(1,489)$ na área 2 e 
1,397 (1,630) na área 3. Estes resultados mostraram uma melhor representação do sistema durante este período quando comparado a toda a atuação da ZCAS, evidenciando o melhor desempenho do modelo regional ao simular a ZCAS em uma resolução suficiente para que os processos convectivos sejam calculados explicitamente.

\subsection{Sugestões Para Trabalhos Futuros}

O presente estudo de caso mostra características de um episódio em específico, o que aponta para a necessidade de que mais episódios de ZCAS sejam estudados com a mesma metodologia, a fim de se buscar padrões comuns entre os casos quanto à contribuição do JBNAS para a quantidade de precipitação observada em superfície. Esta tarefa se torna necessária uma vez que diferentes casos de ZCAS podem apresentar diferentes características (posição e intensidade do JBN, disponibilidade de umidade e acoplamento vertical), o que certamente gera variações nos resultados finais.

Sugere-se também a realização de experimentos numéricos em regiões chave de disponibilidade de umidade, como o Oceano Atlântico tropical e o sul da região amazônica, de modo que seja captada sua influência nos sistemas sinóticos e regionais que atuam na ZCAS e na precipitação gerada pelo sistema.

Por fim, uma vez que os períodos em que o domínio numérico de $3 \mathrm{~km}$ de espaçamento do modelo WRF esteve ativo, onde muitos dos processos físicos envolvidos na convecção profunda foram resolvidos explicitamente, sugere-se uma simulação do período total de atuação da ZCAS com a utilização deste recurso. 


\section{Referências Bibliográficas}

Barnes S. L., Mesoscale Objective Map Analysis Using Weighted Time-Series Observations, NOAA Technical Memorandum ERL NSSL-62, National Severe Storms Laboratory Norman, Oklahoma, 1973, p. 60

Barreiro M., Saravanan R., Variability of the South Atlantic convergence zone simulated by an atmospheric general circulation model, Journal of climate, 2002, vol. 15, p. 745

Berri G. J., Inzunza J. B., The effect of the low-level jet on the poleward water vapour transport in the central region of South America, Atmospheric Environment Part A, General Topics, 1993, vol. 27, p. 335

Blackadar A. K., , 1957 Boundary Layer Wind Maxima and Their Significance for the Growth of Nocturnal Inversions

Bombardi R. J., Carvalho L. M., The South Atlantic dipole and variations in the characteristics of the South American Monsoon in the WCRP-CMIP3 multi-model simulations, Climate Dynamics, 2011, vol. 36, p. 2091

Bonner W., climatology of the low level jet, Monthly Weather Review, 1968, vol. 9

Bonner W. D., Paegle J., Diurnal Variations in Boundary Layer Winds Over T E SouthCentral United S S in S, Monthly Weather Review, 1970, vol. 1

Campetella C. M., Vera C., The influence of the Andes mountains on the South American low-level flow, Geophys. Res. Lett., 2002, vol. 29, p. 1826

Carvalho L. M., V, Jones C., Silva Dias M. A. F. 2002. Intraseasonal large-scale circulations 
and mesoscale convective activity in tropical South America during the TRMM-LBA campaign, Journal of Geophysical Research: Atmospheres, 2002, vol. 107, p. 1

Carvalho L. M., Cavalcanti I. F., The South American Monsoon System (SAMS), The Monsoons and Climate Change, 2016, pp 121-148

Carvalho L. M., Jones C., Liebmann B., Extreme precipitation events in southeastern South America and large-scale convective patterns in the South Atlantic convergence zone, Journal of Climate, 2002, vol. 15, p. 2377

Carvalho L. M., Jones C., Liebmann B., The South Atlantic Convergence Zone : Intensity , Form , Persistence, and Relationships with Intraseasonal to Interannual Activity and Extreme Rainfall, Journal of Climate, 2004, vol. 17, p. 88

Carvalho L. M., Jones C., Silva A. E., Liebmann B., Silva Dias P. L., The South American Monsoon System and the 1970s climate transition, International Journal of Climatology, 2011, vol. 31, p. 1248

Carvalho L. M., Jones C., Silva Dias M. A., Intraseasonal large-scale circulations and mesoscale convective activity in tropical South America during the TRMM-LBA campaign, Journal of Geophysical Research D: Atmospheres, 2002, vol. 107, p. 1

Carvalho L. M., Silva A. E., Jones C., Liebmann B., Dias P. L., Rocha H. R., Moisture transport and intraseasonal variability in the South America monsoon system, Climate Dynamics, 2011, vol. 36, p. 1865

Casarin D., Kousky V., Anomalias de precipitação no sul do Brasil e variações na circulação atmosférica, Revista Brasileira de Meteorologia, 1986, vol. 1, p. 83

Cassol F., O papel do transporte de umidade pelo Jato de Baixos Níveis da América do Sul pela observação e simulação com o modelo WRF de uma banda frontal continental, Universidade de São Paulo, 2019, Tese de Doutorado, 122

Chaves R. R., Nobre P., Interactions between sea surface temperature over the South Atlantic Ocean and the South Atlantic Convergence Zone, Geophysical Research Letters, 2004, vol. 31 , p. 1 
Corrêa C. S., Clarke R. T., da Silveira A. L. L., Estudo da ocorrência de fluxos no perfil vertical do vento na baixa atmosfera com análise das componentes principais (ACP) e a sua relação com a precipitação no Rio Grande do Sul, Revista Brasileira de Meteorologia, 2007, vol. 22, p. 121

da Silva A. E., Carvalho L. M. V., Large-scale index for South America Monsoon ( LISAM ), Royal Meteorological Society, 2007, vol. 57, p. 51

da Silva N. P., Estudo dos Mecanismos Vinculados ao Estabelecimento de um Evento de ZCAS Através de Simulações com o Modelo WRF, Universidade de São Paulo, 2018, Tese de Doutorado, 103

de Campos C. R. J., dos Santos J. G. M., Climatologia sazonal dos Jatos de Baixos Níveis na região metropolitana de Porto Alegre, no período de 1989 a 2003, utilizando dados de radiossondagens, Anuário do Instituto de Geociências, 2007, vol. 30, p. 82

Ding Y., The variability of the Asian summer monsoon, Journal of the Meteorological Society of Japan. Ser. II, 2007, vol. 85, p. 21

dos Santos D. F., Reboita M. S., JATOS DE BAIXOS NÍVEIS A LESTE DOS ANDES: COMPARAÇÃO ENTRE DUAS REANÁLISES, Revista Brasileira de Climatologia, 2018, vol. 22

Farquharson J. S., The diurnal variation of wind over tropical Africa, Quarterly Journal of the Royal Meteorological Society, 1939, vol. 65, p. 165

Ferraz S. E. T., Grimm A. M., Variabilidade intrasazonal no Brasil e Sul da América do Sul, Universidade de São Paulo, 2004, Dissertação de Mestrado

Figueroa S. N., Satyamurty P., Da Silva Dias P. L., Simulations of the summer circulation over the South American region with an eta coordinate model, Journal of Atmospheric Sciences, 1995, vol. 52, p. 1573

Figueroa S. N., Satyamurty P., Dias P. L. d. S., Simulations of the Summer Circulation over the South America Region with an Eta Coordinate Model, Journal of Atmospheric Sciences, 1995, vol. 52, p. 1573 
Findlater J., A major low level air current near the Indian Ocean during the northern summer, Quarterly Journal of the Royal Meteorological Society, 1969, vol. 95, p. 362

Findlater J., Observational aspects of the low-level cross-equatorial jet stream of the western Indian Ocean, Pure and Applied Geophysics PAGEOPH, 1977, vol. 115, p. 1251

Fritsch J. M., Chappell C. F., Numerical prediction of convectively driven mesoscale pressure systems. Part I: Convective parameterization, Journal of the Atmospheric Sciences, 1980, vol. 37 , p. $1722-1733$

Gan M., Kousky V., Ropelewski C., The South America monsoon circulation and its relationship to rainfall over west-central Brazil, Journal of climate, 2004, vol. 17, p. 47

Gandu A. W., Geisler J. E., A Primitive Equations Sodel Study of the Effect of Topography on the Summer Circulations over Tropical South America, J. of the Atm. Sci., 1991, vol. 48 , p. $1822-1836$

Gandu A. W., Silva Dias P. L., Impact of tropical heat sources on the South American tropospheric upper circulation and subsidence, Journal of Geophysical Research: Atmospheres, 1998a, vol. 103, p. 6001

Gandu A. W., Silva Dias P. L., Impact of tropical heat sources on the South American tropospheric upper circulation and subsidence, Journal of Geophysical Research: Atmospheres, 1998b, vol. 103, p. 6001

Gandu A. W., Silva Dias P. L., Impact of tropical heat sources on the South American tropospheric upper circulation and subsidence, Journal of Geophysical Research Atmospheres, 1998, vol. 103, p. 6001

Goualt J., Vents en altitude a Fort Lamy (Tchad, Ann Phys. Globe France dlOutre Me, 1938, vol. 5 , p. 70

Greco S., Ulanski S., Garstang M., Houston S., Low-level nocturnal wind maximum over the central Amazon basin, Boundary-Layer Meteorology, 1992, vol. 58, p. 91

Grell G. A., Prognostic evaluation of assumptions used by cumulus parameterizations, Monthly Weather Review, 1993, vol. 121, p. 764 
Grell G. A., Dévényi D., A generalized approach to parameterizing convection combining ensemble and data assimilation techniques, Geophysical Research Letters, 2002, vol. 29, p. 38

Grell G. A., Freitas S. R., A scale and aerosol aware stochastic convective parameterization for weather and air quality modeling, Atmos. Chem. Phys, 2014, vol. 14, p. 5233

Griffies S. M., Harrison M. J., Pacanowski R. C., Rosati A., A technical guide to MOM4, GFDL Ocean Group Tech. Rep, 2004, vol. 5, p. 342

Hallak R., Pereira Filho A. J., Metodologia para análise de desempenho de simulações de sistemas convectivos na regio metropolitana de So Paulo com o modelo ARPS: sensibilidade a variações com os esquemas de advecção e assimilação de dados, Revista Brasileira de Meteorologia, 2011, vol. 26, p. 591

Herdies D. L., da Silva A., Silva Dias M. A., Nieto Ferreira R., Moisture budget of the bimodal pattern of the summer circulation over South America, Journal of Geophysical Research: Atmospheres, 2002, vol. 107, p. LBA

Holland G. J., Interannual variability of the Australian summer monsoon at Darwin: 195282, Monthly weather review, 1986, vol. 114, p. 594

Holton J. R., The diurnal boundary layer wind oscillation above sloping terrain, Tellus, 1967, vol. 19, p. 200-205

Holton J. R., An introduction to dynamic meteorology. vol. 88, Academic press, 1972

Hong S., Lim J., The WRF Single-Moment 6-Class Microphysics SCheme (WSM6), Journal of the Korean Meteorological Society, 2006, vol. 42, p. 129

Hong S.-Y., Noh Y., Dudhia J., A new vertical diffusion package with an explicit treatment of entrainment processes, Monthly weather review, 2006, vol. 134, p. 2318

Huffman G. J., Adler R. F., Bolvin D. T., Gu G., Nelkin E. J., Bowman K. P., Hong Y., Stocker E. F., Wolff D. B., The TRMM Multisatellite Precipitation Analysis (TMPA): Quasi-global, multiyear, combined-sensor precipitation estimates at fine scales, Journal of Hydrometeorology, 2007, vol. 8, p. 38 
Huffman G. J., Bolvin D. T., Braithwaite D., Hsu K., Joyce R., Kidd C., Nelkin E. J., Xie P., NASA Global Precipitation Measurement (GPM) Integrated Multi-satellitE Retrievals for GPM (IMERG) Prepared for: Global Precipitation Measurement (GPM) National Aeronautics and Space Administration (NASA), Algorithm Theoretical Basis Document (ATBD) Version 4.5, 2015, p. 26

Huffman G. J., Bolvin D. T., Nelkin E. J., Integrated Multi-satellitE Retrievals for GPM (IMERG) Technical Documentation, Nigerian Journal of Environmental Sciences and Technology, 2017, vol. 1, p. 1

Iacono M. J., Delamere J. S., Mlawer E. J., Shephard M. W., Clough S. A., Collins W. D., Radiative forcing by long-lived greenhouse gases: Calculations with the AER radiative transfer models, Journal of Geophysical Research Atmospheres, 2008, vol. 113, p. 2

Jankov I., Gallus W. A., Segal M., Shaw B., Koch S. E., The impact of different WRF model physical parameterizations and their interactions on warm season MCS rainfall, Weather and Forecasting, 2005, vol. 20, p. 1048

Jones C., Carvalho L. M., Active and break phases in the South American monsoon system, Journal of Climate, 2002, vol. 15, p. 905

Kain J. S., The Kain-Fritsch convective parameterization: an update, Journal of applied meteorology, 2004, vol. 43, p. 170

Kalnay E., Mo K. C., Paegle J., Large-amplitude, short-scale stationary Rossby waves in the Southern Hemisphere: Observations and mechanistic experiments to determine their origin, Journal of Atmospheric Sciences, 1986, vol. 43, p. 252

Kannenberg C., Uma visão ampliada sobre os jatos de baixos níveis na América do Sul, Universidade Federal de Santa Maria, 2019, Tese de Doutorado

Kim K.-Y., Kullgren K., Lim G.-H., Boo K.-O., Kim B.-M., Physical mechanisms of the Australian summer monsoon: 2. Variability of strength and onset and termination times, Journal of Geophysical Research: Atmospheres, 2006, vol. 111

Kleeman R., A modeling study of the effect of the Andes on the summertime circulation of tropical South America, Journal of the Atmospheric Sciences, 1989, vol. 46, p. 3344 
Kodama Y., Large-Scale Common Features of Subtropical Precipitation Zones (the Baiu Frontal Zone, the SPCZ, and the SACZ) Part I: Characteristics of Subtropical Frontal Zones, journal of the Meteorological Society of Japan, 1992, pp 813-836

Kodama Y., Large-scale common features of subtropical precipitation zones, (the Baiu frontal zone, the SPCZ, and SACZ) Part II: Conditions of the circulations for generating the STCZs., journal of the Meteorological Society of Japan, 1993, vol. 71, p. 581

Kousky V. E., Pentad outgoing longwave radiation climatology for the South American sector, Revista Brasileira de Meteorologia, 1988, vol. 3, p. 217

Kousky V. E., Alonso Gan M., Upper tropospheric cyclonic vortices in the tropical South Atlantic, Tellus, 1981, vol. 33, p. 538

Lenters J. D., Cook K. H., Summertime precipitation variability over South America: Role of the large-scale circulation, Monthly Weather Review, 1999, vol. 127, p. 409

Liebmann B., Jones C., Carvalho L. M. V. d., Interannual variability of daily extreme precitation events in the state of São Paulo, Brazil, Journal of Climate, 2001

Liebmann B., Kiladis G. N., Marengo J., Ambrizzi T., Glick J. D., Submonthly convective variability over South America and the South Atlantic convergence zone, Journal of Climate, 1999, vol. 12, p. 1877

Marengo J. A., Liebmann B., Kousky V. E., Filizola N. P., Wainer I. C., Onset and end of the rainy season in the Brazilian Amazon Basin, Journal of Climate, 2001, vol. 14, p. 833

Marengo J. A., Soares W. R., Saulo C., Nicolini M., Climatology of the low-level jet east of the Andes as derived from the NCEP-NCAR reanalyses: Characteristics and temporal variability, Journal of Climate, 2004, vol. 17, p. 2261

Montini T. L., Jones C., Carvalho L. M., The South American Low-Level Jet: A New Climatology, Variability, and Changes, Journal of Geophysical Research: Atmospheres, 2018, vol. 124, p. 1200

Nascimento M. G., Herdies D. L., Souza D. O., The South American water balance: The influence of low-level jets, J. Climate, 2016, vol. 29, p. 1429-1449 
Nielsen D. M., Belém A. L., Marton E., Cataldi M., Dynamics-based regression models for the South Atlantic Convergence Zone, Climate Dynamics, 2019, vol. 52, p. 5527

Niu G. Y., Yang Z. L., Mitchell K. E., Chen F., Ek M. B., Barlage M., Kumar A., Manning K., Niyogi D., Rosero E., Tewari M., Xia Y., The community Noah land surface model with multiparameterization options (Noah-MP): 1. Model description and evaluation with local-scale measurements, Journal of Geophysical Research Atmospheres, 2011, vol. 116 , p. 1

Nogués-Paegle J., Mo K. C., Alternating wet and dry conditions over South America during summer, Monthly Weather Review, 1997, vol. 125, p. 279

Oliveira M. I., Nascimento E. L., Kannenberg C., A New Look at the Identification of Low-Level Jets in South America, Monthly Weather Review, 2018, vol. 146, p. 2315

Quadro M. F. d. L., Estudo de episódios de Zona de Convergência do Atlântico Sul (ZCAS) sobre a América do Sul. 1994, 123f, Dissertação (Mestrado em Meteorologia)-Instituto Nacional de Pesquisas ..., 1994, Tese de Doutorado

Quadro M. F. L. d., Dias M. A. F. d. S., Herdies D. L., de Gonçalves L. G. G., Análise Climatógica da Precipitação e do Trasporte de Umidade na Região da ZCAS Através da Nova Geração de Reanálises Instituto Federal de Educação , Ciência e Tecnologia de Santa Catarina ( IFSC ), Florianópolis, SC, Brasil Universidade de São Paulo, Revista Brasileira de Meteorologia, 2012, vol. 27, p. 152

Reboita M. S., Gan M. A., da Rocha R. P., Ambrizzi T., Regimes de precipitação na América do Sul: uma revisão bibliográfica, Revista Brasileira de Meteorologia, 2010, vol. 25

Rife D. L., Pinto J. O., Monagham A. J., Davis C. A., Hannan J. R., Global distribution and characteristics of diurnally varying low-level jets, J. Climate, 2010, vol. 19, p. $5041-5064$

Robertson A. W., Mechoso C. R., Interannual and interdecadal variability of the South Atlantic convergence zone, Monthly Weather Review, 2000, vol. 128, p. 2947 
Rozante J. R., Moreira D. S., de Goncalves L. G. G., Vila D. A., Combining TRMM and surface observations of precipitation: Technique and validation over South America, Weather and Forecasting, 2010, vol. 25, p. 885

Saha S., Moorthi S., Pan H. L., Wu X., Wang J., Nadiga S., Tripp P., Kistler R., Woollen J., Behringer D., Liu H., Stokes D., Grumbine R., Gayno G., Wang J., Hou Y. T., Chuang e. a., The NCEP climate forecast system reanalysis, Bulletin of the American Meteorological Society, 2010, vol. 91, p. 1015

Saha S., Moorthi S., Wu X., Wang J., Nadiga S., Tripp P., Behringer D., Hou Y. T., Chuang H. Y., Iredell M., Ek M., Meng J., Yang R., Mendez M. P., Van Den Dool H., Zhang Q., Wang W., Chen M., Becker E., The NCEP climate forecast system version 2, Journal of Climate, 2014, vol. 27, p. 2185

Salio P., Nicolini M., Saulo A. C., Chaco low-level jet events characterization during the austral summer season, Journal of Geophysical Research, 2002, vol. 107, p. 1

Salio P., Nicolini M., Zipser E. J., Mesoscale convective systems over southeastern South America and their relationship with the South American low-level jet, Monthly Weather Review, 2007, vol. 135, p. 1290

Santos J. G. M. d., Campos C. R. J. d., Carla Lima E. K., Análise de jatos de baixos níveis associados a um sistema convectivo de mesoescala na américa do sul: um estudo de caso, Revista Brasileira de Geofisica, 2008, vol. 26, p. 451

Satyamurty P., Nobre C. A., Dias P. L. S., , 1998 in , Meteorology of the southern hemisphere. Springer pp 119-139

Saulo A. C., Nicolini M., Chou S. C., Model characterization of the South American lowlevel flow during the 1997-1998 spring-summer season., Climate Dyn, 2000, vol. 16, p. $867-881$

Segele Z. T., Richman M. B., Leslie L. M., Lamb P. J., Seasonal-to-interannual variability of ethiopia/horn of Africa monsoon. Part II: Statistical multimodel ensemble rainfall predictions, Journal of Climate, 2015, vol. 28, p. 3511 
Sheng-Ping H., Potential connection between the Australian summer monsoon circulation and summer precipitation over central China, Atmospheric and Oceanic Science Letters, 2015, vol. 8, p. 120

Siqueira J. R., Machado L. A. T., Influence of the frontal systems on the day-to-day convection variability over South America, Journal of Climate, 2004, vol. 17, p. 1754

Skamarock W. C., Klemp J. B., A time-split nonhydrostatic atmospheric model for weather research and forecasting applications, Journal of Computational Physics, 2008, vol. 227, p. 3465

Sperber K., Annamalai H., Kang I.-S., Kitoh A., Moise A., Turner A., Wang B., Zhou T., The Asian summer monsoon: an intercomparison of CMIP5 vs. CMIP3 simulations of the late 20th century, Climate dynamics, 2013, vol. 41, p. 2711

Stensrud D. J., , 1996 Importance of low-level jets to climate: A review

Stensrud D. J., Parameterization schemes: keys to understanding numerical weather prediction models. Cambridge University Press, 2009

Stull R. B., An introduction to boundary layer meteorology. vol. 13, Springer Science \& Business Media, 2009

Sugahara S., Rocha R., Climatologia das correntes de jato de baixos níveis sobre a América do Sul, durante o verão do Hemisfério Sul, Anais do IX cong. Bras. de Meteorologia, 1996, pp 1383-1387

Sultan B., Janicot S., The West African monsoon dynamics. Part II: The "preonset" and "onset" of the summer monsoon, Journal of climate, 2003, vol. 16, p. 3407

Trenberth K. E., Stepaniak D. P., Caron J. M., The global monsoon as seen through the divergent atmospheric circulation, Journal of Climate, 2000, vol. 13, p. 3969

Uccellini L. W., Johnson D. R., , 1979 The Coupling of Upper and Lower Tropospheric Jet Streaks and Implications for the Development of Severe Convective Storms

Uccellini L. W., Kocin P. J., The interaction of jet streak circulations during heavy snow events along the east coast of the United States, Weather and Forecasting, 1987, vol. 2, p. 289 
Velasco I., Fritsch J. M., Mesoscale convective complexes in the Americas, Journal of Geophysical Research: Atmospheres, 1987, vol. 92, p. 9591

Vera C., Baez J., Douglas M., Emmanuel C., Marengo J., Meitin J., Nicolini M., NoguesPaegle J., Paegle J., Penalba O., et al., The South American low-level jet experiment, Bulletin of the American Meteorological Society, 2006, vol. 87, p. 63

Vera C., Higgins W., Amador J., Ambrizzi T., Garreaud R., Gochis D., Gutzler D., Lettenmaier D., Marengo J., Mechoso C., et al., Toward a unified view of the American monsoon systems, Journal of climate, 2006, vol. 19, p. 4977

Virji H., A preliminary study of summertime tropospheric circulation patterns over South America estimated from cloud winds, Monthly Weather Review, 1981, vol. 109, p. 599

Wallace J. M., Hobbs P. V., Atmospheric science: an introductory survey. vol. 92, Elsevier, 2006

Walters C. K., Winkler J. A., Airflow configurations of warm season southerly low-level wind maxima in the Great Plains. Part I: Spatial and temporal characteristics and relationship to convection, Weather and forecasting, 2001, vol. 16, p. 513

Wang H., Fu R., Influence of cross-Andes flow on the South American low-level jet, Journal of climate, 2004, vol. 17, p. 1247

Warner T. T., Numerical weather and climate prediction. Cambridge University Press, 2010

Webster P., , 1987 The elementary monsoon, Monsoons, edited by: Fein, JS and Stephens, PL

Webster P. J., Magana V. O., Palmer T., Shukla J., Tomas R., Yanai M., Yasunari T., Monsoons: Processes, predictability, and the prospects for prediction, Journal of Geophysical Research: Oceans, 1998, vol. 103, p. 14451

Wexler H., A Boundary Layer Interpretation of the Low-level Jet, Tellus, 1961, vol. 13, p. 368 
Whiteman C. D., B. X., Z. S., Low-level jet climatology from enhanced Rawinsonding observations at a site in the Southern Great Plains, Journal of Applied Meteorology, 1997, vol. v. 36, p. p. 1363

Yamamoto R., Investigando Linhas de Instabilidade na Amazônia através da sensibilidade à parametrização de convecção, Universidade de São Paulo, 2016, Tese de Doutorado, 129

Zhang D., Anthes R. A., , 1982 A high-resolution model of the planetary boundary layer - sensitivity tests and comparisons with SESAME-79 data.

Zhou J., Lau K., Does a Monsoon Climate Exist over South America ?, Journal os Climate, 1998, vol. 11, p. 1020 
Apêndice 

Apêndice A

\section{Mecanismos de Formação do JBN}

Os mecanismos envolvidos na formação dos JBNs abrangem escalas espaciais e temporais distintas, que vão desde a escala diurna e fatores locais até a grande escala, sendo os principais deles: Oscilação Inercial; Efeitos Topográficos e Forçantes de escala sinótica. Para um bom entendimento e previsibilidade dos JBNs, faz-se necessário um entendimento mais aprofundado acerca destes fatores.

\section{A.1 Oscilação Inercial}

Os primeiros esforços em tentar entender a formação de JBNs noturnos dentro da CLA pela teoria da Oscilação Inercial foram feitos por Blackadar (1957). Nesta seção, esta teoria é dissertada através das perspectivas de Stull (2009) e Wallace e Hobbs (2006).

Por definição, a CLA é a região da troposfera que está em interação contínua com a superfície da Terra através do atrito e do aquecimento/resfriamento. O escoamento na CLA é turbulento e regido por duas forçantes: 1) térmica, através do aquecimento radiativo da superfície; 2) mecânica, devido a fricção e arrasto com a mesma. Por responder rapidamente a estas forçantes, a CLA possui um ciclo diurno bem definido e pode ser dividida em outras quatro camadas: camada superficial (CS), camada de mistura (CM), camada residual (CR) e camada limite estável (CLE) noturna, como pode ser visto na Figura A.1.

Nos primeiros metros da CLA, encontra-se a CS, que corresponde a região onde os fluxos verticais turbulentos são teoricamente constantes com a altura. Devido ao aquecimento da CLA pela superfície após o nascer do sol, a turbulência começa a realizar a mistura de calor, momento e umidade de forma verticalmente uniforme, através de movimentos 
convectivos, dando origem á CM. Nesta camada, devido a toda essa mistura, praticamente não há variação da velocidade do vento com altura. Dentro da CM, a influência do atrito com a superfície faz com que o balanço geostrófico não seja válido, o que leva a um novo balanço, agora entre as forças de Coriolis, pressão e atrito, resultando num vento mais fraco que o geostrófico.

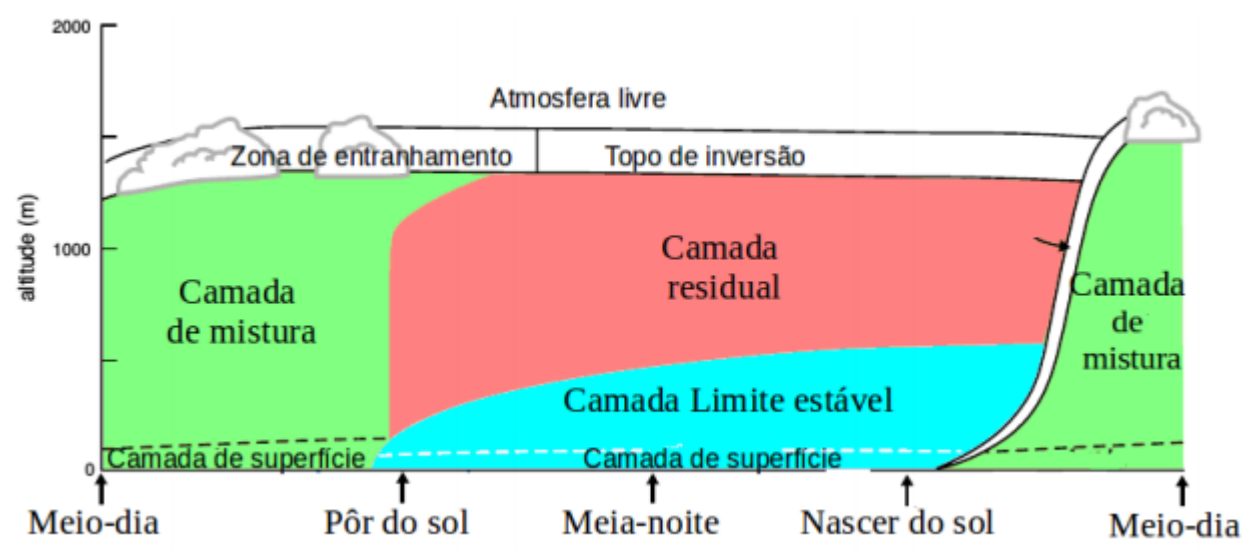

Figura A.1: Ciclo diurno idealizado da CLA sob forçante sinótica fraca, dividida em três partes principais: camada de mistura, camada residual e camada limite estável noturna. Fonte: Kannenberg (2019), adaptado de Stull (2009)

No fim do dia, especialmente após o pôr do sol, a turbulência forçada termicamente começa a diminuir, devido ao resfriamento da superfície. Com isso, inicia-se um processo de inversão térmica, que gera o desacoplamento entre uma camada superior - a CR - , onde ainda ocorre uma mistura turbulenta, e uma camada inferior - a CLE - , onde a perda radiativa da superfície faz com que a turbulência reduza consideravelmente e se mantenha basicamente pela forçante mecânica. O ar presente nos níveis acima da inversão térmica sofre uma aceleração, pois uma vez que o efeito do atrito se reduz drasticamente nos níveis superiores a CLE, a velocidade do vento tende a ser ajustada segundo o equilíbrio geostrófico, o que causa um máximo no perfil vertical do vento em baixos níveis durante a noite, ou seja, um JBN. Com o amanhecer, a radiação volta a aquecer a superfície e produzir turbulência termicamente induzida, iniciando novamente o processo de formação da CM.

Em linhas gerais, a oscilação inercial nada mais é que do que o ajuste do vento real ao vento geostrófico: durante o dia, devido a presença da turbulência (e atrito, consequentemente) em toda a CM, o vento é subgeostrófico; durante a noite, com a ausência de 
aquecimento radiativo e a acentuação da força de Coriolis devido ao aumento da velocidade logo acima da CLE, o vento se torna supergeostrófico nesta região, se equilibrando ao balanço geostrófico nos níveis superiores da CR .

\section{A.2 Efeitos Topográficos}

Um dos mecanismos responsáveis pela formação de JBNs é a variação diurna do gradiente horizontal de temperatura em terrenos inclinados (Holton, 1967). Pela relação do vento térmico, temos que ele é direcionado paralelamente às isotermas e mantém, no Hemisfério Sul (HS), as temperaturas mais elevadas a sua esquerda (Holton, 1972). Imaginando uma superfície inclinada com maior elevação no lado oeste, temos que durante o dia a porção oeste se aquecerá mais rápida e intensamente que a porção leste. Isto resulta em um vento térmico de sul, ou seja, positivo, o que significa que se o vento geostrófico próximo superfície soprar de norte, ele vai enfraquecer com a altura. Durante a noite, o ar adjacente a superfície se resfria, porém o ar logo acima dela não responde rapidamente a esta mudança. Agora, as maiores temperaturas nos níveis mais baixos da CLA estão no setor leste, o que inverte o sentido do vetor vento térmico, que passa a atuar em direção ao norte, fazendo com que os ventos geostróficos neste nível, se forem de norte, intensifiquem com a altura. Na camada acima, entretanto, o sinal do gradiente zonal de temperatura é o mesmo do período diurno, com o vento térmico se mantendo de sul, o que causa um enfraquecimento de ventos geostrófico de norte. A combinação destas duas configurações, durante a noite, favorece a formação de JBNs de norte, neste caso.

Outro efeito topográfico observado na formação do JBN surge da conservação de vorticidade potencial. No caso do JBNAS, ela é observada depois que os ventos alísios defletem em direção ao sul da AS. Adaptando a abordagem descrita por Wexler (1961) para o HS, ao considerar uma coluna de ar em movimento, têm-se que a equação A.1 é constante. Como o ar que se move a leste da Cordilheira dos Andes não sofre alteração na sua profundidade (D) e ao se deslocar para o sul, o parâmetro de Coriolis $(f)$ diminui, há uma necessidade de aumento na vorticidade relativa $(\zeta)$. Ou seja, quando o ar é desviado pelos Andes em direção ao sul, existe a geração de vorticidade positiva (ciclônica no HS), e pela equação da vorticidade em coordenadas naturais (Equação A.2), considerando que não há alteração no gradiente das linhas de corrente $\left(\frac{\partial v}{\partial n}\right)$, existem duas formas de se gerar vorticidade posi- 
tiva: ou diminuindo o raio de curvatura $(\mathrm{R})$, ou aumentando a velocidade (V). Logo, este processo faz com que haja a aceleração do vento horizontal, favorecendo a formação do JBNAS.

$$
\begin{gathered}
\frac{f+\zeta}{D} \\
\zeta=\frac{V}{R}-\frac{\partial v}{\partial n}
\end{gathered}
$$

\section{A.3 Forçantes de escala sinótica}

As circulações de escala sinótica podem atuar de diferentes formas na intensificação do JBN. Uma delas é através da circulação ageostrófica transversa observada na saída do núcleo do Jato de Altos Níveis (JAN), processo descrito por Uccellini e Johnson (1979) num estudo feito para o Hemisfério Norte (HN). Na AS, os estudos de Salio et al. (2002) indicam que o JBNAS não responde a este padrão descrito anteriormente, mas sim que máximos de vento em baixos níveis são encontrados na região de entrada do JAN. Isto porque, no HS, na entrada polar do núcleo JAN é observada divergência em altos níveis, e por continuidade, convergência em baixos níveis. Esta configuração induz movimentos ascendentes intensos e persistentes e consequentemente o estabelecimento de uma célula de circulação termicamente direta nesta área (Berri e Inzunza, 1993), o que ajuda a acelerar o vento horizontal que escoa da região tropical em direção a latitudes médias e gerar JBNs.

Quando uma região favorável a ocorrência de JBN fica posicionada entre um intenso gradiente de pressão, causados por sistemas baroclínicos migratórios, ocorre o "afunilamento" dos ventos, de forma a criar um corredor que ajuda na intensificação e posicionamento dos JBNs (Uccellini e Kocin, 1987). Normalmente, os JBNs forçados por sistemas sinóticos tendem a ser mais elevados do que os formados pelos mecanismos mencionados anteriormente, mostrando-se menos atrelados ao ciclo diurno (Stensrud, 1996). 


\section{Apêndice B}

\section{Figuras Complementares}

\section{B.1 Fluxo de Umidade da Simulação CTRL}
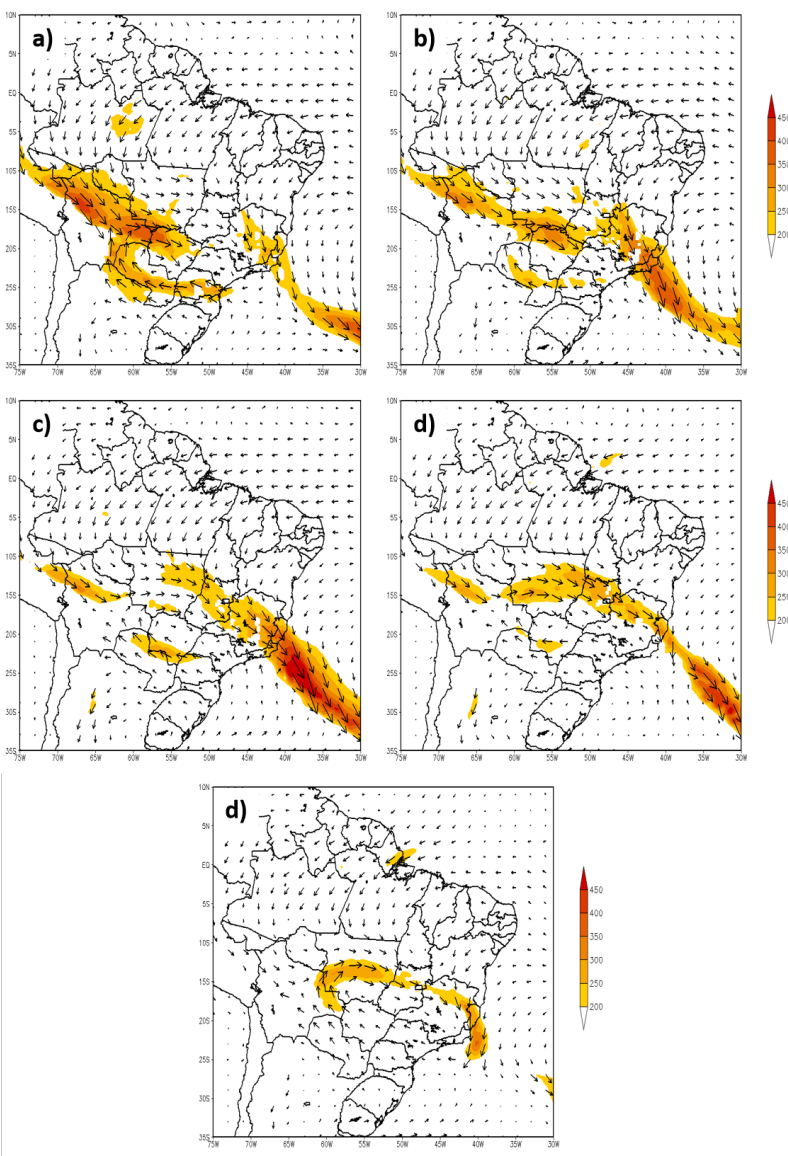

Figura B.1: Transporte de umidade médio diário pela simulação CTRL para os dias: a) 14 de janeiro de 2016; b) 15 de janeiro de 2016; c) 16 de janeiro de 2016; d) 17 de janeiro de 2016; e) 18 de janeiro de 2016. 


\section{B.2 Fluxo de Umidade da Simulação GF}
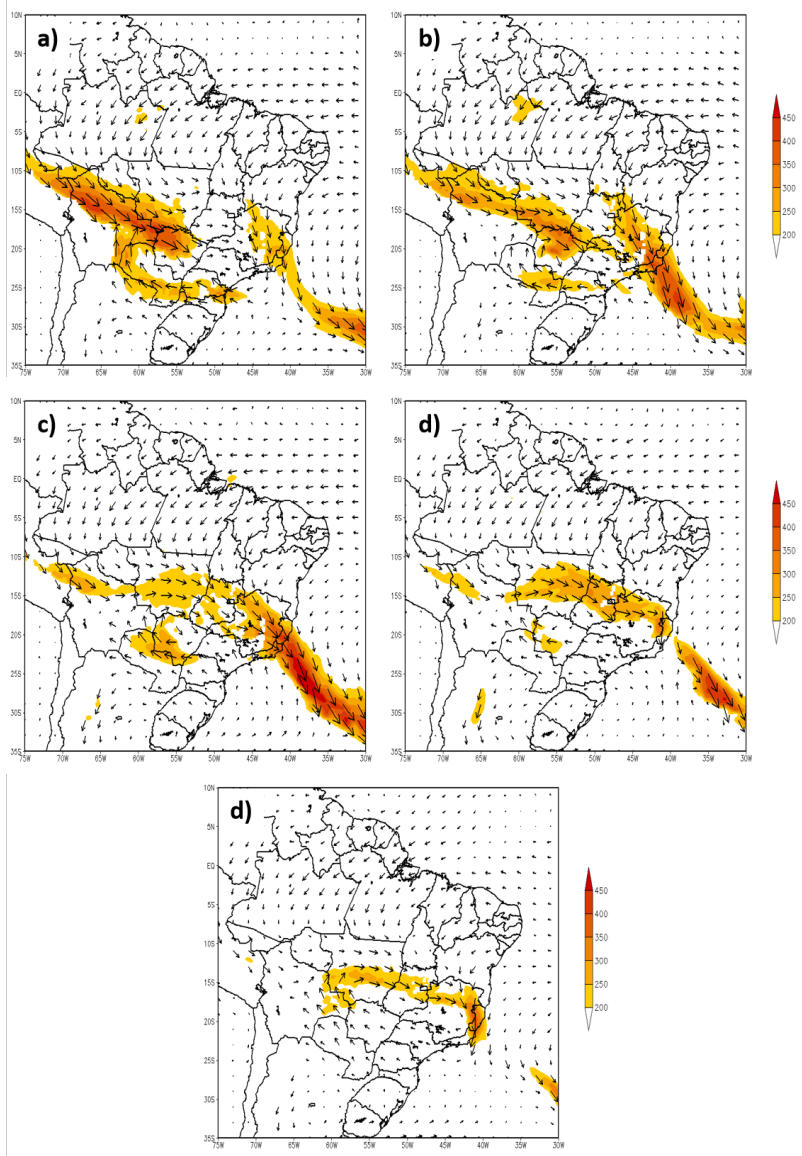

Figura B.2: Transporte de umidade médio diário pela simulação GF para os dias: a) 14 de janeiro de 2016; b) 15 de janeiro de 2016; c) 16 de janeiro de 2016; d) 17 de janeiro de 2016; e) 18 de janeiro de 2016 . 
Apêndice C 


\section{Tabela de Atuação do JBN}

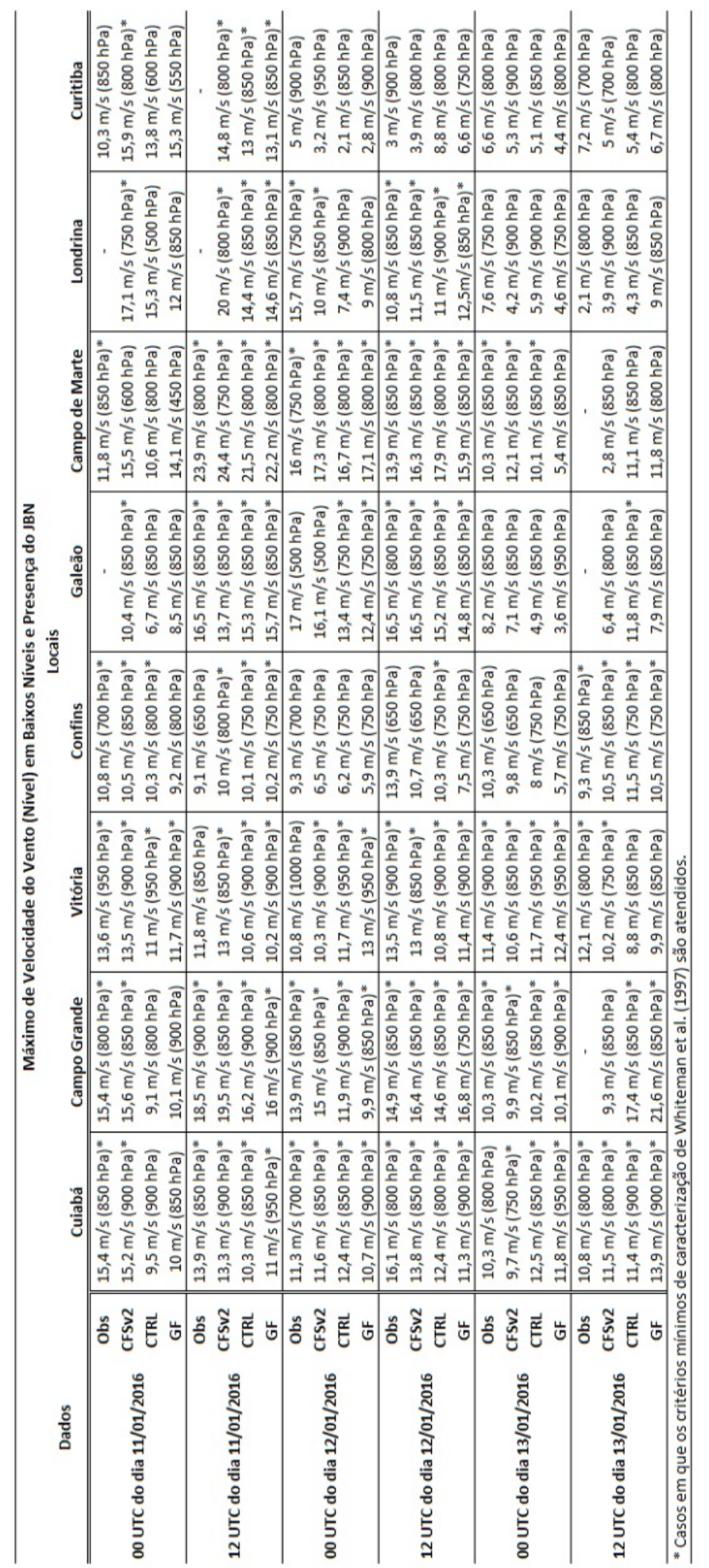

Figura C.1: Valor e nível de máxima intensidade do vento nos baixos níveis da atmosfera nos pontos de lançamento de radiossondagens entre os dias 11/01/2016 e 13/01/2016. 